\title{
Faculty development for medical professionalism in an Arabian Context
}

Citation for published version (APA):

Al-Eraky, M. M. (2015). Faculty development for medical professionalism in an Arabian Context. [Doctoral Thesis, Maastricht University]. Maastricht University. https://doi.org/10.26481/dis.20150521 ma

Document status and date:

Published: 01/01/2015

DOI:

10.26481/dis.20150521ma

Document Version:

Publisher's PDF, also known as Version of record

\section{Please check the document version of this publication:}

- A submitted manuscript is the version of the article upon submission and before peer-review. There can be important differences between the submitted version and the official published version of record.

People interested in the research are advised to contact the author for the final version of the publication, or visit the DOI to the publisher's website.

- The final author version and the galley proof are versions of the publication after peer review.

- The final published version features the final layout of the paper including the volume, issue and page numbers.

Link to publication

\footnotetext{
General rights rights.

- You may freely distribute the URL identifying the publication in the public portal. please follow below link for the End User Agreement:

www.umlib.nl/taverne-license

Take down policy

If you believe that this document breaches copyright please contact us at:

repository@maastrichtuniversity.nl

providing details and we will investigate your claim.
}

Copyright and moral rights for the publications made accessible in the public portal are retained by the authors and/or other copyright owners and it is a condition of accessing publications that users recognise and abide by the legal requirements associated with these

- Users may download and print one copy of any publication from the public portal for the purpose of private study or research.

- You may not further distribute the material or use it for any profit-making activity or commercial gain

If the publication is distributed under the terms of Article $25 \mathrm{fa}$ of the Dutch Copyright Act, indicated by the "Taverne" license above, 


\section{Faculty Development for Medical Professionalism in an Arabian Context}

Mohamed Mostafa Al-Eraky 


\section{Faculty Development for Medical Professionalism in an Arabian Context}

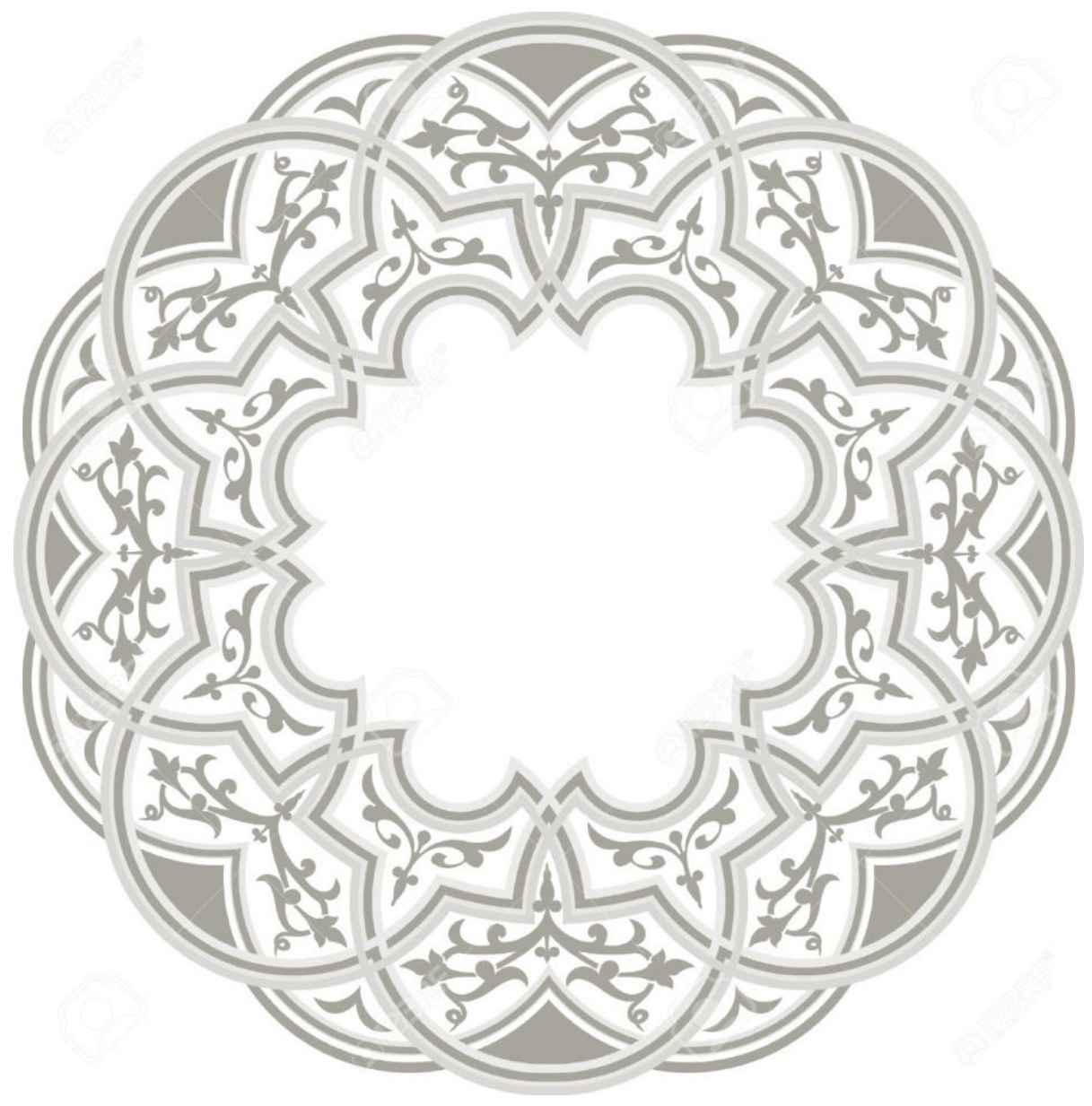

Mohamed Mostafa Al-Eraky 2015 
The research reported here was carried out at

Maastricht University Leading Leanning!

In the School of Health Professions Education
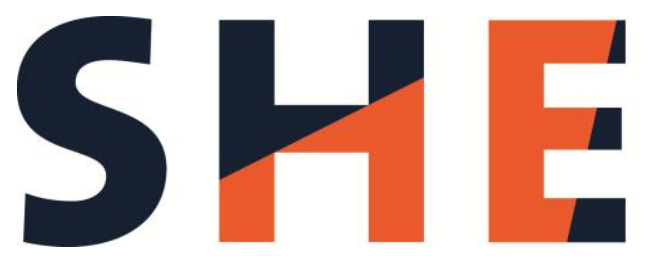

School of Health Professions Education 


\title{
Faculty Development for Medical Professionalism in an Arabian Context
}

\author{
DISSERTATION
}

to obtain the degree of Doctor at Maastricht University, on the authority of the Rector Magnificus Prof.dr. L.L.G. Soete, in accordance with the decision of the Board of Deans, to be defended in public on Thursday $21^{\text {st }}$ May 2015 , at 10:00 hours

by

Mohamed Mostafa Al-Eraky 


\section{Promotors}

Prof. dr. J.J.G. van Merriënboer (promotor)

Dr. H.H.L.M. Donkers (co-promotor)

Dr. G. Wajid, University of Dammam (co-promotor)

\section{Assessment Committee}

Prof. dr. D.H.J.M. Dolmans (chair)

Prof. dr. G. Croiset, VUmc Amsterdam

Dr. E. Helmich, AMC Amsterdam

Dr. W.N.K.A. van Mook

Prof. dr. M.S.R. Segers 



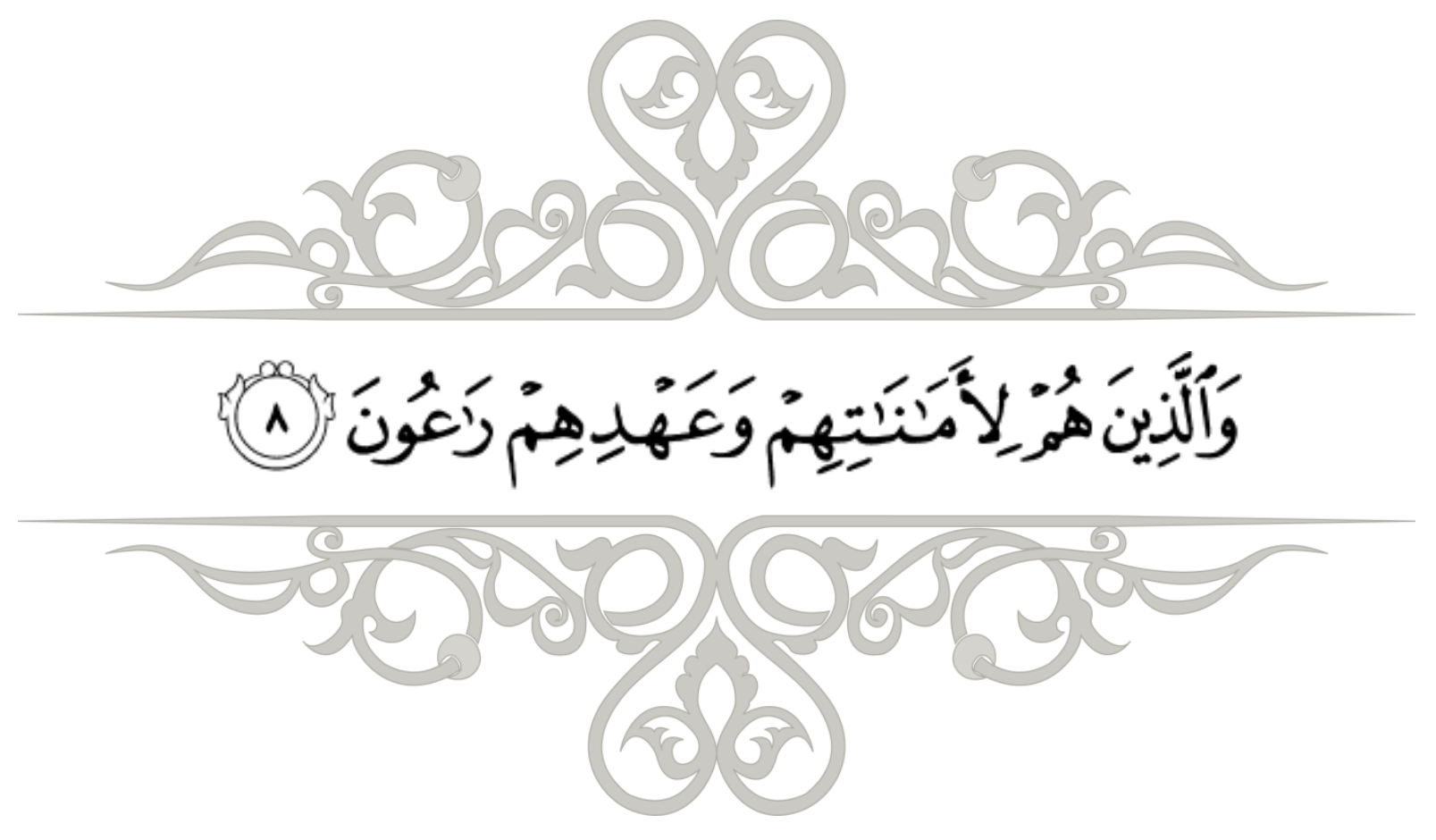

"And those who keep their trusts and their covenants".

Al-Qur'an (Surat Al-Mumenon 23:8) 


\section{Contents}

Chapter 1 .....

General Introduction

Chapter 2

How medical professionalism is conceptualised in Arabian context: A validation study

\section{Chapter 3}

Medical professionalism: Development and validation of the Arabian LAMPS

\section{Chapter 4}

The cultural dimensions of medical professionalism in an Arabian context

65

\section{Chapter 5}

Proto-professionalism: Assessment of professionalism in undergraduate medical students and teachers in the Arabian context

Chapter 6

A Delphi study of medical professionalism in Arabian countries: The Four-Gates model .....

\section{Chapter 7}

Faculty development for learning and teaching professionalism in an Arabian context.

\section{Chapter 8}

Twelve Tips for Teaching Medical Professionalism at all levels of medical education

\section{Chapter 9}

General Discussion

Summary.

Samenvatting

Valorisation

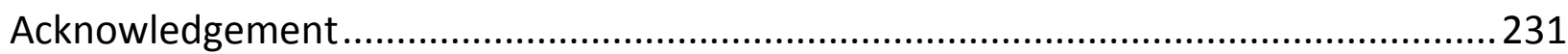

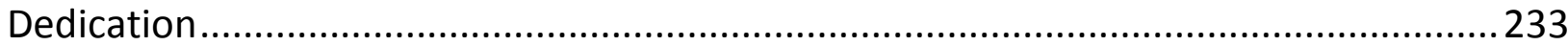

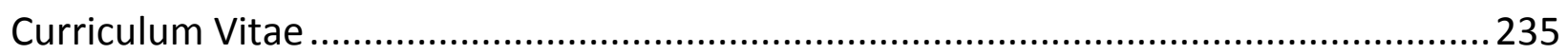

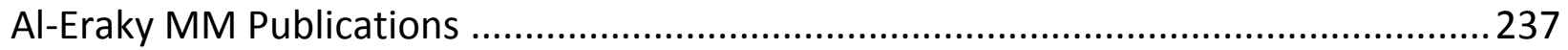

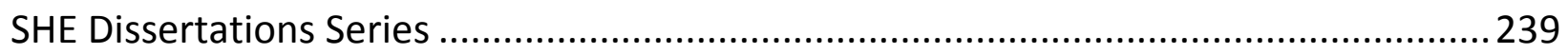




\section{Chapter 1}

\section{General Introduction}

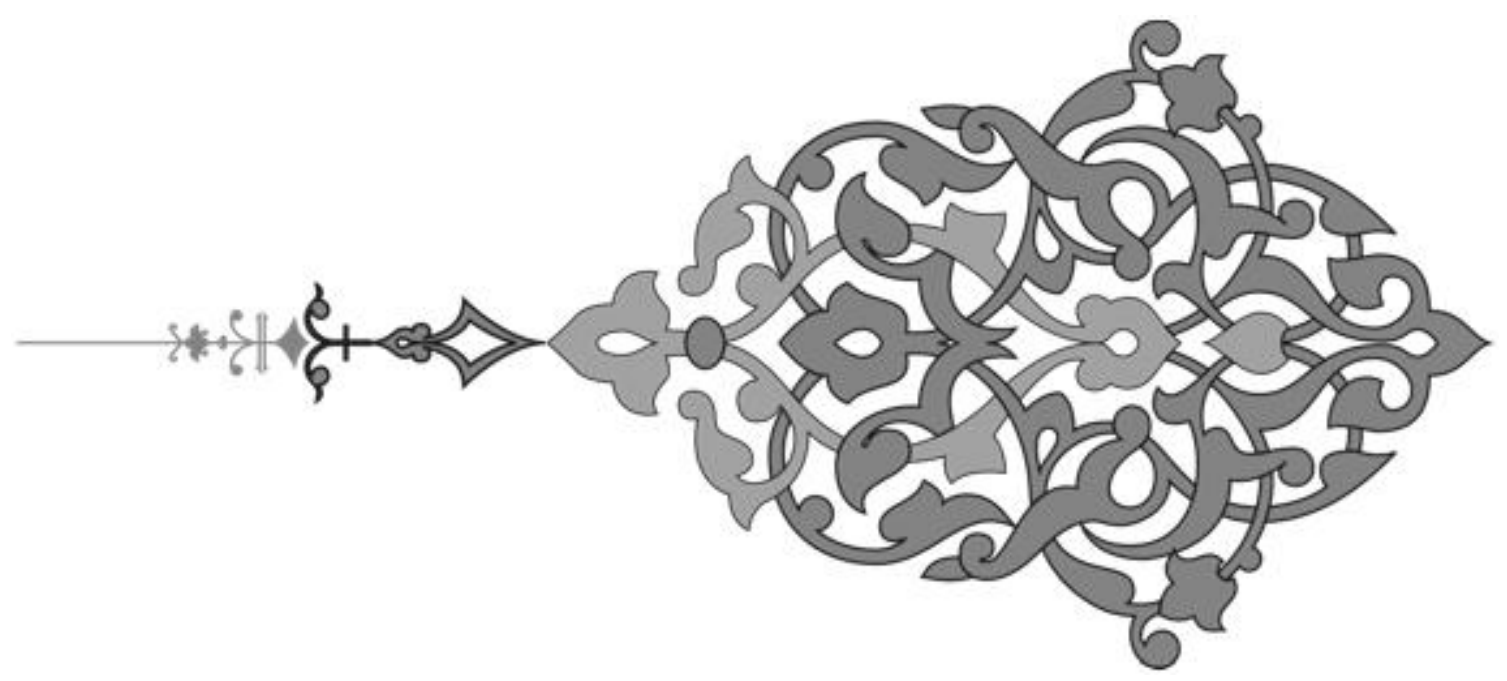




\section{Professionalism has been receiving increasing attention in medical}

education over the past few years. This is reflected by the exponential growth of literature on issues related to defining, teaching, learning and assessing professionalism. Despite the scholarly efforts in studying professionalism, consensus about its definition and domains remains elusive. 'Professionalism', as an emerging buzzword in medical education literature, has been interpreted variably by different national and local organizations and medical schools in different societies and healthcare systems. This reflects the context-specific nature of professionalism that has to be understood in view of the social expectations from the medical profession in a particular culture. The purpose of this introductory Chapter is to provide the reader with some background on what is already known about the concept of professionalism, how people perceive it, and how it can be taught. At the end of this Chapter, the research questions are presented and linked to the structure and different chapters of the thesis.

\section{What is Professionalism?}

The term professional is used with different meanings; sometimes as the opposite of 'amateur'. Medical professionalism exemplifies the expected behaviours and attributes of practitioners (Swick, 2000). The General Medical Council (GMC) has produced guidance on professional behaviour for medical schools and students with a particular focus on fitness to practice (Palmer, Harling, Harrison, Macdonald, \& Snashall, 2002). However, to most scholars and practitioners, a professional is more than being fit to practice medicine. In North America, the concept of professionalism is commonly used to present attributes that are framed in abstract, idealistic terms and character traits, such as honesty, integrity and accountability, while 'professional behaviour' is more prevalent in Europe and reflects observable manners which can be taught and assessed (van Mook et al., 2009). Making lists of desirable professional characteristics is necessary and useful for teaching and assessment, but this discourse is not sufficient either to fully define professionalism or to capture its social functions (Wynia, Papadakis, Sullivan, \& Hafferty, 2014). According to Wynia et al. (2014), medical professionalism is a normative belief system about how to best organize and deliver health care. 
Physicians play two complementary roles: healer and professional $(\mathrm{R} \mathrm{L}$ Cruess, Cruess, \& Johnston, 1999). The role of the 'healer' is more concerned with doctor-patient relationships and the role of the 'professional' is regulating the medicine-society relationship ( $\mathrm{L}$ Cruess et al., 1999). The role of the healer is universal, but how professionalism is expressed differs between countries and cultures due to differences in their social contracts (Cruess, Cruess, \& Steinert, 2010). According to Cruess et al. (2010), the social contract is a relationship that is based on mutual trust between the society and medicine and entails a series of obligations and expectations from both sides. Attributes of medical professionalism reflect societal expectations as they relate to physicians' responsibilities, not only to individual patients but to wider communities as well (Swick, 2000). Professionalism is a dynamic, evolving, and multidimensional construct that can be manifested by individuals and organizations in a particular context ( Hafferty \& Castellani, 2010). Unlike humanism, which is motivated by deep respect to all humans for their general welfare and flourishing, professionalism is a socially-constructed, local phenomenon (Goldberg, 2008). Professionalism should be studied in the context of cross-cultural values, beliefs and attitudes (Jha, Mclean, Gibbs, \& Sandars, 2014). To summarize, there is a need to explore how people think about professionalism as a context-specific construct of every society.

\section{How Do People Perceive Professionalism?}

There is a difference between attitude and perception. An attitude is a mindset which is developed due to an individual's experience and temperament, while perception is the process by which a person interprets and organizes sensation to produce a meaningful experience of the world (Pickens, 2005). Attitudes, therefore, moderate perceptions which may be manifested in explicit behaviours. Attitudes on professionalism are developed in a dynamic process of socialization, which was described by (Hilton \& Slotnick, 2005). Different studies used a variety of quantitative and qualitative approaches to report attitudes of different stakeholders on professionalism over the past ten years. Some authors used questionnaires (Blackall et al., 2007; Nath, Schmidt, \& Gunel, 2006; Tsai, Lin, \& Harasym, 2008), focus groups (Bryden, Ginsburg, \& Kurabi, 2010), thematic catalogue of mission statements written by medical students (Rabow, Wrubel, \& Remen, 2009), semi-structured interview for patient's view on professionalism, 
analysis of students' journals (Huggett, Warrier, \& Maio, 2008) and guided reflection (Stark, Roberts, Newble, \& Bax, 2006).

Medical students have a diverse range of attitudes on professionalism which change over time with the process of socialization in medical education, because their moral and psychological development increase their ability to reflect on their experience as they proceed in clinical practice (Hilton \& Slotnick, 2005). Medical students and junior doctors see medicine as a profession which is learnt through apprenticeship and defined by responsibility towards patients (Chard, Elsharkawy, \& Newbery, 2006). Students' expectations for the attributes of the ideal supervisor indirectly reflect their views on professionalism (Huggett et al., 2008). Professionalism, for students, is not only related to behaviours, but also to appearance, because dressing up as a doctor was strongly perceived by students as a characteristic of being professional (Finn, Garner, \& Sawdon, 2010). This is of a particular importance in the context of the Middle East, where public media portray doctors in full suit, white coats and, most of the time, wearing glasses. This is strongly related to the socialization process, where students are mimicking the appearance and behaviours of their medical teachers. It should be noted that medical students and teachers differ in their understanding of professionalism. The attitudes of professionalism vary mostly with educational rank and age, where undergraduates, females, the youngest age group $(\leq 26$ years), nursing students and faculty are more likely to label particular behaviours as unprofessional (Nath et al., 2006).

\section{Faculty Development on Professionalism}

Faculty development has been defined as the broad range of activities that institutions use to renew or assist faculty in their roles (Centra, 1978) and includes initiatives designed to improve the performance of faculty members in teaching, research and administration (Steinert et al., 2009). Faculty development is not a luxury, but it is an imperative for every medical school (McLean, Cilliers, \& Van Wyk, 2008). Bligh (2005) indicated that faculty development programs are signs of the inner faith that institutions have in their workforce, and that successful faculty development in education is expected to result in improved teaching performance and better learning outcomes for students or doctors. Faculty development activities can include a wide spectrum of specialized workshops, seminars, short courses, longitudinal programs and fellowships (Steinert et al., 
2009). Developing a cadre of competent teachers, educators, researchers and leaders for their new roles and responsibilities in medical education requires faculty development (McLean et al., 2008), which entails their role of teaching professionalism.

Two schools of thought can be acknowledged in teaching and learning medical professionalism (Cruess, R. L., Cruess, S. R., \& Steinert, 2009). The first school believes that professionalism should be approached primarily as a moral endeavour, emphasising altruism and services, the importance of role modelling, and self-awareness. The second school of thought advocates teaching professionalism in an explicit manner, either by defining a cognitive base or outlining a list of traits for professional behaviours. The two schools are complementary, as they engage either the heart or the mind of the learners.

The situated learning theory can act as an overarching framework for teaching professionalism, because it brings together the cognitive base and the experiential learning that is needed to facilitate the acquisition of professionalism (Richard L Cruess \& Cruess, 2006). It is based on the notion that knowledge is contextually situated and fundamentally influenced by the activity, context and culture in which it is used (Lave \& Wenger, 1991). The situated learning theory further bridges the gap between the 'knows what' and the 'knows how' by embedding learning in authentic activities.

\section{Professionalism in the Arabian Context}

According to Hilton and Slotnick (2005), professionalism is an acquired state rather than a trait, and the environmental influences contribute more than biological ones to its development over time. Since professionalism is culturesensitive, its exact definition depends on the contextual variables within the society. To understand professionalism in the Arabian context, there is a need to explore what we mean by the Arabian context. The Arabian context can be perceived as the blend of culture, traditions, beliefs and behaviours that are being practiced by nations of Arabian countries in the Middle East, where Arabic is the official language and Islam is the religion of a majority of the population. Those behaviours and traditions are not necessarily derived from Islamic doctrines, but some common values have been accepted as the norm among populations of these countries. Today, Arabs live in an area of more than 14 millions square kilometres which encompasses almost $10 \%$ of dry land with a population of over 
350 millions inhabiting 22 countries. According to Barakat (1993), although there are differences in ethnic groups, tribes, local cultures and regional entities, the 'Arab world' is a single, overarching society rather than a collection of several independent states. Unfortunately, there is no existing theoretical framework of medical professionalism in the Arabian context. Since professionalism is closely related to the social contract (S. R. Cruess et al., 2010), it is likely that Arabs perceive professionalism different from others. Therefore, this thesis attempts to develop a framework to illustrate the domains of professionalism in the Arabian context.

\section{Problem Statement}

There is a need to define medical professionalism in the Arabian context from the perspectives of Arabian medical students and teachers, in order to develop a genuine framework on medical professionalism that can be used as the foundation for development and evaluation of faculty development programs on professionalism in the Arabian context.

\section{Research Questions}

Six domains of professionalism were identified by the American Board of Internal Medicine or the ABIM, which include: altruism, accountability, duty, excellence, integrity and honour and respect (ABIM (American Board of Internal Medicine), 1995). Those elements provide a good template for validation and, therefore, the ABIM framework has been used as a consistent framework for a number of studies in different countries to define attributes of professionalism over the past decade, not only in the context in which it was originally developed in the USA (Blackall et al., 2007; Quaintance, Arnold, \& Thompson, 2008; Ratanawongsa et al., 2006; Symons, Swanson, McGuigan, Orrange, \& Akl, 2009), but also in other non-western cultures in Taiwan (Tsai et al., 2008), Iran (Aramesh, Mohebbi, Jessri, \& Sanagou, 2009), Vietnam (Nhan, Violato, Le An, \& Beran, 2014) and Japan (Suzuki, 2009). Unfortunately, no similar validation study has been conducted to identify domains of professionalism in the Arabian context. Therefore, it is worth trying to test the same ABIM framework to answer my first research question: What are the basic domains of professionalism in the Arabian context? 
To facilitate discussion and modelling and professional values in medical education and clinical practice, the abstract attributes of professionalism have to reflected in tangible behaviours (Green, Zick, \& Makoul, 2009). In this thesis, short vignettes that describe behaviours will be used to measure attitudes of participants on professionalism. When the elements (domains) of professionalism are identified in the Arabian context, we can use them as a framework to develop an instrument to explore attitudes of students and faculty members on professionalism. Therefore, an instrument that is referring to explicit behaviours in the form of micro-scenarios or vignettes, for example, when a doctor relies on the best available evidence for decision making, is expected to be more valid in measuring attitudes on professionalism than an instrument using abstract definitions, such as duty or excellence. Each vignette is planned to address only one element of professionalism. These behaviours should be realistic and culturespecific to address daily practice of a physician's life. This leads us to my second research question: How to develop and validate a culture-specific instrument to measure attitudes on professionalism in the Arabian context?

Students enter medical schools with positive attitudes towards professionalism attributes (Blue et al., 2009) and their personal standards and ethics derived from past exposure to family, teachers, friends, or other social contacts (Nath et al., 2006). There is a need to explore with a robust scientific approach how medical students perceive professionalism so that their perceptions can be taken into account in the process of curriculum development. The developed instrument in the previous study will be used to answer my third research question: What are the attitudes of Arabian medical students on professionalism?

The attributes of professionalism as viewed by students may (or may not) map onto those perceived by teachers. A number of studies also reported a disparity of views on professionalism between medical students and their teachers (Hur, 2009; Quaintance et al., 2008), which may be attributed to the maturity of the learners and the proposed stage-model of acquiring the essence of professionalism (Hilton \& Slotnick, 2005). Almost all studies comparing professional attitudes across the continuum of medical education were conducted in a Western context. A fourth research question emerged here to study: How do attitudes of medical students on professionalism differ from those of their teachers in an Arabian context? 
Establishing a common ground on professionalism is of paramount importance to be infused in a medical school. There is a need to build a 'cognitive base' within each institution to encompass the core principles for teaching professionalism, which must remain constant throughout the continuum of medical education and faculty development programs (Richard L Cruess \& Cruess, 2006). Faculty development - itself - can be a powerful tool to achieve that consensus and ensure that teachers understand the role they are teaching and modelling (F. Hafferty, 2006; Steinert, Cruess, Cruess, Boudreau, \& Fuks, 2007). My fifth research question, therefore, is: How to develop a consensus on a cognitive base for professionalism among faculty members on an institutional level in the Arabian context?

Despite the value of professionalism in contemporary medical education, as demonstrated above, those who are supposed to teach professionalism (teachers) actually receive minimal attention as evidenced by the limited number of researches studying professionalism in the context of faculty development (Steinert, Cruess, Cruess, \& Snell, 2005). Teachers should be educated on how to teach professionalism with relevance to their ethics, core values, culture and context. This leads us to my sixth research question: How to develop and evaluate a faculty development program for professionalism in an Arabian context?

Faculty members admit that teaching and evaluating professionalism poses a challenge to them (Bryden et al., 2010). What faculty think they have taught regarding professionalism may not have been fully assimilated by their students (Hur, 2009). In a recent Best Evidence in Medical Education (BEME) guide, Birden et al. (2013) referred to the absence of unifying theoretical or practical models to guide teaching of medical professionalism. Teachers may need hands-on guidelines to address such a complex construct as professionalism. A set of accepted practice criteria for teaching professionalism is badly needed which leads to the seventh and last research question of the thesis: What are researchbased practical tips for teaching professionalism across all levels of medical education? 
To summarize, the research reported in this thesis will tackle the following seven research questions:

1- What are the basic domains of professionalism in the Arabian context?

2- How to develop and validate a culture-specific instrument to measure attitudes on professionalism in the Arabian context?

3- What are the attitudes of Arabian medical students on professionalism?

4- How do attitudes of medical students on professionalism differ from those of their teachers in an Arabian context?

5- How to develop a consensus on a cognitive base for professionalism among faculty members on an institutional level?

6- How to develop and evaluate a faculty development program for professionalism in an Arabian context?

7- What are practical tips for teaching professionalism across all levels of medical education?

Together, the answers to the research questions will form a framework for medical professionalism in the Arabian context and offer a basis for faculty development on professionalism. 


\section{Thesis Outline}

Figure 1.1 demonstrates the storyboard of the thesis, including: three discourses (as black boxes), seven studies (Chapters 2-8), and four products (as red banners).

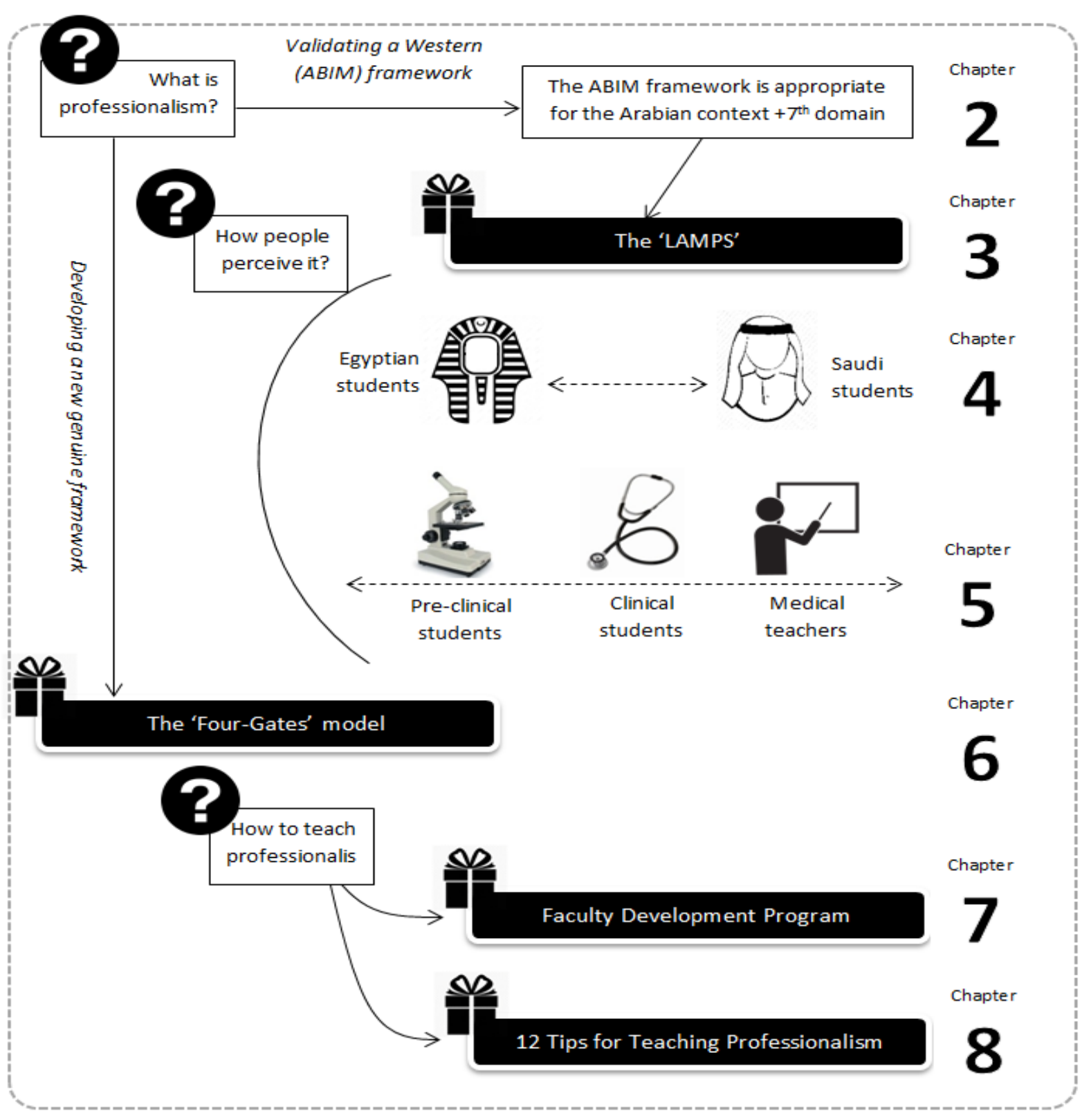

Figure 0-1 The storyboard The storyboard of the thesis, including: three discourses, seven studies (Chapters 2-8), and four products.

Key:
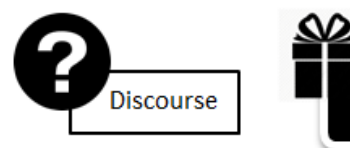

Product 
This thesis encompasses seven related studies in a logical sequence to answer the given seven research questions in nine chapters. After the Introduction, Chapter 2 addresses the first research question and aims to validate the elements of the professionalism framework of the American Board of Internal Medicine ( $A B I M)$ to the Arabian context, using a consensus survey of a reference panel. Medical practitioners and educationalists were invited to contribute to the reference panel. They had to be (a) native Arabic speakers, (b) professionals working in healthcare or health professions education in an Arab country, and (c) engaged in undergraduate medical education and/or residency training in their organizations. They represented a wide range of specialties and seniority levels in a variety of healthcare organizations and medical schools and both genders had to be fairly represented.

Chapter 3 aims at developing, validating and piloting an instrument to measure attitudes on professionalism in the Arabian context, called the LAMPS (Learners' Attitudes on Medical Professionalism Scale). The LAMPS is the first context-specific, reliable, and valid inventory on medical professionalism in the Arabian context. Along with the authors, 32 experts contributed to item generation in particular domains. The instrument used to measure attitudes on professionalism among Egyptian and Saudi medical students. The LAMPS was compared with another similar instrument from a different context (Blackall et al., 2007; Nath et al., 2006; Tsai et al., 2008).

Chapter 4 capitalizes on the evidence presented in a number of scholarly reports that professionalism is a culture-specific construct that applies to a community with shared values and customs. This study investigates the cultural similarities and differences that are hypothesized to moderate the understanding of professionalism in a particular society in Egypt and Saudi Arabia. The study explored the cultural underpinning of professionalism and submitted correlations between certain professionalism domains and cultural values in view of Hofstede's Cultural Dimension Theory (Hofstede, 2014), particularly with relevance to 'power distance' and 'masculinity' values in Egyptian and Saudi societies.

Chapter 5 aims to decipher how professionalism develops across the continuum of medical education using a cross-sectional study by comparing attitudes of medical students and teachers. The Chapter will explore the presence 
of a perception gap between medical teachers and students with respect to different domains of professionalism such as: respect, integrity/honour and excellence. Medical teachers and students will be requested to respond to the survey that is expected to be developed in Chapter 3 to measure their attitudes on professionalism. Findings of this study are expected to shed light on how professionalism is acquired with the influence of a blend of biological (nature) and environmental (nurture) factors (Rees, 2005). The educational and work environments shape the acquisition and maintenance of 'proto-professionalism', which refers to the time period before professionalism has been fully developed, in positive (attainment) and negative (attrition) ways (Hilton \& Slotnick, 2005). Exploring the variance of professional attitudes across different stages of maturation in medical education will inform educators and teachers about approaches to teaching and learning professionalism.

In the same vein of defining professionalism as a context-specific construct, Chapter 6 extends beyond validation of a Western model on professionalism (as in Chapter 2) and highlights the divergent interpretation of medical professionalism between Western and Arabian contexts. This chapter aims to formulate a genuine professionalism framework for healthcare providers as interpreted by local medical professionals in Arabian countries. A purposive sample of experts from diverse disciplines will be invited in a Delphi study. Consensus will be identified by content analysis and by numerical analysis of responses on the basic attributes of medical professionalism in the Arabian context. The model will be used as a cognitive base to plan faculty development in Chapter 7.

Chapter 7 will provide a working plan to teach and learn professionalism in practice using a tailored module of faculty development on professionalism. The study will use a participatory design, where authors and 28 faculty members will share the responsibility in programme design in three steps: (1) orientation workshop for teachers, (2) vignette development, and (3) teaching professionalism to students. The workshop is expected to provide the cognitive base on the salient attributes of professionalism that has to be embedded in situations. After the workshop, authors will be asked to develop professionalism vignettes in various clinical aspects, portraying a blend of professionalism dilemmas. Teachers and authors will be requested to suggest a battery of questions/triggers to guide students' learning and reflection on professionalism vignettes. The programme will be evaluated with regard to its 'construct' and its 
'outcomes', using the four levels of the Kirkpatrick model: reaction, learning, behaviours and results.

Chapter 8 will suggest a list of 12 tips for teaching medical professionalism across all levels of medical education to empower medical educators to teach one of the most challenging constructs in medical education. Teaching professionalism is not an end, but a means to shape the professional identity of future graduates to think, feel and act as physicians (Cruess, Cruess, Boudreau, Snell, \& Steinert, 2014).

Finally, Chapter 9 (General Discussion) will summarize the answers to the seven research questions. Then, it elaborates on the theoretical inferences and venues for future research with reference to the strong points and limitations of the thesis. The practical implications will be suggested with respect to medical education to seven groups of stakeholders in the format of personal letters. The Chapter ends with a concluding remark as a take home message.

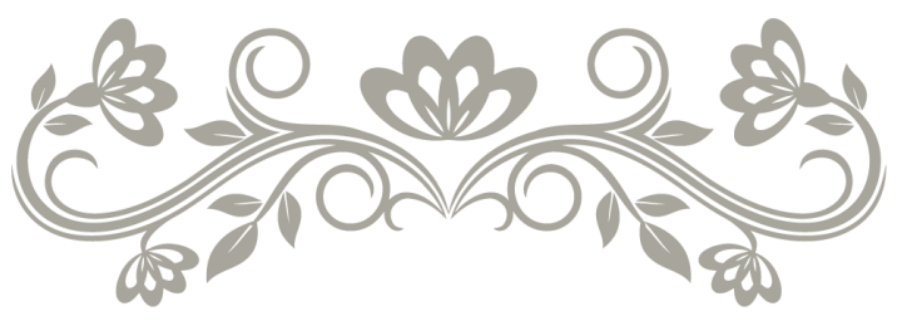




\section{References}

ABIM (American Board of Internal Medicine). (1995). Project Professionalism. Retrieved December 23, 2014, from

http://www.abimfoundation.org/ /media/Foundation/Professionalism/Proje ct professionalism.ashx?la=en

Aramesh, K., Mohebbi, M., Jessri, M., \& Sanagou, M. (2009). Measuring professionalism in residency training programs in Iran. Medical Teacher, 31(8), e356-61. Retrieved from http://www.ncbi.nlm.nih.gov/pubmed/19811199

Barakat, H. (1993). Society, Culture, and State (pp. 1-314). Berkeley: University of California Press.

Birden, H., Glass, N., Wilson, I., Harrison, M., Usherwood, T., \& Nass, D. (2013). Teaching professionalism in medical education: a Best Evidence Medical Education (BEME) systematic review. BEME Guide No. 25. Medical Teacher, 35(7), e1252-66. doi:10.3109/0142159X.2013.789132

Blackall, G. F., Melnick, S. a, Shoop, G. H., George, J., Lerner, S. M., Wilson, P. K., ... Kreher, M. (2007). Professionalism in medical education: the development and validation of a survey instrument to assess attitudes toward professionalism. Medical Teacher, 29(2-3), e58-62. doi:10.1080/01421590601044984

Bligh, J. (2005). Faculty development. Medical Education, 39(2), 120-1. doi:10.1111/j.1365-2929.2004.02098.x

Blue, A. V, Crandall, S., Nowacek, G., Luecht, R., Chauvin, S., \& Swick, H. (2009). Assessment of matriculating medical students' knowledge and attitudes towards professionalism. Medical Teacher, 31(10), 928-32. doi:10.3109/01421590802574565

Bryden, P., Ginsburg, S., \& Kurabi, B. (2010). Professing Professionalism : Are We Our Own Worst Enemy ? Faculty Members' Experiences of Teaching and 
Evaluating Professionalism in Medical Education at One School, 85(June), 1025-1034.

Centra, J. A. (1978). Types of faculty development programs. Journal of Higher Education, 49, 151-162.

Chard, D., Elsharkawy, A., \& Newbery, N. (2006). Medical professionalism: the trainees' views. Clinical Medicine (London, England), 6(1), 68-71. Retrieved from http://www.ncbi.nlm.nih.gov/pubmed/16521359

Cruess, R. L., \& Cruess, S. R. (2006). Teaching professionalism: general principles. Medical Teacher, 28(3), 205-8. doi:10.1080/01421590600643653

Cruess, R. L., Cruess, S. R., Boudreau, J. D., Snell, L., \& Steinert, Y. (2014).

Reframing medical education to support professional identity formation. Academic Medicine : Journal of the Association of American Medical Colleges, 89(11), 1446-51. doi:10.1097/ACM.0000000000000427

Cruess, R. L., Cruess, S. R., \& Johnston, S. E. (1999). Renewing professionalism: an opportunity for medicine. Academic Medicine : Journal of the Association of American Medical Colleges, 74(8), 878-84. Retrieved from http://www.ncbi.nIm.nih.gov/pubmed/10495726

Cruess, S. R., Cruess, R. L., \& Steinert, Y. (2010). Linking the teaching of professionalism to the social contract: a call for cultural humility. Medical Teacher, 32(5), 357-9. doi:10.3109/01421591003692722

Cruess, R. L., Cruess, S. R., \& Steinert, Y. (2009). Teaching medical professionalism. New York, New York, USA: Cambridge University Press..

Finn, G., Garner, J., \& Sawdon, M. (2010). "You"re judged all the time!' Students' views on professionalism: a multicentre study. Medical Education, 44(8), 81425. doi:10.1111/j.1365-2923.2010.03743.x

Goldberg, J. L. (2008). Humanism or professionalism? The White Coat Ceremony and medical education. Academic Medicine : Journal of the Association of American Medical Colleges, 83(8), 715-22.

doi:10.1097/ACM.0b013e31817eba30 
Green, M., Zick, A., \& Makoul, G. (2009). Defining professionalism from the perspective of patients, physicians, and nurses. Academic Medicine : Journal of the Association of American Medical Colleges, 84(5), 566-73. doi:10.1097/ACM.0b013e31819fb7ad

Hafferty, F. (2006). Viewpoint: the elephant in medical professionalism's kitchen. Academic Medicine : Journal of the Association of American Medical Colleges, 81(10), 906-14. doi:10.1097/01.ACM.0000238230.80419.cf

Hafferty, F. W., \& Castellani, B. (2010). The increasing complexities of professionalism. Academic Medicine : Journal of the Association of American Medical Colleges, 85(2), 288-301. doi:10.1097/ACM.0b013e3181c85b43

Hilton, S. R., \& Slotnick, H. B. (2005). Proto-professionalism: how professionalisation occurs across the continuum of medical education. Medical Education, 39(1), 58-65. doi:10.1111/j.1365-2929.2004.02033.x

Hofstede, G. (2014). National Cultural Dimensions. Retrieved December 26, 2014, from http://geert-hofstede.com/countries.html

Huggett, K. N., Warrier, R., \& Maio, A. (2008). Early learner perceptions of the attributes of effective preceptors. Advances in Health Sciences Education : Theory and Practice, 13(5), 649-58. doi:10.1007/s10459-007-9069-z

Hur, Y. (2009). Are there gaps between medical students and professors in the perception of students' professionalism level?--Secondary publication. Yonsei Medical Journal, 50(6), 751-6. doi:10.3349/ymj.2009.50.6.751

Jha, V., Mclean, M., Gibbs, T. J., \& Sandars, J. (2014). Medical professionalism across cultures: A challenge for medicine and medical education. Medical Teacher, 1-7. doi:10.3109/0142159X.2014.920492

Lave, J., \& Wenger, E. (1991). Situated Learning: Legitimate Peripheral Participation. New York, NY, USA: Cambridge University Press.. Retrieved from http://books.google.com/books?hl=ar\&lr=\&id=CAVIOrW3vYAC\&pgis=1

McLean, M., Cilliers, F., \& Van Wyk, J. M. (2008). Faculty development: yesterday, today and tomorrow. Medical Teacher, 30(6), 555-84. doi:10.1080/01421590802109834 
Nath, C., Schmidt, R., \& Gunel, E. (2006). with Educational Rank and Age, (August), 825-834.

Nhan, V. T., Violato, C., Le An, P., \& Beran, T. N. (2014). Cross-cultural construct validity study of professionalism of Vietnamese medical students. Teaching and Learning in Medicine, 26(1), 72-80. doi:10.1080/10401334.2013.857333

Palmer, K. T., Harling, C. C., Harrison, J., Macdonald, E. B., \& Snashall, D. C. (2002). Good medical practice: guidance for occupational physicians. Occupational Medicine (Oxford, England), 52(6), 341-52. Retrieved from http://www.ncbi.nlm.nih.gov/pubmed/12361996

Pickens, J. (2005). Attitudes and perceptions. Organizational Behavior in Health Care. Sudbury, MA ..., Chapter 3, 43-76. Retrieved from http://books.google.com/books?hl=en\&lr=\&id=V0ON3WC9qikC\&oi=fnd\&pg= PA43\&dq=Attitudes+and+Perceptions\&ots=BWMIXa1WNe\&sig=ZvGtRwvKpv OcTJyNZ8tqvyhugGk

Quaintance, J. L., Arnold, L., \& Thompson, G. S. (2008). Development of an Instrument to Measure, 83(10), 5-8.

Rabow, M. W., Wrubel, J., \& Remen, R. N. (2009). Promise of professionalism: personal mission statements among a national cohort of medical students. Annals of Family Medicine, 7(4), 336-42. doi:10.1370/afm.979

Ratanawongsa, N., Bolen, S., Howell, E. E., Kern, D. E., Sisson, S. D., \& Larriviere, D. (2006). Residents' perceptions of professionalism in training and practice: barriers, promoters, and duty hour requirements. Journal of General Internal Medicine, 21(7), 758-63. doi:10.1111/j.1525-1497.2006.00496.x

Rees, C. (2005). Proto-professionalism and the three questions about development. Medical Education, 39(1), 9-11. doi:10.1111/j.13652929.2004.02025.x

Stark, P., Roberts, C., Newble, D., \& Bax, N. (2006). Discovering professionalism through guided reflection. Medical Teacher, 28(1), e25-31. doi:10.1080/01421590600568520 
Steinert, Y., Cruess, R. L., Cruess, S. R., Boudreau, J. D., \& Fuks, A. (2007). Faculty development as an instrument of change: a case study on teaching professionalism. Academic Medicine : Journal of the Association of American Medical Colleges, 82(11), 1057-64.

doi:10.1097/01.ACM.0000285346.87708.67

Steinert, Y., Cruess, S., Cruess, R., \& Snell, L. (2005). Faculty development for teaching and evaluating professionalism: from programme design to curriculum change. Medical Education, 39(2), 127-36. doi:10.1111/j.13652929.2004.02069.x

Steinert, Y., McLeod, P. J., Boillat, M., Meterissian, S., Elizov, M., \& Macdonald, M. E. (2009). Faculty development: a "field of dreams"? Medical Education, 43(1), 42-9. doi:10.1111/j.1365-2923.2008.03246.x

Suzuki, N. (2009). [Certification for specialists on neurology by Japanese Society of Neurology]. Rinshō Shinkeigaku = Clinical Neurology, 49(11), 745-6. Retrieved from http://www.ncbi.nlm.nih.gov/pubmed/20030199

Swick, H. M. (2000). Toward a Normative Definition of Medical Professionalism. Academic Medicine, 75(6), 612-616. doi:10.1097/00001888-20000600000010

Symons, A. B., Swanson, A., McGuigan, D., Orrange, S., \& Akl, E. A. (2009). A tool for self-assessment of communication skills and professionalism in residents. BMC Medical Education, 9, 1. doi:10.1186/1472-6920-9-1

Talbott, J. A. (2006). Professionalism: why now, what is it, how do we do something? Journal of Cancer Education : The Official Journal of the American Association for Cancer Education, 21(3), 118-22. doi:10.1207/s15430154jce2103_4

Tsai, T., Lin, C., \& Harasym, P. H. (2008). Students ' perception on medical professionalism : the psychometric perspective, 6(4), 1-4.

Van Mook, W. N. K. A., van Luijk, S. J., O'Sullivan, H., Wass, V., Harm Zwaveling, J., Schuwirth, L. W., \& van der Vleuten, C. P. M. (2009). The concepts of professionalism and professional behaviour: conflicts in both definition and 
learning outcomes. European Journal of Internal Medicine, 20(4), e85-9. doi:10.1016/j.ejim.2008.10.006

Wynia, M. K., Papadakis, M. a, Sullivan, W. M., \& Hafferty, F. W. (2014). More than a list of values and desired behaviors: a foundational understanding of medical professionalism. Academic Medicine : Journal of the Association of American Medical Colleges, 89(5), 712-4. doi:10.1097/ACM.0000000000000212 


\section{Chapter 2}

\section{How medical professionalism is conceptualised in Arabian context: A validation study}

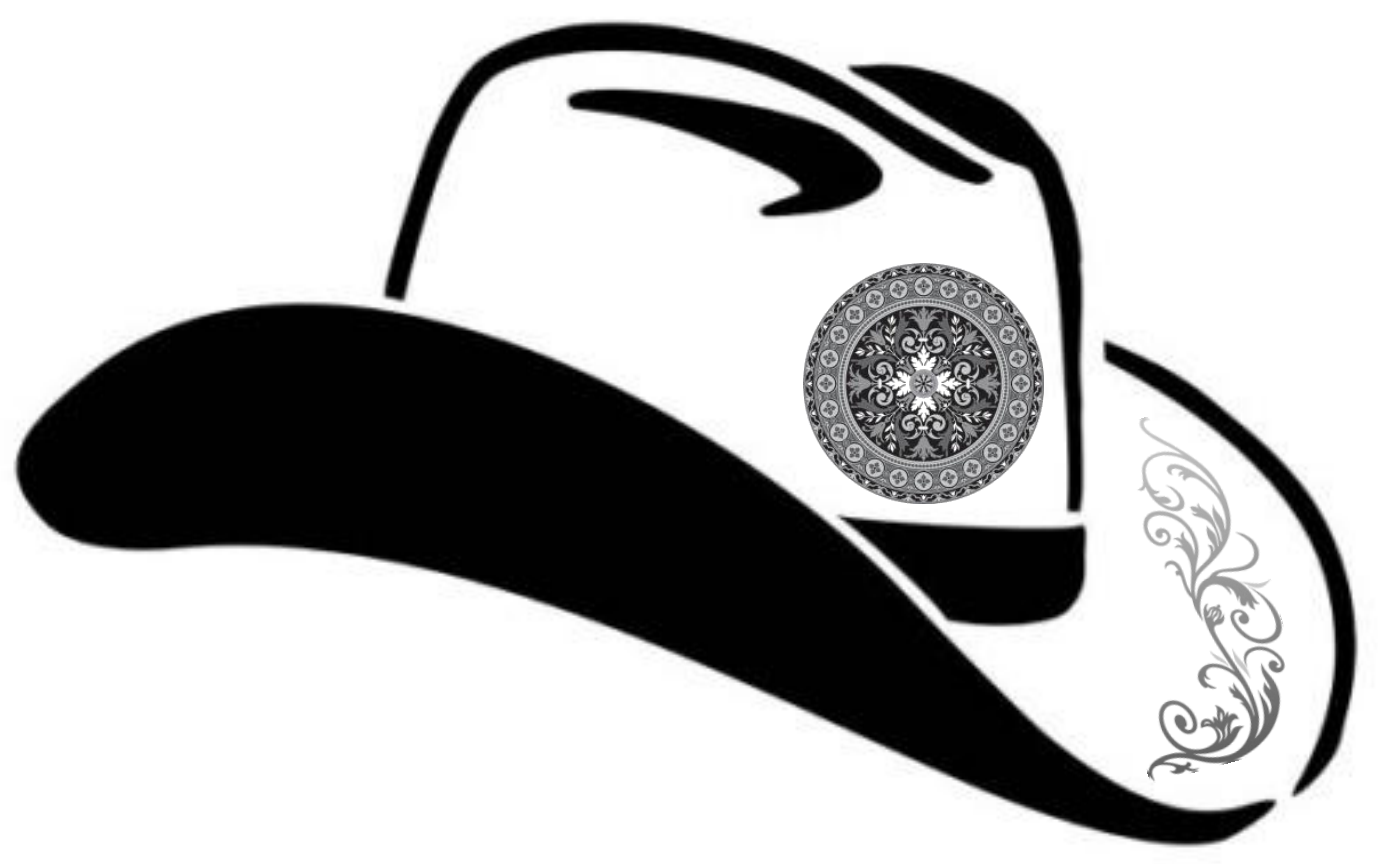

This chapter was published as:

Al-Eraky MM, Chandratilake M. How medical professionalism is conceptualised in Arabian context: a validation study. Med Teach. 2012;34 Suppl 1:S90-5. doi: 10.3109/0142159X.2012.656754. PubMed PMID: 22409198. 


\begin{abstract}
Background: Professionalism has been increasingly recognised as an explicit component of medical education, especially in the western world. Professionalism is culture-sensitive. Few efforts have been made to conceptualise professionalism in relation to the Arabian context.
\end{abstract}

Aim: The aim of this study is to validate the components of professionalism framework of the American Board of Internal Medicine (ABIM) to the Arabian context.

Method: The authors invited a heterogeneous group of native Arab health professionals and academics to contribute to a reference panel. They represented a variety of disciplines, and seniority levels, and from different healthcare institutions and medical schools in Egypt, Saudi Arabia and United Arab Emirates. They were queried about their perception of the importance of each domain of professionalism as proposed by the ABIM, and were encouraged to suggest new domains if they thought it necessary.

Results: Thirty-two out of the 45 invited health professionals and educators (71\%) contributed to the reference panel. The panel confirmed the appropriateness of the six ABIM domains to the Arabian context, and further proposed the Autonomy of professionals as an additional domain.

Discussion: The modified framework, based on ABIM domains, demonstrated the Arabian conceptualisation of professionalism. 


\section{Introduction}

The recent mounting interest on professionalism may have been triggered primarily by the calls for patient rights and autonomy (Talbott, 2006). A precise definition of the values that comprise medical professionalism has proved 'elusive' (Swick, 2000). In its broadest sense, medical professionalism encompasses all of the aspects of the higher attributes of being a physician and a healer. These attributes, however, are not universal; cultural differences exist (Jha, Mclean, Gibbs, \& Sandars, 2014). Most of these behaviours, however, are aspired by physicians while serving their patients and society and, therefore, professionalism is seen as a social contract between doctors and society (Cruess, Cruess, \& Steinert, 2010). The social contract, as described by Cruess et al. (2010), is a contractual relationship with a series of obligations and expectations based on mutual trust between the society and medicine.

There is a growing recognition of professionalism as an explicit component of medical education in the gulf region, for example, professionalism as a key aspect of Saudi doctors in Saudi-MEDs, which is a competency framework for medical education in Saudi Arabia (Zaini et al., 2011). However, the emerging frameworks on professionalism have not yet been extended to define its constituent domains. Therefore, in this study, we attempt to adapt a wellestablished framework of professionalism as developed by the American Board of Internal Medicine (ABIM) in the salient document of Project Professionalism (ABIM, 1995) to Arabian context while appreciating cultural differences.

\section{Why ABIM framework?}

We selected the ABIM framework of professionalism to be validated in Arabian context because over the past decade, different studies validated ABIM domains not only in the context in which it was originally developed in the USA (Blackall et al., 2007; Quaintance, Arnold, \& Thompson, 2008; Ratanawongsa et al., 2006; Symons, Swanson, McGuigan, Orrange, \& Akl, 2009), but also in other non-western cultures such as Taiwan (Tsai, Lin, Harasym, \& Violato, 2007), Iran (Aramesh, Mohebbi, Jessri, \& Sanagou, 2009), Japan (Suzuki, 2009) and Vietnam (Nhan, Violato, Le An, \& Beran, 2014). 


\section{The Arabian context}

Today, Arabs live in an area of more than 14 millions square kilometres which encompass almost $10 \%$ of dry land with a population of over 340 millions inhabiting 22 countries. We perceive Arabian context as a blend of culture, traditions, beliefs and behaviours that are being practiced by nations of Arabian countries in the Middle East where Arabic is the official language and Islam is the religion of majority of population. Those behaviours and traditions are not necessarily derived from Islamic doctrines but some common values have been accepted as the norm among populations of these countries. In this study, we will address the research question: how professionalism is perceived in Arabian context?

\section{Method}

\section{Study design}

This study attempts to validate the components of the ABIM framework to the Arabian context. Validation is largely a process of achieving the consensus on relevance of the content (Polit \& Beck, 2006). Therefore, we designed a consensus survey of a reference panel to establish the validity of different components of the ABIM professionalism framework, while encouraging panelists to suggest additional components if they think are relevant.

\section{Participants}

In a consensus survey, the selection of participants should not necessarily be random, but should be representative of relevant groups (Polit \& Beck, 2006). Therefore, a purposive sample of 45 medical practitioners was invited to participate in the panel. We used the following inclusion criteria in selecting the panel, as they should be (a) native Arabic speakers; (b) professional working in healthcare or health professions education in an Arab country and (c) engaged in undergraduate medical education and/or residency training in their organisations. Thirty two out of 45 invitees accepted to participate in the reference panel. An invitation was sent via email to all potential members of the reference panel with explanation of the study objectives and the expected role. Those who accepted to join the reference panel received a second email with brief definitions of ABIM domains of medical professionalism (ABIM, 1995). The email also contained our definition of Arabian context as indicated above. 


\section{Data collection procedures}

An email invitation was sent to each of the members of the reference panel. Communications with members was single-blinded throughout the study, i.e., they were not aware about other participants, even if they were working at the same institution. This precaution was taken to maintain the 'individuality' of responses and each member was expected to respond without consulting others. The invitation described their role in the research and they were provided with definitions of the six elements of the ABIM domains: altruism, accountability, excellence, duty, integrity and honour and respect (Table 2.1).

\section{Table 2.1: Domains of medical professionalism as proposed by the ABIM*}

\begin{tabular}{ll} 
Element & Description \\
Altruism & $\begin{array}{l}\text { It is the essence of professionalism. The best interest of patients, not } \\
\text { self-interest, is the rule. }\end{array}$ \\
\hline Accountability & $\begin{array}{l}\text { It is required at many levels - individual patients, society and the } \\
\text { profession for fulfilling the implied contract governing the } \\
\text { patient/physician relationship. }\end{array}$ \\
\hline It entails a conscientious effort to exceed ordinary expectations and to \\
make a commitment to life-long learning.
\end{tabular}

*Source: The American Board of Internal Medicine (ABIM, 1995)

Each panelist was asked to respond via email to an attached 6-item questionnaire; one question for every domain of ABIM framework. The question was: how do you view the importance of this particular domain of professionalism in Arabian context? Their responses were analysed in a 5-point Likert scale with each rating point was allocated with a particular score: $5=$ =xtremely important, 4=very important, 3=important, $2=$ slightly important, 1=not important. An openended question encouraging panelists to suggest additional components was included at the end of the questionnaire. In addition, demographic data such as 
gender, country of birth and specialty were expected to be included in completing the questionnaire.

\section{Data analysis}

Descriptive statistics was planned to analyse responses of the panelists to identify the measures of central tendency (mean, mode and median) for each domain along with the standard deviation (SD).

\section{Results}

Thirty two out of the 45 invited professionals contributed to the reference panel (71\%). Respondents represented a blend of seniority levels ranging from staff physicians, specialist, consultants up to medical directors and vice-deans. Both genders were fairly represented in the panel: 18 males and 14 females. They were full-time practitioners of 25 different subspecialties; they have been working in 11 medical schools and healthcare organisations in Egypt, Kingdom of Saudi Arabia (KSA) and United Arab Emirates (UAE) (Table 2.2).

All ABIM domains were thought to be highly important by the panelists. Descriptive statistics were provided, including: the mean, SD, frequency, median, mode, minimum and maximum scores along with the range (Table 2.3). In response to the open-ended question, 22 members of the panel suggested 24 elements of professionalism in addition to the ABIM domains, while 10 respondents did not add new elements. Almost all 'new suggestions', however, could be mapped against the ABIM components of professionalism (Table 2.4), except professional autonomy which was, therefore, considered the seventh element of professionalism in the Arabian context. 
Table 2.2: Demography and background of the panelists

\begin{tabular}{|c|c|c|c|c|c|c|}
\hline No. & Seniority* & Gender & $\begin{array}{l}\text { Country } \\
\text { of Birth }\end{array}$ & $\begin{array}{l}\text { Professional } \\
\text { Qualification }\end{array}$ & Specialty & Setting \\
\hline 1 & Senior & Male & Egypt & Medicine & Family Medicine & Clinical \\
\hline 2 & Junior & Male & Egypt & Medicine & Laboratory Medicine & Clinical \\
\hline 3 & Senior & Male & Saudi & Medicine & Cardiology & Clinical \\
\hline 4 & Junior & Male & Sudan & Medicine & General Practitioner & Clinical \\
\hline 5 & Senior & Female & Egypt & Medicine & General Surgery & Clinical \\
\hline 6 & Senior & Male & Egypt & Medicine & Anesthesia & Clinical \\
\hline 7 & Senior & Male & Egypt & Medicine & Anesthesia & Clinical \\
\hline 8 & Senior & Male & Egypt & Medicine & Biochemistry & Academic \\
\hline 9 & Junior & Female & Egypt & Medicine & Microbiology & Clinical \\
\hline 10 & Senior & Female & Iraq & Medicine & Gynecology & Clinical \\
\hline 11 & Senior & Female & Saudi & Medicine & Gynecology & Clinical \\
\hline 12 & Senior & Female & Egypt & Medicine & Microbiology & Academic \\
\hline 13 & Senior & Male & Egypt & Medicine & Administration & Academic \\
\hline 14 & Junior & Female & Egypt & Pharmacy & Clinical Pharmacy & Clinical \\
\hline 15 & Senior & Male & Egypt & Medicine & Anatomy & Academic \\
\hline 16 & Senior & Male & Syria & Medicine & Pediatrics & Clinical \\
\hline 17 & Junior & Male & Lebanon & Medicine & Urology & Clinical \\
\hline 18 & Senior & Male & Saudi & Medicine & Medical ethics & Academic \\
\hline 19 & Senior & Male & Egypt & Medicine & Emergency Medicine & Clinical \\
\hline 20 & Senior & Male & Egypt & Medicine & Anatomy & Academic \\
\hline 21 & Junior & Male & Egypt & Dentistry & General Dentist & Clinical \\
\hline 22 & Junior & Male & Egypt & Medicine & Radiology & Clinical \\
\hline 23 & Senior & Female & Lebanon & Nursing & Nursing & Clinical \\
\hline 24 & Senior & Female & Saudi & Medicine & Endocrinology & Clinical \\
\hline 25 & Senior & Female & Lebanon & Medicine & Internal Medicine & Clinical \\
\hline 26 & Senior & Female & Egypt & Medicine & Physiology & Academic \\
\hline 27 & Junior & Female & $\mathrm{UAE}^{* *}$ & Pharmacy & Pharmacy & Academic \\
\hline 28 & Junior & Male & Syria & Medicine & Orthopedics Surgery & Clinical \\
\hline 29 & Senior & Female & Egypt & Medicine & Forensic Medicine & Academic \\
\hline 30 & Senior & Female & Egypt & Medicine & Biochemistry & Academic \\
\hline 31 & Senior & Female & Lebanon & Nursing & Nursing & Clinical \\
\hline 32 & Senior & Male & Saudi & Medicine & Critical Care Medicine & Clinical \\
\hline
\end{tabular}

* Senior is attributed to a professional with 20 years of experience or more.

** Clinical setting indicates working in patient-care, while academic does not. 
Table 2.3: Descriptive statistics of results from the panelists $(n=32)$ on the importance of the ABIM domains of professionalism in an Arabian context:

\begin{tabular}{|c|c|c|c|c|c|c|c|c|}
\hline Domains & Mean & $\begin{array}{l}\text { St. } \\
\text { Dev. }\end{array}$ & Raw score* (Frequency) & $\begin{array}{l}\frac{3}{\mathrm{D}} \\
\frac{\mathrm{O}}{\mathrm{D}} \\
\frac{\mathrm{O}}{3}\end{array}$ & $\begin{array}{l}3 \\
\frac{3}{0}\end{array}$ & $\frac{3}{3}$ & $\frac{3}{x}$ & 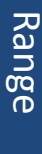 \\
\hline Altruism & 4.38 & 0.71 & $1(0), 2(0), 3(4), 4(12), 5(16)$ & 4.5 & 5 & 3 & 5 & 2 \\
\hline Accountability & 4.66 & 0.55 & $1(0), 2(0), 3(1), 4(9), 5(22)$ & 5.0 & 5 & 3 & 5 & 2 \\
\hline Excellence & 4.16 & 0.88 & $1(0), 2(2), 3(4), 4(13), 5(13)$ & 4.0 & 4,5 & 2 & 5 & 3 \\
\hline Integrity \& Honor & 4.69 & 0.47 & $1(0), 2(0), 3(0), 4(10), 5(22)$ & 5.0 & 5 & 4 & 5 & 1 \\
\hline Duty & 4.34 & 0.79 & $1(0), 2(1), 3(3), 4(12), 5(16)$ & 4.5 & 5 & 2 & 5 & 3 \\
\hline Respect & 4.53 & 0.76 & $1(0), 2(1), 3(2), 4(8), 5(21)$ & 5.0 & 5 & 2 & 5 & 3 \\
\hline
\end{tabular}

* Note: Raw score - 1: strongly disagree, 2: disagree, 3: not decided/neutral, 4: agree, 5: strongly agree

The seventh domain

Professional autonomy of physicians is a privilege, which is not enjoyed by many other professions and medical professionalism is based on liberty of the clinician to exploit all of his potential as a healer (G. Beauchamp, 2004). Given the general cultural outlook of the Middle-Eastern and eastern societies, where the power balance between a doctor and a patient is more towards the doctor, i.e., physicians have more authority in decision-making process than patients (Morrow, Rothwell, Burford, \& Illing, 2013). Identifying professionals' autonomy as a component of professionalism in Arabic context, therefore, was not surprising. This may not be the case in the West. The health reforms and governance in the western world advocate more on autonomy of patients, i.e., patients have greater say in healthcare delivery than on the autonomy of professionals (Quill, 1996). Patient autonomy is one of the four moral principles of biomedical ethics, along with justice, beneficence and non-maleficence ( $T$. L. Beauchamp, 2003). Patient autonomy entails explaining not only what is wrong with that person, but also the options and implications of any proposed investigation and treatment and the associated risks and benefits. The profile of patient autonomy has also been raised further as the media and the Internet have provided the public with greater access to information on medicine and health professional (Gillon, 2003). 
Table 2.4: Other elements of professionalism that were proposed by the members of the reference panel as categorized in light of the six ABIM domains.

Element of professionalism as suggested by the reference panel*
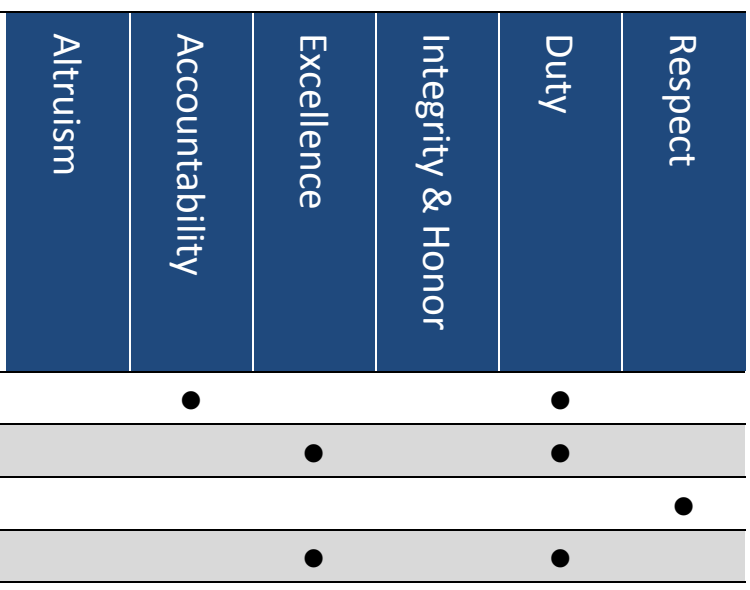

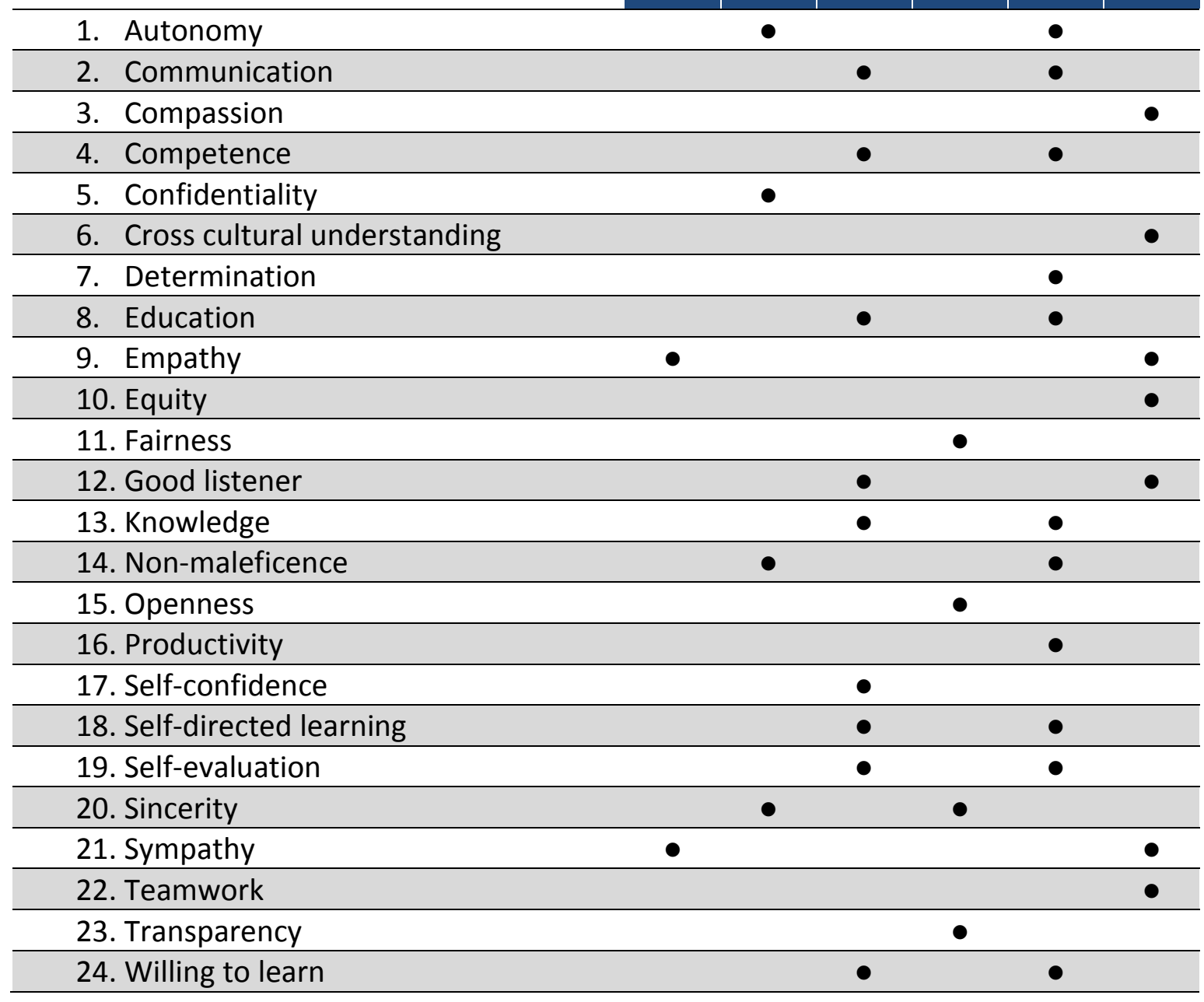

Notes:

- All of the above elements were proposed by a single member of the reference panel, but only Knowledge and Autonomy were suggested by two members.

- Ten out of the 32 members of the panel did not suggest new elements of professionalism other than those of the ABIM. 


\section{Discussion}

In this study, the reference panel, with acceptable consensus, identified all components of the ABIM framework of professionalism as appropriate for the Arabian context. In addition, they indicated professional autonomy as an important component of professionalism. As described in the 'Introduction' section, the ABIM framework has been accepted as it is by different groups. However, in many cases, like in this study, it has been adapted with amendments. In the North American context, Blackall et al. (2007) reported two new elements of professionalism: enrichment and equity, in addition to the six domains of ABIM. Nevertheless, when Tsai et al. (2007) attempted to validate ABIM domains to the Taiwanese context, eight new domains emerged: commitment to care, righteous and rule-binding, pursuing quality patient care, habit of practice, interpersonal relationship, patient-oriented issues, self-development and respect for others. It appears that the 'difference' is greater when the context shares an 'eastern culture' than a 'western' culture. This confirms the existence of cultural variations and context-specificity of professionalism. However, in this study, the only inclusion was the professional autonomy. Unlike in this study, only three factors were found to be valid in the Farsi (Persian) context: excellence, integrity/honour, and altruism/respect (Aramesh et al., 2009).

\section{Implications}

To the best of our knowledge, this is the first study which attempts to operationalise a conceptual framework of professionalism for Arabian context. This study, therefore, fills a gap in the professionalism literature and provides a basis for teaching, learning and assessment of professionalism in the Arab world.

\section{Limitations}

Although this study provides insight into a very important area which has been scarcely researched, it has several limitations. First, though the number of panelists participating in this study was acceptable for a validation study, a higher number may have provided more credible results. Second, there might be selection bias, because of the high percentage of Egyptians among participants, while there are 21 other Arab countries. This bias was not intended but can be justified in light of the Egypt Demographic Profile report (2011), Egyptians 
exceeded 82 million, which represents almost $22 \%$ of the total population of Arabs. In establishing the content validity, we tried our best to recruit panelists from different related professional groups. As demonstrated in Table 2, panelists represent a wide range of professions (medicine, dentistry, pharmacy, nursing, medical technology), who are working in a variety of clinical and academic settings from both genders. Given the nature of this study, i.e., validation exercise, the composition of the reference panel is acceptable. Third, as the Arab world constitutes several countries, one can argue that the findings are not generalisable citing the differences between countries. According to Barakat (1993), although there are differences, 'Arab world' is a single, overarching society rather than a collection of several independent states. Minor differences, however, may be identified by furthering this research in the future using this study as a basis.

\section{Conclusion}

The Arabian conceptualisation of professionalism appeared to largely, but not entirely, overlap that of their western counterparts, North Americans for example. The differences may be attributable to the cultural background. The framework identified for the Arabian context appreciating such differences will be helpful in reforming professionalism education in the region. We hope this study acts as a building block towards addressing professionalism as an integral outcome of the new medical education framework in Saudi Arabia, namely SaudiMEDs, which can be considered as a leading initiative to explicitly teach and assess professionalism in the formal curricula of Arabian medical schools.

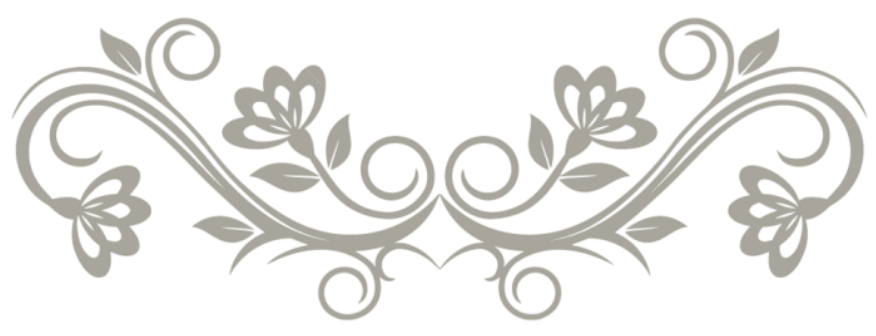




\section{References}

ABIM (American Board of Internal Medicine). (1995). Project Professionalism. Retrieved December 23, 2014, from http://www.abimfoundation.org/ /media/Foundation/Professionalism/Proje ct professionalism.ashx?la=en

Aramesh, K., Mohebbi, M., Jessri, M., \& Sanagou, M. (2009). Measuring professionalism in residency training programs in Iran. Medical Teacher, 31(8), e356-61. Retrieved from http://www.ncbi.nlm.nih.gov/pubmed/19811199

Barakat, H. (1993). Society, Culture, and State (pp. 1-314). Berkeley: University of California Press.

Beauchamp, G. (2004). The Challenge of Teaching Professionalism †, 33(6), 697705.

Beauchamp, T. L. (2003). Methods and principles in biomedical ethics. Journal of Medical Ethics, 29(5), 269-274. doi:10.1136/jme.29.5.269

Blackall, G. F., Melnick, S. a, Shoop, G. H., George, J., Lerner, S. M., Wilson, P. K., ... Kreher, M. (2007). Professionalism in medical education: the development and validation of a survey instrument to assess attitudes toward professionalism. Medical Teacher, 29(2-3), e58-62. doi:10.1080/01421590601044984

Cruess, S. R., Cruess, R. L., \& Steinert, Y. (2010). Linking the teaching of professionalism to the social contract: a call for cultural humility. Medical Teacher, 32(5), 357-9. doi:10.3109/01421591003692722

Gillon, R. (2003). Ethics needs principles--four can encompass the rest--and respect for autonomy should be "first among equals". Journal of Medical Ethics, 29(5), 307-12. Retrieved from http://www.pubmedcentral.nih.gov/articlerender.fcgi?artid=1733792\&tool= pmcentrez\&rendertype=abstract 
Jha, V., Mclean, M., Gibbs, T. J., \& Sandars, J. (2014). Medical professionalism across cultures: A challenge for medicine and medical education. Medical Teacher, 1-7. doi:10.3109/0142159X.2014.920492

Morrow, G., Rothwell, C., Burford, B., \& Illing, J. (2013). Cultural dimensions in the transition of overseas medical graduates to the UK workplace. Medical Teacher, 35(10), e1537-45. doi:10.3109/0142159X.2013.802298

Nhan, V. T., Violato, C., Le An, P., \& Beran, T. N. (2014). Cross-cultural construct validity study of professionalism of Vietnamese medical students. Teaching and Learning in Medicine, 26(1), 72-80. doi:10.1080/10401334.2013.857333

Polit, D. F., \& Beck, C. T. (2006). The content validity index: are you sure you know what's being reported? Critique and recommendations. Research in Nursing \& Health, 29(5), 489-97. doi:10.1002/nur.20147

Quaintance, J. L., Arnold, L., \& Thompson, G. S. (2008). Development of an Instrument to Measure, 83(10), 5-8.

Quill, T. E. (1996). Physician Recommendations and Patient Autonomy: Finding a Balance between Physician Power and Patient Choice. Annals of Internal Medicine, 125(9), 763. doi:10.7326/0003-4819-125-9-199611010-00010

Ratanawongsa, N., Bolen, S., Howell, E. E., Kern, D. E., Sisson, S. D., \& Larriviere, D. (2006). Residents' perceptions of professionalism in training and practice: barriers, promoters, and duty hour requirements. Journal of General Internal Medicine, 21(7), 758-63. doi:10.1111/j.1525-1497.2006.00496.x

Suzuki, N. (2009). [Certification for specialists on neurology by Japanese Society of Neurology]. Rinshō Shinkeigaku = Clinical Neurology, 49(11), 745-6. Retrieved from http://www.ncbi.nlm.nih.gov/pubmed/20030199

Swick, H. M. (2000). Toward a Normative Definition of Medical Professionalism. Academic Medicine, 75(6), 612-616. doi:10.1097/00001888-20000600000010

Symons, A. B., Swanson, A., McGuigan, D., Orrange, S., \& Akl, E. A. (2009). A tool for self-assessment of communication skills and professionalism in residents. BMC Medical Education, 9, 1. doi:10.1186/1472-6920-9-1 
Talbott, J. A. (2006). Professionalism: why now, what is it, how do we do something? Journal of Cancer Education : The Official Journal of the American Association for Cancer Education, 21(3), 118-22. doi:10.1207/s15430154jce2103_4

Tsai, T.-C., Lin, C.-H., Harasym, P. H., \& Violato, C. (2007). Students' perception on medical professionalism: the psychometric perspective. Medical Teacher, 29(2-3), 128-34. doi:10.1080/01421590701310889

Zaini, R. G., Bin Abdulrahman, K. a, Al-Khotani, A. a, Al-Hayani, A. M. a, Al-Alwan, I. a, \& Jastaniah, S. D. (2011). Saudi Meds: a competence specification for Saudi medical graduates. Medical Teacher, 33(7), 582-4.

doi:10.3109/0142159X.2011.578180 
44 


\section{Chapter 3}

\section{Medical professionalism: Development and validation of the Arabian LAMPS}

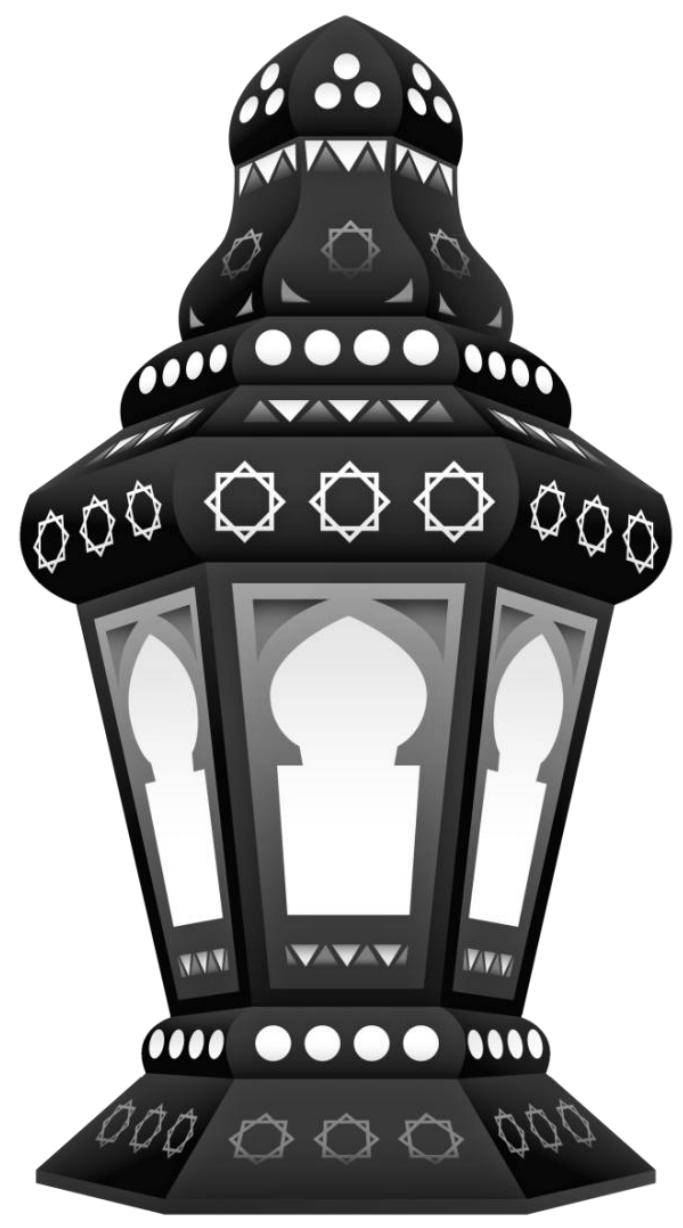

This chapter was published as:

Al-Eraky MM, Chandratilake M, Wajid G, Donkers J, van Merrienboer J. Medical professionalism: development and validation of the Arabian LAMPS. Med Teach. 2013;35 Suppl 1:S56-62. doi: 10.3109/0142159X.2013.765553. PubMed PMID: 23581897. 


\begin{abstract}
Aim: This study aims to develop and validate a questionnaire that measures attitudes of medical students on professionalism in the Arabian context.

Method: Thirty-two experts contributed to item generation in particular domains. The instrument was administered to Arab medical students and interns and responses were collected using five-point Likert scale. Data were analyzed to estimate the reliability of the instrument. The inventory in its final version was labeled as the Learners' Attitude of Medical Professionalism Scale (LAMPS).

Results: A total of 413 medical students and interns responded from two universities in Egypt and Saudi Arabia. Means of item response ranged from 2.38 to 4.72. The highest mainly deals with Respect to others, while the lowest belong to Honor/Integrity. The final version of the LAMPS has 28 items in five domains, with a reliability of 0.79 .
\end{abstract}

Discussion: The LAMPS has salient features compared to other similar instrument. It was designed based on a reliable framework in explicit behavioural items, not abstract attributes of professionalism. The LAMPS can help teachers identify learning gaps regarding professionalism amongst their students and track attitude changes over time or as the result of interventions.

Conclusion: To the best of our knowledge, the LAMPS is the first context-specific inventory on medical professionalism attitudes in the Arabian context. 


\section{Introduction}

Medical professionalism rests on "a contractual relationship with a series of obligations and expectations based on mutual trust between the society and medicine" (Sylvia R Cruess, Cruess, \& Steinert, 2010). Professionalism is a culturesensitive construct and, therefore, is perceived and expressed with respect to local customs, beliefs, and cultures (Chandratilake, McAleer, \& Gibson, 2012; Vikram Jha, Mclean, Gibbs, \& Sandars, 2014). This has initiated a global trend of re-visiting professionalism education and, as a result, professionalism has become an explicit component of medical curricula (ABIM, 1995; Zaini et al., 2011).

Professionalism must be taught through the formal curriculum in the form of planned teaching and learning sessions and be assessed throughout the continuum of medical education ( $S R$ Cruess \& Cruess, 1997). Although professionalism education is gaining momentum in the Arabian context, the literature from that region on that topic is still scarce. Arabian teachers and students feel that professionalism education remains as a gap in formal curricula (Sadat-Ali, 2004) and they consider professionalism as a major contributor to the hidden curriculum, rather than the formal one (Adkoli, Al-Umran, Al-Sheikh, Deepak, \& Al-Rubaish, 2011). Incorporating professionalism in medical education should be based on the core attributes of what people think of a professional doctor in a particular culture.

A number of studies reported the attitudes on professionalism among students (Tsai, Lin, \& Harasym, 2008), residents (Chard, Elsharkawy, \& Newbery, 2006; Ephgrave et al., 2006), faculty members (Hur, 2009; Quaintance, Arnold, \& Thompson, 2008), patients (Davis, Wiggins, Mercado, \& O'Sullivan, 2007), and the public at large (Chandratilake, McAleer, Gibson, \& Roff, 2010). The attitude of medical students toward professionalism is of great educational value, because they are supposed to be the future professionals.

The "socially-exclusive" medical students enter medical school with positive attitudes toward professionalism attributes (Blakey, Blanshard, Cole, Leslie, \& Sen, 2008). Their personal standards and ethics are driven from past exposure to family, teachers, friends, and other social contacts (Nath, Schmidt, \& Gunel, 2006). Exploring students' attitudes has been used widely to measure different components of professionalism and related areas in the Western context (Blackall et al., 2007; Chard et al., 2006; Finn, Garner, \& Sawdon, 2010), 
south Asian context (Hur, 2009; Tsai et al., 2008), and Turkish context (Sehiralti, Akpinar, \& Ersoy, 2010), but unfortunately, none has been validated contextualized to be used in the Arabian context.

By Arabian context, we mean the culture, traditions, beliefs, and behaviours that are being practiced by nations of Arabian countries in the MiddleEast, where Arabic is the official language and Islam is the religion of the majority of the population. Those behaviours and traditions are not necessarily driven from Islamic doctrines, but some common values have been accepted as the norm among populations of these countries (Barakat, 1993).

The American Board of Internal Medicine (ABIM) identified six domains as a framework of medical professionalism (ABIM, 1995). In a previous study, we have used these domains as a basis to define a framework for medical professionalism in a consensus survey recruiting professionals who validated the ABIM domains in the Arabian context (Al-Eraky \& Chandratilake, 2012). They accepted all six domains of the ABIM framework, yet a new seventh domain, namely "Professional Autonomy," emerged. Medical students, however, do not know how attributes of professionalism function in practice (Blue et al., 2009). A questionnaire should be developed to express these abstract domains into behavioural items (Green, Zick, \& Makoul, 2009)

The aim of this study is two-fold. First, it aims to develop a questionnaire based on the seven domains to measure the attitude of Arabian medical students toward medical professionalism. Second, it aims to validate this questionnaire.

\section{Methodology}

The instrument that will be developed is called the Learners 'Attitudes on Medical Professionalism Scale (LAMPS). Development of the LAMPS passes through four steps: (1) defining the constructs/domains of professionalism that are being measured, (2) generating behavioural items for each domain, (3) pilot testing of the LAMPS, and (4) finalizing the scale based on data collected in Step 3. 


\section{Step 1: Defining the construct}

Thirty-two experts volunteered to contribute to content validation of domains and item generation. The panelists were a convenient but representative sample of different disciplines and seniority levels from both genders. Panelists were provided with definitions of the seven domains of professionalism to be clear on the constructs being measured.

\section{Step 2: Item generation}

As a rationale step, authors developed 35 behavioural items to represent the seven domains of professionalism. We invited the panelists to review these items and sort out each item in one single construct/domain, based on the definitions provided earlier. Item categorization into domains was done by counting the votes, which were received independently from each member of the reference panel. When votes for a particular item were dispersed over more than one domain, the item was considered multi-directional (query) and, therefore, excluded from the initial pool before pilot testing. We further asked the panelists to suggest new situations (behavioural items), if any, from their current practice and indicate their domain. They submitted 17 more items to the authors independently without communicating with their peers. Subsequently, it was expected to find closely related scenarios or even addressing almost the same situation. These items were considered redundant, but we decided to keep them in pilot testing and postpone 'trimming' of the instrument after checking the internal consistency of subscales for different domains.

\section{Step 3: Pilot testing}

Participants:

We targeted medical students and interns from Zagazig University in Egypt and Dammam University in Saudi Arabia, who filled the questionnaire.

Data collection:

The inventory was translated to Arabic to minimize the misinterpretation of items and reviewed by two independent native Arabic speakers. The preliminary 
version of the instrument was distributed in a paper format by hand to medical students and interns. Seven teachers volunteered to distribute the survey questionnaire to students in both the universities. A cover letter was attached to standardize instructions to all participants. The cover letter explained the objectives of the study and instructed students to indicate what they personally thought of the behaviour in each situation, not what they experienced as "common" in practice.

\section{Data analysis:}

Five-point Likert scale was used to record responses on items. For positively-worded item statements that represented professional behaviours, we used a scale of 1 to 5 (1=strongly disagree, $5=$ strongly agree). For negativelyworded statements that represent unprofessional behaviours, the scale was reversed ( $1=$ strongly agree, $5=$-strongly disagree). Mean and standard deviation for each item and domain were reported, along with the reliability using Cronbach's alpha.

\section{Step 4: Finalizing the LAMPS}

The final version of the LAMPS was contoured in light of different aspects of validity and reliability of domains and items of each domain. In content validation, we found some commonalities of behaviours between specific pairs of domains, while other domains remain. In the original validated framework of the $A B I M$, Honor/Integrity was the title of a single domain. Likewise, we decided to merge two pairs of domains together; Duty/Accountability and Excellence/Autonomy. Items of the LAMPS, therefore, were sorted out into five final domains, rather than seven. We found it more practical for identifying learning gaps and designing modules on particular areas in professionalism.

In item filtration, our objective was not to maximize the reliability at the expense of validity, i.e. we did not exclude important items that address common behaviours just to get higher alpha coefficient. It was rather a tradeoff between maximizing, validating, and achieving an appropriate number of items that address important aspects of each domain. Throughout the four steps in development and validation, the LAMPS has been matured through a number of processes, while excluding query and redundant items, till it has been evaluated in its final shape (Figure 3.1). 


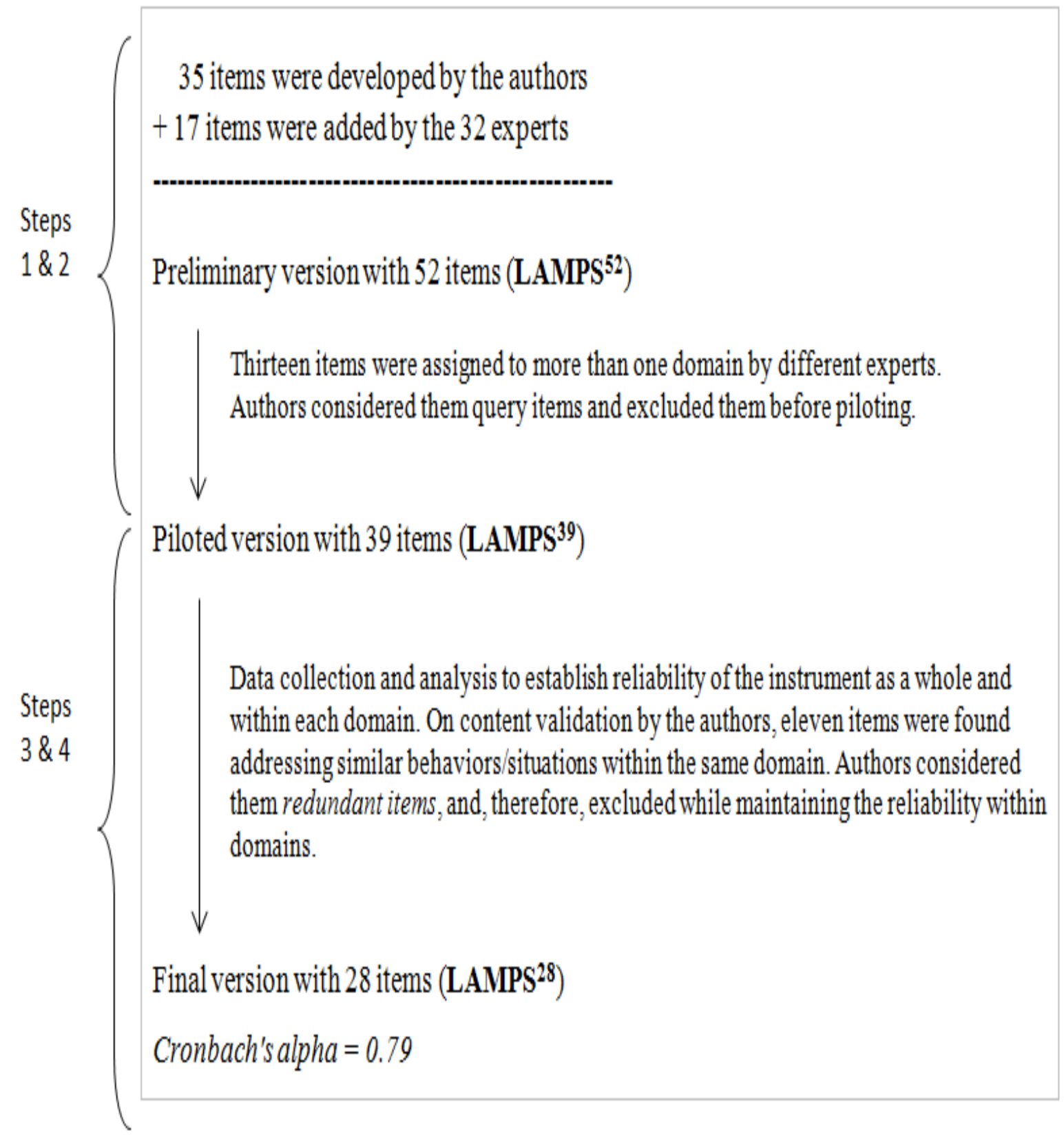

Figure 3.1 The Evolution of the LAMPS through its four developmental stages

\section{Results}

The final version of the LAMPS has 28 items and is presented in Table 3.1. 
Table 3.1 The final version of the instrument with 28 items $\left(\right.$ LAMPS $\left.^{28}\right)$.

Behavioural item within domains

"Do you agree when the doctor ...?"
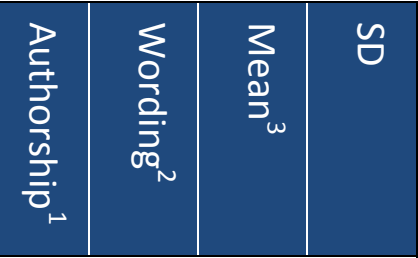

\section{Duty/Accountability}

1. Admits wrong diagnosis before a patient

2. Leaves before handing over patients to the next colleague on duty

3. Commits to actively participate in orientation for new residents

4. Encourages patients to contribute to decision making

5. Discusses patients cases with colleagues in a crowded elevator

6. Calls insurance company to follow up a valid patient claim

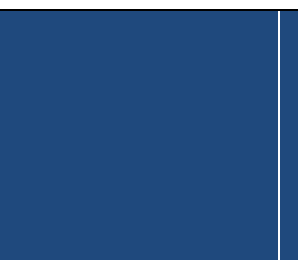

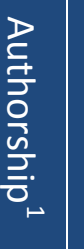

7. Declines an invitation to an infection control committee meeting

\section{Excellence/Autonomy}

1. Reflects on clinical cases to discover his/her unmet learning needs

Pn. $\quad+$ ve $4.35 \quad 0.78$

2. Attend pt. questions to explain their illness in a busy clinic

3. Search for the best evidence available in patient care.

Pn. $\quad$-ve $\quad 4.25 \quad 0.79$

Pn. $\quad+$ ve $4.16 \quad 0.72$

Au. +ve 4.160 .81

Au. $\quad$-ve $\quad 4.10 \quad 0.95$

Pn. $\quad+$ ve $\quad 3.77 \quad 0.91$

4. Collaborates with colleagues to draft new hospital guidelines

Pn. $\quad$-ve $\quad 3.30 \quad 0.91$

5. Invests part of his/her income on attending medical conferences

Au. $\quad+$ ve $4.61 \quad 0.67$

6. Makes a deal with a pharma company to sponsor his/her conference

\section{Honor/Integrity}

1. Gives wrong information to patient to protect a colleague

2. Issues a false sick leave for a kid of a friend to study home

Pn. $\quad+$ ve $4.37 \quad 0.74$

Au. +ve $4.37 \quad 0.79$

Au. +ve $4.30 \quad 0.74$

3. Changes actual data in his/her research based on supervisor's advice

Pn. $\quad+$ ve 3.510 .95

Au. $\quad$-ve $\quad 3.38 \quad 1.11$

4. hides information about fatal diagnosis to avoid patient disturbance

5. Introduce medical students as doctors to patients

Au. $\quad$-ve $\quad 4.37 \quad 0.85$

Au. $\quad$-ve $\quad 3.98 \quad 1.04$

Au. $\quad$-ve $\quad 3.47 \quad 1.01$

Altruism

1. Declines sport club to respond to an emergency call

Au. $\quad$-ve $\quad 3.34 \quad 1.17$

2. Frequently skips clinical teaching to prepare for a conference

Au. $\quad+$ ve $\quad 4.45 \quad 0.77$

3. Cancels a family appointment for an urgent patient's need

Au. $\quad$-ve $\quad 4.24 \quad 0.92$

4. Do not witness against employer hospital in favor of a pt. before court

Au. $\quad+$ ve $\quad 4.150 .82$

5. Turns down a home visit to a disable patient due to busy clinic

Pn. $\quad$-ve $\quad 3.78 \quad 0.99$

Respect

1. Respects the roles of all members of the healthcare team in the dept. $\quad$ Au. $\quad+$ ve $\quad \begin{array}{lll}4.72 & 0.67\end{array}$

2. Considers patient background when explaining their clinical illness

3. Keeps patients waiting in his/her clinic without apology

4. Give priority to some patients based on social status or nationality

Au. +ve $4.66 \quad 0.62$

5. Criticizes a prescription written by a colleague in front of patients.

Au. $\quad$-ve $\quad 4.54 \quad 0.75$

Au. $\quad$-ve $\quad 4.47 \quad 0.89$

${ }^{1}$ Authorship: Au.: proposed by the authors, Pn.: added by the panel of expert.

${ }^{2}$ Wording: +ve.: Positively-worded item, -ve : Negatively-worded item.

${ }^{3}$ Items are sorted out within each domain in a descending order, based on their means. 
Descriptive statistics

A total of 413 responses were received from Egyptians and Saudi medical students and interns from two universities. The mean scores of items varies between 2.38 (SD 1.20, scale 1-5) and 4.72 (SD 0.67, scale 1-5). The highest scoring items mainly deal with the domain of "Respect to others," while the lowest ones mostly belong to "Honor/Integrity."

Reliability of the LAMPS

Cronbach's alpha of 0.70 or more normally indicates acceptable internal consistency (Gable \& Wolf, 1993). The reliability of the final version of the LAMPS was 0.79 , which can be considered high in view of the multifaceted nature of the construct being measured (medical professionalism). The inter-item correlation for items intended to measure the same factor/domain should be moderate, but not too high (i.e. between 0.30 and 0.60 ), because higher inter-item correlations within the domain suggest that each separate item does not contribute something unique to the construct (Pett, Lackey, \& Sullivan, 2003). The subscales of the LAMPS have an internal consistency range from 0.42 to 0.57 (Table 3.2).

Table 3.2: Means and reliability of domains of the LAMPS.

\begin{tabular}{lcl} 
Domain & Mean & $\begin{array}{l}\text { Reliability by Cronbach's } \\
\text { alpha* }\end{array}$ \\
Respect (5 items) & 4.53 & 0.57 \\
\hline Excellence/Autonomy (6 items) & 4.09 & 0.48 \\
\hline Altruism (5 items) & 4.02 & 0.42 \\
\hline Duty/Accountability (7 items) & 4.01 & 0.57 \\
\hline Honor/Integrity (5 items) & 3.50 & 0.43
\end{tabular}

Note: * Reliability within each factor/domain should be moderate ranging from 0.3-0.6 (Pett, 2003)

\section{Discussion}

The LAMPS is intended to measure attitudes of Arabian medical students and interns toward medical professionalism. We claim that the LAMPS fits for its purpose, because it stems from the ABIM framework of professionalism. The ABIM domains have been used repeatedly as a basis to develop similar instruments, not only in the USA as its original context (Blackall et al., 2007; 
Quaintance et al., 2008; Ratanawongsa et al., 2006), but also in non-Western cultures in Taiwan (Tsai et al., 2008), Iran (Aramesh, Mohebbi, Jessri, \& Sanagou, 2009), and Japan (Suzuki, 2009). Those domains of professionalism have been found also appropriate for the Arabian context, with some amendments (Al-Eraky \& Chandratilake, 2012).

\section{Evidence for validity}

Content-related evidence of validity refers to the content and format of the LAMPS. How comprehensive is the content? How adequately does the sample of items represent the domains of professionalism? Using an existing reference framework, like the ABIM domain, is a highly recommended method in establishing the content validity of a measurement (Clark \& Watson, 1995). Most studies define professionalism in vague terms like altruism, humanism, and excellence, while few studies "operationalized" medical professionalism in behaviours (V Jha, Bekker, Duffy, \& Roberts, 2006). Green et al. (2009), however, argued that tangible behaviours, not domains, are important to facilitate discussion, assessment, and modeling of professionalism. Unlike other similar instruments, the LAMPS is designed in expressive behavioural items in the form of micro-vignettes, which are developed and reviewed by the authors along with 32 panelists. The wording of these vignettes was reviewed by two independent Arabic native professionals, who did not contribute to authoring the items to safeguard the clarity of each vignette.

In pilot testing the LAMPS, students were instructed to report their own perceptions on different micro-vignettes on professionalism, not what they experienced from doctors around them in the local environment. This helped students to focus on the construct that was being measured. Sample size recommendation for piloting an instrument should include either a minimum of 10 respondents per item (Nunnally, J. C., Bernstein, I. H., \& Berge, 1967). or a minimum overall sample of 300 respondents (Comrey \& Lee, 1992).

Our sample size is considered adequate for validation of the instrument in its piloted version. The Arab world constitutes several countries; one can argue that the inferences of the LAMPS may not be externally valid (generalizable) citing the differences between countries. According to Barakat (1993), although there are differences, 'Arab world' is a single, overarching society rather than a collection of several independent states. We deliberately enrolled medical students and interns from Egypt and Saudi Arabia, where almost one quarter of 
Arabs live, to expand the spectrum of responses. It was not a surprise that the overall mean scores of the LAMPS among Egyptians and Saudis were 3.9 and 4.0, respectively, which reflects close similarities of attitudes towards medical professionalism. The

Implications and use of the Arabian LAMPS

A useful inference is the one that helps us make a decision. The LAMPS not only measures students' attitudes, but also score of the LAMPS' domains and items that can be used to identify the learning gaps in particular areas of professionalism. Identifying the gaps and misconceptions in professionalism among students and helping them rectify these gaps is a key step in fostering professionalism (Hur, 2009) and fulfilling social accountability of a medical school (Woollard \& Boelen, 2012). Now, the question is: how does the "LAMPS" enable teachers to identify these learning gaps and act accordingly? The score of respondents on particular domains on the LAMPS represents their views on professionalism on these domains. If they score low on "respect," for instance, it indicate misunderstanding of the concept of respect. We, as medical teachers, then may consider introducing some educational interventions and using vignettes for reflection to address "respect." Students should also recognize the boundaries of each domain. Every virtue is midway between two non-virtues, e.g. respect to superiors is midway between disrespect and apple polishing. The same is applicable for other domains.

\section{LAMPS versus similar instruments}

Since professionalism is closely related to the social contract. Most of reported studies were conducted on medical students in Western societies; USA $(n=11)$, UK $(n=6)$, and Canada $(n=5)$. None of these instruments may be appropriate for the Arabian context. When reviewing relevant literature, salient features of the "Arabian LAMPS" can be identified. Many of the reported instruments on professionalism do not stem from known domains. The LAMPS, however, was primarily developed based on ABIM (1995) elements of professionalism. The LAMPS is compared with three similar instruments (Blackall et al., 2007; Nath et al., 2006; Tsai et al., 2008), two of them stemming from the same ABIM framework (Table 3.3). 
Table 3.3: Comparison between the LAMPS and three similar instruments.

\begin{tabular}{|c|c|c|c|c|}
\hline Instrument & Nath (2006) & Tsai (2007) & Blackall (2007) & The LAMP (2011) \\
\hline $\begin{array}{l}\text { Objective } \\
\text { of the } \\
\text { study }\end{array}$ & $\begin{array}{l}\text { To assess whether } \\
\text { the perception of } \\
\text { what constituted } \\
\text { professionalism } \\
\text { caries with age, } \\
\text { discipline, gender, } \\
\text { educational level. }\end{array}$ & $\begin{array}{l}\text { To explore how } \\
\text { Taiwanese } 7^{\text {th }} \\
\text { year medical } \\
\text { students value } \\
\text { medical } \\
\text { professionalism }\end{array}$ & $\begin{array}{l}\text { To examine } \\
\text { attitudes toward } \\
\text { professionalism }\end{array}$ & $\begin{array}{l}\text { To Develop and } \\
\text { validate an inventory } \\
\text { to measure attitudes } \\
\text { of medical students } \\
\text { towards } \\
\text { professionalism in } \\
\text { Arabian context }\end{array}$ \\
\hline Context & American & Taiwanese & American & Arabian \\
\hline $\begin{array}{l}\text { Target } \\
\text { groups }\end{array}$ & $\begin{array}{ll}\text { - } & \text { Medical } \\
\text { students } \\
\text { - } & \text { Residents } \\
\text { - } & \text { Faculty } \\
\end{array}$ & $\begin{array}{l}\text { - Senior } \\
\text { medical } \\
\text { students }\end{array}$ & $\begin{array}{ll}\text { - } & \text { Medical } \\
\text { students } \\
\text { - } & \text { Residents } \\
\text { - } & \text { Faculty } \\
\end{array}$ & $\begin{array}{l}\text { - Senior medical } \\
\text { students } \\
\text { - Interns (junior } \\
\text { doctors) }\end{array}$ \\
\hline Country & USA & Taiwan & USA & Egypt \& Saudi Arabia \\
\hline Domains & Not identified & ABIM & ABIM & ABIM \\
\hline Items* & 29 items & 32 items & 36 items & 28 items \\
\hline $\begin{array}{l}\text { Items were } \\
\text { developed }\end{array}$ & By the panel & $\begin{array}{l}\text { By medical } \\
\text { experts }\end{array}$ & By the panel & $\begin{array}{l}\text { Jointly by the author } \\
\text { and the panel }\end{array}$ \\
\hline Panel & 7 members & Not identified & 9 members & 32 members \\
\hline $\begin{array}{l}\text { Leading } \\
\text { question }\end{array}$ & $\begin{array}{l}\text { How do you classify } \\
\text { the following } \\
\text { behaviour? }\end{array}$ & $\begin{array}{l}\text { How do you rate } \\
\text { the importance } \\
\text { of the following } \\
\text { attribute of } \\
\text { professionalism? }\end{array}$ & $\begin{array}{l}\text { To what extent } \\
\text { the item reflects } \\
\text { your definition } \\
\text { of } \\
\text { professionalism? }\end{array}$ & $\begin{array}{l}\text { Do you agree when } \\
\text { the doctor ...? }\end{array}$ \\
\hline Scale & $\begin{array}{l}\text { Three option: } \\
\text { - Professional } \\
\text { - Unprofessional } \\
\text { - Unrelated to } \\
\quad \text { professionalism }\end{array}$ & $\begin{array}{l}\text { Five-point Likert } \\
\text { scale } \\
\text { - Extremely } \\
\text { important, } \\
\text { - Important, } \\
\text { - Uncertain, } \\
\text { - Not } \\
\text { important, } \\
\text { - Least } \\
\text { important. }\end{array}$ & $\begin{array}{l}\text { Five-point Likert } \\
\text { scale } \\
\text { - } \quad \text { Never } \\
\text { - } \quad \text { Little } \\
\text { - } \quad \text { Some } \\
\text { - } \quad \text { Much } \\
\text { - } \quad \text { Great deal. }\end{array}$ & $\begin{array}{l}\text { Five-point Likert scale } \\
\text { - Strongly agree, } \\
\text { - Agree, } \\
\text { - Uncertain, } \\
\text { - Disagree, } \\
\text { - Strongly disagree. }\end{array}$ \\
\hline $\begin{array}{l}\text { Responden } \\
\text { ts, Rate (\%) }\end{array}$ & $n=610,(45 \%)$ & $\begin{array}{l}n=133,(\% \text { was } \\
\text { not identified) }\end{array}$ & $n=765,(51 \%)$ & $n=413,(76 \%)$ \\
\hline $\begin{array}{l}\text { Reliability } \\
\text { Cronbach's } \\
\text { alpha) }\end{array}$ & Not reported & $\begin{array}{l}\text { Ranged from } \\
0.66 \text { to } 0.86\end{array}$ & $\begin{array}{l}\text { Ranged from } \\
0.51 \text { to } 0.78\end{array}$ & $\begin{array}{l}\text { Ranged from } \\
0.41 \text { to } 0.85\end{array}$ \\
\hline
\end{tabular}

* Number of items of the final version of the instrument 
Items of the LAMPS have been developed jointly by the authors and the panelists. The number of experts who were recruited for content validation of the LAMPS was by far more than others. Also the LAMPS has been administered in two institutions. With critical analysis of items of other instruments, we found that the questionnaire of Nath et al. (2006) consisted of 29 anecdotal statements that are not categorized into domains. The survey of Tsai et al. (2008), however, included extremely short broad terms, such as: prudence, integrity fair or being straightforward, and long compound ones such as: respect other physicians and professional colleagues such as nurses, medical students, residents, and subspecialty fellows. Items of the LAMPS represent explicit behaviours as microscenarios in a comparable word count.

The LAMPS can also be used to track attitude changes on professionalism across different groups and over time. Application of the LAMPS before and after an educational intervention on professionalism helps in evaluating the intervention by the progress in students' learning. Even without intervention, the LAMPS can demonstrate how professionalism is transformed in the minds of medical students throughout medical education by comparing senior and junior students or using the LAMPS in a longitudinal study. This transformation is particularly important in Arabian medical schools for two reasons: (1) professionalism is not, so far, addressed in teaching or assessment, and (2) there is a minimal integration between basic and clinical sciences in traditional curricula.

If the LAMPS is administered to medical students and their teachers, it can estimate the perception gaps in attitudes toward certain aspects of professionalism between the two groups. The perception of teachers can be viewed as a benchmark on professionalism for students, as reported in the Korean context (Hur, 2009). Fine tuning the scale of the LAMPS introduces new implications. The LAMPS can be used to estimate the trend of these behaviours in the community. The leading question can be changed from: "Do you agree when the doctor. . .?" to be "How often do you encounter a doctor. . .?" In the "trendy LAMPS," the scale from 1 to 5 represents the frequency of observed behaviour (1=never, 5=always). Naturally, common behaviours should be handled with special care depending whether they are positively-worded items (recommended behaviours) or negatively-word items (discouraged behaviours).

When the 'trendy LAMPS' is administered to all stakeholders, e.g. students, doctors, nurses, technicians, health administrators, and patients, it will reflect the 
professional environment within a particular institution, which can be called: 'environmental LAMPS' If a negative behaviour is found popular, it should be addressed explicitly in faculty development programs to encourage positive rolemodels among teachers. Students' views can be also used to identify problems in faculty' behaviours to customize appropriate faculty development modules in professionalism (Quaintance et al., 2008; Szauter \& Turner, 2001).

\section{Limitations of the LAMPS}

There is always darkness under the LAMPS. No single instrument can be inclusive of all traits and behaviours of professionalism. We tired our best to sample commonest behaviours within domains of professionalism in a particular context. Medical professionalism is a complex construct that relatively requires more items to address its dimensions. Interestingly, the 28 items of the LAMPS is even less than the average number of similar instruments, which may range from 29 items (Nath et al., 2006) to 36 items (Blackall et al., 2007). The LAMPS is designed as a context-specific instrument. This is a double-bladed feature which can be considered as a strength and limitation as well. Unlike the culture-free inventories like the Dundee Ready Educational Environment Measure (DREEM) (Roff, 2005), the Arabian LAMPS is designed to be a culturally-specific inventory for Arabs. Although the number of responses achieved and the multi-centered approach are quite adequate for a validation study, the LAMPS should be tested more widely to confirm its external validity. We will be looking forward to see our LAMPS shining in other Arabian countries.

\section{Conclusion}

Professionalism must be taught in medical schools, because there is a growing body of evidence that unprofessional behaviours of undergraduates are associated with future disciplinary actions by health authorities. But, teaching professionalism should rely on needs assessment with respect to the context of the learners. To the best of our knowledge, the LAMPS is the first validated and reliable tool to measure attitudes toward professionalism in the Arabian context.

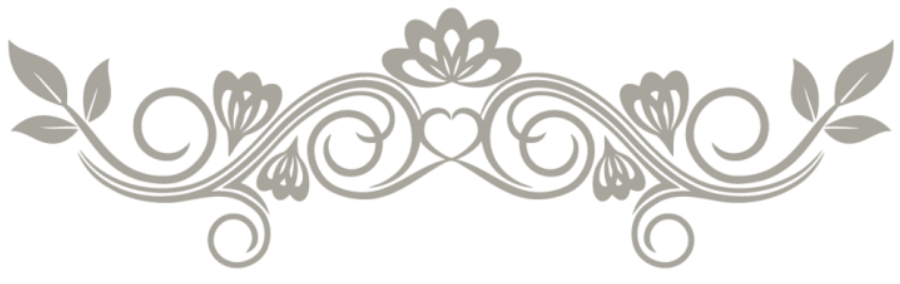




\section{References}

ABIM (American Board of Internal Medicine). (1995). Project Professionalism. Retrieved December 23, 2014, from http://www.abimfoundation.org/ /media/Foundation/Professionalism/Proje ct professionalism.ashx?la=en

Adkoli, B. V, Al-Umran, K. U., Al-Sheikh, M., Deepak, K. K., \& Al-Rubaish, A. M. (2011). Medical students' perception of professionalism: a qualitative study from Saudi Arabia. Medical Teacher, 33(10), 840-5. doi:10.3109/0142159X.2010.541535

Al-Eraky, M. M., \& Chandratilake, M. (2012). How medical professionalism is conceptualised in Arabian context: A validation study. Medical Teacher.

Aramesh, K., Mohebbi, M., Jessri, M., \& Sanagou, M. (2009). Measuring professionalism in residency training programs in Iran. Medical Teacher, 31(8), e356-61. Retrieved from http://www.ncbi.nlm.nih.gov/pubmed/19811199

Barakat, H. (1993). Society, Culture, and State (pp. 1-314). Berkeley: University of California Press.

Blackall, G. F., Melnick, S. a, Shoop, G. H., George, J., Lerner, S. M., Wilson, P. K., ... Kreher, M. (2007). Professionalism in medical education: the development and validation of a survey instrument to assess attitudes toward professionalism. Medical Teacher, 29(2-3), e58-62. doi:10.1080/01421590601044984

Blakey, H., Blanshard, E., Cole, H., Leslie, F., \& Sen, R. (2008). Are medical students socially exclusive? A comparison with economics students. Medical Education, 42(11), 1088-91. doi:10.1111/j.1365-2923.2008.03126.x

Blue, A. V, Crandall, S., Nowacek, G., Luecht, R., Chauvin, S., \& Swick, H. (2009). Assessment of matriculating medical students' knowledge and attitudes towards professionalism. Medical Teacher, 31(10), 928-32. doi:10.3109/01421590802574565 
Chandratilake, M., McAleer, S., \& Gibson, J. (2012). Cultural similarities and differences in medical professionalism: a multi-region study. Medical Education, 46(3), 257-66. doi:10.1111/j.1365-2923.2011.04153.x

Chandratilake, M., McAleer, S., Gibson, J., \& Roff, S. (2010). Medical professionalism: what does the public think? Clinical Medicine (London, England), 10(4), 364-9. Retrieved from http://www.ncbi.nlm.nih.gov/pubmed/20849011

Chard, D., Elsharkawy, A., \& Newbery, N. (2006). Medical professionalism: the trainees' views. Clinical Medicine (London, England), 6(1), 68-71. Retrieved from http://www.ncbi.nlm.nih.gov/pubmed/16521359

Clark, L. A., \& Watson, D. (1995). Constructing validity: Basic issues in objective scale development., 7(3), 309-319.

Comrey, A. L., \& Lee, H. B. (1992). A First Course in Factor Analysis. New Jersey: Lawrence ErlbaumAssociates, Inc. Retrieved from http://books.google.com/books?hl=ar\&lr=\&id=RSsVAgAAQBAJ\&pgis=1

Cruess, S. R., \& Cruess, R. L. (1997). Professionalism must be taught. BMJ (Clinical Research Ed.), 315(7123), 1674-7. Retrieved from http://www.pubmedcentral.nih.gov/articlerender.fcgi?artid=2128025\&tool= pmcentrez\&rendertype=abstract

Cruess, S. R., Cruess, R. L., \& Steinert, Y. (2010). Linking the teaching of professionalism to the social contract: a call for cultural humility. Medical Teacher, 32(5), 357-9. doi:10.3109/01421591003692722

Davis, R. L., Wiggins, M. N., Mercado, C. C., \& O'Sullivan, P. S. (2007). Defining the core competency of professionalism based on the patient's perception. Clinical \& Experimental Ophthalmology, 35(1), 51-4. doi:10.1111/j.14429071.2006.01383.x

Ephgrave, K., Stansfield, R. B., Woodhead, J., Sharp, W. J., George, T., \& Lawrence, J. (2006). The resident view of professionalism behavior frequency in outstanding and "not outstanding" faculty. American Journal of Surgery, 191(5), 701-5. doi:10.1016/j.amjsurg.2006.02.002 
Finn, G., Garner, J., \& Sawdon, M. (2010). "You"re judged all the time!' Students' views on professionalism: a multicentre study. Medical Education, 44(8), 81425. doi:10.1111/j.1365-2923.2010.03743.x

Gable, R. K., \& Wolf, M. B. (1993). Instrument Development in the Affective Domain: Measuring Attitudes and Values in Corporate and School Settings. Kluwer Academic Publishers. Retrieved from http://books.google.com.sa/books/about/Instrument_Development_in_the_ Affective.html?id=wQvlhDB05skC\&pgis=1

Green, M., Zick, A., \& Makoul, G. (2009). Defining professionalism from the perspective of patients, physicians, and nurses. Academic Medicine : Journal of the Association of American Medical Colleges, 84(5), 566-73. doi:10.1097/ACM.0b013e31819fb7ad

Hur, Y. (2009). Are there gaps between medical students and professors in the perception of students' professionalism level?--Secondary publication. Yonsei Medical Journal, 50(6), 751-6. doi:10.3349/ymj.2009.50.6.751

Jha, V., Bekker, H. L., Duffy, S. R. G., \& Roberts, T. E. (2006). Perceptions of professionalism in medicine: a qualitative study. Medical Education, 40(10), 1027-36. doi:10.1111/j.1365-2929.2006.02567.x

Jha, V., Mclean, M., Gibbs, T. J., \& Sandars, J. (2014). Medical professionalism across cultures: A challenge for medicine and medical education. Medical Teacher, 1-7. doi:10.3109/0142159X.2014.920492

Nath, C., Schmidt, R., \& Gunel, E. (2006). with Educational Rank and Age, (August), 825-834.

Nunnally, J. C., Bernstein, I. H., \& Berge, J. M. T. (1967). Psychometric Theory. New York, NY, USA: McGraw-Hill.

Pett, M. A., Lackey, N. R., \& Sullivan, J. J. (2003). Making Sense of Factor Analysis: The Use of Factor Analysis for Instrument Development in Health Care Research (p. 348). SAGE Publications.

Quaintance, J. L., Arnold, L., \& Thompson, G. S. (2008). Development of an Instrument to Measure, 83(10), 5-8. 
Ratanawongsa, N., Bolen, S., Howell, E. E., Kern, D. E., Sisson, S. D., \& Larriviere, D. (2006). Residents' perceptions of professionalism in training and practice: barriers, promoters, and duty hour requirements. Journal of General Internal Medicine, 21(7), 758-63. doi:10.1111/j.1525-1497.2006.00496.x

Roff, S. (2005). The Dundee Ready Educational Environment Measure (DREEM)--a generic instrument for measuring students' perceptions of undergraduate health professions curricula. Medical Teacher, 27(4), 322-5.

Sadat-Ali, M. (2004). Professionalism: are we doing enough? Saudi Medical Journal, 25(5), 676-7. Retrieved from http://www.ncbi.nlm.nih.gov/pubmed/15138544

Sehiralti, M., Akpinar, A., \& Ersoy, N. (2010). Attributes of a good physician: what are the opinions of first-year medical students? Journal of Medical Ethics, 36(2), 121-5. doi:10.1136/jme.2009.032854

Suzuki, N. (2009). [Certification for specialists on neurology by Japanese Society of Neurology]. Rinshō Shinkeigaku = Clinical Neurology, 49(11), 745-6. Retrieved from http://www.ncbi.nlm.nih.gov/pubmed/20030199

Szauter, K., \& Turner, H. E. (2001). Using students' perceptions of internal medicine teachers' professionalism. Academic Medicine : Journal of the Association of American Medical Colleges, 76(5), 575-6. Retrieved from http://www.ncbi.nlm.nih.gov/pubmed/11346634

Tsai, T., Lin, C., \& Harasym, P. H. (2008). Students ' perception on medical professionalism : the psychometric perspective, 6(4), 1-4.

Woollard, B., \& Boelen, C. (2012). Seeking impact of medical schools on health: meeting the challenges of social accountability. Medical Education, 46(1),217.

Zaini, R. G., Bin Abdulrahman, K. a, Al-Khotani, A. a, Al-Hayani, A. M. a, Al-Alwan, I. a, \& Jastaniah, S. D. (2011). Saudi Meds: a competence specification for Saudi medical graduates. Medical Teacher, 33(7), 582-4. doi:10.3109/0142159X.2011.578180 


\section{Chapter 4}

\section{The cultural dimensions of medical professionalism in an Arabian context}

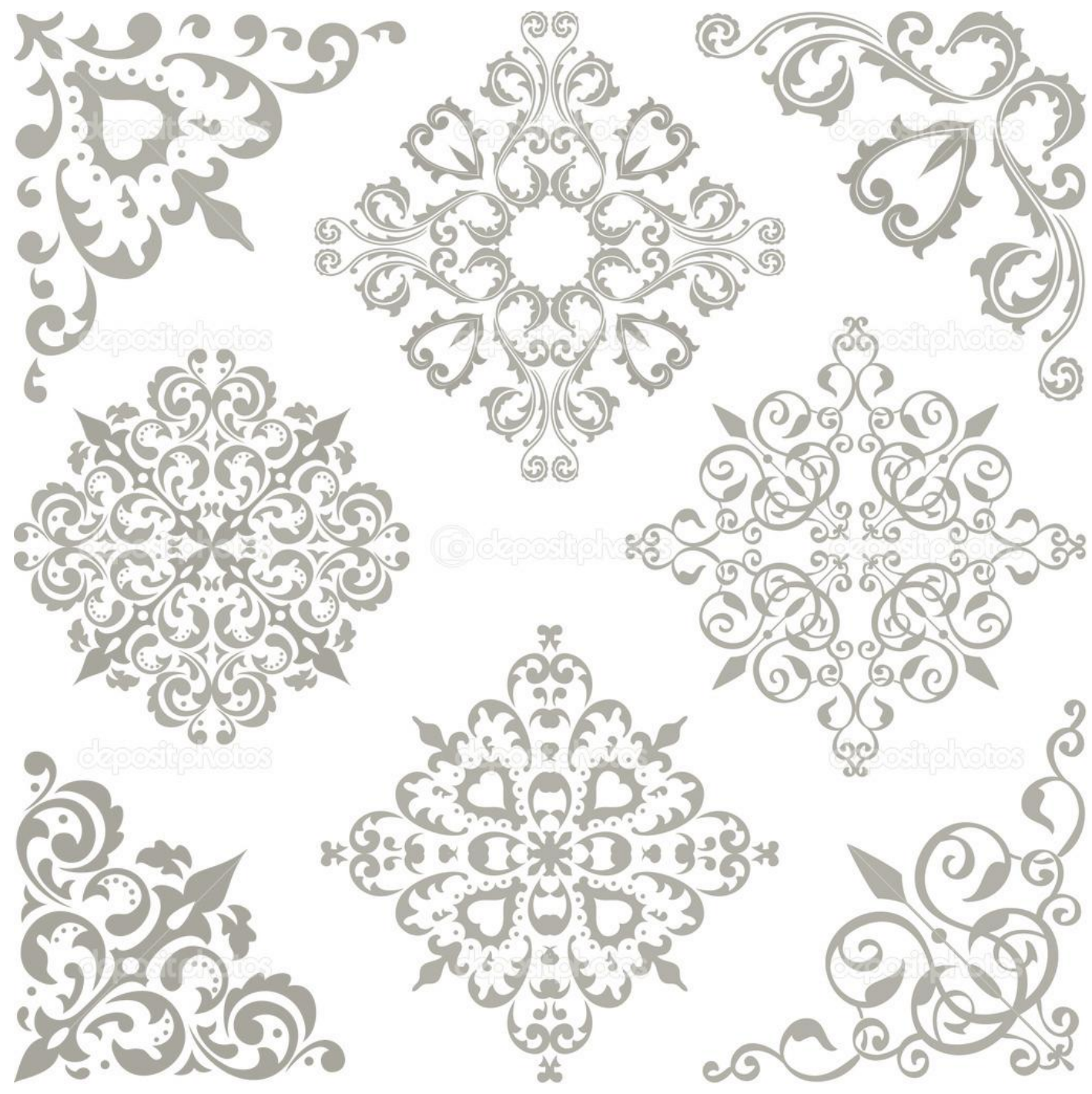


$6 6 \longdiv { 2 }$ 


\begin{abstract}
Background: Professionalism is culture-specific, but little is known about the cultural underpinning of professional attitudes of medical education.

Aim: To measure attitudes of medical students in Egypt and Saudi Arabia on professionalism and to interpret the findings in light of the cultural differences between the two countries to suggest correlations between cultural dimensions and professionalism domains.

Method: We used a validated instrument called Learners' Attitudes on Medical Professionalism Scale (LAMPS) to compare attitudes of medical students on five domains of professionalism: altruism, duty/accountability, excellence/autonomy, honour/integrity and respect. Hofstede's cultural dimensions were used to interpret attitudes on medical professionalism.
\end{abstract}

Results: Saudi medical students from a country with a large power distance were significantly more attentive towards behaviours related to Honour/Integrity (3.6 $\pm 0.54, \mathrm{p}<0.0001, \mathrm{D}=0.72)$ and Respect $(4.6 \pm 0.41, \mathrm{p}=0.01, \mathrm{D}=0.42)$ as compared to Egyptian students ( $3.2 \pm 0.57$ and $4.4 \pm 0.53$ ).

Discussion: The study used empirical data to explore the cultural underpinning of professionalism. The vigilance of Saudi students towards Honour/Integrity and Respect may be attributed to the large power distance, where they aspire to maintain their privilege in the community and preserve the respect and trust they earn from their patients. Authors advocated a number of practical implications to medical practitioners, educators and researchers in professionalism issues, particularly in societies where hierarchy and competitiveness are highly regarded. 


\section{Introduction}

Medical professionalism signifies a set of values and behaviours that physicians aspire while serving their patients and the community (Hafferty, 2006). Any profession needs two elements to develop within a society: (1) The interest of the public in the services provided and (2) the trust in the members of that profession. Professionalism is a socially constructed phenomenon that applies to a community with shared values and customs (S. R. Cruess, Cruess, \& Steinert, 2010a). A social contract is built between the professional and the public, which changes over time, but has always been central to the medical profession (Reid, 2011). Those obligations and social expectations vary according to culture, which justify why medical professionalism is culture-sensitive and the situations used to measure its constructs or domains should reflect cultural differences.

Culture is the 'collective programming of the mind distinguishing the members of one group or category of people from others' (Hofstede, 2014a). It is the total of the inherited ideas, beliefs, values, and knowledge, which constitute the shared basis of social action.

To decipher the relationship between culture and professionalism, we have to analyse each to its basic elements. With respect to culture, Hofstede devised a model to measure its dimensions so that countries can be compared (Hofstede, 2014b). According to Hofstede's work, the influence of culture on a particular society can be observed using a set of values. Hofstede clustered the values that distinguish countries into four different groups that became his dimensions of national culture: (1) Power Distance Index (PDI); the extent to which the less powerful members of a society accept and expect that power is distributed unequally, (2) Individualism (IND) versus collectivism; the degree to which individuals are integrated into groups, (3) Masculinity (MAS) versus femininity; whether the society is competitive or consensus-oriented, and (4) Uncertainty Avoidance Index (UAI); how comfortable the society is in novel, unknown, unusual and ambiguous situations.

Table 4.1 lists the values of the Hofstede's cultural dimensions in selected Arab countries in comparison to the available global ones. Arab nations - in general - have relatively high values of Power Distance that range from 70 (in Egyptians) to 95 (in Saudis), relatively low Individualism, moderate Masculinity and variable Uncertainty Avoidance values (Hofstede, 2014b) 
Table 4.1. Values of the cultural domains in selected Arab countries in comparison with the world.

\begin{tabular}{|c|c|c|c|c|c|}
\hline \multicolumn{2}{|c|}{$\begin{array}{l}\text { Hofstede's Cultural } \\
\text { Dimensions* }\end{array}$} & \multirow{2}{*}{$\begin{array}{c}\text { PDI } \\
70\end{array}$} & \multirow{2}{*}{$\begin{array}{l}\text { IND } \\
25\end{array}$} & \multirow{2}{*}{$\begin{array}{c}\text { MAS } \\
45\end{array}$} & \multirow{2}{*}{$\begin{array}{l}\text { UAI } \\
80\end{array}$} \\
\hline \multirow{6}{*}{ 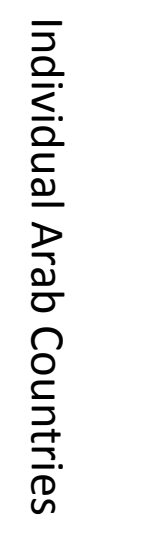 } & Egypt** & & & & \\
\hline & Emirates & 90 & 25 & 50 & 80 \\
\hline & Iraq & 95 & 30 & 70 & 85 \\
\hline & Kuwait & 90 & 25 & 40 & 80 \\
\hline & Lebanon & 75 & 40 & 65 & 50 \\
\hline & Saudi** & 95 & 25 & 60 & 80 \\
\hline \multirow{4}{*}{$\begin{array}{l}\frac{D}{D} \\
\frac{D}{\sigma} \\
\frac{\Phi}{D} \\
\frac{D}{D} \\
\stackrel{D}{\omega}\end{array}$} & Highest & 95 & 40 & 70 & 85 \\
\hline & Lowest & 70 & 25 & 40 & 50 \\
\hline & Range & 25 & 15 & 30 & 35 \\
\hline & Mean & 86 & 28 & 55 & 76 \\
\hline \multirow[t]{4}{*}{ 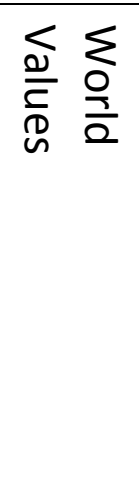 } & Highest & $\begin{array}{c}104 \\
\text { (Malaysia) }\end{array}$ & $\begin{array}{c}91 \\
\text { (USA) }\end{array}$ & $\begin{array}{c}95 \\
\text { (Japan) } \\
\end{array}$ & $\begin{array}{c}112 \\
\text { (Greece) }\end{array}$ \\
\hline & Lowest & $\begin{array}{c}11 \\
\text { (Austria) }\end{array}$ & $\begin{array}{c}6 \\
\text { (Guatemala) }\end{array}$ & $\begin{array}{c}5 \\
\text { (Sweden) }\end{array}$ & $\begin{array}{c}8 \\
\text { (Singapore) }\end{array}$ \\
\hline & Range & 93 & 85 & 90 & 104 \\
\hline & Mean & 59 & 45 & 50 & 68 \\
\hline
\end{tabular}

* Values were retrieved from Hofstede Center from http://geert-hofstede.com/countries.html on 21 November 2013.

** Egypt and Saudi Arabia represent the context of the current study.

PDI: $\quad$ Power Distance Index

IND: Individualism index

MAS: Masculinity index

UAI: Uncertainty Avoidance Index 
In societies with large power distance, there is an emphasis on hierarchy in medical professionalism, as portrayed in Figure 4.1.

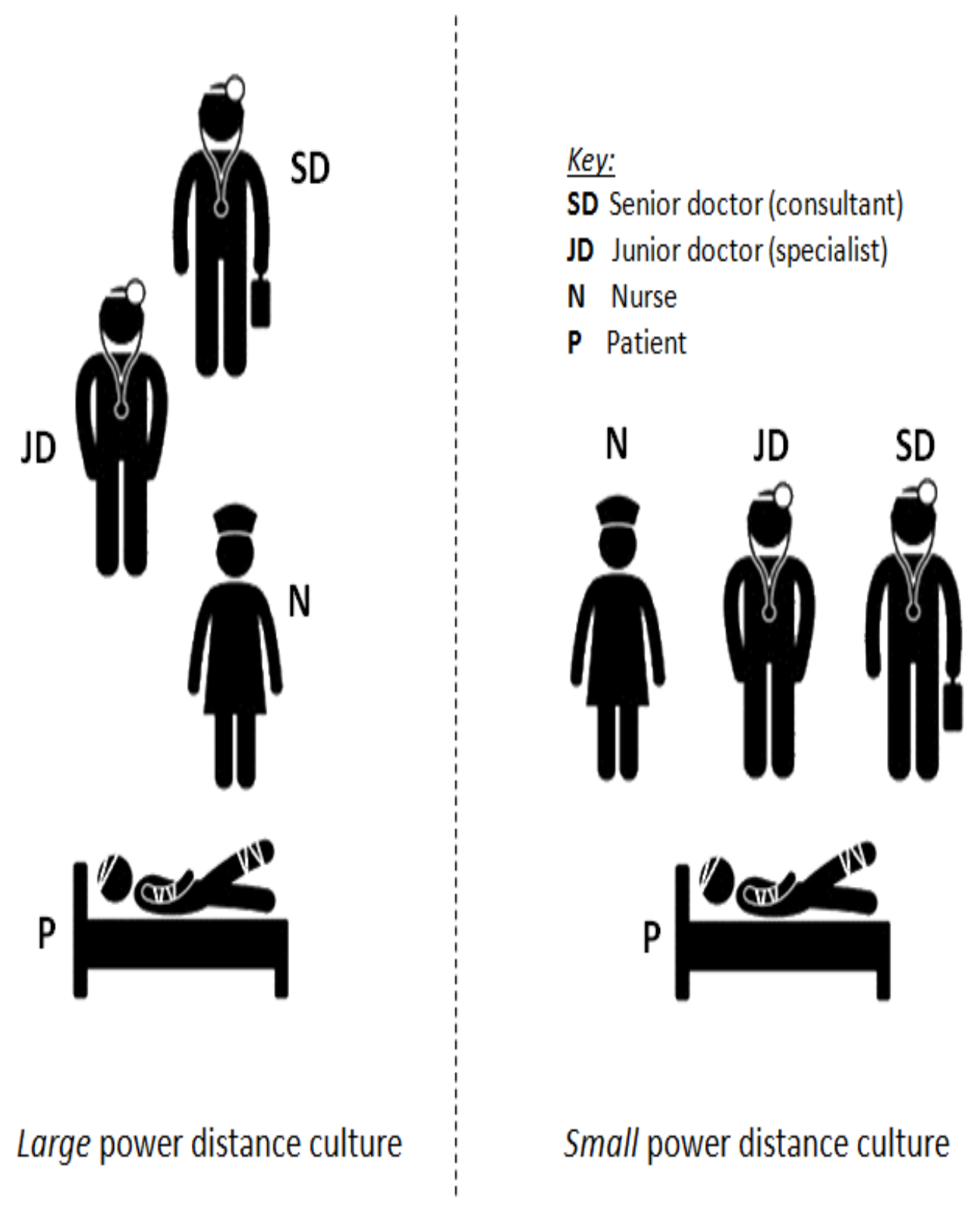

Figure 4.1. Two illustrations portraying the relationship between doctors, nurses, and patients in large and small power distance cultures. 
The large power distance have a number of implications on medical practice (Morrow, Rothwell, Burford, \& Illing, 2013). For instance, multidisciplinary teams do not really exist, commination within the team is mainly in a dictatorial role, rather than in a negotiation, senior doctors always have the leadership, junior doctors are reluctant to seek help from seniors and nurses are not regarded as colleagues or team members. Patients treat doctors as "gurus" who are supposed to know everything and consultations are shorter and controlled by the doctor (Morrow et al., 2013).

Another cultural dimension is related to masculinity and femininity are regarded as societal, not individual characteristics. In high masculinity societies, people are assertive; compete openly with peers and over-rate their own performance to be rewarded (Hofstede, 2014b), as portrayed in Figure 4.2. In short, 'seniority' and 'respect' are highly regarded in societies with large power distance, while 'competition' and 'reward' are keywords in high masculinity cultures.
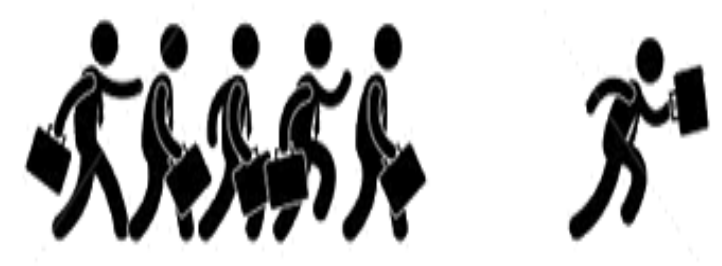

High masculinity culture (competitive)

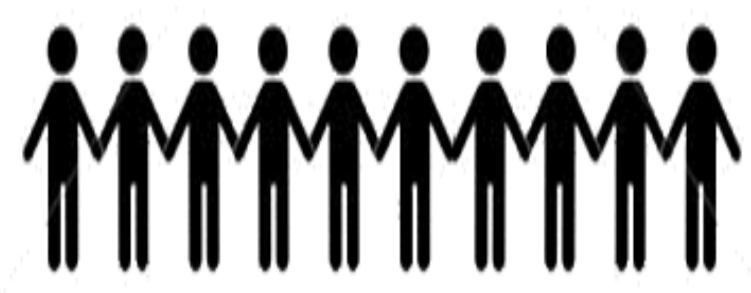

Low masculinity culture (collaborative)

Figure 4.2. Two illustrations portraying the relationship between peer students or colleagues physicians in high and low masculinity cultures. 
While culture can be decoded in dimensions (Hofstede, 2014b), professionalism was also described as a set of domains (ABIM, 1995; Escobar-Poni \& Poni, 2006; Pan, Norris, Liang, Li, \& Ho, 2013). Five domains were identified to portray professionalism in an Arabian context, namely; (1) Altruism, where the best interest of patients, not self-interest, is the rule, (2) Duty and Accountability, the free acceptance of a commitment to service, (3) Excellence and Autonomy, a conscientious effort to exceed ordinary expectations and to make a commitment to life-long learning, (4) Honour and Integrity, the consistent regard for the highest standards of behaviour and the refusal to violate one's personal and professional codes, and (5) Respect for others, including patients and their families, other physicians and professional colleagues such as nurses, medical students, residents and subspecialty fellows. (M. M. Al-Eraky \& Chandratilake, 2012). These five domains portrays a spectrum of complementary colours, that when united they form the 'pure white light' of medical professionalism, as illustrated in Figure 4.3.

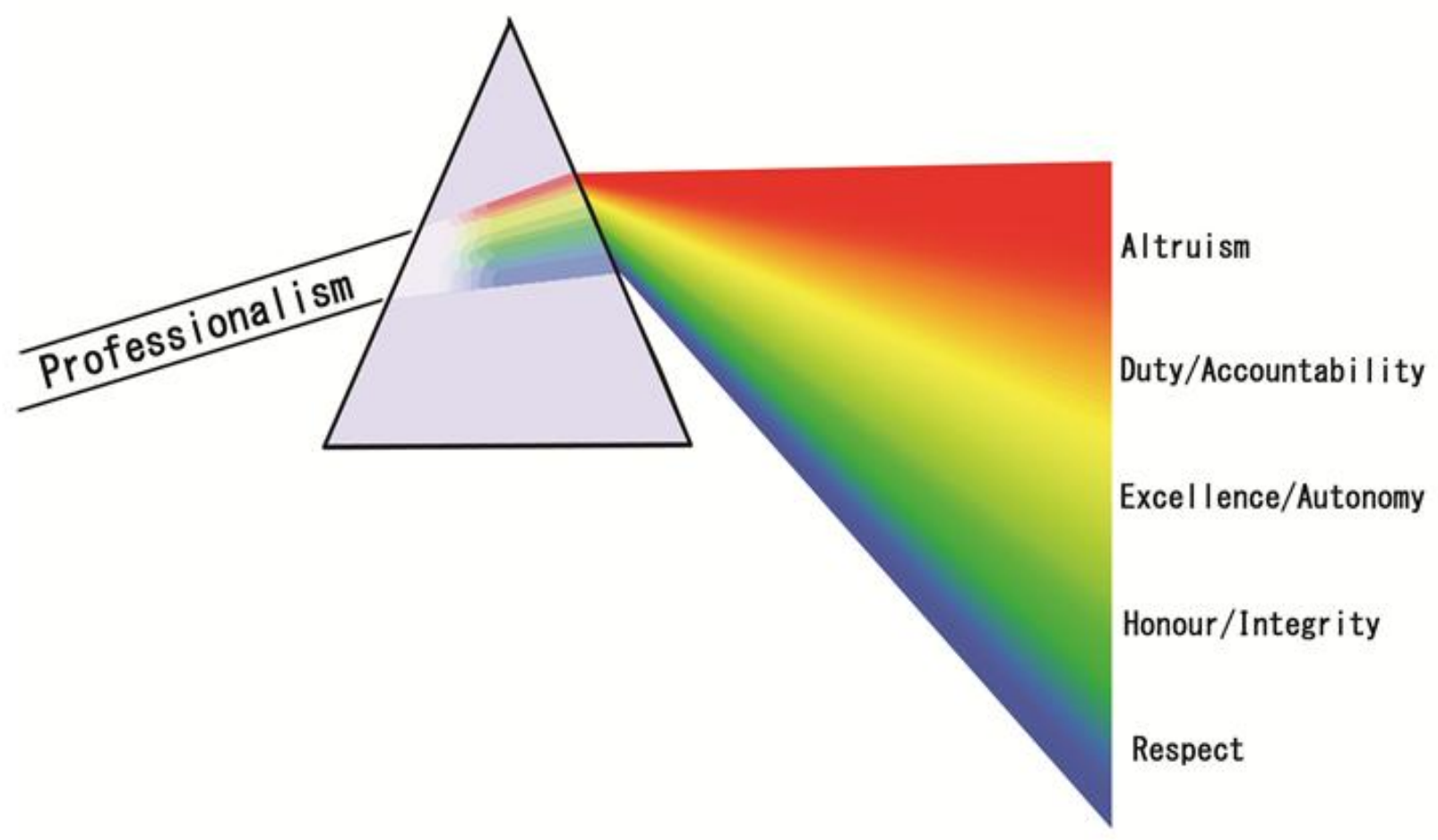

Figure 4.3. The spectrum of medical professionalism in an Arabian context that includes five colors (domains). 
Cultural differences were reported to moderate the understanding of professionalism in a particular society (Haidet et al., 2006; Ho, Lin, Chiu, Lingard, \& Ginsburg, 2012; van der Horst \& Lemmens, 2012), but this has been subject to little research, possibly because of the practical difficulties of doing so (Chandratilake, McAleer, \& Gibson, 2012). In a country with large power distance, physicians become more vigilant about their behaviours with patients to preserve their 'integrity' and reinforce their special high ranking in the community and earn the 'respect' and trust of their patients (Chandratilake et al., 2012). This implies that power distance may be correlated with the professionalism domains of honour/integrity and respect.

The aim of this study is to measure attitudes of medical students in Egypt and Saudi Arabia on medical professionalism and to interpret the findings in light of the cultural differences between both countries. Egypt and Saudi Arabia vary in two cultural dimensions, namely: power distance and masculinity, while others are constant.

Given the large 'power distance' in Saudi Arabia, we hypothesize that Saudi medical students would score higher in behaviours related to 'honour/integrity' and 'respect' more than their Egyptian peers. The more competitive Saudi society with high masculinity index may be manifested in higher scores in Duty/Accountability and Excellence/Autonomy domains of professionalism.

\section{Method}

\section{Participants}

Medical students were recruited from Dammam University in Saudi Arabia and Zagazig University in Egypt. These two universities were selected on pragmatic grounds because two authors are affiliated to them and they met the criterion to compare cultural impacts on professionalism in Egypt and Saudi Arabia. Both universities belong to the public sectors and were established in 1973 and 1975 respectively. Undergraduate medical students were invited to report their attitudes in a professionalism questionnaire. Students were included from different educational stages. 
Instrument

We used the pre-validated instrument called: Learners Attitude on Medical Professionalism Scale or the LAMPS that was designed to measure attitudes of medical students on professionalism in an Arabian context (M. M. Al-Eraky, Chandratilake, Wajid, Donkers, \& van Merrienboer, 2013). The LAMPS includes 28 items in five domains: Altruism ( 5 items), Duty/Accountability ( 7 items), Excellence/Autonomy ( 6 items), Honour/Integrity (5 items) and Respect (5 items).

Each item of the LAMPS briefly describes a behaviour that represents one domain of professionalism. For instance, when a physician searches for the best evidence available in patient care (Excellence/Autonomy), issues a false sick leave for a kid of a friend to study home (Honour/Integrity), or keeps patients waiting in his/her clinic without apology (Respect). Items were balanced in wording (13 positively-worded and 15 negatively-worded items) and responses were recorded on a five-point Likert scale. For positively-worded items (i.e., items which represent professional behaviours) 5 points were allocated for 'Strongly Agree', 4 for 'Agree', 3 for 'neutral', 2 for 'Disagree', and 1 point for 'Strongly Disagree', and the reverse was used for negatively-worded items (i.e., items which represent unprofessional behaviours).

\section{Procedure}

The LAMPS was handed over to students via their teachers in a paper format in classes and in clinical rounds. Three Egyptian from Zagazig University and six Saudi teachers contributed to data collection and they explained the rationale of the study to potential respondents. Students' participation was a sign of their consent, because teachers did not indicate any obligation or motivation to their response. There were no open-ended questions in the survey.

\section{Data analysis}

Statistical analysis was done using SPSS (Statistical Package for Social Sciences, version-16). The mean scores per domain were calculated and compared using the Student $t$-test for independent samples to determine the similarities/differences for each of the five domains of professionalism and they were compared between different cohorts with respect to nationality and gender. Effect sizes were calculated by using Cohen's D to compare mean score of items between two cultures and between two genders; an effect size of .2 to .3 is 
interpreted as a small effect, around .5 as a medium effect, and above .8 as a large effect.

\section{Results}

A total of 413 medical students filled in the survey out of 600 (response rate was 71\%), including 120 Egyptian and 293 Saudi undergraduate medical students. Saudi medical students scored higher in behaviours related to 'Respect' (4.6 $\pm 0.41, p=0.01, D=0.42)$ and Honour/Integrity $(3.6 \pm 0.54, p<0.0001, D=$ 0.72 ) and as compared to Egyptian students ( $4.4 \pm 0.53$ and $3.2 \pm 0.57)$. The Dvalue nevertheless indicates a medium to large effect (Table 4.2).

Table 4.2. Nationality-based based differences in attitudes of medical students on domains of medical professionalism

\begin{tabular}{lcc|c}
$\begin{array}{l}\text { Domains of medical } \\
\text { professionalism }\end{array}$ & $\begin{array}{l}\text { Egyptian Students } \\
\mathrm{n}=120\end{array}$ & $\begin{array}{l}\text { Saudi Students } \\
\mathrm{n}=293\end{array}$ & $\begin{array}{l}\text { P-value* } \\
\text { (Cohen's D) }\end{array}$ \\
\hline Altruism & $4.1 \pm 0.51$ & $4 \pm 0.48$ & $0.133(0.2)$ \\
\hline Duty/Accountability & $4 \pm 0.46$ & $4 \pm 0.43$ & $0.11(0.0)$ \\
\hline Excellence/Autonomy & $4.1 \pm 0.48$ & $4.1 \pm 0.43$ & $0.6(0.0)$ \\
\hline Honor/Integrity & $3.2 \pm 0.57$ & $3.6 \pm 0.54$ & $<0.0001^{*}(0.72)$ \\
\hline Respect & $4.4 \pm 0.53$ & $4.6 \pm 0.41$ & $0.01^{*}(0.42)$ \\
\hline
\end{tabular}

Note: *independent $t$-test, significance at $<0.05$.

Egyptian students were more likely to tolerate negative behaviours against fairness and respect towards patients and colleagues, such as: 'keeping patients waiting without apology', 'prioritizing patients based on their social status' and 'criticising a prescription written by a colleague in front of patients'. Saudi students were vigilant towards the above behaviours and they scored higher in the domain of respect. In the domain of Honour and Integrity, again Saudi students were more likely to disagree with behaviours like: 'issuing a fake sick leave', 'giving wrong information to patients to protect colleagues' and 'hiding information about fatal diagnosis to avoid patient disturbance'. There was no significant statistical difference in scores related to Duty/Accountability and Excellence/Autonomy domains, which nullified the second hypothesis. 


\section{Discussion}

This study explores possible bridges between cultural dimensions and domains of medical professionalism in Arabian context. Saudi medical student, in a large power distance society, were more attentive to behaviours related to respect and Honour/Integrity, as compared to their Egyptian peers, which confirm our first hypothesis. The high masculinity index, which reflects a competitive Saudi society, was supposed to be reflected to higher score of attitudes of Saudi students on behaviours of Duty/Accountability and Excellence/Autonomy domain. No significant differences were reported in these domains, which nullifies the second hypothesis.

The current study used empirical data to shed some light, using the LAMPS, on the relationship between culture and professionalism. These findings are only suggestive, but they do not settle conclusive evidence to correlate particular cultural dimensions and professionalism domains. The differences may be attributed to other variables in both societies. Besides, medical students are exposed to what is called: a powerful tacit socialization process throughout their medical education and training (Coulehan \& Williams, 2003), which may raise concerns whether they have similar characteristics as the general population of their societies or not. More importantly, the study triggers reflections on the interaction between culture and professionalism to link theory to practice and submit key implications for: medical practitioners, educators and researchers.

\section{Implications for practitioners}

The role of the physician is moderated by cultural differences and the nature of the health care system in which medicine is practiced (Welie, 2012). In the Middle East and Eastern societies, the power balance of doctor-patient relationship is more towards the doctor, i.e. physicians have more authority in decision-making process than patients. Unlike the Western model where patient autonomy is a key principle of biomedical ethics (Gillon, 2003), professional autonomy of physicians was highly regarded in the Arabian context (M. M. AlEraky \& Chandratilake, 2012). Arabian doctors are perceived as 'masters' who are supposed to know (and decide) what is best for their patients and they may lose the confidence of their patients, if they express diagnostic uncertainty (Morrow et al., 2013). 
In Saudi Arabia, large power distance and hierarchy exists even within among members of the same family. This social structure permeates medical practice as well, particularly in issues related to physicians' responsibility to confidentiality. For instance, Saudi doctors share information with the head of the patient's family instead of the patient and when the patient is a female, doctors have to obtain consent from her 'Wali Amr' or male guardian (a husband, father, brother, or son) (Ho et al., 2012; Jha, Mclean, Gibbs, \& Sandars, 2014). The extreme of patient autonomy is manifested in the 'Gillick competence' in UK, which advocates physicians seeking consent from minors, under 16 years old, in challenging decision related to their healthcare with absolutely no family support (Perera, 2008).

A key advice to all practitioners, particularly those working in a different culture from home, is to study the cultural background of the society you are working for to avoid unpleasant conflicts with patients, peers and professional bodies (Jha et al., 2014).

Implications for educators

Developing medical professionalism curriculum has to explicitly consider local cultural needs and social expectations (O'Sullivan, van Mook, Fewtrell, \& Wass, 2012). With reference to the cultural characteristic of Arabian societies, a number of educational strategies can be suggested to help students learn professionalism. In a large power distance societies, medical educators should recognize that respect and hierarchy are highly regarded and may be overexpressed. Role models remain the most potent means of transmitting the intangibles that have been called the art of medicine across generations (R. L. Cruess \& Cruess, 2006). In a large power distance culture, role modelling has an exceptional standing in professionalism education, because students follow their teachers and junior doctors shadow their seniors. The deficient perception of Arab medical students' on professional behaviour to the negative role models in their faculty members (Adkoli, Al-Umran, Al-Sheikh, Deepak, \& Al-Rubaish, 2011), which calls for policy implications on faculty recruitment and development that supports professionalism (Steinert, Cruess, Cruess, \& Snell, 2005).

On the downside, the socialization process of medical education itself can foster the development of arrogance, vanity, assertiveness, and a sense of entitlement in the physician. Medical students and graduate should not feel privileged over nurses and technicians, just because they are physicians. Perhaps 
the most difficult virtue to understand, practice and teach is humility (Coulehan, 2010). Educators should plan their curricula to explicitly address humility, teambuilding and effective communication skills. Inter-professional education can play a role in bridging the gaps between doctors, nurses and technicians and admitting the complimentary roles of different members of the healthcare team.

Teaching professionalism is usually based on discussing vignettes of un/professional behaviours in a collaborative learning approach (Boenink, de Jonge, Smal, Oderwald, \& van Tilburg, 2005). Reflection among peers is fundamental to the understanding and development of professionalism (Horlick, Masterton, \& Kalet, 2006). Peer-assisted learning, however, may be challenging in a competitive culture with high masculinity index, particularly in the presence of a defective assessment system that promotes ranking and individual achievements over group work. Educators can encourage team-based learning by assigning tasks to groups, not to individuals.

Implications for researchers

In the modern era of globalization, some may underestimate the cultural variations, because new technological advances, social media and the existence of shared life styles may bring all societies more and more similar. Yet, evidence from literature actually rejects the convergence of cultures in understanding professionalism. The Western frameworks of medical professionalism may not resonate with the cultural values of non-Western countries. For instance, a new professionalism framework was reported for Chinese health professionals that is derived from Confucian values, leading to more divergent interpretation of medical professionalism between the East and the West (Pan et al., 2013). Similarly, we have also published another framework for professionalism in the Arabian context, namely the Four-Gate model, in which 'faith', in God (Allah) and the hereafter (Day of Judgment), plays an axiomatic role in interpreting professional attributes and behaviours (M. M. Al-Eraky, Donkers, Wajid, \& van Merrienboer, 2014)

Self-accountability for own behaviours in absence of human monitoring can be interpreted as "taqwa" in Arabic. Self-motivation, or "ehtesab" in Arabic, is not fuelled by rewards from people (patients, families, individuals, professional bodies or community at large), but it is when doctors do their best in clinical work, teaching and research duties and then expect reward from God or a superpower that owns everything, whether in this life or afterwards (M. M. Al- 
Eraky et al., 2014). Faith and culture-based ethics have to be integrated in professionalism education in the Arabian context (El Metwally, Azzam, \& Abou AlSeoud, 2012).

Almost all Arab countries have high uncertainty avoidance index (Table 1), where members of a culture feel threatened by ambiguous or unknown future situations (Hofstede, 2014b). This may justify why Arabs needs belief, as a platform for their security and internal peace. Barakat (1993) advocated that the 'Arab world' is a single, overarching society rather than a collection of several independent states. Egypt and Saudi Arabia belong to the same geographical region, but they have similarities and differences in the social contract governing medical practice in each country.

\section{Strengths and Limitations}

This is an exploratory study that suggested correlations that have not been reported before, to decipher the cultural dimensions of medical professionalism. It is the first study in the Arabian context to use Hofstede's cultural dimensions as a framework to interpret attitudes of medical students on medical professionalism. The analytical approach that we used to decipher professionalism in domains and culture in dimensions can be replicated to find more connections between them in other settings, particularly in contexts with different cultural indices. The study provided insightful notions and suggested implications for medical practitioners, educators and researchers, as elaborated above.

This study is not without limitations. The sample included more Saudi students than Egyptians, because authors have better access to Saudi medical school. Also, Hofstede's framework has been criticized for oversimplifying culture as a set of numeric indices and static matrices, while it is actually a more complex, dynamic and multi-layered construct. Still Hofstede's work is considered central to academic dealing with cultural matters and his work was used and admired at a high level generalization. Recently, Hofstede's cultural dimension have been used in studying cross-national differences in communication patterns (Meeuwesen, van den Brink-Muinen, \& Hofstede, 2009), the readiness of students to problembased learning (M. Al-Eraky, 2013; Frambach, Driessen, Chan, \& van der Vleuten, 2012), and attitudes on professionalism (Chandratilake et al., 2012; S. R. Cruess, Cruess, \& Steinert, 2010b; Morrow et al., 2013). 
Venues for future research

Our study sought answers for a couple of questions, but due to the complexity of the constructs of professionalism and culture, a series of other queries have been unfolded. The phenomenon of exchange of international medical students stimulates a number of research questions. For instance, What happens to Arabs who learn or practice medicine in other cultures? Do they acquire the professionalism model of the new culture or they keep theirs? How long does it take for Saudi or Egyptian medical students to adjust themselves to the Western model of doctor-patient relationship with more patient autonomy? For those who received their medical training home and then immigrated to practice medicine in the West, do they easily adjust themselves to act as a team members, rather than team leaders?

Ho et al. (2014) referred to the dynamic influence of cultural values on the construction of medical professionalism frameworks within a particular society, but does teaching professionalism shape the culture? Can we think of a reciprocal interplay between culture and professionalism? For instance, when Arab medical graduates received their postgraduate training in the West and have been exposed to the Western model of professionalism, do they maintain their homeland professional codes or they adopt the Western ones? It is interesting to study, whether this impression is reversible or not? In other words, when Arab physicians who practiced medicine in the West return home, will they revert to their original cultural values or they will keep advocating the Western model of the doctor-patient relationship?

Most of these questions require more in-depth qualitative studies, not only to measure attitudes of students and practitioners, but also to explain the reasoning behind their attitudes and explore the cultural dynamics that influence their understanding of professionalism domains. It seems that there is still a long road to decode the chemistry between culture and professionalism and this article hopefully marks a rationale step on the way, hopefully in the right direction.

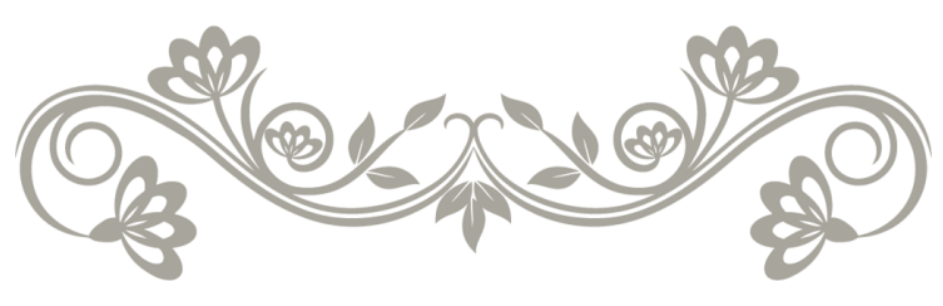




\section{References}

ABIM (American Board of Internal Medicine). (1995). Project Professionalism. Retrieved December 23, 2014, from http://www.abimfoundation.org/ /media/Foundation/Professionalism/Proje ct professionalism.ashx?la=en

Adkoli, B. V, Al-Umran, K. U., Al-Sheikh, M., Deepak, K. K., \& Al-Rubaish, A. M. (2011). Medical students' perception of professionalism: a qualitative study from Saudi Arabia. Medical Teacher, 33(10), 840-5. doi:10.3109/0142159X.2010.541535

Al-Eraky, M. (2013). The cultural flavours of problem-based learning. Medical Education, 47(10), 1049. doi:10.1111/medu.12285

Al-Eraky, M. M., \& Chandratilake, M. (2012). How medical professionalism is conceptualised in Arabian context: A validation study. Medical Teacher.

Al-Eraky, M. M., Chandratilake, M., Wajid, G., Donkers, J., \& van Merrienboer, J. (2013). Medical professionalism: development and validation of the Arabian LAMPS. Medical Teacher, 35 Suppl 1, S56-62. Retrieved from http://www.ncbi.nlm.nih.gov/pubmed/23581897

Al-Eraky, M. M., Donkers, J., Wajid, G., \& van Merrienboer, J. J. G. (2014). A Delphi study of medical professionalism in Arabian countries: the Four-Gates model. Medical Teacher, 36 Suppl 1, S8-16. doi:10.3109/0142159X.2014.886013

Barakat, H. (1993). Society, Culture, and State (pp. 1-314). Berkeley: University of California Press.

Boenink, A. D., de Jonge, P., Smal, K., Oderwald, A., \& van Tilburg, W. (2005). The effects of teaching medical professionalism by means of vignettes: an exploratory study. Medical Teacher, 27(5), 429-32.

doi:10.1080/01421590500069983

Chandratilake, M., McAleer, S., \& Gibson, J. (2012). Cultural similarities and differences in medical professionalism: a multi-region study. Medical Education, 46(3), 257-66. doi:10.1111/j.1365-2923.2011.04153.x 
Coulehan, J. (2010). On humility. Annals of Internal Medicine, 153(3), 200-1. doi:10.7326/0003-4819-153-3-201008030-00011

Coulehan, J., \& Williams, P. C. (2003). Conflicting professional values in medical education. Cambridge Quarterly of Healthcare Ethics : CQ : The International Journal of Healthcare Ethics Committees, 12(1), 7-20. Retrieved from http://www.ncbi.nlm.nih.gov/pubmed/12625198

Cruess, R. L., \& Cruess, S. R. (2006). Teaching professionalism: general principles. Medical Teacher, 28(3), 205-8. doi:10.1080/01421590600643653

Cruess, S. R., Cruess, R. L., \& Steinert, Y. (2010a). Linking the teaching of professionalism to the social contract: a call for cultural humility. Medical Teacher, 32(5), 357-9. doi:10.3109/01421591003692722

Cruess, S. R., Cruess, R. L., \& Steinert, Y. (2010b). Teaching professionalism across cultural and national borders: lessons learned from an AMEE workshop. Medical Teacher, 32(5), 371-4. doi:10.3109/01421591003692730

El Metwally, D., Azzam, M., \& Abou Al-Seoud, M. (2012). Medical professionalism adapted to faith and cultural beliefs. Medical Education, 46(5), 524-5. doi:10.1111/j.1365-2923.2012.04249.x

Escobar-Poni, B., \& Poni, E. S. (2006). The role of gross anatomy in promoting professionalism: a neglected opportunity! Clinical Anatomy (New York, N.Y.), 19(5), 461-7. doi:10.1002/ca.20353

Frambach, J. M., Driessen, E. W., Chan, L.-C., \& van der Vleuten, C. P. M. (2012). Rethinking the globalisation of problem-based learning: how culture challenges self-directed learning. Medical Education, 46(8), 738-47. doi:10.1111/j.1365-2923.2012.04290.x

Gillon, R. (2003). Ethics needs principles--four can encompass the rest--and respect for autonomy should be "first among equals". Journal of Medical Ethics, 29(5), 307-12. Retrieved from http://www.pubmedcentral.nih.gov/articlerender.fcgi?artid=1733792\&tool= pmcentrez\&rendertype=abstract 
Hafferty, F. (2006). Viewpoint: the elephant in medical professionalism's kitchen. Academic Medicine : Journal of the Association of American Medical Colleges, 81(10), 906-14. doi:10.1097/01.ACM.0000238230.80419.cf

Haidet, P., Kelly, P. A., Bentley, S., Blatt, B., Chou, C. L., Fortin, A. H., ... Inui, T. S. (2006). Not the same everywhere. Patient-centered learning environments at nine medical schools. Journal of General Internal Medicine, 21(5), 405-9. doi:10.1111/j.1525-1497.2006.00417.x

Ho, M.-J., Lin, C.-W., Chiu, Y.-T., Lingard, L., \& Ginsburg, S. (2012). A cross-cultural study of students' approaches to professional dilemmas: sticks or ripples. Medical Education, 46(3), 245-56. doi:10.1111/j.1365-2923.2011.04149.x

Ho, M.-J., Yu, K.-H., Pan, H., Norris, J. L., Liang, Y.-S., Li, J.-N., \& Hirsh, D. (2014). A tale of two cities: understanding the differences in medical professionalism between two Chinese cultural contexts. Academic Medicine : Journal of the Association of American Medical Colleges, 89(6), 944-50. doi:10.1097/ACM.0000000000000240

Hofstede, G. (2014a). Culture. Retrieved December 26, 2014, from http://geerthofstede.nl/culture.aspx

Hofstede, G. (2014b). National Cultural Dimensions. Retrieved December 26, 2014, from http://geert-hofstede.com/countries.html

Horlick, M., Masterton, D., \& Kalet, A. (2006). Learning Skills of Professionalism : a Student-Led Professionalism Curriculum.

Jha, V., Mclean, M., Gibbs, T. J., \& Sandars, J. (2014). Medical professionalism across cultures: A challenge for medicine and medical education. Medical Teacher, 1-7. doi:10.3109/0142159X.2014.920492

Meeuwesen, L., van den Brink-Muinen, A., \& Hofstede, G. (2009). Can dimensions of national culture predict cross-national differences in medical communication? Patient Education and Counseling, 75(1), 58-66. doi:10.1016/j.pec.2008.09.015 
Morrow, G., Rothwell, C., Burford, B., \& Illing, J. (2013). Cultural dimensions in the transition of overseas medical graduates to the UK workplace. Medical Teacher, 35(10), e1537-45. doi:10.3109/0142159X.2013.802298

O'Sullivan, H., van Mook, W., Fewtrell, R., \& Wass, V. (2012). Integrating professionalism into the curriculum: AMEE Guide No. 61. Medical Teacher, 34(2), e64-77. doi:10.3109/0142159X.2012.655610

Pan, H., Norris, J. L., Liang, Y.-S., Li, J.-N., \& Ho, M.-J. (2013). Building a professionalism framework for healthcare providers in China: a nominal group technique study. Medical Teacher, 35(10), e1531-6. doi:10.3109/0142159X.2013.802299

Perera, A. (2008). Can I decide please? The state of children's consent in the UK. European Journal of Health Law, 15(4), 411-20. Retrieved from http://www.ncbi.nlm.nih.gov/pubmed/19180980

Reid, L. (2011). Medical professionalism and the social contract. Perspectives in Biology and Medicine, 54(4), 455-69. doi:10.1353/pbm.2011.0048

Steinert, Y., Cruess, S., Cruess, R., \& Snell, L. (2005). Faculty development for teaching and evaluating professionalism: from programme design to curriculum change. Medical Education, 39(2), 127-36. doi:10.1111/j.13652929.2004.02069.x

Van der Horst, F., \& Lemmens, P. (2012). Medical education and professionalism across different cultures. Medical Education, 46(3), 238-9. doi:10.1111/j.1365-2923.2011.04201.x

Welie, J. V. M. (2012). Social contract theory as a foundation of the social responsibilities of health professionals. Medicine, Health Care, and Philosophy, 15(3), 347-55. doi:10.1007/s11019-011-9355-7 


\section{Chapter 5}

Proto-professionalism: Assessment of professionalism in undergraduate medical students and teachers in the Arabian context

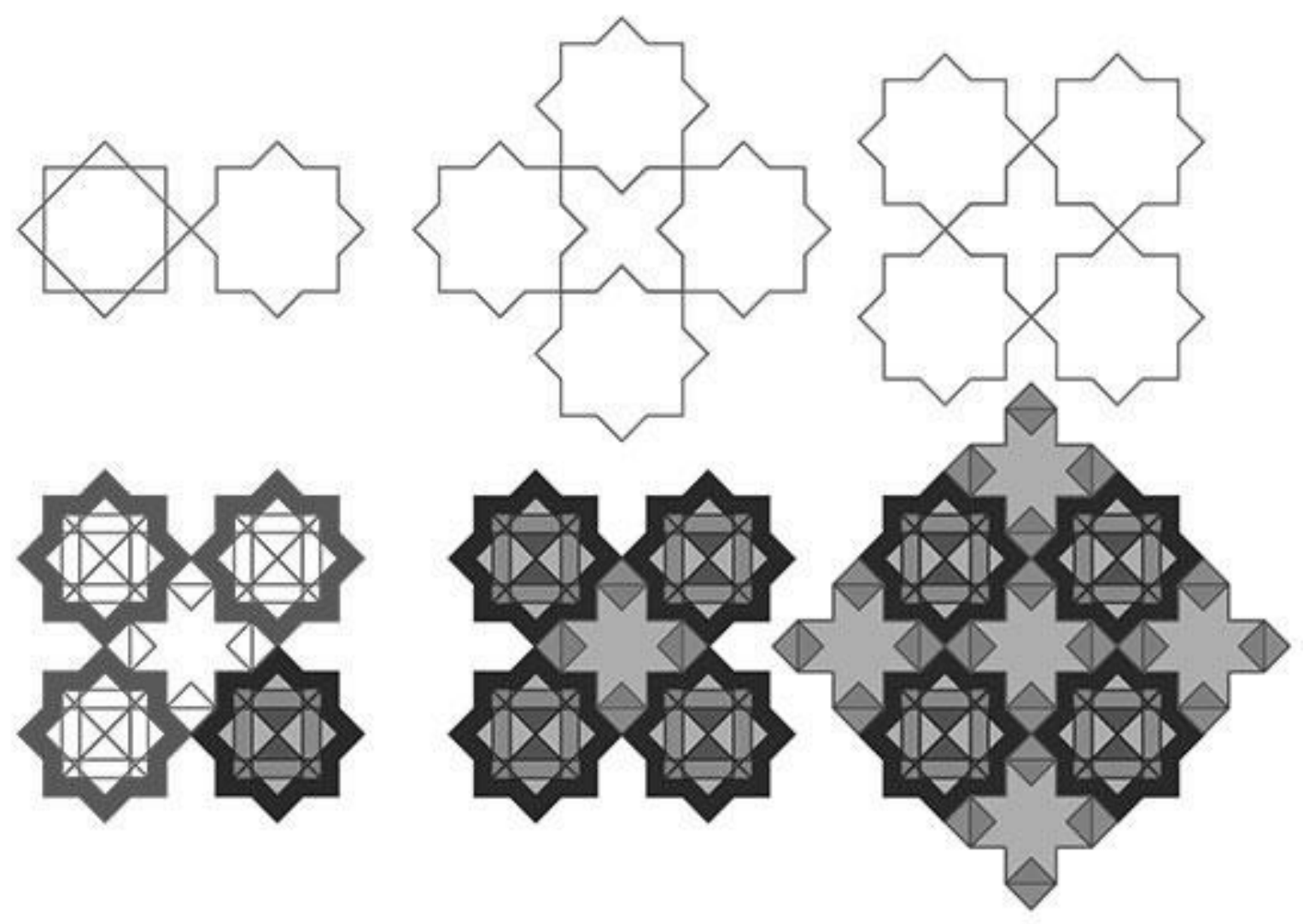




\begin{abstract}
Introduction: There is a growing interest in professionalism, but few studies addressed its development across the continuum of medical education.

Aim: This study aims to decipher the genesis of proto-professionalism in three cohorts: pre-clinical students, clinical students and medical teachers in five domains of professionalism: Altruism, Duty/Accountability, Excellence/Autonomy, Integrity/Honour, and Respect.
\end{abstract}

Method: We used a pre-validated 28-items survey tool called Learners' Attitudes on Medical Professionalism Scale (LAMPS) to measure attitudes on professionalism among the three cohorts in the above five domains to decipher how professionalism develops in the Arabian context.

Results: ANOVA showed significant differences between the three groups. Posthoc pairwise comparisons between pre-clinical students and clinical students showed no significant differences in the five domains. Teachers showed significantly lower attitudes than clinical students on four domains, but in Integrity/honour they scored unexpectedly higher than the clinical students.

Discussion: Teachers were more likely to disagree with behaviours related to misrepresentation, forgery, lying, deception, hiding information and unethical practices, probably because they sensibly recognize the destructive repercussions of committing them to their professional identity and reputation. Comparing three groups does not imply that professionalism is developed in three stages. Staged-development of professionalism was based on stage theories and is in line with our results, but it has to be validated by longitudinal studies.

Conclusion: Mounting evidence demonstrates that professionalism is under threat, because attrition is documented with the progress of practice. This study marks one step in understanding the genesis of medical professionalism in the Arabian context. 


\section{Introduction}

Over the past few decades, there has been a growing interest in the subject of medical professionalism, as reflected in the increasing number of relevant articles. Much of the existing literature on professionalism discusses three key questions: (1) What is professionalism in view of different contexts? (Al-Eraky \& Chandratilake, 2012; Pan, Norris, Liang, Li, \& Ho, 2013), (2) How can professionalism be taught? (Birden et al., 2013; Cruess \& Cruess, 2006), and how can it be assessed? (Hodges et al., 2011; O'Sullivan \& Toohey, 2008; van Mook et al., 2009). Few authors have tackled an equally important issue, namely, to decipher how professionalism develops across the continuum of medical education (Rees, 2005).

Hilton and Slotnick (2005) coined the term 'Proto-professionalism' to refer to the time period before professionalism has been fully developed. Protoprofessionalism begins when an individual starts his or her career as a medical student and acquires the skills and knowledge and gains the experience needed to practice, and it ends when $s /$ he becomes a 'mature professional' (S. R. Hilton \& Slotnick, 2005). Students enter medical schools with personal standards on professionalism and ethics that are derived from their past exposure to family, teachers and friends (Nath, Schmidt, \& Gunel, 2006). Excited to join one of the most esteemed professions as recognized by society, students start their medical education with positive attitudes toward medical professionalism, based on their personal experiences and coursework (Huggett, Warrier, \& Maio, 2008). They aspire toward being successful physicians with professional attributes, but they initially do not necessarily know how these professional attributes function in practice (Blue et al., 2009).

Lave and Wenger (1991) used situated learning theory to explain how learning progresses in occupations by legitimate peripheral participation. They explained that medical students start at the periphery of the occupation by mimicking what practicing clinicians do (e.g. take history and perform clinical examinations), but without a direct impact on patients, then their efforts gradually become more central to the occupation, when they start to act as independent practitioners (Lave \& Wenger, 1991). 
Professionalism is an acquired state that is developed with the influence of a blend of biological (nature) and environmental (nurture) factors (Rees, 2005). The educational and work environments shape the acquisition and maintenance of proto-professionalism in positive (attainment) and negative (attrition) ways (S. R. Hilton \& Slotnick, 2005). Attainment of professionalism occurs over a prolonged period of learning, experience and reflection on experience until learners develop practical wisdom (S. Hilton \& Southgate, 2007).

The abstract principles of professionalism in the minds of fresh medical students are being transformed into applied concepts and rational behaviours in the minds of experts. Practitioners learn which rules to break, when to do so and to what extend to accommodate reality at hand (Stephenson, Higgs, \& Sugarman, 2001). They recognize their potentials and limitations, as there is no cure for all human illnesses. They also learn to live with uncertainty and develop an insight to accept and expect inevitable consequences.

In view of the above positive attainment, the professional identify of physicians is matured and developed (Stephenson et al., 2001). In contrast, attrition is noticed when students gradually abundant their ideal notions on professionalism and develop a sense of cynicism (Smith, Saavedra, Raeke, \& O'Donell, 2007). With the progress of clinical education, medical students become less empathic towards patients (Hojat et al., 2009) and show a decline of moral judgment (Hegazi \& Wilson, 2013). Evidently, this is bad news to medical educators, but we need to investigate this further by answering two questions: (1) what are the factors contributing to attrition of professionalism? and (2) what are the manifestations of that attrition?

Medical students are overwhelmed by the quantity and complexity of factual knowledge and technical interventions, excessive clinical and non-clinical responsibilities, tough competition in assessment, humiliation by supervisors and long working hours (Stephenson et al., 2001). With the progress of clinical experience, medical students are confronted by another challenge. They encounter more ill and dying patients and, therefore, they have to preserve their emotions by using a number of strategies (sometimes unconsciously) to look objectively at, and think dispassionately about, an ill or dying patient (Stephenson et al., 2001). 
Medical students learn to be emotionally detached from their patients, using different defensive strategies such as: (1) transforming the patient or the procedure into an analytic object or event, (2) blaming the patient, (3) joking with/about the patient to avoid sensitive contact. Adding more insult to injury, medical students usually receive very little support or time to think, relax and reflect on their emotional involvement with patients (Stephenson et al., 2001), particularly in the absence of positive role models (Adkoli, Al-Umran, Al-Sheikh, Deepak, \& Al-Rubaish, 2011).

Coulehan and Williams (2001) reported that medical students adopt a clinical detachment approach and they eventually develop non-reflective professionalism and treat patients only as objects of technical services. That is why physicians - and other healthcare team members - are frequently labelled in the literature as healthcare service providers, while a few decades ago, a physician in the Arabian context was regarded as 'hakeem حكيم', a title that reflects wisdom and insight in Arabic.

The above factors infringe professionalism in many aspects. Medical students learn to perform below their optimal level and commit to the least possible duties and responsibilities, just to survive the system ( $\mathrm{S}$. Hilton \& Southgate, 2007). Measuring attitudes of learners on professionalism across different phases of medical education and training is of great educational value, because results may decipher how professionalism develops over time. Attrition of proto-professionalism is documented by a decline of attitudes on professionalism with the progress of medical education and training, particularly, related to 'respect for others', 'sense of duty', and 'caring attitude towards patients' (Hur, 2009; Nath et al., 2006).

The current study uses a pre-validated instrument on professionalism in Arabian context (Al-Eraky, Chandratilake, Wajid, Donkers, \& van Merrienboer, 2013) to compare attitudes of three groups; pre-clinical students, clinical students and practitioners on five domains of medical professionalism: Altruism, Duty/Accountability, Excellent/Autonomy, Integrity/Honour, and Respect. These domains have been found to be relevant to the Arabian context (Al-Eraky \& Chandratilake, 2012). In agreement with the above literature findings, we hypothesize a decline in all domains with the progress of medical education. 


\section{Method}

\section{Participants}

Medical students were recruited from Dammam University in Saudi Arabia and Zagazig University in Egypt. Both universities embrace a traditional educational system, where there are two distinct phases of basics sciences (Years 1-3) and clinical sciences (Years 4-6) with no integration. There are no early clinical encounters and medical students are engaged in the communities of practice in teaching hospitals only in their late clinical years.

Medical teachers were invited from a wide-spectrum of Arab nationalities and disciplines and subspecialties. They vary in seniority levels from senior consultants to specialist from both genders. They practice medicine in different healthcare systems in private and governmental setting, but they were all native Arab physicians who are practicing in the Arabian context. All participants have contributed to the survey on voluntary basis.

Instrument

We used a pre-validated instrument called: Learners Attitude on Medical Professionalism Scale (LAMPS) to measure attitudes on professionalism in an Arabian context.27 The LAMPS includes 28 items in five domains: Altruism (5 items), Duty/Accountability ( 7 items), Excellence/Autonomy (6 items), Honour/Integrity (5 items), and Respect (5 items). These domains have been found to be relevant to the Arabian context.1 Each item of the LAMPS briefly describes a behaviour of a doctor in a common situation that $s /$ he may encounter on a daily basis. Responses were recorded on a five-point Likert scale. For positively-worded items (i.e. items which represent professional behaviours), 5 points were allocated for 'Strongly Agree', 4 for 'Agree', 3 for 'neutral', 2 for 'Disagree', and 1 for 'Strongly Disagree', and the reverse was used for negativelyworded items (i.e. items which represent unprofessional behaviours).

\section{Procedure}

For students, we used a paper-based format of the LAMPS to control student participation. The survey was distributed to students via their teachers in classes and collected on the spot to improve response rates. For practitioners, we designed the same survey in an electronic format using SurveyMonkey ${ }^{\circledR}$ to 
encourage their contribution from different departments of health professions colleges in universities and hospitals from Saudi Arabia, Egypt, UAE, and Oman.

Data analysis

Statistical analysis was done using SPSS (Statistical Package for Social Sciences, verson-16) software. The means of items were calculated and compared between each pair of cohorts using t-test and also in the three groups: preclinical students, clinical students and practitioners, using one-way ANOVA with 5\% level of significance. For the effect size, we used partial eta-squared, where a small effect is around 0.01, a medium effect is around 0.05, and a large effect is above 0.1. After differences between the three groups were confirmed, post-hoc tests were used to determine which of the mean for the three groups was significantly different from the others, with $5 \%$ significance. Effect sizes were calculated by using Cohen's D; an effect size of up to 0.3 is interpreted as a small effect, around 0.5 as a medium effect, and 0.7 or above as a large effect.

\section{Results}

We received a total of 413 responses from medical students (211 preclinical and 202 clinical) out of 600 (68\% response rate), and 78 responses from practitioners out of 110 (70\% response rate). Post-hoc pairwise comparisons between pre-clinical students and clinical students showed statistically significant differences in Honour/Integrity and Respect, but the effect size was small (Table 5.1).

Table 5.1. Attitudes of pre-clinical vs. clinical students on selected domains of professionalism

\begin{tabular}{lllll} 
Domains & $\begin{array}{l}\text { Pre-clinical } \\
\text { Students } \\
\mathrm{n}=211\end{array}$ & $\begin{array}{l}\text { Clinical } \\
\text { Students } \\
\mathrm{n}=202\end{array}$ & P-value* & Cohen D \\
\hline Altruism & $4.02 \pm 0.48$ & $4.00 \pm 0.5$ & 0.74 & 0.04 \\
\hline Duty/Accountability & $4.05 \pm 0.38$ & $3.97 \pm 0.49$ & 0.08 & 0.2 \\
\hline Excellence/Autonomy & $4.06 \pm 0.39$ & $4.12 \pm 0.49$ & 0.190 & -0.14 \\
\hline Honor/Integrity & $3.6 \pm 0.57$ & $3.41 \pm 0.59$ & $0.002^{*}$ & 0.33 \\
\hline Resect & $4.59 \pm 0.37$ & $4.48 \pm 0.52$ & $0.01^{*}$ & 0.24
\end{tabular}

$*$ Independent t-test, significance at $<0.05$. 
Comparing attitudes between clinical students and medical practitioners showed significant differences, as clinical students scored higher in all domains, one. There was a difference with a large effect size in the Honour/Integrity domain, but in a reverse direction $(-0.73)$, because the means of practitioners were unexpectedly higher than the means of clinical students (Table 5.2).

Table 5.2: Attitudes of clinical students vs. practitioners on selected domains of professionalism

\begin{tabular}{lllll} 
Domains & $\begin{array}{l}\text { Clinical } \\
\text { Students } \\
\mathrm{n}=202\end{array}$ & $\begin{array}{l}\text { Medical } \\
\text { Practitioners } \\
\mathrm{n}=92\end{array}$ & P-value* & Cohen D \\
\hline Altruism & $4.00 \pm 0.5$ & $3.75 \pm 0.6$ & 0.006 & 0.45 \\
\hline Duty/Accountability & $3.97 \pm 0.49$ & $3.75 \pm 0.61$ & 0.0028 & 0.34 \\
\hline Excellence/Autonomy & $4.12 \pm 0.49$ & $3.79 \pm 0.62$ & $<0.0001$ & 0.59 \\
\hline Honor/Integrity & $3.41 \pm 0.59$ & $3.86 \pm 0.64$ & $<0.0001$ & 0.73 \\
\hline Resect & $4.48 \pm 0.52$ & $4.11 \pm 0.77$ & $<0.0001$ & 0.56 \\
\hline
\end{tabular}

* Independent t-test, significance at $<0.05$.

ANOVA was used to compare the three groups and it showed significant differences $(p<0.0001)$ in all five domains, with effect sizes ranging from 0.035 (Altruism) to 0.092 (Respect) (Table 5.3).

Table 5.3. Mean of the five domains on professionalism among the three cohorts.

\begin{tabular}{l|llll} 
Domains & $\begin{array}{l}\text { Pre-clinical } \\
\text { students } \\
\mathrm{n}=211\end{array}$ & $\begin{array}{l}\text { Clinical } \\
\text { students } \\
\mathrm{n}=202\end{array}$ & $\begin{array}{l}\text { Medical } \\
\text { Practitioners } \\
\mathrm{n}=78\end{array}$ & $\begin{array}{l}\text { Effect Size } \\
\eta^{2 *}\end{array}$ \\
\hline Altruism & $4.02 \pm 0.48$ & $4.00 \pm 0.5$ & $3.75 \pm 0.6$ & 0.035 \\
\hline Duty/Accountability & $4.05 \pm 0.38$ & $3.97 \pm 0.49$ & $3.75 \pm 0.61$ & 0.044 \\
\hline Excellence/Autonomy & $4.06 \pm 0.39$ & $4.12 \pm 0.49$ & $3.79 \pm 0.62$ & 0.053 \\
\hline Honor/Integrity & $3.6 \pm 0.57$ & $3.41 \pm 0.59$ & $3.86 \pm 0.64$ & 0.063 \\
\hline Respect & $4.59 \pm 0.37$ & $4.48 \pm 0.52$ & $4.11 \pm 0.77$ & 0.092
\end{tabular}

By ANOVA: significance at $<0.05$ and P-value was 0.0001 for all domains.

$* \eta^{2}$ : small effect 0.01 , medium effect 0.05 , large effect 0.13 
Clearly there was a trendy decline in all domains over time was found, as hypothesized, except for Honour/Integrity, where practitioners showed a surprising rise, as demonstrated in Figure 5.1.

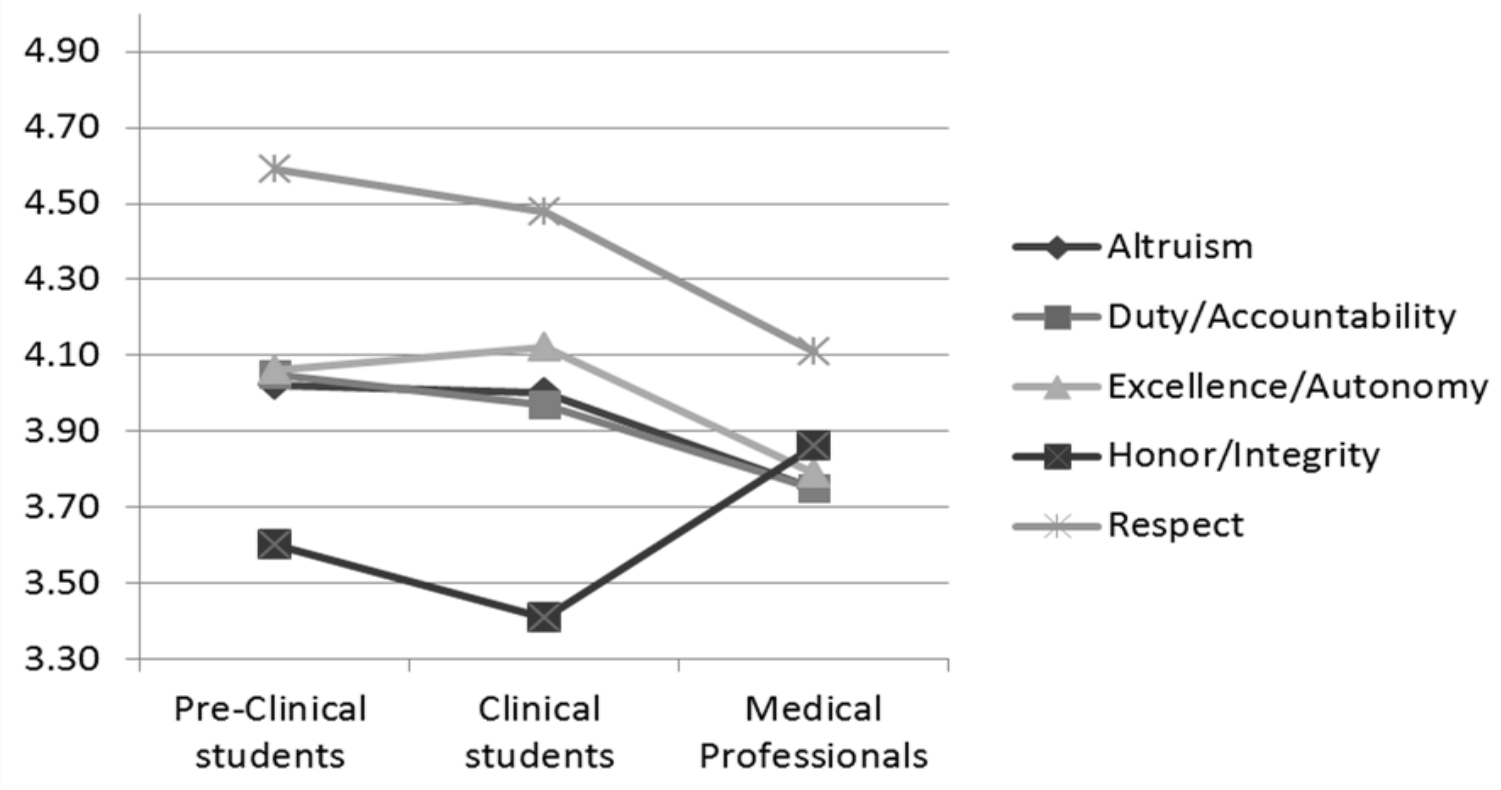

Figure 5.1. The Mean of the five domains on professionalism of three cohorts to show the overall trend.

\section{Discussion}

The study compared professional attitudes in three groups. The main finding is that there was little difference between pre-clinical and clinical students' attitudes in two domains only and a statistically difference between clinical students and practitioners in all five domains.

Pre-clinical vs. Clinical Students

Pre-clinical students reported slightly higher means than clinical students in all domains of professionalism, but these differences were not statistically significant. This can be justified in view of the situated learning theory (Lave \& Wenger, 1991). Clinical students may have close encounters with patients as compared with pre-clinical peers, but both groups of undergraduate medical students are still acting in the periphery of the occupation, with no direct impact 
on patients. That is probably why their attitudes on professionalism were quite similar. The transformation of their proto-professionalism has not yet ripened to a mature professional as independent practitioners in the center of the occupation.

\section{Clinical Students vs. Teachers}

Our hypothesis was predominantly confirmed, because the means of clinical students were significantly higher than those of the practitioners in Altruism, Duty/Accountability, Excellence/Autonomy, and Respect. Surprisingly, there was one finding against our literature-based hypothesis: Practitioners reported a significantly greater awareness on Honour/Integrity than clinical students. 'Honor \& Integrity' is "the consistent regard for the highest standards of behaviour and the refusal to violate one's personal and professional codes. It implies being fair, being truthful, keeping one's word, meeting commitments, and being straight-forward" (ABIM, 1995).

In attempt to rationalize this unexpected rise on that particular domain, we carefully re-examined the five behavioural items of Honour/Integrity in the LAMPS. Behaviours were related to misrepresentation, forgery, lying, deception, hiding information and unethical practices. The items also exemplify complex situations with a considerable level of uncertainty and conflict of interests of different stakeholders; patients, colleagues, students and supervisors. Another observation regarding behaviours of Honour/Integrity is that they have a longterm effect on the credibility of physicians. We may justify that practitioners were more likely to disagree with the above behaviours, because they sensibly recognize the destructive repercussions of committing them to their professional identity and reputation.

Similarly, Nath et al. (2006) conducted a 29-item survey on professionalism using an instrument that was also derived from the ABIM framework and reported that expert practitioners ( $\geq 51$ years) were more likely to rank four statements that reflected honesty and responsibilities, as unprofessional, as compared to novice practitioners and students ( $\leq 26$ years). This is consistent with our findings that practitioners were less tolerant to behaviours that conflict with ethics, integrity and honesty. 
Three groups, but not necessarily three stages

The study compared three groups, which suggests that professionalism is developed in a staged process. Hilton and Southgate (2007) put forward different stage theories to advocate the presence of four definable stages in the development of medical professionalism, namely: junior medical student, senior medical student, junior physician, and senior physician. They claim that stages 1-3 describe proto-professionals (immature) and stage 4 indicates 'mature professionals'. This could be a valuable contribution to better understand how professionalism develops, but we have to concede the doubts on the validity of the presence of these discrete stages to describe a continuum that is infinitely variable among cultures and between individuals studying and working in the same context.

To validate the staged-development of professionalism, there is a need to provide evidence from longitudinal studies using not only quantitative but also qualitative methods, such as observations, interviews and analysis of students' narratives with relevance to professionalism. If the staged-process model is to be confirmed in the development of professionalism, the triggering factors that influence each developmental stage should be studied (Rees, 2005).

We further ponder whether the staged-process is time-bound, that is, related to the four phases as indicated by Hilton and Southgate (2007), or if the process can be accelerated by active reflection on experiences. And if so, what are the teaching and learning strategies that augment the development of a 'mature professional' early on?

\section{Strengths and Implications}

This is one of the few studies that assess professional attitudes in different groups in the Arabian context. The study advocates that medical professionalism is a dynamic construct, that is shaped by attainment and attrition across the medical education continuum. The process of socialization of medical student throughout their education and training includes a number of contextual, institutional and environmental variables that shape their professional attitudes and approaches to medical practice later on. The findings support the body of evidence that professionalism declines with the progress of medical education and training, but it further analyzes the decline in various domains. The drop in the attitudes related to Duty/Accountability and Excellence/Autonomy in 
practitioners can be manifested by the failure to attend and lack of care, and failure to decide or act, which accounts for a large proportion of adverse events and errors in medicine. 36

The results of the current study is consistent with the available evidence that practicing physicians, not students, are the most vulnerable group for attrition on key professionalism qualities like altruism, respect, excellence, duty and accountability. These findings signal alerts to policy makers and educational leaders to explicitly inculcate professionalism in continuing professional development and re-certification of medical practitioners.

Professionalism education for undergraduate, postgraduate students, or practitioners should be derived from cultural values and the norms of the society they work for. For instance, in China, a new framework was reported to acknowledge the traditional Chinese Confucian values in addressing professionalism (Pan et al., 2013). In the Arabian context, another model on professionalism was described called: the Four-Gate Model, that is based on multiple levels of accountability to self, to tasks, to others and to God (Al-Eraky, Donkers, Wajid, \& van Merrienboer, 2014).

\section{Limitations and venues for further research}

This study is not without limitations. The findings were only suggestive and it is unlikely to decipher the genesis of professionalism over time using survey instrument in a cross-sectional study. We only compared attitudes among different cohorts, but we did not intend to over-interpret the results to submit a theoretical framework on the staged development of professionalism. Selfreports on hypothetical situations do not offer convincing inferences about people's actual behaviours and attitudes.33 A longitudinal, qualitative approach to assess actual behaviours of medical students and practitioners can explain the genesis of professional attitudes over time.

We acknowledge that some domains of professionalism may have different interpretations, depending on educational experiences. For instance, 'excellence' for pre-clinical students is mainly concerned with their dedication to learning, but for practitioners excellence is perceived with relevance to patient care and scholarly activities. A future study can be designed to explore how students perceive different elements of professionalism according to their educational stage. 
Narratives on critical incidents can be used to complement the above data and shed light from a different angle on the evolution of proto-professionalism. More interesting questions include: Is honesty in the classroom a precursor to honesty in the clinical setting? Does courtesy to faculty and peers predict courtesy to patients, their families, and ancillary staff? This study marks one step in understanding how undergraduate medical students and practitioners perceive professionalism in the Arabian context.

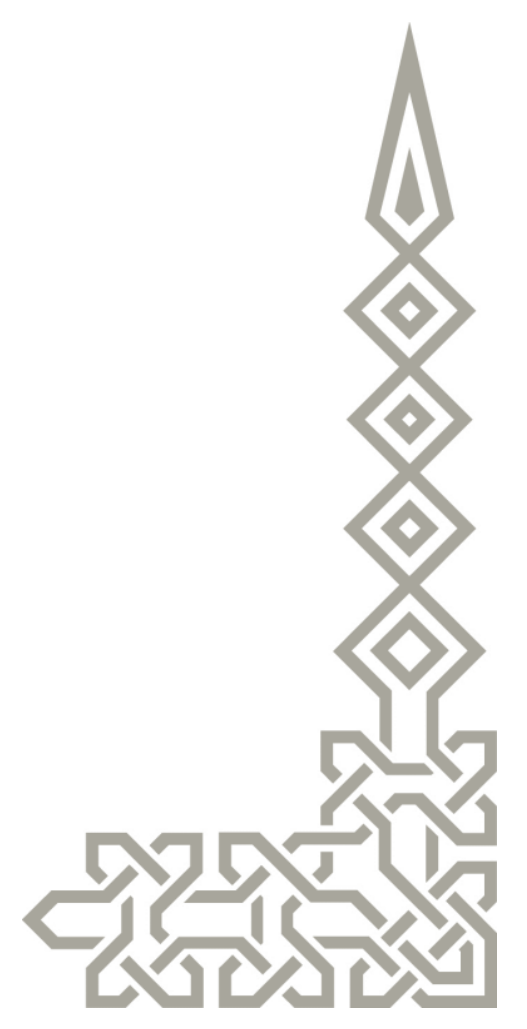




\section{References}

ABIM (American Board of Internal Medicine). (1995). Project Professionalism. Retrieved December 23, 2014, from http://www.abimfoundation.org/ /media/Foundation/Professionalism/Proje ct professionalism.ashx?la=en

Adkoli, B. V, Al-Umran, K. U., Al-Sheikh, M., Deepak, K. K., \& Al-Rubaish, A. M. (2011). Medical students' perception of professionalism: a qualitative study from Saudi Arabia. Medical Teacher, 33(10), 840-5. doi:10.3109/0142159X.2010.541535

Al-Eraky, M. M., \& Chandratilake, M. (2012). How medical professionalism is conceptualised in Arabian context: a validation study. Medical Teacher, 34 Suppl 1, S90-5. doi:10.3109/0142159X.2012.656754

Al-Eraky, M. M., Chandratilake, M., Wajid, G., Donkers, J., \& van Merrienboer, J. (2013). Medical professionalism: development and validation of the Arabian LAMPS. Medical Teacher, 35 Suppl 1, S56-62. Retrieved from http://www.ncbi.nlm.nih.gov/pubmed/23581897

Al-Eraky, M. M., Donkers, J., Wajid, G., \& van Merrienboer, J. J. G. (2014). A Delphi study of medical professionalism in Arabian countries: the Four-Gates model. Medical Teacher, 36 Suppl 1, S8-16. Retrieved from http://www.ncbi.nlm.nih.gov/pubmed/24617789

Birden, H., Glass, N., Wilson, I., Harrison, M., Usherwood, T., \& Nass, D. (2013). Teaching professionalism in medical education: a Best Evidence Medical Education (BEME) systematic review. BEME Guide No. 25. Medical Teacher, 35(7), e1252-66. doi:10.3109/0142159X.2013.789132

Blue, A. V, Crandall, S., Nowacek, G., Luecht, R., Chauvin, S., \& Swick, H. (2009). Assessment of matriculating medical students' knowledge and attitudes towards professionalism. Medical Teacher, 31(10), 928-32. doi:10.3109/01421590802574565

Coulehan, J., \& Williams, P. C. (2001). Vanquishing Virtue: The Impact of Medical Education, 598-605. 
Cruess, R. L., \& Cruess, S. R. (2006). Teaching professionalism: general principles. Medical Teacher, 28(3), 205-8. doi:10.1080/01421590600643653

Hegazi, I., \& Wilson, I. (2013). Medical education and moral segmentation in medical students. Medical Education, 47(10), 1022-8. doi:10.1111/medu.12252

Hilton, S. R., \& Slotnick, H. B. (2005). Proto-professionalism: how professionalisation occurs across the continuum of medical education. Medical Education, 39(1), 58-65. doi:10.1111/j.1365-2929.2004.02033.x

Hilton, S., \& Southgate, L. (2007). Professionalism in medical education. Teaching and Teacher Education, 23(3), 265-279.

Hodges, B. D., Ginsburg, S., Cruess, R., Cruess, S., Delport, R., Hafferty, F., ... Wade, W. (2011). Assessment of professionalism: recommendations from the Ottawa 2010 Conference. Medical Teacher, 33(5), 354-63. doi:10.3109/0142159X.2011.577300

Hojat, M., Vergare, M. J., Maxwell, K., Brainard, G., Herrine, S. K., Isenberg, G. A., ... Gonnella, J. S. (2009). The devil is in the third year: a longitudinal study of erosion of empathy in medical school. Academic Medicine : Journal of the Association of American Medical Colleges, 84(9), 1182-91. doi:10.1097/ACM.0b013e3181b17e55

Huggett, K. N., Warrier, R., \& Maio, A. (2008). Early learner perceptions of the attributes of effective preceptors. Advances in Health Sciences Education : Theory and Practice, 13(5), 649-58. doi:10.1007/s10459-007-9069-z

Hur, Y. (2009). Are there gaps between medical students and professors in the perception of students' professionalism level?--Secondary publication. Yonsei Medical Journal, 50(6), 751-6. doi:10.3349/ymj.2009.50.6.751

Lave, J., \& Wenger, E. (1991). Situated Learning: Legitimate Peripheral Participation. New York, NY, USA: Cambridge University Press.. Retrieved from http://books.google.com/books?hl=ar\&lr=\&id=CAVIOrW3vYAC\&pgis=1

Nath, C., Schmidt, R., \& Gunel, E. (2006). with Educational Rank and Age, (August), 825-834. 
O'Sullivan, A. J., \& Toohey, S. M. (2008). Assessment of professionalism in undergraduate medical students. Medical Teacher, 30(3), 280-6. doi:10.1080/01421590701758640

Pan, H., Norris, J. L., Liang, Y.-S., Li, J.-N., \& Ho, M.-J. (2013). Building a professionalism framework for healthcare providers in China: a nominal group technique study. Medical Teacher, 35(10), e1531-6. doi:10.3109/0142159X.2013.802299

Rees, C. (2005). Proto-professionalism and the three questions about development. Medical Education, 39(1), 9-11. doi:10.1111/j.13652929.2004.02025.x

Smith, K. L., Saavedra, R., Raeke, J. L., \& O'Donell, A. A. (2007). The journey to creating a campus-wide culture of professionalism. Academic Medicine : Journal of the Association of American Medical Colleges, 82(11), 1015-21. doi:10.1097/ACM.0b013e318157633e

Stephenson, A., Higgs, R., \& Sugarman, J. (2001). Medical education quartet Teaching professional development in medical schools, 357, 867-870.

Van Mook, W. N. K. A., Gorter, S. L., O'Sullivan, H., Wass, V., Schuwirth, L. W., \& van der Vleuten, C. P. M. (2009). Approaches to professional behaviour assessment: tools in the professionalism toolbox. European Journal of Internal Medicine, 20(8), e153-7. doi:10.1016/j.ejim.2009.07.012 
102 


\section{Chapter 6}

\section{A Delphi study of medical professionalism in Arabian countries: The Four-Gates model}

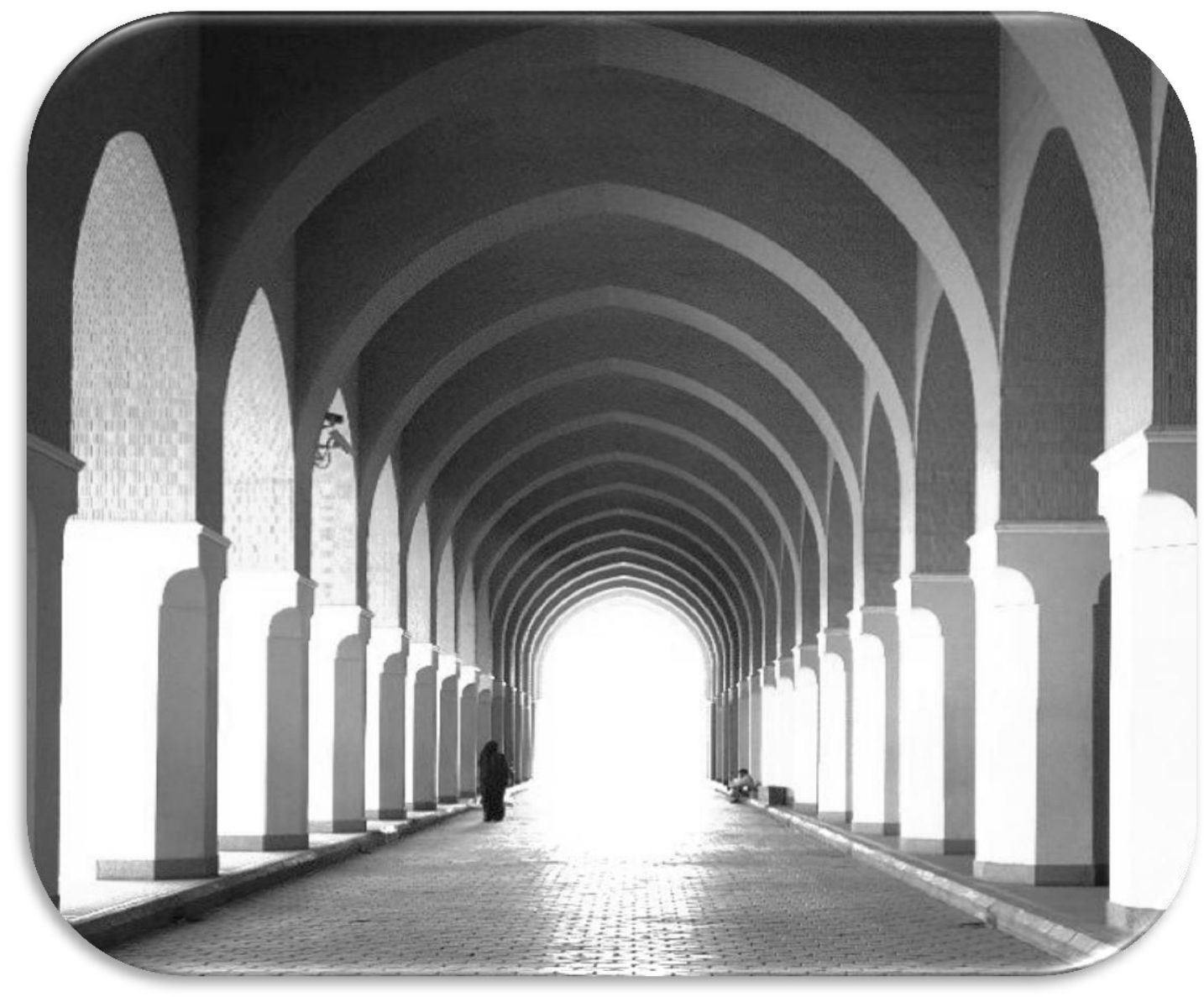

This chapter was published as:

Al-Eraky MM, Donkers J, Wajid G, van Merrienboer JJ. A Delphi study of medical professionalism in Arabian countries: the Four-Gates model. Med Teach. 2014 Apr;36 Suppl 1:S8-16. doi: 10.3109/0142159X.2014.886013. PubMed PMID: 24617789. 
$104)$ 


\begin{abstract}
\end{abstract}
Background: Medical professionalism has been described as a set of attributes and behaviours, yet the Western frameworks of medical professionalism may not resonate with the cultural values of non-Western countries.

Aim: This study aims to formulate a professionalism framework for healthcare providers as interpreted by local medical professionals in Arabian countries.

Methods: A purposive sample of 17 experts from diverse disciplines participated in a Delphi study in three rounds. Consensus was identified by content analysis and by numerical analysis of responses on the basic attributes of medical professionalism in the Arabian context.

Results: Eight professional traits were shortlisted and coupled in four themes (Gates): dealing with self, dealing with tasks, dealing with others, and dealing with God. Self-accountability and self-motivation were interpreted from a faithful viewpoint as "taqwa" and "ehtesab", respectively, in Arabic.

Discussion: The Four-Gates Model helps in better understanding of medical professionalism as grounded in the minds and culture of Arabs. The model may act as a genuine framework for teaching and learning of medical professionalism in Arab medical schools.

Conclusion: The study highlights the divergent interpretation of medical professionalism between Western and Arabian contexts. The Four-Gates Model may work for faith-driven societies, but not for non-Muslim Arab students or teachers, or in institutions with humanistic values. 


\section{Introduction}

Medical professionalism has received growing attention in the literature of medical education, particularly during the past decade. The international accord on the value of professionalism in medicine is not supported with a shared concrete understanding of its nature and elements. There is no conclusive definition for medical professionalism that can be universally addressed in medical education. Professionalism is a generic term (R. L. Cruess \& Cruess, 2010) and therefore, should be operationalized into workable attributes and behaviours (Hafferty, 2004). Professionalism has been explicitly addressed as an outcome of different medical education systems worldwide, but there is no consensus on the interpretation of the elements contributing to medical professionalism as reported by leading organizations and seminal scholarly reports, as listed in Table 6.1.

Table 6.1. Keywords used to indicates elements of medical professionalism, as reported by leading professional organizations and scholarly reports.

\begin{tabular}{|c|c|c|c|c|}
\hline $\begin{array}{l}\text { ABIM }^{1} \\
(1995)\end{array}$ & $\begin{array}{c}\mathrm{RCP}^{2} \\
(2005)\end{array}$ & $\begin{array}{c}\text { McGill }^{4} \\
(2005)\end{array}$ & $\begin{array}{l}\text { Hilton } \\
(2005)\end{array}$ & $\begin{array}{l}\text { Rogers } \\
(2010)\end{array}$ \\
\hline $\begin{array}{l}\text { - Accountability } \\
\text { - Altruism } \\
\text { - Duty } \\
\text { - Excellence } \\
\text { - Honor } \\
\text { - Integrity } \\
\text { - Respect for others }\end{array}$ & $\begin{array}{l}\text { - Appraisal } \\
\text { - Careers } \\
\text { - Education } \\
\text { - Leadership } \\
\text { - Research } \\
\text { - Teams }\end{array}$ & $\begin{array}{l}\text { - Altruism } \\
\text { - Autonomy } \\
\text { - Commitment } \\
\text { - Competence } \\
\text { - Ethics } \\
\text { - Honesty } \\
\text { - Integrity } \\
\text { - Morality } \\
\text { - Responsibility to } \\
\text { - } \text { society } \\
\text { - Responsibility to } \\
\text { - Self-regulation } \\
\text { - Teamwork }\end{array}$ & $\begin{array}{l}\text { - Ethical practice } \\
\text { - Reflection } \\
\text { - Respect for } \\
\text { patients } \\
\text { - Responsibility for } \\
\text { actions } \\
\text { - Self-awareness } \\
\text { - Social } \\
\text { responsibility } \\
\text { - Teamwork }\end{array}$ & $\begin{array}{l}\text { - Care for colleagues } \\
\text { - Collaboration } \\
\text { - Honesty } \\
\text { - Probity } \\
\text { - Reflection capacity } \\
\text { - Relationship with } \\
\text { - patients } \\
\text { - Respect for } \\
\text { - patients } \\
\text { - Responsibility } \\
\text { - Self-awareness } \\
\text { - Teamwork }\end{array}$ \\
\hline
\end{tabular}

${ }^{1}$ ABIM: American Board of Internal Medicine, USA

${ }^{2}$ RCP: Royal College of Physicians, UK

${ }^{3}$ McGill University in Canada, as reported by Steinert (2005)

Medical professionalism is a blend of implicit moral commitment and core attributes that are demonstrated in explicit behaviours. To this point, it is significant to highlight the two terms that are used in this discourse, sometimes interchangeably. The term professionalism, which is commonly used in North America, seems to contrast the term professional behaviour that is more 
frequently used in Europe (Walther N K A van Mook et al., 2009). Professionalism is an abstract term that embraces elements like integrity, honor, compassion, altruism, etc. (inner core), while professional behaviour refers to the observable manners and conducts of professionals that can be viewed and assessed by the public (outer shell). It makes sense to approach the core (attributes) of professionalism to learn more about its manifestations on the outer shell (behaviours).

Our quest for understanding medical professionalism is further complicated by the concept of the social contract. Any profession needs two elements to survive; interest of the public in the services provided and trust in the members of that profession. The medical profession is not an exception. Based on knowledge and moral authority of the doctor, a true social contract is built between the professional and the public (Collier, 2012; S. R. Cruess, Cruess, \& Steinert, 2010; Reid, 2011; Welie, 2012). The social contract is "a contractual relationship with a series of obligations and expectations based on mutual trust between the society and medicine". Different societies vary in their expectations from medicine and, therefore, what is considered professional from an American or European physician may not be perceived so - by patients and society - in Arabian or Asian context.

Professionalism is culture-sensitive and the situations used to measure its constructs or domains should reflect the cultural similarities and differences (Chandratilake, McAleer, \& Gibson, 2012). What are the implications for this notion in medical education? Professionalism can best be taught, learned or assessed when clearly described in its local context. Cruess and Cruess (2006) further advocated that each institution should develop its own so called cognitive base on medical professionalism. This cognitive base encompasses definition, description, elements and attributes of medical professionalism and it dictates what will be taught, evaluated and expected of students, trainees and physicians. We should seek a consensus on the substance of that cognitive base and this must remain consistent throughout the educational process, as a basis for teaching, learning and assessing medical professionalism.

Medical professionalism has been recently addressed as an explicit outcome and as a core value in medical education in Arabian context (Zaini et al., 2011). The Arabian context is a blend of culture, traditions, beliefs and behaviours that are being practiced by nations of Arabian countries in the Middle East where Arabic is the official language and Islam is the religion of the majority of the 
population. Those behaviours and traditions are not necessarily derived from Islamic doctrines, but some common values have been accepted as the norm among populations of these countries. Although there are differences, 'Arab world' is a single, overarching society rather than a collection of several independent states (Barakat, 1993). Therefore, it was not surprising to find similarities of the attitudes of Egyptians and Saudis on medical professionalism (Al-Eraky, Chandratilake, Wajid, Donkers, \& van Merrienboer, 2013). Listing the attributes of good physicians was the aim of scholarly studies on medical professionalism in other contexts. Brownell and Cote (2001) reported the attributes of professionalism as perceived by senior residents in Canada, while Sehiralti et al. (2010) studies them from the perspectives of first-year students in Turkey.

Identifying attributes of medical professionals in the Arabian context may follow one of two approaches to content analysis of qualitative data (Hsieh \& Shannon, 2005). The first one is called: directive content analysis, where an established framework on professionalism is used as scaffold to structure responses. It is like borrowing someone's white coat and check if it may also fit your size. One of these established frameworks was reported by the American Board of Internal Medicine (ABIM, 1995), which includes six domains of professionalism; altruism, accountability, excellence, duty, honor and integrity and respect for others (ABIM, 1995). Despite it was originally developed and used in the Western context (Blackall et al., 2007; Quaintance, Arnold, \& Thompson, 2008; Symons, Swanson, McGuigan, Orrange, \& Akl, 2009), the ABIM framework of medical professionalism has been found to be also applicable for other contexts in Taiwan (Tsai, Lin, \& Harasym, 2008), Iran (Aramesh, Mohebbi, Jessri, \& Sanagou, 2009), Vietnam (Nhan, Violato, Le An, \& Beran, 2014), Japan (Suzuki, 2009) and also in the Arab world (Al-Eraky \& Chandratilake, 2012) with minor adjustments.

Unlike the first approach of the borrowed white coat, there is another customized approach to tailor your own coat, which is based on conventional content analysis (Hsieh \& Shannon, 2005). Here, there is no preset reference framework to anticipate elements of professionalism. The absence of a preliminary platform is challenging, but this method has the advantage of gaining direct information on the attributes and behaviours of medical professionalism, as they are grounded in the minds of native experts without imposing preconceived categories or theoretical perspectives, which makes it also more authentic and 
defensible. Knowledge generated from conventional content analysis is founded on participants' unique perspectives who are supposed to respond to open ended questions to explore what they consider as the essential tenets of medical professionalism in the Arabian context. In brief, the codes of medical professionalism are derived from pre-existent frameworks in the first directive content analysis, while they are defined during data analysis - on the go - in the second approach of conventional content analysis.

This study will follow the second approach aiming at bargaining a consensus on the attributes (core) and behaviours (shell) of medical professionalism in the Arabian context. This approach is expected to obtain a better understanding of the nature of medical professionalism as perceived by Arabs. We aim to develop a framework on medical professionalism that is genuine to Arabian countries.

\section{Method}

\section{Study design}

For conventional content analysis, we used a Delphi technique in a series of sequential questionnaires or "rounds", interspersed by controlled feedback. The Delphi technique is an established method of harnessing the opinions of an often diverse group of experts on practice-related problems (Powell, 2003). We pursue consensus on essential professional values and behaviours among selected health professionals and educators. The Delphi process extended to three rounds in an iterative manner; i.e. stimulus of the second round is decided based on anonymous responses of the first round and so on.

\section{Participants}

The Delphi does not call for expert panels to be representative samples for statistical purposes, but representativeness is assessed on the qualities of the expert panel rather than its numbers (Powell, 2003). The selection of participants for a Delphi study should not necessarily be random, but may be purposive to epitomize relevant groups (Polit \& Beck, 2006).

Our sampling technique was designed to maximize diversity of participants

from both genders. Invited experts had to represent a wide spectrum of specialties and background from four Arab universities from Egypt, Saudi Arabia, 
Oman and Sudan. Almost one quarter of Arabian populations lives in the first two countries and, therefore, we purposely enrolled more experts from Egypt and Saudi Arabia. Participants fulfilled particular inclusion criteria, as they had to be (a) native Arabic speakers; (b) medical or dental professionals in clinical and nonclinical disciplines, and (c) engaged in undergraduate medical education and/or residency training. Four dentists were included along with 13 medical doctors, because both professions are entitled as doctors in our culture. The demography of the members of the reference panel is shown in Table 6.2.

Almost half of the candidates were certified medical educators and, therefore, were quite oriented about the value of the concept of professionalism in medical education. An invitation was sent via e-mail as blind carbon copy (bcc) to all potential members of the reference panel with explanation of the study objectives and their expected role. There was no direct communication between experts on the study subject and none of them was aware about the list of participants.

Table 6.2. Demography of experts in the reference panel, which represents the diversity of gender and background of its members.

\begin{tabular}{cccll} 
Panelist No. & Gender & Profession & Setting* & Specialty \\
1 & M & Medicine & Clinical & Psychiatry \\
2 & F & Medicine & Clinical & Surgery \\
3 & M & Medicine & Academic & Medical Education \\
4 & M & Dentistry & Clinical & Dental Radiology \\
5 & F & Medicine & Academic & Microbiology \\
6 & M & Dentistry & Clinical & Maxillofacial surgery \\
7 & M & Medicine & Clinical & Pediatrics \\
8 & M & Medicine & Clinical & Pediatrics \\
9 & M & Medicine & Clinical & Pediatrics \\
10 & F & Medicine & Academic & Physiology \\
11 & F & Medicine & Clinical & Hepatology \\
12 & $\mathrm{~F}$ & Dentistry & Academic & Dental Pathology \\
13 & $\mathrm{~F}$ & Medicine & Academic & Medical Education \\
14 & $\mathrm{M}$ & Medicine & Clinical & Family Med. \\
15 & $\mathrm{~F}$ & Medicine & Academic & Biochemistry \\
16 & $\mathrm{M}$ & Medicine & Clinical & Emergency \\
17 & $\mathrm{M}$ & Dentistry & Clinical & Pediatric Dentistry \\
\hline$*$ 'Clinical' setting involves direct patient care while 'academic' does not.
\end{tabular}




\section{Procedure}

Three rounds were planned and administered. In each round participants reflected on subsequent stimuli designed by authors then confirm their inputs to reach agreement.

\section{Round 1}

The first round questionnaire is recommended to be unstructured and include open-ended questions to motivate participants to elaborate on the topic under investigation and increase the richness of the data collected (Powell, 2003).We started by asking experts to answer four questions regarding: what a professional doctor should be, should do, should not be and should not do. This round intended to gather all possible attributes and behaviours of medical professionalism as well as unprofessional ones. A qualitative content analysis of responses was then undertaken and this provides the basis for subsequent rounds.

\section{Round 2}

Respondents to round 1 were contacted and provided with the results and they were asked to select the top-10 foremost qualities for medical professionalism. The sum of votes was calculated and professional attributes of the highest votes were sorted in higher-order categories.

\section{Round 3}

All respondents from round 2 received one more request to review and confirm their selection as categorized in four main themes. A new framework was designed to describe the domains and traits of medical professionalism in Arabian context.

\section{Data analysis}

Qualitative content analysis focused on manifest content only (Kondracki, Wellman, \& Amundson, 2012), because all communication was written to and from panelists via emails. Knowledge generated from our content analysis is based on participants' unique perspectives as grounded in the actual data. We followed the conventional approach to content analysis to gain direct information 
from study participants without imposing preconceived categories or theoretical perspectives.

The response from each panelist was considered the unit of analysis (answers to the four questions in Round 1), which included a number of meaning units (texts). Meaning units represented features of un/professionalism and varied in length, ranging from one word, e.g. 'respect' and 'truthful' to a couple of lines, e.g. "doctors should keep secrets of their patients and never disclose them to people outside the healthcare practice'. Short meaning units were condensed and coded as such, but longer ones were shortened with the preservation of their gist to form condensed meaning units. Many condensed meaning units were found similar and shared the same synonyms or antonyms, e.g. "truthful", "telling the truth" and "lying", and therefore one code was given to them all, e.g. truthful, as shown in the last column of Table 6.3.

Table 6.3. Examples of meaning units, condensed meaning units and codes.

\begin{tabular}{|c|c|c|}
\hline Meaning Unit & $\begin{array}{l}\text { Condensed } \\
\text { Meaning Unit }\end{array}$ & Code \\
\hline $\begin{array}{l}\text { The doctor should be transparent with patients and never lie to } \\
\text { them about their illness, diagnosis and management. }\end{array}$ & $\begin{array}{l}\text { Transparent and truthful } \\
\text { with patients. }\end{array}$ & Truthful \\
\hline Doctors should not lie & Do not lie. & Truthful \\
\hline Always tell the truth & Tell the truth & Truthful \\
\hline Respect patients in diagnosis and management. & Respect patients & Respect \\
\hline Respect & Respect & Respect \\
\hline Respect students in front of patients, nurses, peers & Respect students & Respect \\
\hline Do not underestimate views of other doctors & Respect colleagues & Respect \\
\hline $\begin{array}{l}\text { Professional doctors should keep the secrets of their patients } \\
\text { and never disclose them to outsiders. }\end{array}$ & Keep patient secrets. & Confidentiality \\
\hline Doctors should know his limits and shortcomings & Know about own limits & Self-awareness \\
\hline Doctors should learn about their potentials and strengths & Learn about own potentials & Self-awareness \\
\hline $\begin{array}{l}\text { Doctors should create a balance between personal life and } \\
\text { professional commitments }\end{array}$ & $\begin{array}{l}\text { Balance between personal } \\
\text { and professional duties. }\end{array}$ & Balanced life \\
\hline $\begin{array}{l}\text { Doctors should not be committed to extra duties that interfere } \\
\text { with their normal life }\end{array}$ & $\begin{array}{l}\text { No extra duties that } \\
\text { interfere with normal life. }\end{array}$ & Balanced life \\
\hline
\end{tabular}

Codes were then grouped under higher headings (categories), which were eventually clustered in four themes. Credibility can be established through activities such as peer debriefing and review of content analysis. Two authors contributed to the content analysis independently and then agreed on the final codes, categories and themes. Consensus was identified by content analysis (in round 1 and 3 ) and by numerical analysis (in round 2 ). 


\section{Round 1}

\section{Results}

Of the 21 invited experts, 17 responded to round 1 and sent their answers to the given four open-ended questions (Figure 6.1). Each participant listed 2-5 attributes (meaning units) to catalog professional and unprofessional manners of doctors. Meaning units reached up to 192 in total and they were condensed, coded, merged and sorted into 24 higher order categories to portray qualities of medical professionalism in Arabian context (see Appendix 6.1). The categories were decided by two authors and send back to panelists for evaluation.

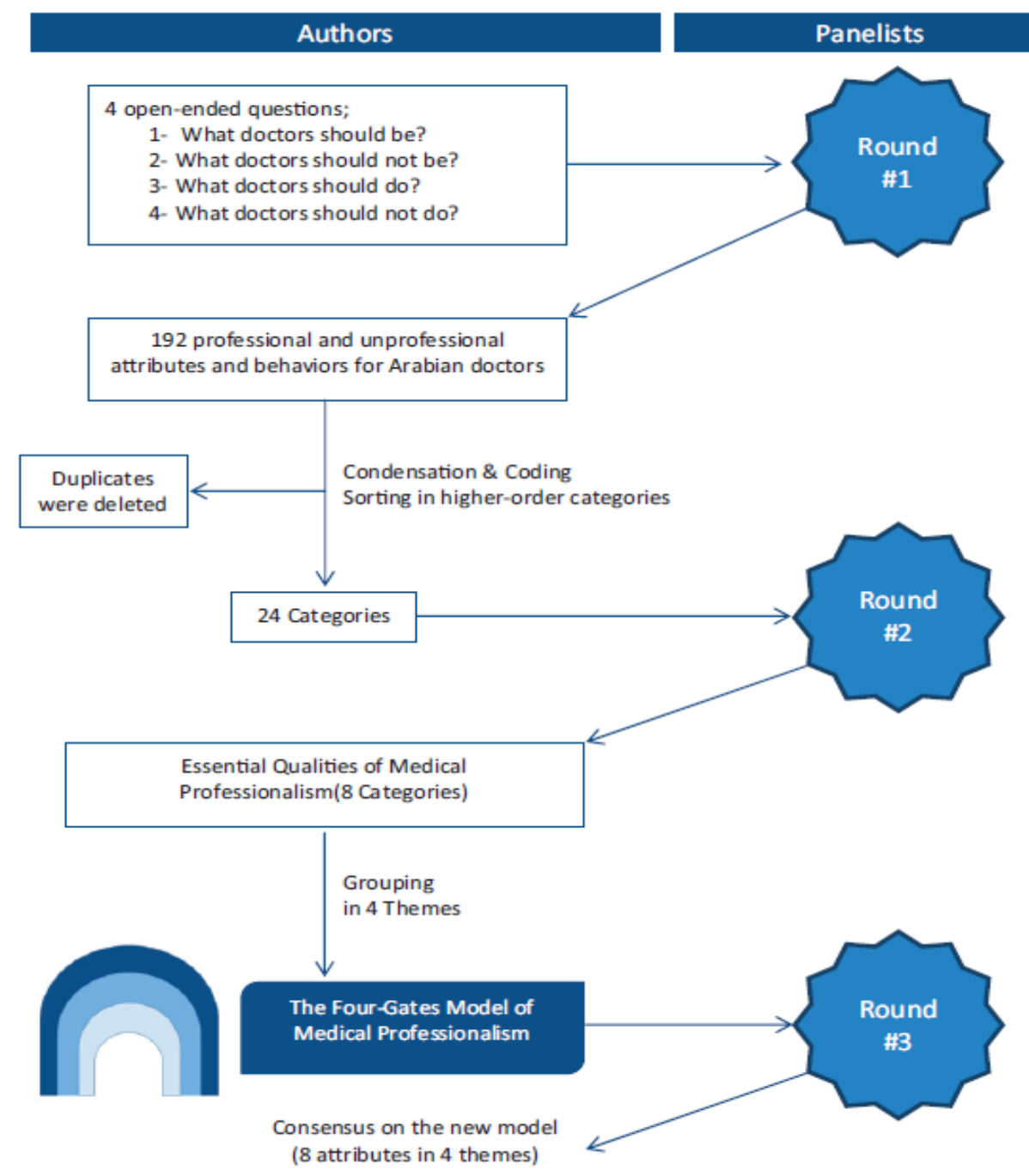

Figure 6.1. Storyboard of the Delphi technique showing the flow of communication between authors (on the left) and panelists (on the right) throughout the process over 3 rounds. 


\section{Round 2}

Panelists listed the top-10 professional categories (of the 24), which they perceive as essential without ranking from 1 to 10 . Eight categories received nine votes (half of participants plus one) or more, and therefore considered of prime importance. Authors found links between each pair of categories and, therefore, provide the rationale for the Four-Gates Model of Arabian medical professionalism, as shown in Figure 2. The Four-Gates Model encompasses eight professional traits as coupled in four themes; dealing with self, dealing with task, dealing with others and dealing with God (Figure 6.2)

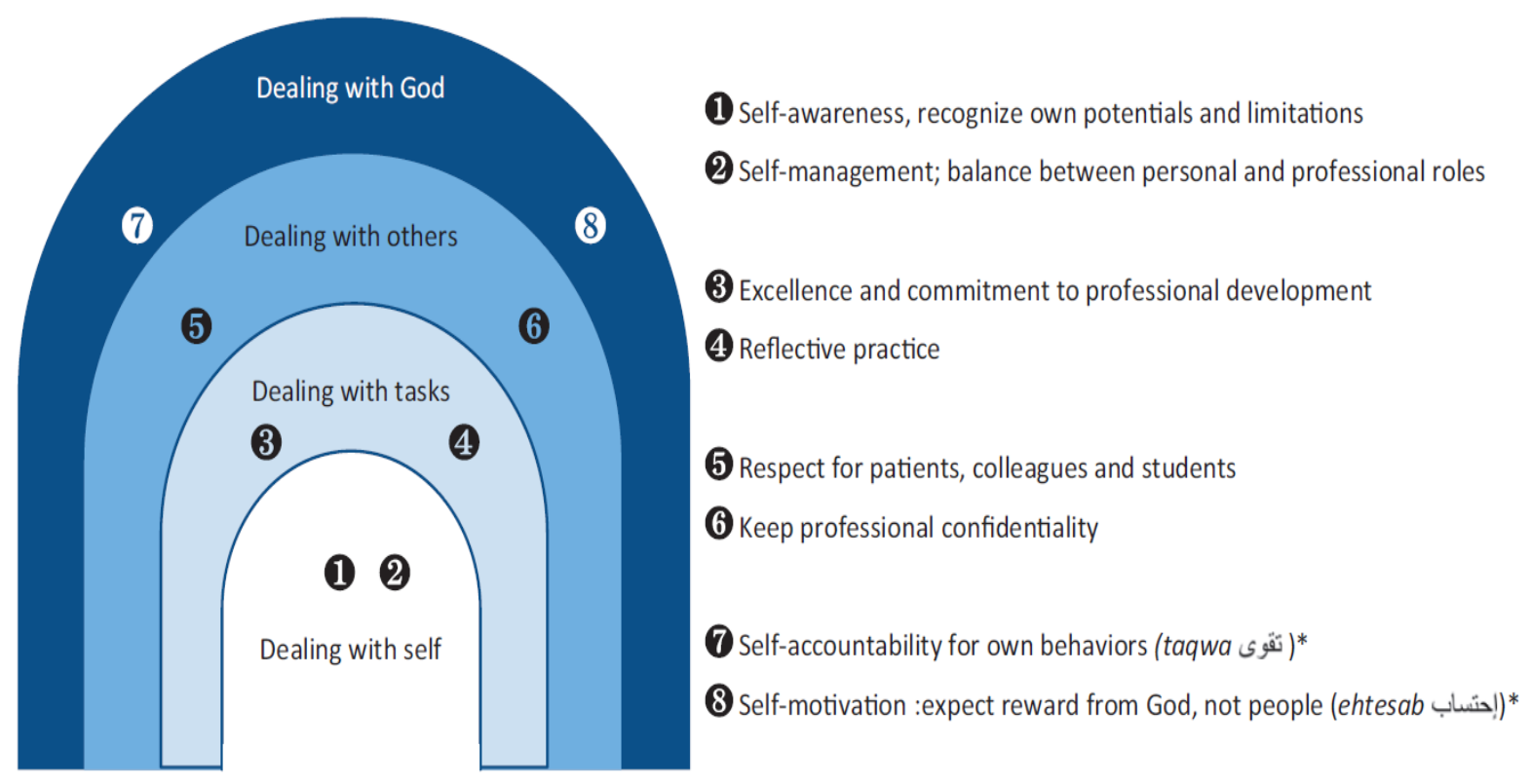

Figure 6.2. The Four-Gates Model of Arabian Medical Professionalism.

The first gate - 'dealing with self - included two attributes: self-awareness and self-management. Doctors should learn about themselves first (dealing with self) to recognize their potentials and limitations, then find out how to fulfill their needs and learning gaps (Self-awareness). Self-management is not only about time management, but about life management. Medical professionals have to allocate the appropriate time and effort for their various professional roles as clinicians, teachers, scholars and community leaders. At the same time, they should also attend to their personal and family responsibilities. 
The second gate - 'dealing with tasks' - is mainly about excellence and reflection. Medical professionals have to commit to professional development to fulfill the growing patients' needs and keep abreast with advancement of technology in diagnosis and treatment. Aspiring towards excellence is not only for clinical practice, but also to enhance performance in teaching and research as well. Reflective practice is a key attribute while dealing with any task, because such skill helps doctors to identify their learning gaps and so it is also connected with dealing with self in the first gate.

The third gate'dealing with others', is about communication with patients, colleagues, supervisors, subordinates and may extent to other members of the institution and the community at large. Experts of the panel found that respect and confidentiality are key attributes when dealing with others.

The fourth gate - 'dealing with God' - is fairly new to the main stream literature on medical professionalism. Self-accountability and self-motivation have been addressed in the literature, but the current study interprets them from a different take, as linked to a Super Power (God) that monitors and rewards for all actions, as it will be further elaborated in the Discussion section.

\section{Round 3}

Participants agreed that the Four-Gate model is relevant to Arabian context and represents the most essential elements of medical professionalism that should be taught, learned and assessed in medical education.

\section{Discussion}

This study is an attempt to identify attributes of Arabian professional doctors as grounded in the minds of native Arabian members of the medical and dental academic and clinical community. In a Delphi process, we have reached an agreement to list eight principal traits of medical professionalism in Arabian context, which can be compared against the keywords reported from Western perspectives in Table 1. Shared qualities included self-awareness, accountability, excellence, reflective practice and respect. The third gate addressed dealing with others, but did not attend to attributes like collaboration, teamwork, leadership and social accountability. Yet, the Four-Gate Model stands out with a new theme, in its fourth gate (dealing with God), which was rarely addressed in the discourse of medical professionalism in the Western context. 
Grouping professional qualities in clusters was recently reported in a number of scholarly articles on medical professionalism (Chandratilake, McAleer, Gibson, \& Roff, 2010; Ghadirian, Salsali, \& Cheraghi, 2014; Jha, Bekker, Duffy, \& Roberts, 2007; Leung, Hsu, \& Hui, 2012; Pan, Norris, Liang, Li, \& Ho, 2013; Sehiralti et al., 2010; Surdyk, Lynch, \& Leach, 2003; van Mook et al., 2011; van Mook et al., 2012). No list, though, is ever claimed to be comprehensive or conclusive.

\section{Faith and medical professionalism}

Faith, in God (Allah) and the hereafter (Day of Judgment), is what more than $90 \%$ of Arabs share, regardless of their diverse affiliations and nationalities (Barakat, 1993). Like the metaphor of the elephant in the room, Arabs (particularly Muslims) tend to overlook faith as a core cultural value of medical students, teachers and patients. In Arab countries, linking self-accountability and self-motivation to faith (dealing with God) might possibly lead to tangible improvement in professional conducts. Such improvement, in presence of good role models who practice what they preach, may be expected to be sustained, even in absence of direct supervision or instant reward. Faith may further provide the doctor with an internal North and insight to navigate his/her path in a sophisticated healthcare environment. This study attested that faith plays an axiomatic role in shaping medical professionalism in Arabian context, which is clearly demonstrated in the two attributes in the fourth gate; self-accountability and self-motivation.

Self-accountability for own behaviours in absence of human monitoring is also known as 'taqwa' تقوى in Arabic. Doctors are smart creatures who can cunningly commit themselves to the minimum without being legally caught. It is time to shift from extrinsic drives which we trust to moderate medical practice. The medical profession is not (only) governed by professional bodies, rules, patients' needs or societal expectations. There is something far beyond the social contract with its series of expectations and obligations between society and medical profession. When self-accountability is interpreted as "taqwa", it empowers an intrinsic drive for reflection, vigilance and careful estimation of actions and their consequences, because they are witnessed by God, even in absence of people. 
Self-motivation - or 'ehtesab' إحتساب in Arabian context is not fueled by rewards from people (patients, families, individuals, professional bodies or community at large), but it is when doctors do their best in clinical work, teaching and research duties and then expect reward from God or a superpower that owns everything, whether in this life or afterwards. This makes it less necessary to rely on immediate carrots (incentives, decoration and acknowledgment) to motivate doctors to stick to professional conduct. The notion of the genuine selfmotivation - in a faithful society - is expected to energize excellence and commitment. Think of an Arab doctor who is working for long duty hours in night shifts and is doing utmost efforts to provide the finest medical care to never satisfied patients, family or employers. Faith in God almighty who compensates people for their deeds, may inspire that doctor to replenish his/her passion for services and commitment to excellence. Self-motivation in an Arabian or religious cultures, therefore, can probably be better linked to the divine accountability than social accountability.

\section{Salient features of the Four-Gate Model}

The Four-Gates Model has also four salient features. First, the Four-Gates model suggests a move from the classical perception of medical professionalism as a short list of standalone attributes (as in Table 6.1), to link them in a structural pattern of connected professional qualities as coupled in four logical domains (Gates). It is important for medical students and teachers to correlate professional attributes, as demonstrated in the Four-Gates Model, because such coupling is expected to advance teaching and learning of medical professionalism. For instance, Self-awareness and self-management (\#1 and \#2 in the smaller arch) are interconnected, because they both contribute to emotional intelligence, which maps on to professionalism (Taylor, Farver, \& Stoller, 2011) and is gaining more attention in medical education (Cherry, Fletcher, O'Sullivan, \& Dornan, 2014).

Second, four of the eight attributes started with 'self'. This observation implies the value of developing and nurturing self-awareness and selfmanagement (\#1 and \#2 in the inner arch) as the route to the inner peace and having self-accountability and self-motivation (\#7 and \#8 in the outer arch). Medical professionalism starts by preparing professionals - themselves - to work in a complex healthcare system, with major key players like pharmaceutical and insurance companies along with the escalating stress from vocal patients' complaints and longer duty hours from one hand, and commitment to other non- 
clinical roles like teaching and research, let alone the family responsibilities of doctors on the other hand. Countless temptations, precaution and obligations made modern medical profession incredibly sophisticated, like no other professions, simply because doctors are dealing with human lives. In concert with being competent, fulfilling patients' needs and meeting societal expectations, doctors also need to learn about how to keep their internal serenity and true North. Success -and failure by the way- starts from within, but unfortunately, these notions are rarely attended to in the discourse of medical professionalism. Addressing professional qualities about self may stimulate further discussion in this track.

Third, the model stimulates lateral thinking on medical professionalism. Notice that the eight qualities were portrayed in gates, not in intersecting circles or building boxes. Illustrating domains of medical professionalism in gates captures the dynamic nature of professionalism, as a pathway; a notion that resonates well with the term 'aspiring towards' that was eloquently used by the American Board of Internal Medicine when listing attributes of medical professionalism in their milestone publication named: 'Project Professionalism'. The model implies that: being a professional doctor is not a destination, but rather a lifelong journey through these four gates. The gates were intentionally sketched of variable heights. The forth gate is not only larger, but it also overarch other gates, because it acts as a beacon in the dark ocean with high tides.

Fourth, despite the Four-Gates Model has emerged from Arabian background, it may be also applicable (after validation) to other similar cultures, where faith represents a cornerstone in communication and the basis for social values. Faith, however, was not reported as a key principle in interpreting professionalism in non-Arab countries with Muslim majorities like Iran (Aramesh et al., 2009) or Turkey (Sehiralti et al., 2010).

The fourth gate of the model should be addressed with care with nonbelievers in Arab countries or in institutions whose mission and vision are based on humanistic rather than religious principles. Each institution should decide on the cognitive base of professionalism that will remain constant throughout the continuum of medical education (Cruess \& Cruess, 2006).

Professionalism is a social construct and is culture-sensitive. Regional similarities and differences in understandings of professionalism have been reported by medical practitioners in UK, Europe, North America and Asia 
(Chandratilake et al., 2012; Jha, Mclean, Gibbs, \& Sandars, 2014; Morrow, Rothwell, Burford, \& Illing, 2013). In China, professionalism encompasses Confucian values like ren ai (humane love) and gong xin (public spiritedness) (Pan et al., 2013). Professionalism, therefore, should be interpreted in view of local traditions and ethos. To the best of our knowledge, this study provides a basis for understanding professionalism apart from Western ideologies, but as grounded in the minds of local medical practitioners in the Arab region.

\section{Limitations}

This study has several limitations. The study relied on a convenience sample of Arab professionals, so results may not be applicable to the general population. Other stakeholders like medical students, patients, policy makers and community leaders may be included in future studies to tap on their views on the Four-Gates Model. The fourth gate included two attributes of taqwa and ehtesab, which are known to the Muslim majority of Arabs, but it may limit the applicability of the model on Arab non-Muslim minorities. To avoid this, educators may focus on the generic understanding of self-accountability and self-motivation and demonstrate relevant examples in the daily life of Arabs of all nationalities and beliefs of these two professional qualities. Some attributes of the Four-Gates Model might be challenging for teaching, learning and assessment, particularly those in the inner and outer gates of the model. These attributes may need more attention in future studies to explore them further and decide the best practice to address them in undergraduate and postgraduate curricula.

\section{Conclusion}

The new Four-Gates Model on medical professionalism is expected to improve the interpretation of medical professionalism in Arabian context, beyond fulfilling patients' needs and meeting societal expectations. This study suggested that faith-driven concepts like taqwa and ehtesab can be used to advance professionalism education and practice of Arab medical practitioners. These notions, however, may not be all relevant to non-Muslims Arabs or in institutions whose principles are based on humanistic values. This study stimulates further discussion on interpretation of medical professionalism in view of local traditions and ethos.

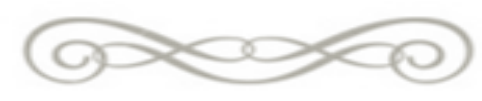




\section{References}

ABIM (American Board of Internal Medicine). (1995). Project Professionalism. Retrieved December 23, 2014, from http://www.abimfoundation.org/ /media/Foundation/Professionalism/Proje ct professionalism.ashx?la=en

Al-Eraky, M. M., \& Chandratilake, M. (2012). How medical professionalism is conceptualised in Arabian context: A validation study. Medical Teacher.

Al-Eraky, M. M., Chandratilake, M., Wajid, G., Donkers, J., \& van Merrienboer, J. (2013). Medical professionalism: development and validation of the Arabian LAMPS. Medical Teacher, 35 Suppl 1, S56-62. Retrieved from http://www.ncbi.nlm.nih.gov/pubmed/23581897

Aramesh, K., Mohebbi, M., Jessri, M., \& Sanagou, M. (2009). Measuring professionalism in residency training programs in Iran. Medical Teacher, 31(8), e356-61. Retrieved from http://www.ncbi.nlm.nih.gov/pubmed/19811199

Barakat, H. (1993). Society, Culture, and State (pp. 1-314). Berkeley: University of California Press.

Blackall, G. F., Melnick, S. a, Shoop, G. H., George, J., Lerner, S. M., Wilson, P. K., ... Kreher, M. (2007). Professionalism in medical education: the development and validation of a survey instrument to assess attitudes toward professionalism. Medical Teacher, 29(2-3), e58-62. doi:10.1080/01421590601044984

Brownell, A. K. W., \& Cote, L. (2001). Senior Residents ' Views on the Meaning of Professionalism and How They Learn about It. Academic Medicine, 76(7), 734-737.

Chandratilake, M., McAleer, S., \& Gibson, J. (2012). Cultural similarities and differences in medical professionalism: a multi-region study. Medical Education, 46(3), 257-66. doi:10.1111/j.1365-2923.2011.04153.x

Chandratilake, M., McAleer, S., Gibson, J., \& Roff, S. (2010). Medical professionalism: what does the public think? Clinical Medicine (London, 
England), 10(4), 364-9. Retrieved from

http://www.ncbi.nlm.nih.gov/pubmed/20849011

Cherry, M. G., Fletcher, I., O'Sullivan, H., \& Dornan, T. (2014). Emotional intelligence in medical education: a critical review. Medical Education, 48(5), 468-78. doi:10.1111/medu.12406

Collier, R. (2012). Professionalism: the historical contract. CMAJ : Canadian Medical Association Journal = Journal de l'Association Medicale Canadienne, 184(11), 1233-4. doi:10.1503/cmaj.109-4230

Cruess, R. L., \& Cruess, S. R. (2006). Teaching professionalism: general principles. Medical Teacher, 28(3), 205-8. doi:10.1080/01421590600643653

Cruess, R. L., \& Cruess, S. R. (2010). Professionalism is a generic term: practicing what we preach. Medical Teacher, 32(9), 713-4.

doi:10.3109/0142159X.2010.505971

Cruess, S. R., Cruess, R. L., \& Steinert, Y. (2010). Linking the teaching of professionalism to the social contract: a call for cultural humility. Medical Teacher, 32(5), 357-9. doi:10.3109/01421591003692722

Ghadirian, F., Salsali, M., \& Cheraghi, M. A. (2014). Nursing professionalism: An evolutionary concept analysis. Iranian Journal of Nursing and Midwifery Research, 19(1), 1-10. Retrieved from http://www.pubmedcentral.nih.gov/articlerender.fcgi?artid=3917177\&tool= pmcentrez\&rendertype=abstract

Hafferty, F. (2004). Toward the operationalization of professionalism: a commentary. The American Journal of Bioethics : AJOB, 4(2), 28-31. doi:10.1162/152651604773067532

Hsieh, H.-F., \& Shannon, S. E. (2005). Three approaches to qualitative content analysis. Qualitative Health Research, 15(9), 1277-88. doi:10.1177/1049732305276687

Jha, V., Bekker, H. L., Duffy, S. R., \& Roberts, T. E. (2007). A systematic review of studies assessing and facilitating attitudes towards professionalism in 
medicine. Medical Education, 41(8), 822-9. doi:10.1111/j.1365-

2923.2007.02804.x

Jha, V., Mclean, M., Gibbs, T. J., \& Sandars, J. (2014). Medical professionalism across cultures: A challenge for medicine and medical education. Medical Teacher, 1-7. doi:10.3109/0142159X.2014.920492

Kondracki, N. L., Wellman, N. S., \& Amundson, D. R. (2012). Content analysis: review of methods and their applications in nutrition education. Journal of Nutrition Education and Behavior, 34(4), 224-30. Retrieved from http://www.ncbi.nlm.nih.gov/pubmed/12217266

Leung, D. C., Hsu, E. K., \& Hui, E. C. (2012). Perceptions of professional attributes in medicine: a qualitative study in Hong Kong. Hong Kong Medical Journal = Xianggang Yi Xue Za Zhi / Hong Kong Academy of Medicine, 18(4), 318-24. Retrieved from http://www.ncbi.nlm.nih.gov/pubmed/22865176

Morrow, G., Rothwell, C., Burford, B., \& Illing, J. (2013). Cultural dimensions in the transition of overseas medical graduates to the UK workplace. Medical Teacher, 35(10), e1537-45. doi:10.3109/0142159X.2013.802298

Nhan, V. T., Violato, C., Le An, P., \& Beran, T. N. (2014). Cross-cultural construct validity study of professionalism of Vietnamese medical students. Teaching and Learning in Medicine, 26(1), 72-80. doi:10.1080/10401334.2013.857333

Pan, H., Norris, J. L., Liang, Y.-S., Li, J.-N., \& Ho, M.-J. (2013). Building a professionalism framework for healthcare providers in China: a nominal group technique study. Medical Teacher, 35(10), e1531-6. doi:10.3109/0142159X.2013.802299

Polit, D. F., \& Beck, C. T. (2006). The content validity index: are you sure you know what's being reported? Critique and recommendations. Research in Nursing \& Health, 29(5), 489-97. doi:10.1002/nur.20147

Powell, C. (2003). The Delphi technique: myths and realities. Journal of Advanced Nursing, 41(4), 376-82. Retrieved from http://www.ncbi.nlm.nih.gov/pubmed/12581103 
Quaintance, J. L., Arnold, L., \& Thompson, G. S. (2008). Development of an Instrument to Measure, 83(10), 5-8.

Reid, L. (2011). Medical professionalism and the social contract. Perspectives in Biology and Medicine, 54(4), 455-69. doi:10.1353/pbm.2011.0048

Sehiralti, M., Akpinar, A., \& Ersoy, N. (2010). Attributes of a good physician: what are the opinions of first-year medical students? Journal of Medical Ethics, 36(2), 121-5. doi:10.1136/jme.2009.032854

Surdyk, P. M., Lynch, D. C., \& Leach, D. C. (2003). Professionalism: identifying current themes. Current Opinion in Anaesthesiology, 16(6), 597-602. Retrieved from http://www.ncbi.nlm.nih.gov/pubmed/17021516

Suzuki, N. (2009). [Certification for specialists on neurology by Japanese Society of Neurology]. Rinshō Shinkeigaku = Clinical Neurology, 49(11), 745-6. Retrieved from http://www.ncbi.nlm.nih.gov/pubmed/20030199

Symons, A. B., Swanson, A., McGuigan, D., Orrange, S., \& Akl, E. A. (2009). A tool for self-assessment of communication skills and professionalism in residents. BMC Medical Education, 9, 1. doi:10.1186/1472-6920-9-1

Taylor, C., Farver, C., \& Stoller, J. K. (2011). Perspective: Can emotional intelligence training serve as an alternative approach to teaching professionalism to residents? Academic Medicine : Journal of the Association of American Medical Colleges, 86(12), 1551-4. doi:10.1097/ACM.0b013e318235aa76

Tsai, T., Lin, C., \& Harasym, P. H. (2008). Students ' perception on medical professionalism : the psychometric perspective, 6(4), 1-4.

Van Mook, W. N. K. A., De Grave, W. S., Gorter, S. L., Zwaveling, J. H., Schuwirth, L. W., \& van der Vleuten, P. M. (2011). Intensive care medicine trainees' perception of professionalism: a qualitative study. Anaesthesia and Intensive Care, 39(1), 107-15. Retrieved from http://www.ncbi.nlm.nih.gov/pubmed/21375100

Van Mook, W. N. K. A., Gorter, S. L., Kieboom, W., Castermans, M. G. T. H., de Feijter, J., de Grave, W. S., ... van der Vleuten, C. P. M. (2012). Poor 
professionalism identified through investigation of unsolicited healthcare complaints. Postgraduate Medical Journal, 88(1042), 443-50.

doi:10.1136/postgradmedj-2011-130083

Van Mook, W. N. K. A., van Luijk, S. J., O'Sullivan, H., Wass, V., Harm Zwaveling, J., Schuwirth, L. W., \& van der Vleuten, C. P. M. (2009). The concepts of professionalism and professional behaviour: conflicts in both definition and learning outcomes. European Journal of Internal Medicine, 20(4), e85-9. doi:10.1016/j.ejim.2008.10.006

Welie, J. V. M. (2012). Social contract theory as a foundation of the social responsibilities of health professionals. Medicine, Health Care, and Philosophy, 15(3), 347-55. doi:10.1007/s11019-011-9355-7

Zaini, R. G., Bin Abdulrahman, K. a, Al-Khotani, A. a, Al-Hayani, A. M. a, Al-Alwan, I. a, \& Jastaniah, S. D. (2011). Saudi Meds: a competence specification for Saudi medical graduates. Medical Teacher, 33(7), 582-4. doi:10.3109/0142159X.2011.578180 
Appendix 6.1: Attributes and behaviours of Arabian medical professionals, as retrieved from content analysis of narratives from medical professionals and educators.

\section{Attributes of medical professionalism in Arabian context}

1. Altruism; put patient interest first

2. Competent, skillful and knowledgeable

3. Excellence and commitment to professional development.

4. Fair with everyone

5. Flexible, ready to seek help and benefit from feedback

6. Honest, always

7. Humble with everyone

8. Keep professional confidentiality

9. Leadership

10. Listen, smile and communicate well with patients and colleagues

11. Recognize different professional roles; as a clinician, teacher, mentor and scholar

12. Reflect on practice

13. Respect for patients, colleagues and students

14. Scholarship and evidence-based practice

15. Seek power and support from God, not people (ESTEANAH إستعانة)*

16. Self-accountability for own behaviours and stay away from suspicions (TAKWA تقوى )*

17. Self-awareness; recognize own potentials and limitations

18. Self-Management; balance between personal and professional roles

19. Self-monitoring of behaviours in the absence of supervision (MORAKABAH مر اقبة (20. )

20. Self-motivation and expect reward from God, not people (EHTESAB إحتساب) *

21. Show mercy, care, empathy and sympathy with patients and juniors.

22. Teamwork

23. Truthful, always

24. Volunteer support when needed

* Arabic expressions that eloquently describes each concept in one word.

Attributes in bold were shortlisted by experts to contribute to the Four-Gates Model. 
$126)$ 


\section{Chapter 7}

\section{Faculty development for learning and teaching professionalism in an Arabian context}

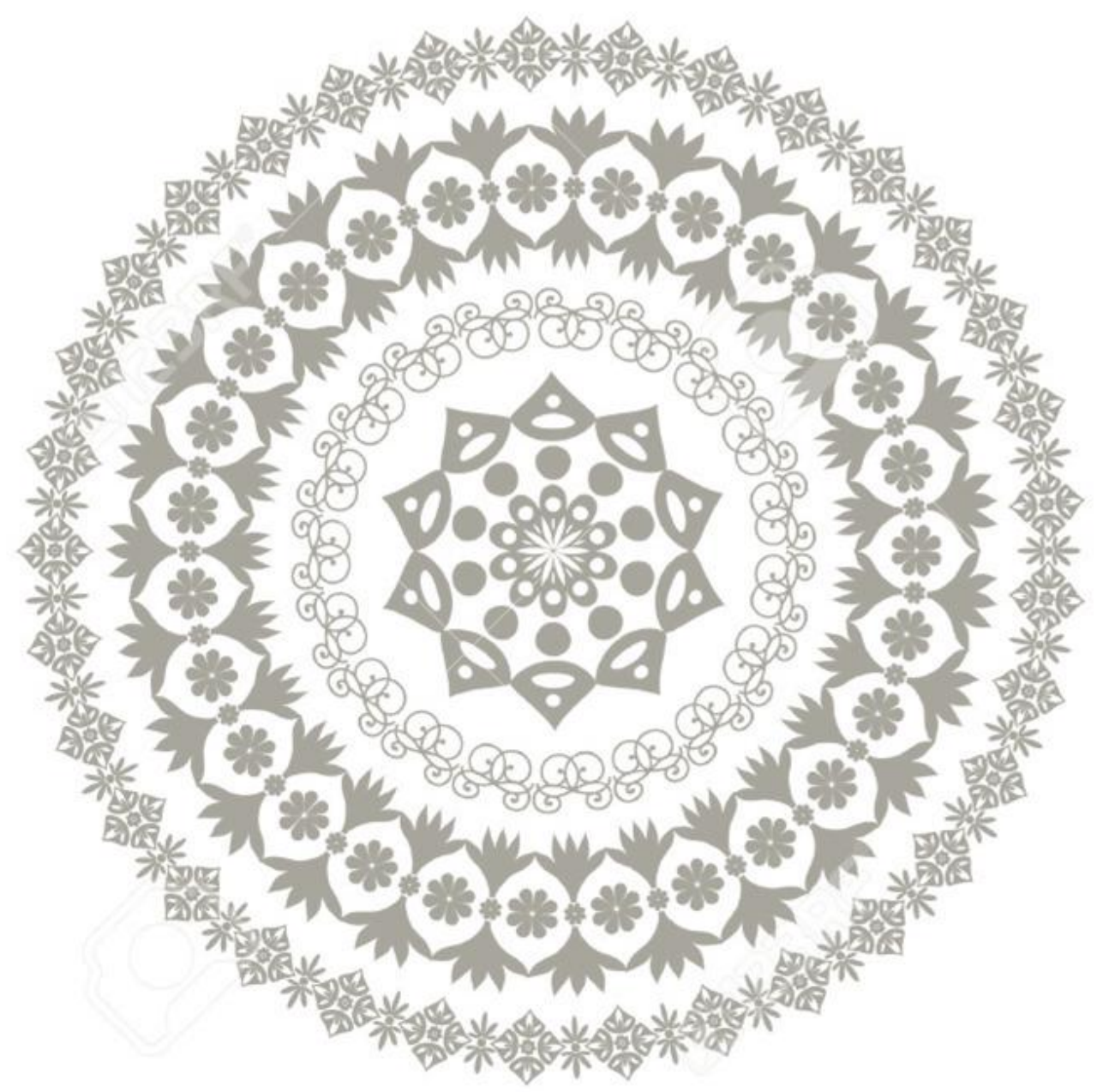

This chapter was published as:

Al-Eraky MM, Donkers J, Wajid G, Van Merrienboer JJ. Faculty development for learning and teaching of medical professionalism. Med Teach. 2015 Apr;37 Suppl 1:S40-6. doi: 10.3109/0142159X.2015.1006604. PubMed PMID: 25803591. 
$128)$ 


\begin{abstract}
Introduction: Professionalism must be explicitly taught, but teaching professionalism is challenging because medical teachers are often not well prepared to teach this content area.
\end{abstract}

Aim: This study aims at designing and evaluating a faculty development programme on learning and teaching professionalism in the Arabian context.

Programme development: The study used a participatory design, where four authors and 28 teachers shared the responsibility in programme design in three steps: orientation workshop for teachers, vignette development, and teaching professionalism to students. The workshop provided the cognitive base on the salient attributes of professionalism in the Arabian context. After the workshop, authors helped teachers to develop a total of 32 vignettes in various clinical aspects, portraying a blend of professionalism dilemmas. A battery of seven questions/triggers was suggested to guide students' reflection.

Programme evaluation: The programme was evaluated with regard to its 'construct' and its 'outcomes'. The programme has fulfilled the guiding principles for its design and it has emerged from a genuine professionalism framework from local scholarly studies in the Arabian context. Programme outcomes were evaluated at the four levels of Kirkpatrick's model; reaction, learning, behaviour and results.

Discussion: The study communicates a number of context-specific issues that should be considered when teaching professionalism in the Arabian culture with respect to teachers and students. Three lessons were learned from developing vignettes, as reported by the authors. This study advocates the significance of transforming faculty development from the training discourse of standalone interventions to the mentorship paradigm in communities of learning.

Conclusion: A three-step approach (orientation workshop, vignettes development, and teaching professionalism) proved effective for faculty development for learning and teaching of professionalism. Professionalism can be taught using vignettes that demonstrate professionalism dilemmas in a particular context. 


\section{Introduction}

Professionalism exemplifies the desired behaviours and attributes towards which physicians - and other health professionals - aspire while serving their patients and society (Hafferty, 2004; Swick, 2000). Professionalism received a global interest in recent years, mainly because of the high profile failures in the practice of medicine, which are often related to unprofessional behaviour (Talbott, 2006). Traditionally, professional values and behaviours have been caught from role models (Al-Abdulrazzaq, Al-Fadhli, \& Arshad, 2014; R. L. Cruess \& Cruess, 2006; Ramani \& Leinster, 2008; Steinert, 1993; van Mook et al., 2010).

The presence of role models is essential in promoting professionalism, but this informal process is no longer considered sufficient with the current heterogeneity of medical students, who were admitted to medical schools with different social, cultural and socioeconomic backgrounds (Swick, 1999). Such diversity nourishes a full spectrum of views among learners about what is professional and what is not professional in different contexts. Professionalism, therefore, must be explicitly taught in the formal curriculum (Cruess \& Cruess, 1997), and it has already been incorporated into many medical education systems for both undergraduates (Batt-Rawden, Chisolm, Anton, \& Flickinger, 2013; Helmich, Bolhuis, Prins, Laan, \& Koopmans, 2011; A. J. O'Sullivan \& Toohey, 2008; Swick, 1999) and postgraduates (Batalden, Leach, Swing, Dreyfus, \& Dreyfus, 2002; Brownell \& Cote, 2001; Eldeek et al., 2012; H. O'Sullivan, van Mook, Fewtrell, \& Wass, 2012; Steinert, Cruess, Cruess, \& Snell, 2005)

Teaching professionalism is challenging for faculty members (Bryden, Ginsburg, \& Kurabi, 2010), because of two main concerns. The first concern is related to the context-specific nature of professionalism, because it is a privilege granted by the society in return of specific expectations from medical professionals (Cruess \& Cruess, 2006; Ho, Lin, Chiu, Lingard, \& Ginsburg, 2012; Jha, Mclean, Gibbs, \& Sandars, 2014; van der Horst \& Lemmens, 2012). That's why professionalism is sensitive to culture and there is no one-size-fits-all curriculum on professionalism (Ho, Yu, Hirsh, Huang, \& Yang, 2011). An institutional cognitive base should be developed to encompass the core professional values, attributes and behaviours that should be addressed in teaching and learning professionalism (Cruess \& Cruess, 2006). 
The second concern is about how professionalism can be taught and learned. The domains of professionalism cannot be taught as abstract concepts (Steinert, Cruess, Cruess, Boudreau, \& Fuks, 2007). Lectures on preaching what doctors 'should do' and 'should not do' proved to have least educational impact on students and may "...force all students into the straight jacket of political correctness" (Gordon, 2003, p. 342). A more promising approach is described in 'situated learning theory', where knowledge needs to be presented in authentic contexts (Birden et al., 2013; Lave \& Wenger, 1991). A set of scenarios (or vignettes) to describe professionalism dilemmas, can be used to trigger discussion and reflection that facilitate learning professionalism (Arawi, 2010; Bernabeo, Holmboe, Ross, Chesluk, \& Ginsburg, 2013; Boenink, de Jonge, Smal, Oderwald, \& van Tilburg, 2005). Professionalism vignettes reflect the complexities of medical practice and offer opportunities in an open and safe forum to guide students' learning on un/professional behaviour (Bernabeo et al., 2013). Self-reflection and reflection among peers is fundamental to the understanding and development of professionalism (Horlick, Masterton, \& Kalet, 2006).

Unfortunately, faculty members are not competent in teaching professionalism as a content area and they are unable to articulate the attributes and behaviours within their courses (Steinert et al., 2007, 2005). Furthermore, there is a literature gap on faculty development for teaching professionalism and the few available scholarly reports in the area have been written from a Western perspective. Faculty development is fundamental to empower educators to teach professionalism and promote institutional agreement on definitions and characteristics of professionalism (Adkoli, Al-Umran, Al-Sheikh, Deepak, \& AlRubaish, 2011; McLean, Cilliers, \& Van Wyk, 2008; Steinert et al., 2007, 2005).

This study has two aims: (1) to design a faculty development programme in learning and teaching professionalism in the Arabian context, and (2) to evaluate the 'structure' of this programme in view of educational guiding principles for teaching professionalism and evaluate the 'outcomes' of the programme on the reaction, learning and behaviour of faculty members.

\section{Programme Development}

The programme was planned and delivered by the Department for Medical Education and it was approved by the Deanship for Educational Development at the University of Dammam, Saudi Arabia. The preparation and implementation of the study extended from September 2013 to May 2014. 
The programme was developed with two guiding principles in mind related to culture-sensitivity and situated learning. It has to embody professionalism in Arabian context and present the core values of professionalism as operationalized in behaviours of health practitioners in selected situations. The programme intended to achieve five learning outcomes, as listed in Table 7.1.

Table 7.1. Learning outcomes of the faculty development programme:

By the end of the programme, teachers should be able to:

- Identify relevant key attributes of professionalism in their specialties

- Develop vignettes that demonstrate professionalism dilemmas to be used for teaching professionalism

- Use pre-set questions/triggers to guide students' reflection on the given vignettes

- Report students' learning experiences

- Act as advocate to teaching professionalism in their departments and institutions

\section{Method}

Two groups shared the responsibility for programme development, namely: authors and teachers in a participatory design approach. Authors reviewed the literature in three tracks: professionalism in Arabian context, educational principles for teaching professionalism and faculty development programme planning and evaluation. The programme was designed in a 3-step process, as demonstrated in Figure 7.1.
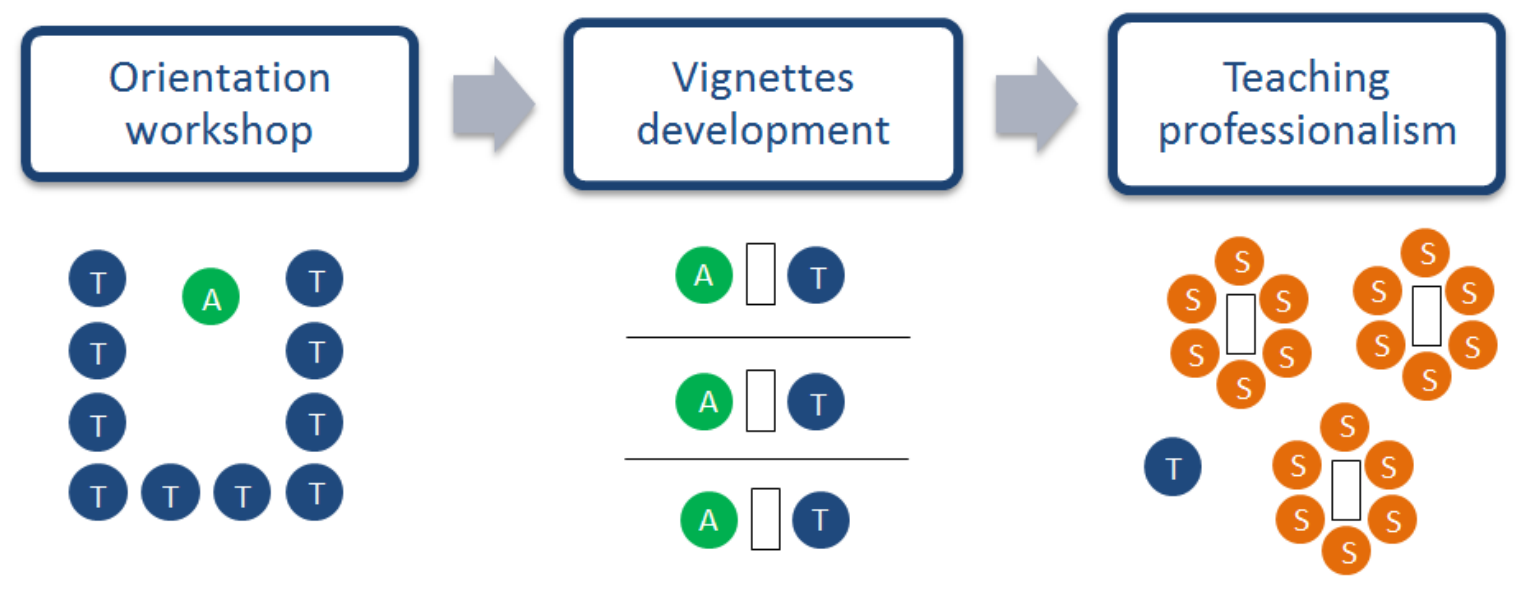

Figure 7.1. Developing a programme for faculty development for learning and teaching professionalism in a 3-step process. Key: A: Author(s), T: Teacher, $\mathbf{S}$ : Student. 


\section{Orientation workshop}

Teachers of different health professions colleges were invited to a full-day faculty-wise workshop on professionalism that encompassed short presentations and interactive discussions in seven topics, as listed in Table 7.2. Teachers were invited to share their experiences on professional lapses or moments of deep reflection in their actual clinical practice.

Table 7.2. Topics for presentations and activities of the workshop:

- The growing significance of professionalism

- Why professionalism must be taught?

- The cultural basis of professionalism and its domains in the Arabian context

- The guiding principles to inculcate professionalism in health professions curricula

- Teaching professionalism in clinical sciences

- The neglected opportunity to teach professionalism in basic sciences

- Using vignettes for guided reflection on professionalism issue

\section{Vignettes development}

After the workshop, authors helped teachers in private meetings to describe critical situations and professionalism dilemmas with relevance to their specialities. Authors and teachers, together, developed multi-dimensional professionalism vignettes that describe real-life scenarios of conflicting interests between practitioners, patients and colleagues.

\section{Teaching professionalism}

Teachers presented the developed vignettes (in written format) to students in their classes and clinical rounds. Teachers and authors, agreed on a preferred learning setting, where the class was divided in small groups of five to seven students. Each group discussed the different aspects of the professionalism dilemma in a particular vignette for 15 minutes. During reflection, students were encouraged to carefully consider the different aspects of the professionalism dilemma, express their feelings, debate on the possible decisions to be taken with justification and anticipate the consequences of each course of action on different stakeholders in the scenario, namely, on themselves, patients and colleagues. Ten minutes were allocated for a student leader from each group to present and defend the argument of his/her peers and seek feedback from members of the other groups and the instructor. 


\section{Results}

A total of 28 teachers attended the workshop from a variety of backgrounds of health professions education in medicine (n.=13), nursing ( $\mathrm{n} .=$ 10), applied medical sciences (.$=3$ ) and dentistry (.$=2)$. After the workshop, authors and teachers developed a total of 32 vignettes in various clinical aspects, portraying a blend of professionalism dilemmas. Sample vignettes are narrated in Table 7.3.

Table 7.3. Sample vignettes on professionalism:

\section{Vignette 1:}

While you are examining a patient in the outpatient clinic, an old lady opens the door suddenly without an appointment and asks you to order two sophisticated investigations for her and renew her prescription. The lady is a patient of another colleague who went to vacation and will be back to his clinic after 3 weeks. The nurse attending your clinic complained that the old lady has shouted at her.

\section{Vignette 2:}

A patient enters your office and shouted: "Doctor, I want to leave the hospital now". You asked: "Why?" Suddenly the patient moved a chair with anger and seems as if he is about to hit you.

\section{Vignette 3:}

You are a nurse at the family planning clinic. A patient was examined by Dr. $\mathrm{X}$ and he asked you to insert an intrauterine device (IUD). You examined her and successfully inserted the IUD. When you started educating her on the common problems of IUD, you discovered that she has a history of ectopic pregnancy, which is a clear contraindication to IUD.

\section{Vignette 4:}

Your kinds ranked top in their schools. You promised them an exceptional outing this weekend. When you were planning to leave the hospital after the end of your shift, a friend of yours arrived at the ER and requested you to stay to care for his wife, who was in a critical condition. You have already singed out to one of your competent and conscientious colleagues. You know he is capable to take care of the case. You decided to meet your friend to assure him then proceed with your personal plans with your family. Your friend, however, pleads you to stay. 
Teachers and authors suggested a battery of seven questions/triggers to guide students' reflection on professionalism vignettes, as listed in Table 7.4.

Table 7.4. Triggers/questions to guide reflection on professionalism vignettes:

- Describe your feelings, if you were in that situation.

- What is the professionalism dilemma of the given scenario?

- What would you do in that situation? and why?

- What if you were in the shoes of the colleague or the patient? (swapping roles)

- What are the expected consequences of your decision?

- What did you learn from discussing this scenario?

- Do you feel more prepared in case if you encounter a similar situation in reality?

Teachers piloted the developed vignettes on 126 students in clinical years. Students reported their feedback on the new learning experience in response to a 4-item questionnaire in five-point Likert scales. Students agreed that learning experience was enjoyable (Mean $=4.28, S D=0.81$ ), reflection followed a logical sequence (Mean $=4.11, \mathrm{SD}=0.91$ ), vignettes were authentic to real practice (Mean $=4.17, S D=0.82$ ), and the time was properly allocated throughout the session (Mean= 3.81, $\mathrm{SD}=1.17$ ).

\section{Programme Evaluation}

Our faculty development programme on learning and teaching professionalism can be evaluated with regard to its 'construct' and its 'outcomes', as in Figure 7.2.

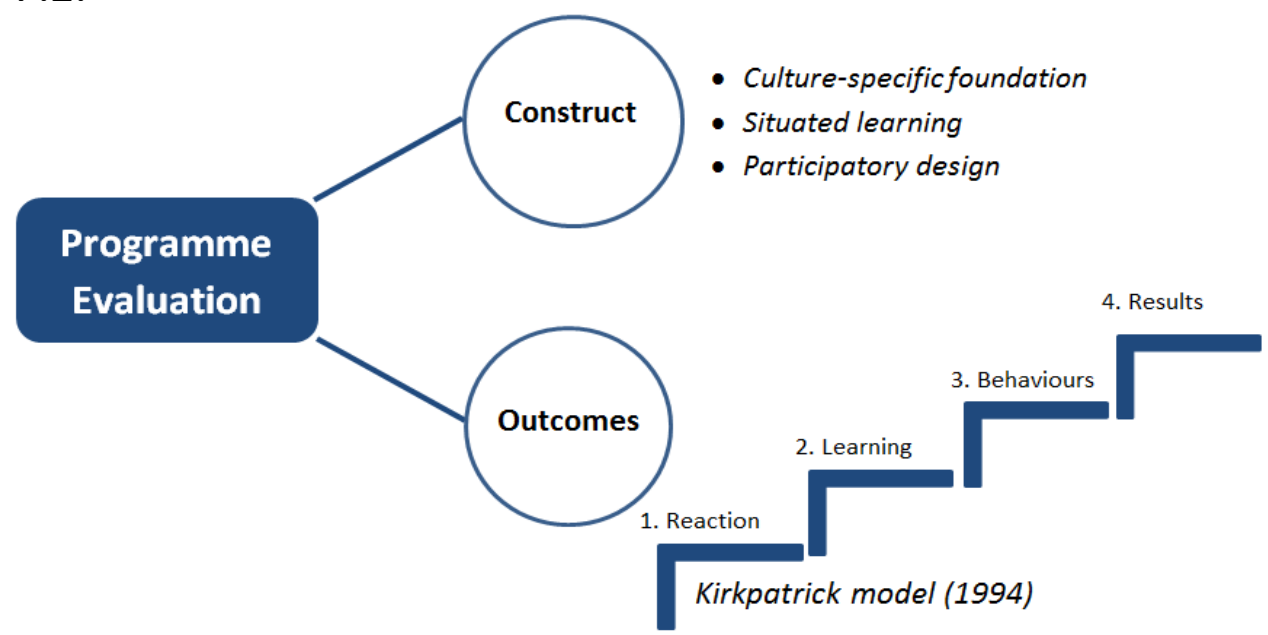

Figure 7.2. Programme evaluation for its construct (in 3 principles) and its outcomes (in 4 levels) 


\section{Construct evaluation}

Evaluation of programme construct is planned against three main guiding principles in professionalism education: (1) professionalism has to emerge from a context-specific foundation that fits the Arabian culture, (2) programme design should acknowledge the situated learning theory, and (3) the participatory design approach has to be manifested by the shared responsibilities between authors and teachers in programme development.

There are indications to confirm that our programme has already fulfilled the above three guiding principles. First, the domains of professionalism have emerged from local studies that addressed professionalism in Arabian context (Adkoli et al., 2011; Al-Eraky, Chandratilake, Wajid, Donkers, \& van Merrienboer, 2013; Al-Eraky \& Chandratilake, 2012).

Eight professional traits were shortlisted and coupled in four themes (Gates), namely: dealing with self, dealing with tasks, dealing with others, and dealing with God. The forth gate (Dealing with God) is pertinent to societies, where 'faith' represents a cornerstone in communication and the basis for social values for a majority of the health-care professionals. In the Arabian context, selfaccountability and self-motivation were interpreted as taqwa and ehtesab, respectively, in Arabic (Al-Eraky, Donkers, Wajid, \& van Merrienboer, 2014)

These studies were used to establish the foundation of the cognitive base of the faculty development programme for teaching professionalism. Second, the program used situated learning theory, where these attributes and values were operationalized in real-life situations to stimulate reflection among students on professionalism dilemmas. Third, teachers contributed with authors throughout programme by: sharing their personal experiences on professionalism lapses during the orientation workshop (step 1), developing the vignettes (step 2), designing an appropriate learning setting, and propose triggers to guide students' reflection (step 3), as demonstrated in Figure 1

\section{Outcomes evaluation}

Evaluation of programme outcomes was planned as per the Kirkpatrick's model (Kirkpatrick, 1979). The model describes four levels of outcomes: (1) Reaction (of learners to the educational experience); (2) Learning (which refers to changes in attitudes, knowledge and skills of teachers); (3) Behaviour (which refers to the change of teaching practice); and (4) Results (which refers to impact 
of the programme on students learning and organizational change). We attempt to evaluate the programme in the four levels, as follows:

Reaction

Participating teachers actively contributed to the three steps of programme development. The workshop inspired teachers to reflect on and express a number of stories portraying un/professional behaviours of themselves, students, and colleagues in real practice with respect to their specialties. Teachers' engagement in the discussion was an indicator of their satisfaction about the quality of workshop and reflected their interest in the topic.

\section{Learning}

The programme produced more knowledgeable teachers on the complexity of professionalism and how it can be taught. Gain in cognitive knowledge of the teachers was manifested by (1) the quality of vignettes they developed, as reviewed by content experts in professionalism and colleagues of the same specialties, (2) the developed battery of questions/triggers for reflection, (3) teachers' ability to plan the appropriate learning setting and allocate proper time for reflection and discussion.

\section{Behaviour}

Teachers learned about professionalism and they transferred their learning to their workplace. The change of behaviour was measured by the selfreported gain in instructional design skills in teaching professionalism in classes using the developed vignettes. Teachers expressed that they were empowered to pass their tacit knowledge on professionalism to their students in a structured manner.

\section{Results}

Results or the impact of the programme can be measured in two directions: the improvement in students' learning and a wider change in the system or organizational practice. Students' feedback on their learning experiences was promising as indicated in the results of the questionnaire. We admit that a longer period is required to evaluate our programme at this advanced level, but we, as authors, are optimistic that our study is 
expected to promote an organizational change in the nearest future for two reasons. First, participants who have voluntarily contributed to this study can act as professionalism advocates to call for curriculum reform and mentor their peers in different specialties to teach this relatively complex content area. Second, the 32 developed vignettes can be a nucleus for a professionalism vignette bank, where dilemmas can be sorted out by their domain, discipline, learning outcomes and educational level.

\section{General Discussion}

This study aimed to design and evaluate a faculty development programme for learning and teaching professionalism. The programme used genuine Arabian framework on professionalism as indicated in local scholarly reports. The design follows the educational principles for teaching professionalism using situated learning theory, where professional attributes were embedded in situations or vignettes. The engagement of teachers in interactive discussion during the orientation workshop and afterwards in the subsequent phases of vignettes development along with students' feedback on their learning experiences indicated that the programme was feasible, constructive and productive.

Context-specific remarks

From our experience, we would like to reflect on some context-specific issues related to teaching professionalism in an Arabian context from the perspective of both teachers and students. We noticed that teachers of traditional educational systems, that is based on information provision, like to be in control of their sessions. They plan to impart knowledge in a classical approach, for example, by using PowerPoint or a whiteboard. Teachers are keen to cover the materials in hand and they usually plan a limited period for discussion or clarification, usually at the end of the session. That's why some teachers admitted that they felt unsecure at the beginning; because they are not familiar with teaching this content area and they could not anticipate the sequence of the discussion in advance. But, when enough time is allocated for reflection, the session turned out to be exciting for both teachers and students. Professionalism education can drive a more student-centered approach to learning, because there is not much content to be presented, but professional values are contextualized in situations which stimulate discussion and reflection. 
On the other side, students also felt unprepared for the session, because they are not familiar with that form of highly interactive learning experience. Students have to build a rationale to advocate their decisions in each professionalism dilemma. Students listed a number of benefits they learned during sessions regarding critical thinking, being accountable for own actions, feeling empathy to patients, integrity and honour, prompt decision making, respecting the scope of service, and collaboration with other members of the health team. Students also reported that they felt better prepared to manage similar situations, if they would encounter them in real life practice.

The use of vignettes was particularly valuable to teach professionalism in Arabian context. Arab students have been raised in an educational environment that fosters competition and they usually seek the 'single' best answer, as the only truth (Frambach, Driessen, Chan, \& van der Vleuten, 2012). Medical practice, however, is not that straightforward, but it is full of uncertainty and ambiguity. We advised teachers not to turn professionalism teaching into 'preaching' on what should or should not be done. Alternatively, teachers should help students to explore different views and elements on each professionalism dilemma, because in reality, professionals are not supposed to find the absolute correct answer, but develop a sort of professional judgment and advocate what they think 'most appropriate and feasible' action in each situation.

\section{Lessons learned}

We would like to indicate three lessons that we learned from planning, conducting and evaluating our faculty development intervention for learning and teaching of professionalism. First, developing vignettes on professionalism is not an easy job. It has to reflect the complexity of real situations. For instance, in Vignette 1 (Table 3) learners acknowledged the conflict of interest of four stakeholders; the doctor (self), the patient, the absent colleague and the nurse.

Second, some vignettes can help learners prioritize their roles to enjoy balanced life. For instance, vignette 4 (Table 3) demonstrates the typical tension between duties and family responsibilities. It was a learning opportunity to decide the 'limits' of professionalism values. All virtues are midway between two nonvirtues. For instance, extreme altruism can lead to burn-out with the consequences of impairment and lack of conscientiousness. Students, particularly residents, should create a balance between professional duties and personal commitments. 
Third, we recognized that different versions may evolve from a single vignette by fine-tuning some contextual details. For instance, in Vignette 1 (Table 3), what if the absent doctor will stay away for three months, instead of three weeks? what if the patient is asking to just renew a routine monthly prescription for her chronic illness? Also swapping the roles of the same vignette may offer different perspectives of the same vignette. For instance, if you were the absent doctor, how would you react to a colleague who dares to examine 'your' patient in your absence? And what is you were in the shoes of the nurse who has been abused by the angry patient? It is amazing to identify different learning objectives with each of the above questions that emerged from the same scenario.

We also realized the implication of transforming faculty development from the classical formal standalone events (mainly workshops) to informal meetings and collaborative learning among teachers to create a move towards the 'communities of practice' in teaching professionalism.

Strengths and limitations

The growing interest in teaching, learning and assessment of professionalism was not supplemented with scholarly initiatives for faculty development to train teachers in that important content area (Steinert et al., 2005). This study adds to the scarce evidence available on the feasibility and impact of faculty development on professionalism on teachers and students. With the recent national framework of competencies that focuses on professionalism as a salient outcome of medical education in Saudi Arabia (Zaini et al., 2011), we expect other initiatives to be materialized in the nearest future. We intentionally submitted a detailed manual including outcomes, topics for presentations, sample vignettes and triggers for reflection. We hope our report would help educators to design similar, and even better, prorgrammes in their institutions.

The study is not without limitations. The selection of participating faculty members was based on their personal interest to learn and teach professionalism in their courses. An alternative approach may engage chairpersons of departments to define a strategy to officially inculcate professionalism as an explicit outcome and then define tools for teaching and assessment. We admit that our programme represents an ad-hoc initiative, but faculty development on professionalism can bring about curricular change, which we desperately hope (Steinert et al., 2005; Steinert, Naismith, \& Mann, 2012). 


\section{Conclusion}

Professionalism can be taught and learned by vignettes that describe professionalism dilemma in different specialties. A three-step approach (orientation workshop, vignettes development and teaching professionalism) proved effective for faculty development on professionalism. Teaching professionalism is a shared responsibility between educationists and teachers. Teachers, who contributed to this study, can be professionalism advocates to motivate their peers for teaching professionalism in their specialties. Future efforts should be synchronized with the curriculum committee and departments to transform the individual experiences of teachers into an institutional reform to explicitly teach professionalism across all specialties.

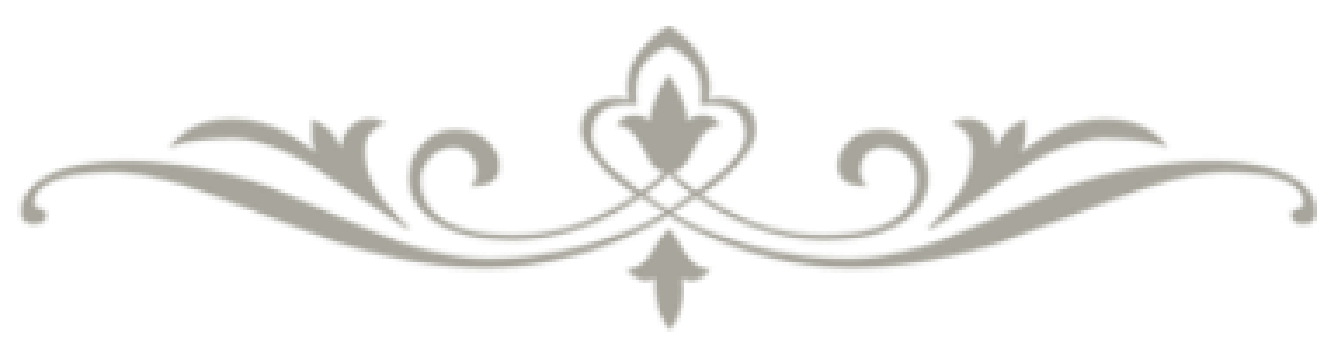




\section{References}

Adkoli, B. V, Al-Umran, K. U., Al-Sheikh, M., Deepak, K. K., \& Al-Rubaish, A. M. (2011). Medical students' perception of professionalism: a qualitative study from Saudi Arabia. Medical Teacher, 33(10), 840-5. doi:10.3109/0142159X.2010.541535

Al-Abdulrazzaq, D., Al-Fadhli, A., \& Arshad, A. (2014). Advanced medical students' experiences and views on professionalism at Kuwait University. BMC Medical Education, 14, 150. doi:10.1186/1472-6920-14-150

Al-Eraky, M. M., \& Chandratilake, M. (2012). How medical professionalism is conceptualised in Arabian context: A validation study. Medical Teacher.

Al-Eraky, M. M., Chandratilake, M., Wajid, G., Donkers, J., \& van Merrienboer, J. (2013). Medical professionalism: development and validation of the Arabian LAMPS. Medical Teacher, 35 Suppl 1, S56-62. Retrieved from http://www.ncbi.nlm.nih.gov/pubmed/23581897

Al-Eraky, M. M., Donkers, J., Wajid, G., \& van Merrienboer, J. J. G. (2014). A Delphi study of medical professionalism in Arabian countries: the Four-Gates model. Medical Teacher, 36 Suppl 1, S8-16. doi:10.3109/0142159X.2014.886013

Arawi, T. (2010). Using medical drama to teach biomedical ethics to medical students. Medical Teacher, 32(5), e205-10. doi:10.3109/01421591003697457

Batalden, P., Leach, D., Swing, S., Dreyfus, H., \& Dreyfus, S. (2002). General competencies and accreditation in graduate medical education. Health Affairs (Project Hope), 21(5), 103-111. Retrieved from http://www.ncbi.nlm.nih.gov/pubmed/12224871

Batt-Rawden, S. a, Chisolm, M. S., Anton, B., \& Flickinger, T. E. (2013). Teaching empathy to medical students: an updated, systematic review. Academic Medicine : Journal of the Association of American Medical Colleges, 88(8), 1171-7. doi:10.1097/ACM.0b013e318299f3e3

Bernabeo, E. C., Holmboe, E. S., Ross, K., Chesluk, B., \& Ginsburg, S. (2013). The utility of vignettes to stimulate reflection on professionalism: theory and practice. Advances in Health Sciences Education : Theory and Practice, 18(3), 463-84. doi:10.1007/s10459-0129384-x

Birden, H., Glass, N., Wilson, I., Harrison, M., Usherwood, T., \& Nass, D. (2013). Teaching professionalism in medical education: a Best Evidence Medical Education (BEME) systematic review. BEME Guide No. 25. Medical Teacher, 35(7), e1252-66. doi:10.3109/0142159X.2013.789132 
Boenink, A. D., de Jonge, P., Smal, K., Oderwald, A., \& van Tilburg, W. (2005). The effects of teaching medical professionalism by means of vignettes: an exploratory study. Medical Teacher, 27(5), 429-32. doi:10.1080/01421590500069983

Brownell, A. K. W., \& Cote, L. (2001). Senior Residents ' Views on the Meaning of Professionalism and How They Learn about It. Academic Medicine, 76(7), 734-737.

Bryden, P., Ginsburg, S., \& Kurabi, B. (2010). Professing Professionalism : Are We Our Own Worst Enemy ? Faculty Members ' Experiences of Teaching and Evaluating Professionalism in Medical Education at One School, 85(June), 1025-1034.

Cruess, R. L., \& Cruess, S. R. (2006). Teaching professionalism: general principles. Medical Teacher, 28(3), 205-8. doi:10.1080/01421590600643653

Cruess, S. R., \& Cruess, R. L. (1997). Professionalism must be taught. BMJ (Clinical Research Ed.), 315(7123), 1674-7. Retrieved from

http://www.pubmedcentral.nih.gov/articlerender.fcgi?artid=2128025\&tool=pmcentrez\&r endertype=abstract

Eldeek, B. S., Ayuob, N. N., Alshawa, L. a, Al Sharif, A. T., Alshareef, N., \& Bokhari, R. F. (2012). Impact of medical curriculum on conceptualization of professionalism by residents at a University Hospital, Jeddah, Saudi Arabia. The Journal of the Egyptian Public Health Association, 87(3-4), 45-50. doi:10.1097/01.EPX.0000417979.76553.dd

Frambach, J. M., Driessen, E. W., Chan, L.-C., \& van der Vleuten, C. P. M. (2012). Rethinking the globalisation of problem-based learning: how culture challenges self-directed learning. Medical Education, 46(8), 738-47. doi:10.1111/j.1365-2923.2012.04290.x

Gordon, J. (2003). Fostering students' personal and professional development in medicine: a new framework for PPD. Medical Education, 37(4), 341-9. Retrieved from http://www.ncbi.nlm.nih.gov/pubmed/12654119

Hafferty, F. (2004). Toward the operationalization of professionalism: a commentary. The American Journal of Bioethics : AJOB, 4(2), 28-31. doi:10.1162/152651604773067532

Helmich, E., Bolhuis, S., Prins, J., Laan, R., \& Koopmans, R. (2011). Emotional learning of undergraduate medical students in an early nursing attachment in a hospital or nursing home. Medical Teacher, 33(11), e593-601. doi:10.3109/0142159X.2011.610837

Ho, M.-J., Lin, C.-W., Chiu, Y.-T., Lingard, L., \& Ginsburg, S. (2012). A cross-cultural study of students' approaches to professional dilemmas: sticks or ripples. Medical Education, 46(3), 245-56. doi:10.1111/j.1365-2923.2011.04149.x 
Ho, M.-J., Yu, K.-H., Hirsh, D., Huang, T.-S., \& Yang, P.-C. (2011). Does one size fit all? Building a framework for medical professionalism. Academic Medicine : Journal of the Association of American Medical Colleges, 86(11), 1407-14. doi:10.1097/ACM.0b013e31823059d1

Horlick, M., Masterton, D., \& Kalet, A. (2006). Learning Skills of Professionalism : a Student-Led Professionalism Curriculum.

Jha, V., Mclean, M., Gibbs, T. J., \& Sandars, J. (2014). Medical professionalism across cultures: A challenge for medicine and medical education. Medical Teacher, 1-7. doi:10.3109/0142159X.2014.920492

Kirkpatrick, D. L. (1979). Techniques for evaluating training programs. Training and Development Journal, 33(78-92). Retrieved from http://agris.fao.org/agrissearch/search.do?recordID=US201302107125

Lave, J., \& Wenger, E. (1991). Situated Learning: Legitimate Peripheral Participation. New York, NY, USA: Cambridge University Press.. Retrieved from http://books.google.com/books?hl=ar\&lr=\&id=CAVIOrW3vYAC\&pgis=1

McLean, M., Cilliers, F., \& Van Wyk, J. M. (2008). Faculty development: yesterday, today and tomorrow. Medical Teacher, 30(6), 555-84. doi:10.1080/01421590802109834

O'Sullivan, A. J., \& Toohey, S. M. (2008). Assessment of professionalism in undergraduate medical students. Medical Teacher, 30(3), 280-6. doi:10.1080/01421590701758640

O’Sullivan, H., van Mook, W., Fewtrell, R., \& Wass, V. (2012). Integrating professionalism into the curriculum: AMEE Guide No. 61. Medical Teacher, 34(2), e64-77.

doi:10.3109/0142159X.2012.655610

Ramani, S., \& Leinster, S. (2008). AMEE Guide no. 34: Teaching in the clinical environment. Medical Teacher, 30(4), 347-64. doi:10.1080/01421590802061613

Steinert, Y. (1993). using role-plays in clinical teaching, 15(4), 283-291.

Steinert, Y., Cruess, R. L., Cruess, S. R., Boudreau, J. D., \& Fuks, A. (2007). Faculty development as an instrument of change: a case study on teaching professionalism. Academic Medicine: Journal of the Association of American Medical Colleges, 82(11), 1057-64. doi:10.1097/01.ACM.0000285346.87708.67

Steinert, Y., Cruess, S., Cruess, R., \& Snell, L. (2005). Faculty development for teaching and evaluating professionalism: from programme design to curriculum change. Medical Education, 39(2), 127-36. doi:10.1111/j.1365-2929.2004.02069.x 
Steinert, Y., Naismith, L., \& Mann, K. (2012). Faculty development initiatives designed to promote leadership in medical education. A BEME systematic review: BEME Guide No. 19. Medical Teacher, 34(6), 483-503. doi:10.3109/0142159X.2012.680937

Swick, H. M. (1999). Teaching Professionalism in Undergraduate Medical Education. Jama, 282(9), 830. doi:10.1001/jama.282.9.830

Swick, H. M. (2000). Toward a Normative Definition of Medical Professionalism. Academic Medicine, 75(6), 612-616. doi:10.1097/00001888-200006000-00010

Talbott, J. A. (2006). Professionalism: why now, what is it, how do we do something? Journal of Cancer Education : The Official Journal of the American Association for Cancer Education, 21(3), 118-22. doi:10.1207/s15430154jce2103_4

Van der Horst, F., \& Lemmens, P. (2012). Medical education and professionalism across different cultures. Medical Education, 46(3), 238-9. doi:10.1111/j.1365-2923.2011.04201.x

Van Mook, W. N. K. a, de Grave, W. S., Gorter, S. L., Muijtjens, A. M. M., Zwaveling, J. H., Schuwirth, L. W., \& van der Vleuten, C. P. M. (2010). Fellows' in intensive care medicine views on professionalism and how they learn it. Intensive Care Medicine, 36(2), 296-303. doi:10.1007/s00134-009-1644-8

Welie, J. V. M. (2012). Social contract theory as a foundation of the social responsibilities of health professionals. Medicine, Health Care, and Philosophy, 15(3), 347-55. doi:10.1007/s11019-011-9355-7

Zaini, R. G., Bin Abdulrahman, K. a, Al-Khotani, A. a, Al-Hayani, A. M. a, Al-Alwan, I. a, \& Jastaniah, S. D. (2011). Saudi Meds: a competence specification for Saudi medical graduates. Medical Teacher, 33(7), 582-4. doi:10.3109/0142159X.2011.578180 
146 


\section{Chapter 8}

\section{Twelve Tips for Teaching Medical Professionalism at all levels of medical education}

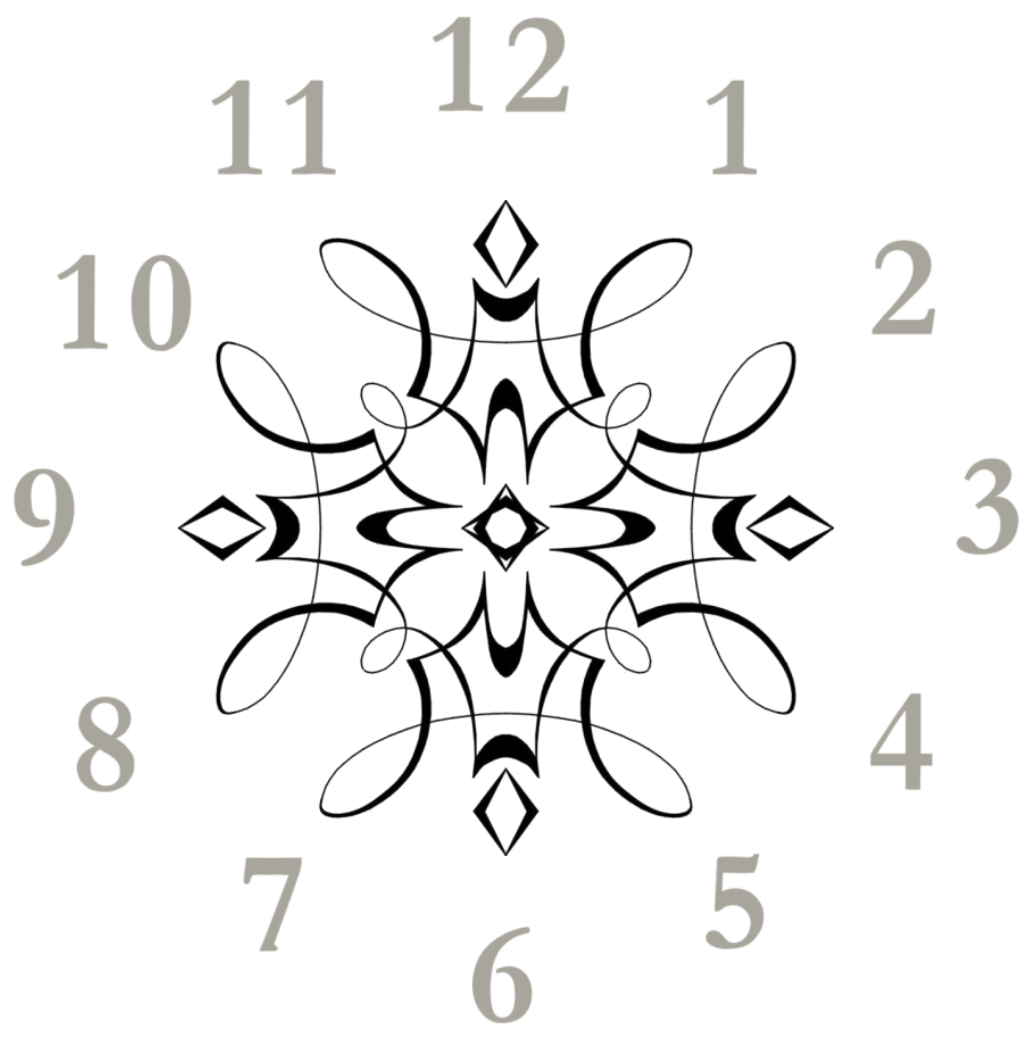

This chapter was published as:

Al-Eraky MM. Twelve Tips for teaching medical professionalism at all levels of medical education. Med Teach. 2015 Mar 17:1-8. [Epub ahead of print] PubMed PMID: 25776227. 
148 


\begin{abstract}
Review of studies published in medical education journals over the last decade reveals that teaching medical professionalism is essential, yet challenging. According to a recent Best Evidence in Medical Education (BEME), there is no consensus on a theoretical or practical model to integrate the teaching of professionalism into medical education. The aim of this article is to outline a practical manual for teaching professionalism at all levels of medical education. Drawing from research literature and author's experience, Twelve Tips are listed and organized in four clusters with relevance to (1) the context, (2) the teachers, (3) the curriculum, and (4) the networking. With a better understanding of the guiding educational principles for teaching medical professionalism, medical educators will be able to teach one of the most challenging constructs in medical education.
\end{abstract}




\section{Introduction}

"Professionalism must be taught" (Cruess \& Cruess, 1997, p. 1674).

"It is never easy teaching professionalism" (Beauchamp, 2004, p. 699).

These two quotes imply the necessity and intricacy of teaching professionalism. Professionalism exemplifies the expected behaviours and attributes towards which physicians - and other health professionals - aspire while serving their patients and society (Sylvia R Cruess, Johnston, \& Cruess, 2002). For decades, professional values and behaviours have been caught from role-models through an informal process of socialization (Loh \& Nalliah, 2010), but role modelling - alone - is no longer enough for transmitting professional values in view of the emerging complexity of medical practice and the heterogeneity of medical students who enter the study of medicine from diverse social, cultural and socioeconomic backgrounds (Cruess \& Cruess, 2006). The disciplinary action by regulatory bodies was strongly associated with prior unprofessional behaviours in medical school (Papadakis, Hodgson, Teherani, \& Kohatsu, 2004). Now a better informed community is asking for accountability, transparency and sound professional standards to meet their expectations ( $\mathrm{R} L$ Cruess, Cruess, \& Johnston, 2000). Professionalism, therefore, must be planned, taught, learned and assessed explicitly (Sivalingam \& Mal, 2001).

Two schools of thoughts guide the teaching and learning of professionalism, either by outlining a list values and desirable professional behaviours (Cruess, R. L., Cruess, S. R., \& Steinert, 2009) or as a normative belief system about how best to organize and deliver health care (Wynia, Papadakis, Sullivan, \& Hafferty, 2014). The two schools are complementary to each other as they engage, not only the minds, but also the hearts and souls of professionals (Wood, 2004).

Professionalism remains one of the most challenging competencies to define, teach and evaluate, because of the complex and context-specific nature of professionalism as a competence (Bryden, Ginsburg, \& Kurabi, 2010; F. W. Hafferty \& Castellani, 2010; Stern, 2003; Swick, 2000). Considering that the modern professionalism debate has been going on for the past two decades, it is surprising that the literature does not contain clear practical examples of how professionalism can be taught (Birden et al., 2013). This article proposes twelve 
practical tips to empower faculty members to teach professionalism, with reference to relevant theoretical background. The tips are organized in four clusters with relevance to (1) the context, (2) the teachers, (3) the curriculum, and (4) the networking, as illustrated in Figure 8.1.

The Context

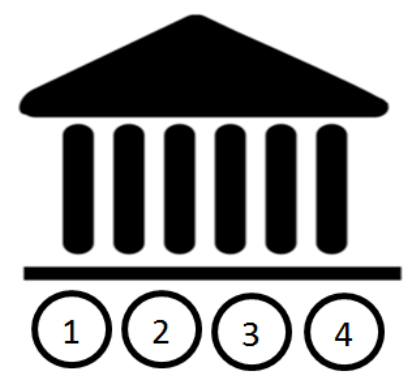

The Teachers

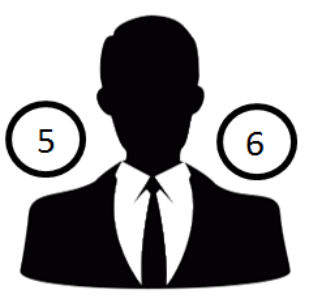

The Curriculum

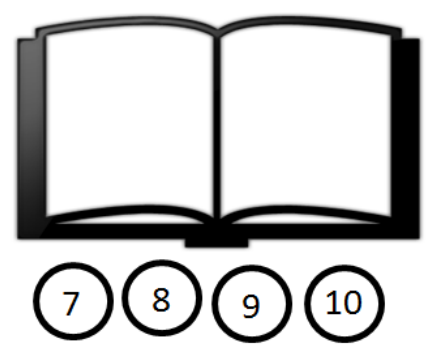

The Networking

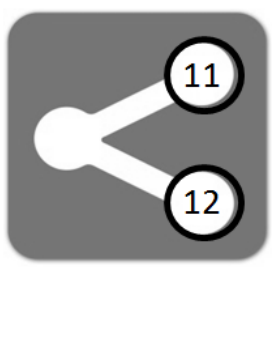

Figure 8.1 The Twelve Tips for teaching professionalism at all levels of medical education, as grouped in four themes (clusters).

\section{Tip 1: Determine the cultural context}

Medical professionalism is a complex social construct and the context, geographical location and culture are important considerations in any discussion of professional behaviour (Jha, Mclean, Gibbs, \& Sandars, 2014). Some regional similarities and dissimilarities in understandings of professionalism exist (Chandratilake, McAleer, \& Gibson, 2012), but there is no overarching conceptual framework of professionalism that is universally agreed upon (Ho, $\mathrm{Yu}$, Hirsh, Huang, \& Yang, 2011).

The professionalism framework of the American Board of Internal Medicine (ABIM) includes six domains; namely: altruism, accountability, excellence, duty, honour and integrity, and respect for others (ABIM, 1995). The Western frameworks of medical professionalism, however, did not resonate with the cultural values of non-Western countries (Pan, Norris, Liang, Li, \& Ho, 2013). For instance, while Western frameworks dichotomized physicians' professional and personal lives, Taiwanese stakeholders were influenced by Confucian cultural traditions toward harmonizing these roles (Ho et al., 2011). 
The evident cultural variations and context specificity of professionalism stimulates scholarly efforts to develop more authentic frameworks to represent professionalism in non-western cultures. Pan et al. (2013) proposed a professionalism framework for healthcare providers in China, using a nominal group technique, that register particular Confucian attributes like 'ren ai' or humane love and 'gong xin' $^{\prime}$ or public spiritedness. Nishigori et al. (2014) compared the tenets of professionalism in the American context with the seven virtues of Bushido, a Japanese code of personal conduct originating from the ancient samurai warriors.

In the same vein, another framework was also reported for Arabian health providers, named the Four-Gates model, as in Chapter 6 . The fourth gate (dealing with God) interpret self-accountability and self-motivation from a faithful perspective as "taqwa" and "ehtesab", respectively, in Arabic, which recognize faith as a cornerstone in communication and social values in the Arabian context (Al-Eraky et al., 2014). The first tip is about recognizing or building a framework that encompasses the salient domains of professionalism in your own context.

\section{Tip 2: Outline the cognitive base}

Each institution should agree on the 'cognitive base' of professionalism that defines its nature, elements and priorities, which dictates what will be taught, evaluated and expected of students, trainees and physicians (Cruess \& Cruess, 2006). The cognitive base is the basis of the social contract (Welie, 2012) which acknowledges the series of expectations and obligations between society and medicine and it manifests the social accountability of the institution to address the essential professional concerns of the community, region and/or nation they serve (Boelen \& Woollard, 2011; Woollard, 2006).

Understanding professionalism in a particular institution is influenced by variables related to its vision, scope of services, ownership (public or private), priorities and future plans. Within the same institution or university, colleges and departments may prioritize professional attributes differently. For instance, more emphasis can be given to empathy in nursing, humility in surgery, excellence in laboratory medicine, accountability in pharmacy, and confidentiality in psychiatry. Teaching the cognitive base of professionalism is not difficult (Cruess \& Cruess, 2006). Gaining the institutional support and establishing an environment, where 
the process of socialization in its most positive sense can take place, is much harder.

\section{Tip 3: Seek institutional support}

Professionalism education is primarily an institutional responsibility (Goldstein et al., 2006). You have to advocate the value of teaching professionalism to educational leaders, colleagues, faculty members and students. Establishing a sense of urgency is crucial to seek support from leadership to teach professionalism (Steinert, Cruess, Cruess, \& Snell, 2005). This can be done by notifying the leadership by the current erosions in ethical obligations, medical errors, professional lapses (Ainsworth \& Szauter, 2006) and sometimes reports of medical litigations and law suits (Marei, 2013) to advocate the mounting importance of teaching professionalism at all levels of medical education. Engaging the Deans, department chairs and program directors to send a clear message of the significance of professionalism education ( Cruess \& Cruess, 2006). The institutional support must be manifested by 'decisions' to allocate appropriate recourses, 'rewards' for those who participate in teaching professionalism and 'policies' to promote a professional environment (Suchman et al., 2004).

\section{Tip 4: Promote professional environment}

Professionalism cannot be taught and learned in a vacuum. The institutional culture can either support professional behaviour or subvert it. Students learn aspects of professionalism as integrated in the stated curriculum (O'Sullivan, van Mook, Fewtrell, \& Wass, 2012) and also as they explore it in the hidden one (Al-Abdulrazzaq, Al-Fadhli, \& Arshad, 2014; Glicken \& Merenstein, 2007; MacLeod, 2014). The hidden curriculum represents the actions of faculty members that are observed by medical students throughout the course.

The institutional support - gained in Tip 3 - can be invested to direct administrators, medical educators, residents, and students to address the hidden curriculum openly and proactively. A top-down approach may not be enough to promote an environment that fosters professionalism. Roff and Dherwani (2011) advocated a bottom-up approach where junior trainees and (even) medical students should be vigilant and responsive to professional lapses in educational and clinical practice. They should learn when they may ignore, challenge the individual, discuss with peers or report the lapse to a more senior person, if their 
teachers exhibit certain behaviours. This approach fosters a culture of 'local resolution' in which juniors feel empowered to address poor professionalism and guide undergraduate fitness to practice procedures (Roff \& Dherwani, 2011).

\section{Tip 5: Foster role-modelling}

"The most important, indeed the only, thing we have to offer our students is ourselves. Everything else they can read in a book" (Tosteson, 1979).

We - faculty - should keep in mind that we are being judged by students and colleagues all the time (Finn, Garner, \& Sawdon, 2010). Almost 90\% of medical graduates remember role models who shaped their professional attitudes (Wright, Wong, \& Newill, 1997). Role-modelling is a powerful (Cruess, Cruess, \& Steinert, 2008), yet underexploited teaching strategy (Kenny, Mann, \& MacLeod, 2003). The characteristics of role models can be categorized into three clusters related to: clinical competence, teaching skills and personal qualities (Cruess et al., 2008). Virtuous role models who actually 'walk their talk' are invaluable for transmitting the intangible elements of professionalism (Finn et al., 2010). Students identify the need for strong positive role models in their learning environment (Byszewski, Hendelman, McGuinty, \& Moineau, 2012). But also the negative role-modelling is a major potential obstacle for developing professional behaviours among medical students (Adkoli, Al-Umran, Al-Sheikh, Deepak, \& AlRubaish, 2011).

The educational value of role-modelling can be enhanced via two complementary approaches. Firstly, the institution should communicate pre-set criteria for excellence in education and clinical practice and reward individuals who were acknowledged by students, patients and peers as exemplary models. On the other hand, unprofessional behaviours should be clearly labelled and categorised. Policies and procedures for reporting and remediation have to be communicated to students and health professionals (Smith, Saavedra, Raeke, \& O'Donell, 2007). Secondly, students and residents should learn how to be reflective and selective to filter and emulate positive behaviours that are worth imitation and modelling (Benbassat, 2014). 


\section{Tip 6: Train faculty members to teach professionalism}

Professionalism is one of the most challenging competencies to define, teach and evaluate for faculty members (Bryden et al., 2010; Joyner \& Vemulakonda, 2007). Also, those who are supposed to teach professionalism actually receive minimal attention as evidenced by the limited number of researches studying professionalism in the context of faculty development (AlEraky et al., in press; Lu et al., 2014; Steinert, Cruess, Cruess, Boudreau, \& Fuks, 2007; Steinert et al., 2005). Faculty development programmes can be designed not only to empower faculty members with teaching tools to address professionalism in their courses, but it can also supplement professionalism education in different levels. Specialized workshops or longitudinal programmes can be planned for a number of objectives: to conceptualize the cultural framework of professionalism in a particular context (Tip 1), to help in defining the cognitive base on professionalism on the institutional level (Tip 2), to seek institutional support and validate the leadership's commitment to professionalism education to all stakeholders (Tip 3), to communicate un/professional behaviours and policies governing performance in education and clinical practice to promote professional environment (Tip 4), to develop more knowledgeable faculty members, who will, hopefully, become more effective role models (Tip 5) and to finally bring about curricular changes to set clear expectations on professionalism across the continuum of medical education (Tip 7 - Next).

\section{Tip 7: Define expectations as observable behaviours}

Generally it is difficult to observe and measure values. In addition, the use of value terms in giving feedback to students, residents, and colleagues can be very threatening, because it implies character defects. In contrast, behaviours can be observed and measured and it is less threatening to tell someone that in a particular circumstance he or she lapsed from the desirable behaviour (Kirk, 2007). The learning outcomes of professionalism have to be operationalized in tangible behaviours, rather than a set of abstract attributes and values (Blue et al., 2009; F. Hafferty, 2004). Defining expectations as observable behaviours facilitates discussion, assessment, and modelling of professionalism in both medical education and clinical care (Green, Zick, \& Makoul, 2009). 
My colleague van Mook et al. (2009) indicated a trans-Atlantic conflict of terminology. The Americans tend to use the term 'professionalism' in their literature which is mainly a theoretical construct, and described in abstract and idealistic terms. The Europeans used 'professional behaviours' to frame professionalism in observable actions that can facilitate learning and assessment. Perhaps the Europeans were more precise than the Americans when setting expectations for medical professionalism, but there is a need to acknowledge both terms to indicate the overarching attributes and the tangible behaviours. Professionalism values and attributes have to be linked to specific behaviours. For instance, responsibility is manifested by 'arriving on time' and 'following through on tasks' (Kirk, 2007). When changing focus from values to behaviours, the sight of the overarching values should not be lost, because behaviours tell students 'what' to do, while values explain the rationale 'why' they should do so.

\section{Tip 8: Provide learning opportunities appropriate to learners' levels}

While the cognitive base of professionalism (Tip 2) must remain constant, the capacity of the learners to internalize professional values and reflect on experience varies according to their educational stages and professional maturity. Professionalism has to be integrated in every course and activity throughout the years of medical education (Wear \& Castellani, 2000). Learning opportunities for professionalism can be planned in five phases, as follows:

\subsection{Orientation on admission}

Professionalism can be introduced to medical students in a number of approaches. The 'White Coat Ceremonies' are widely prevalent as a celebration of matriculation in medical schools to mark the beginning of educational, personal and professional formation processes (Karnieli-Miller, Frankel, \& Inui, 2013). The 'Swearing of Oaths' is another symbolic ritual where students repeat certain phrases that launch the process of their professional identity transformation into doctors 'worthy of trust' (Kao \& Parsi, 2004). In contract to these passive activities, the 'Mission Statement Day' is an exceptional opportunity to help students express their own mission statements as a spark for self-reflection and the exploration of personal values (Kenyon \& Brown, 2007). 


\subsection{Early undergraduate years}

Authors used to focus on teaching professionalism in the clinical arena, but there are 'neglected opportunities' for teaching professionalism in basic sciences (Macpherson \& Kenny, 2008). For instance, Neurophysiology courses may embrace discussions around brain death and vegetative state with its ethical dilemma (Siegler, 2002). Even courses such as Gross Anatomy that, in the past, offered pure content, can be used to introduce students to professional values and behaviours such as: respect for human tissue, fulfil the expectations of the donors by dissecting with purpose and preserve confidentiality of the identifying information of the cadaver (Bryan, Krych, Carmichael, Viggiano, \& Pawlina, 2005; Derstine, 2002; Escobar-Poni \& Poni, 2006; Lachman \& Pawlina, 2006).

\subsection{Late undergraduate years}

Hojat et al. (2009) recognized 'the devil in third year', when a significant drop in empathy scores among students that persist till (and perhaps beyond) the day of their graduation. Ironically, as the curriculum is shifting toward patientcare activities, students gradually abandon their ideal notions on professionalism and develop a sense of cynicism, with a decline of empathy and moral judgment (Hegazi \& Wilson, 2013; Kirk, 2006). Professionalism can be taught through vignettes either written, displayed in role-plays or recorded video from real practice (Bernabeo, Holmboe, Ross, Chesluk, \& Ginsburg, 2013; Boenink, de Jonge, Smal, Oderwald, \& van Tilburg, 2005). Popular medical drama can also present a wealth of situations depicting un/professional manners and selected clips can be used as triggers for reflection on specific professionalism dilemmas or discussing particular behaviours (Hirt, Wong, Erichsen, \& White, 2013; Pavlov \& Dahlquist, 2010; Weaver \& Wilson, 2011).

\subsection{Residency training}

Residents are immature professionals who practice under supervision (Hilton \& Southgate, 2007). Residents are vulnerable to burnout, because of the long working hours and excessive clinical and non-clinical responsibilities, tough competition in assessment, humiliation by supervisors and very little support or time to think, relax and reflect on their emotional involvement with patients (Stephenson, Higgs, \& Sugarman, 2001). As they encounter more ill and dying 
patients, residents adopt a clinical detachment approach as a defensive strategy to preserve their emotions and to look objectively at, and think dispassionately about, their patients (Coulehan \& Williams, 2001; Stephenson et al., 2001). Residents tend to transform patients into analytic objects or room numbers and think of a procedure as a technical event to avoid sensitive contact with patients and they eventually develop a non-reflective professionalism approach to their practice (Stephenson et al., 2001).

Teaching professionalism to residents should enrich the reflective element of their residents' experience to transform 'Patients Unmet Needs' (PUNs) into 'Doctors Educational Needs' (DENs) (Gammon, 2001) and reward residents with the positive role-models in practice from patient care perspective. Joyner and Vemulakonda (2007) reminded us to include residents and clinical preceptors in faculty development programs for professionalism.

\subsection{Independent medical practice}

Independent practitioners can transform the principles and ethos of professionalism into applied concepts and rational behaviours in reality, as they develop what is called 'practical wisdom' (Hilton \& Southgate, 2007). By experience and reflection on experience, they learn which rules to break, when to do so and to what extend in order to accommodate reality at hand (Stephenson et al., 2001). They recognize their potentials and limitations, as there is no cure for all human illnesses. They also learn to live with uncertainty and develop an insight to accept and expect inevitable consequences.

Professionalism, therefore, should be presented to practitioners from a more fundamental and comprehensive standpoint. Teaching professionalism should not only focus on the perspective of "what-to-be" (attributes) and "whatto-do" (behaviours), because the definitions of "what" change over time in an evolving social context. For physicians to be able to continue incorporating desirable attitudes to meet the societal expectations, they must develop a "knowwhy" perspective as well (Nomura, 2008). Physicians should conceptualize professionalism as a dynamic, evolving, and multidimensional construct (Hafferty \& Castellani, 2010). 


\section{Tip 9: Allow structured time for guided reflection}

Reflection is a metacognitive process that creates greater understanding of self and situations to inform future action (Sandars, 2009). It is the process of analyzing, questioning, and reframing (real or simulated) experiences to make an assessment of it for the purposes of learning (reflective learning) and/or to improve practice (reflective practice) (Aronson, 2011). Effective reflection, then, requires structured time to question actions, underlying beliefs and values and to solicit different viewpoints (Gaiser, 2009). It is recommended to use a battery of triggers (questions) to stimulate guided reflection on professionalism vignettes (Al-Eraky et al., in press; Boenink et al., 2005).

Reflection-on-action, is about thinking back on what was done in order to discover how one's knowing in action may have contributed to an unexpected outcome, while reflection-in-action is a hallmark of professionals where learners instantly connect with their feelings, emotions and prior experiences to attend to a current professionalism dilemma (Stark, Roberts, Newble, \& Bax, 2006). Hodges (2014) recently cataloged four practices/purposes for reflection to be used as: metacognition (think aloud), as mindfulness (spiritual guidance), as psychoanalysis (seeking interpretation for own thoughts), and as confession (seeking judgment for own behaviours). Teachers, therefore, should be trained to use reflection wisely to serve any of the above purposes, whenever indicated.

\section{Tip 10: Evaluate the outcome, provide feedback and suggest appropriate remediation plans}

Evaluation of professional attitudes and behaviour is integral to teaching professionalism (Cruess \& Cruess, 2006) and assessment has to be done at different levels: individual, inter-personal, societal-institutional (Hodges et al., 2011). Assessment and feedback should focus on behaviours, not attributes. Students may argue if they have been labelled as 'irresponsible', but they usually accept remarks on specific observed behaviours, such as, "You forgot to check on Mrs. Jones' lab work, which is essential to follow up her condition". This type of feedback does not indicate that the student has a flaw in character; rather, it implies that he or she didn't exhibit the ideal behaviour in that situation, but is likely to do so next time (Kirk, 2007). Students and residents with persistent lapses of professionalism have to be documented and closely monitored. A well- 
structured mentoring, remediation and probation plan is integral to teaching and assessing professionalism (Domen, 2014).

Teachers and program directors may use non-threatening statements when discussing lapses in professional behaviours, as suggested by Buchanan et al., (2012), such as:

- "You don't have to agree with me, but I want you to understand me."

- "I am not saying you are totally at fault but we need to work together to help you understand what is viewed as a professional lapse."

- "If you were on this side of the desk, how would you handle this issue?"

- "You may have meant it in another way, but that (behaviour) was perceived as being unprofessional."

\section{Tip 11: Share your teaching experience}

Share your teaching experience with your peers to create 'communities of learning' and 'communities of practice' in teaching professionalism in your specialties. Discuss what worked and what did not work and why with them and explore better approaches for future practice. Some methods may be more rewarding and effective than others. For instance, medical students considered clinically associated training (role modelling, case conferences) as most effective in teaching professionalism, multidisciplinary expertise approaches (discussion with ethicists, attorneys, chaplains) as effective, and formal didactic approaches (lectures, videos, grand rounds presentations) as least effective (Birden et al., 2013; Roberts, Green Hammond, Geppert, \& Warner, 2004).

Medical teachers can share vignettes, learning objectives, triggers used in reflection sessions and students' feedback on each vignette in a sort of a 'vignette bank'. Educationalists can also review the actual learning outcomes with the intended ones and amend the course in view of teaching experience, students' feedback and teacher's reflection. The experience in teaching professionalism can be documented and reported in scientific meetings and published in local, regional or international journals. 


\section{Tip 12: Consider the evolving digital aspects of medical professionalism (e-Professionalism).}

The rapid emergence of social media, including Facebook, Twitter and YouTube, has added a new dimension to defining, teaching and role-modelling professionalism in the medical field, called: e-professionalism. Kaczmarczyk et al. (2013) defined e-professionalism as the attitudes and behaviours that reflect traditional professionalism paradigms but are manifested through digital media. In this new digital age, trainees and lifelong learners must learn to be mindful of professionalism while using social media in order to protect their privacy as well as the image of physicians (Baer \& Schwartz, 2011). Tech-savvy, medical students, residents and practitioners need to learn what is and isn't appropriate to do on the Internet (Ross, Lai, Walton, Kirwan, \& White, 2013) and, therefore, awareness on 'e-professionalism' has to be addressed early on as part of the firstyear undergraduate medical students' induction programme.

The American Medical Association (AMA) (2011) indicated that the formal professionalism curriculum should include a digital media component, which could include instruction on managing the 'digital footprint' and regulate eprofessionalism, such as: (1) Maintain patient confidentiality in all environments, including online environments, (2) Use privacy settings to safeguard personal information, (3) Consider separating personal and professional content online, and (4) Maintain appropriate boundaries of the patient-physician relationship (AMA, 2011). The gist of these instructions is to preserve the traditional core values of medicine (privacy, confidentiality, one-on-one interactions, and formal conduct) in the milieu of social media which promotes other values (sharing and openness, connection, transparency, and informality) (Gholami-Kordkheili, Wild, \& Strech, 2013).

Institutional responses to violations of e-professionalism have been escalated from filing a disciplinary notice and academic sanctions up to revocation of licensure (Kaczmarczyk et al., 2013). Some behaviours can be 'strongly discouraged' such as: use of vulgar language, implying disrespect for any individual due to age, race, gender, etc ..., substance abuse, sexual promiscuity, and posting unflattering material on another individual's website. While others have to be 'strictly forbidden' and mandate disciplinary actions, such as: violating patient confidentiality, reporting private academic information, and neglecting official work commitments when interacting online. 
Authors usually discuss challenges, but few also admit the social mediarelated opportunities, such as: improvement in sharing information, access to care, and quality of care (Gholami-Kordkheili et al., 2013). The social media and collaborative websites (wikis) act as knowledge bases for hard-to-find resources on professionalism and they can be used to foster positive group dynamics and peer-assisted learning (Varga-Atkins, Dangerfield, \& Brigden, 2010).

\section{Conclusion}

Teaching professionalism is challenging and it is conditioned with understanding its domains in a particular context. Professionalism has to be defined in view of each institution to develop the cognitive base for professionalism education. Professionalism must be taught across the medical education continuum in stage-appropriate learning opportunities. Role-modelling, reflection, institutional support and faculty development are key success factors in teaching medical professionalism.

Finally, teaching professionalism is not an end, but a means to professional identity formation (Cruess, Cruess, Boudreau, Snell, \& Steinert, 2014). The above Twelve Tips are meant to be applied beyond teaching professional attitudes and behaviours. Our future graduates should gradually think, act and feel like physicians (Cruess et al., 2014; Wilson, Cowin, Johnson, \& Young, 2013) and learn to appreciate the significant roles played by members of other professions like nurses (Helmich et al., 2010). Medical educators should help students to be sensitive to their emotions, maintain a portfolio of narrative reflections and suggest alternative interpretations that foster the development of desired professional identities (Helmich, Bolhuis, Laan, Prins, \& Koopmans, 2012; Wong \& Trollope-Kumar, 2014). This is the overarching strategy and the implicit objective for addressing medical professionalism as a fundamental theme of medical education.

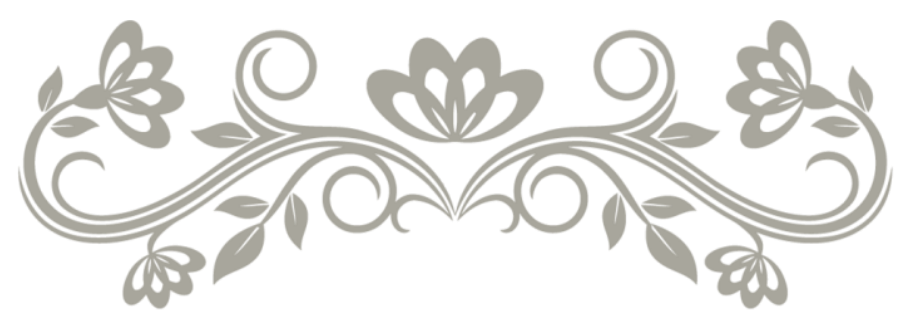




\section{References}

ABIM (American Board of Internal Medicine). (1995). Project Professionalism. Retrieved December 23, 2014, from http://www.abimfoundation.org/ /media/Foundation/Professionalism/Proje ct professionalism.ashx?la=en

Adkoli, B. V, Al-Umran, K. U., Al-Sheikh, M., Deepak, K. K., \& Al-Rubaish, A. M. (2011). Medical students' perception of professionalism: a qualitative study from Saudi Arabia. Medical Teacher, 33(10), 840-5. doi:10.3109/0142159X.2010.541535

Ainsworth, M. A., \& Szauter, K. M. (2006). Medical student professionalism: are we measuring the right behaviors? A comparison of professional lapses by students and physicians. Academic Medicine : Journal of the Association of American Medical Colleges, 81(10 Suppl), S83-6. Retrieved from http://www.ncbi.nlm.nih.gov/pubmed/17001143

Al-Abdulrazzaq, D., Al-Fadhli, A., \& Arshad, A. (2014). Advanced medical students' experiences and views on professionalism at Kuwait University. BMC Medical Education, 14, 150. doi:10.1186/1472-6920-14-150

Al-Eraky, M. M., Donkers, J., Wajid, G., \& van Merrienboer, J. J. G. (n.d.). Faculty development for learning and teaching medical professionalism. Medical Teacher, in Press.

Al-Eraky, M. M., Donkers, J., Wajid, G., \& van Merrienboer, J. J. G. (2014). A Delphi study of medical professionalism in Arabian countries: the Four-Gates model. Medical Teacher, 36 Suppl 1, S8-16. doi:10.3109/0142159X.2014.886013

American Medical Association (AMA). (2011). Opinion 9.124 - Professionalism in the Use of Social Media. Retrieved January 02, 2015, from http://virtualmentor.ama-assn.org/2011/07/pdf/coet1-1107.pdf

Aronson, L. (2011). Twelve tips for teaching reflection at all levels of medical education. Medical Teacher, 33(3), 200-5.

doi:10.3109/0142159X.2010.507714

Baer, W., \& Schwartz, A. C. (2011). Teaching professionalism in the digital age on the psychiatric consultation-liaison service. Psychosomatics, 52(4), 303-9. doi:10.1016/j.psym.2011.02.002

Beauchamp, G. (2004). The Challenge of Teaching Professionalism †. Annals of the Academy of Medicine, Singapore Academy of Medicine, Singapore, 33(6), 697-705. 
Benbassat, J. (2014). Role modeling in medical education: the importance of a reflective imitation. Academic Medicine : Journal of the Association of American Medical Colleges, 89(4), 550-4. doi:10.1097/ACM.0000000000000189

Bernabeo, E. C., Holmboe, E. S., Ross, K., Chesluk, B., \& Ginsburg, S. (2013). The utility of vignettes to stimulate reflection on professionalism: theory and practice. Advances in Health Sciences Education : Theory and Practice, 18(3), 463-84. doi:10.1007/s10459-012-9384-x

Birden, H., Glass, N., Wilson, I., Harrison, M., Usherwood, T., \& Nass, D. (2013).

Teaching professionalism in medical education: a Best Evidence Medical Education (BEME) systematic review. BEME Guide No. 25. Medical Teacher, 35(7), e1252-66. doi:10.3109/0142159X.2013.789132

Blue, A. V, Crandall, S., Nowacek, G., Luecht, R., Chauvin, S., \& Swick, H. (2009). Assessment of matriculating medical students' knowledge and attitudes towards professionalism. Medical Teacher, 31(10), 928-32. doi:10.3109/01421590802574565

Boelen, C., \& Woollard, R. (2011). Social accountability: the extra leap to excellence for educational institutions. Medical Teacher, 33(8), 614-9. doi:10.3109/0142159X.2011.590248

Boenink, A. D., de Jonge, P., Smal, K., Oderwald, A., \& van Tilburg, W. (2005). The effects of teaching medical professionalism by means of vignettes: an exploratory study. Medical Teacher, 27(5), 429-32. doi:10.1080/01421590500069983

Bryan, R. E., Krych, A. J., Carmichael, S. W., Viggiano, T. R., \& Pawlina, W. (2005). Assessing professionalism in early medical education: experience with peer evaluation and self-evaluation in the gross anatomy course. Annals of the Academy of Medicine, Singapore, 34(8), 486-91. Retrieved from http://www.ncbi.nlm.nih.gov/pubmed/16205826

Bryden, P., Ginsburg, S., \& Kurabi, B. (2010). Professing Professionalism : Are We Our Own Worst Enemy ? Faculty Members' Experiences of Teaching and Evaluating Professionalism in Medical Education at One School, 85(June), 1025-1034.

Buchanan, A. O., Stallworth, J., Christy, C., Garfunkel, L. C., \& Hanson, J. L. (2012). Professionalism in practice: strategies for assessment, remediation, and promotion. Pediatrics, 129(3), 407-9. doi:10.1542/peds.2011-3716 
Byszewski, A., Hendelman, W., McGuinty, C., \& Moineau, G. (2012). Wanted: role models--medical students' perceptions of professionalism. BMC Medical Education, 12, 115. doi:10.1186/1472-6920-12-115

Chandratilake, M., McAleer, S., \& Gibson, J. (2012). Cultural similarities and differences in medical professionalism: a multi-region study. Medical Education, 46(3), 257-66. doi:10.1111/j.1365-2923.2011.04153.x

Coulehan, J., \& Williams, P. C. (2001). Vanquishing Virtue: The Impact of Medical Education, 598-605.

Cruess, R. L., \& Cruess, S. R. (2006). Teaching professionalism: general principles. Medical Teacher, 28(3), 205-8. doi:10.1080/01421590600643653

Cruess, R. L., Cruess, S. R., Boudreau, J. D., Snell, L., \& Steinert, Y. (2014). Reframing medical education to support professional identity formation. Academic Medicine : Journal of the Association of American Medical Colleges, 89(11), 1446-51. doi:10.1097/ACM.0000000000000427

Cruess, R. L., Cruess, S. R., \& Johnston, S. E. (2000). Professionalism: an ideal to be sustained. Lancet, 356(9224), 156-9. doi:10.1016/S0140-6736(00)02458-2

Cruess, S. R., \& Cruess, R. L. (1997). Professionalism must be taught. BMJ (Clinical Research Ed.), 315(7123), 1674-7. Retrieved from http://www.pubmedcentral.nih.gov/articlerender.fcgi?artid=2128025\&tool= pmcentrez\&rendertype=abstract

Cruess, S. R., Cruess, R. L., \& Steinert, Y. (2008). Role modelling--making the most of a powerful teaching strategy. BMJ (Clinical Research Ed.), 336(7646), 71821. doi:10.1136/bmj.39503.757847.BE

Cruess, S. R., Johnston, S., \& Cruess, R. L. (2002). Professionalism for medicine : opportunities and obligations, 177(August), 6-9.

Cruess, R. L., Cruess, S. R., \& Steinert, Y. (2009). Teaching Medical Professionalism. New York, New York, USA: Cambridge University Press..

Derstine, P. L. (2002). Implementing goals for non-cognitive outcomes within a basic science course. Academic Medicine : Journal of the Association of American Medical Colleges, 77(9), 931-2. Retrieved from http://www.ncbi.nlm.nih.gov/pubmed/12228102

Domen, R. E. (2014). Resident remediation, probation, and dismissal basic considerations for program directors. American Journal of Clinical Pathology, 141(6), 784-90. doi:10.1309/AJCPSNPAP5R5NHUS

Escobar-Poni, B., \& Poni, E. S. (2006). The role of gross anatomy in promoting professionalism: a neglected opportunity! Clinical Anatomy (New York, N.Y.), 19(5), 461-7. doi:10.1002/ca.20353 
Finn, G., Garner, J., \& Sawdon, M. (2010). "You"re judged all the time!' Students' views on professionalism: a multicentre study. Medical Education, 44(8), 81425. doi:10.1111/j.1365-2923.2010.03743.x

Gaiser, R. R. (2009). The teaching of professionalism during residency: why it is failing and a suggestion to improve its success. Anesthesia and Analgesia, 108(3), 948-54. doi:10.1213/ane.0b013e3181935ac1

Gammon, M. (2001). PUNs and PUEs, DENs and SANs. The British Journal of General Practice : The Journal of the Royal College of General Practitioners, 51(469), 676. Retrieved from

http://www.pubmedcentral.nih.gov/articlerender.fcgi?artid=1314090\&tool= pmcentrez\&rendertype=abstract

Gholami-Kordkheili, F., Wild, V., \& Strech, D. (2013). The impact of social media on medical professionalism: a systematic qualitative review of challenges and opportunities. Journal of Medical Internet Research, 15(8), e184. doi:10.2196/jmir.2708

Glicken, A. D., \& Merenstein, G. B. (2007). Addressing the hidden curriculum: understanding educator professionalism. Medical Teacher, 29(1), 54-7. doi:10.1080/01421590601182602

Goldstein, E. A., Maestas, R. R., Fryer-Edwards, K., Wenrich, M. D., Oelschlager, A.M. A., Baernstein, A., \& Kimball, H. R. (2006). Professionalism in medical education: an institutional challenge. Academic Medicine : Journal of the Association of American Medical Colleges, 81(10), 871-6. doi:10.1097/01.ACM.0000238199.37217.68

Green, M., Zick, A., \& Makoul, G. (2009). Defining professionalism from the perspective of patients, physicians, and nurses. Academic Medicine : Journal of the Association of American Medical Colleges, 84(5), 566-73. doi:10.1097/ACM.0b013e31819fb7ad

Hafferty, F. (2004). Toward the operationalization of professionalism: a commentary. The American Journal of Bioethics : AJOB, 4(2), 28-31. doi:10.1162/152651604773067532

Hafferty, F. W., \& Castellani, B. (2010). The increasing complexities of professionalism. Academic Medicine : Journal of the Association of American Medical Colleges, 85(2), 288-301. doi:10.1097/ACM.0b013e3181c85b43

Hegazi, I., \& Wilson, I. (2013). Medical education and moral segmentation in medical students. Medical Education, 47(10), 1022-8. doi:10.1111/medu.12252 
Helmich, E., Bolhuis, S., Laan, R., Prins, J., \& Koopmans, R. (2012). Medical students' responses to their first clinical experiences. Medical Teacher, 34(5), 424-5. doi:10.3109/0142159X.2012.669091

Helmich, E., Derksen, E., Prevoo, M., Laan, R., Bolhuis, S., \& Koopmans, R. (2010). Medical students' professional identity development in an early nursing attachment. Medical Education, 44(7), 674-82. doi:10.1111/j.1365-

2923.2010.03710.x

Hilton, S., \& Southgate, L. (2007). Professionalism in medical education. Teaching and Teacher Education, 23(3), 265-279.

Hirt, C., Wong, K., Erichsen, S., \& White, J. S. (2013). Medical dramas on television: a brief guide for educators. Medical Teacher, 35(3), 237-42. doi:10.3109/0142159X.2012.737960

Ho, M.-J., Yu, K.-H., Hirsh, D., Huang, T.-S., \& Yang, P.-C. (2011). Does one size fit all? Building a framework for medical professionalism. Academic Medicine : Journal of the Association of American Medical Colleges, 86(11), 1407-14. doi:10.1097/ACM.0b013e31823059d1

Hodges, B. D. (2014). Sea monsters \& whirlpools: Navigating between examination and reflection in medical education. Medical Teacher, 00(00), 16. doi:10.3109/0142159X.2014.993601

Hodges, B. D., Ginsburg, S., Cruess, R., Cruess, S., Delport, R., Hafferty, F., ... Wade, W. (2011). Assessment of professionalism: recommendations from the Ottawa 2010 Conference. Medical Teacher, 33(5), 354-63. doi:10.3109/0142159X.2011.577300

Hojat, M., Vergare, M. J., Maxwell, K., Brainard, G., Herrine, S. K., Isenberg, G. A., ... Gonnella, J. S. (2009). The devil is in the third year: a longitudinal study of erosion of empathy in medical school. Academic Medicine : Journal of the Association of American Medical Colleges, 84(9), 1182-91. doi:10.1097/ACM.0b013e3181b17e55

Jha, V., Mclean, M., Gibbs, T. J., \& Sandars, J. (2014). Medical professionalism across cultures: A challenge for medicine and medical education. Medical Teacher, 1-7. doi:10.3109/0142159X.2014.920492

Joyner, B. D., \& Vemulakonda, V. M. (2007). Improving professionalism: making the implicit more explicit. The Journal of Urology, 177(6), 2287-90; discussion 2291. doi:10.1016/j.juro.2007.01.149

Kaczmarczyk, J. M., Chuang, A., Dugoff, L., Abbott, J. F., Cullimore, A. J., Dalrymple, J., ... Casey, P. M. (2013). e-Professionalism: a new frontier in 
medical education. Teaching and Learning in Medicine, 25(2), 165-70. doi:10.1080/10401334.2013.770741

Kao, A. C., \& Parsi, K. P. (2004). Content analyses of oaths administered at U.S. medical schools in 2000. Academic Medicine : Journal of the Association of American Medical Colleges, 79(9), 882-7. Retrieved from http://www.ncbi.nlm.nih.gov/pubmed/15326016

Karnieli-Miller, O., Frankel, R. M., \& Inui, T. S. (2013). Cloak of compassion, or evidence of elitism? An empirical analysis of white coat ceremonies. Medical Education, 47(1), 97-108. doi:10.1111/j.1365-2923.2012.04324.x

Kenny, N. P., Mann, K. V, \& MacLeod, H. (2003). Role modeling in physicians' professional formation: reconsidering an essential but untapped educational strategy. Academic Medicine : Journal of the Association of American Medical Colleges, 78(12), 1203-10. Retrieved from

http://www.ncbi.nlm.nih.gov/pubmed/14660418

Kenyon, C. F., \& Brown, J. B. (2007). Mission Statement Day: the impact on medical students of an early exercise in professionalism. Medical Teacher, 29(6), 606-10. doi:10.1080/01421590701602079

Kirk, L. M. (2006). definitions and considerations for teaching, 75390, 13-16.

Kirk, L. M. (2007). Professionalism in medicine: definitions and considerations for teaching. Proceedings (Baylor University. Medical Center), 20(1), 13-6.

Retrieved from

http://www.pubmedcentral.nih.gov/articlerender.fcgi?artid=1769526\&tool= pmcentrez\&rendertype $=$ abstract

Lachman, N., \& Pawlina, W. (2006). Integrating professionalism in early medical education: the theory and application of reflective practice in the anatomy curriculum. Clinical Anatomy (New York, N.Y.), 19(5), 456-60.

doi:10.1002/ca.20344

Loh, K.-Y., \& Nalliah, S. (2010). Learning professionalism by role-modelling. Medical Education, 44(11), 1123. Retrieved from http://www.ncbi.nlm.nih.gov/pubmed/20963918

Lu, W.-H., Mylona, E., Lane, S., Wertheim, W. A., Baldelli, P., \& Williams, P. C. (2014). Faculty development on professionalism and medical ethics: the design, development and implementation of Objective Structured Teaching Exercises (OSTEs). Medical Teacher, 36(10), 876-82. doi:10.3109/0142159X.2014.916780

MacLeod, A. (2014). The hidden curriculum: is it time to re-consider the concept? Medical Teacher, 36(6), 539-40. doi:10.3109/0142159X.2014.907876 
Macpherson, C., \& Kenny, N. (2008). Professionalism and the basic sciences: an untapped resource. Medical Education, 42(2), 183-8. doi:10.1111/j.13652923.2007.02967.x

Marei, H. F. (2013). Medical litigation in oral surgery practice: lessons learned from 20 lawsuits. Journal of Forensic and Legal Medicine, 20(4), 223-5. doi:10.1016/j.jflm.2012.09.025

Nishigori, H., Harrison, R., Busari, J., \& Dornan, T. (2014). Bushido and medical professionalism in Japan. Academic Medicine : Journal of the Association of American Medical Colleges, 89(4), 560-3. doi:10.1097/ACM.0000000000000176

Nomura, H. (2008). Developing the "why" facet of medical professionalism. The Kaohsiung Journal of Medical Sciences, 24(1), 31-4. doi:10.1016/S1607$551 \times(08) 70070-6$

O'Sullivan, H., van Mook, W., Fewtrell, R., \& Wass, V. (2012). Integrating professionalism into the curriculum: AMEE Guide No. 61. Medical Teacher, 34(2), e64-77. doi:10.3109/0142159X.2012.655610

Pan, H., Norris, J. L., Liang, Y.-S., Li, J.-N., \& Ho, M.-J. (2013). Building a professionalism framework for healthcare providers in China: a nominal group technique study. Medical Teacher, 35(10), e1531-6. doi:10.3109/0142159X.2013.802299

Papadakis, M. A., Hodgson, C. S., Teherani, A., \& Kohatsu, N. D. (2004). Unprofessional behavior in medical school is associated with subsequent disciplinary action by a state medical board. Academic Medicine : Journal of the Association of American Medical Colleges, 79(3), 244-9. Retrieved from http://www.ncbi.nlm.nih.gov/pubmed/14985199

Pavlov, A., \& Dahlquist, G. E. (2010). Teaching communication and professionalism using a popular medical drama. Family Medicine, 42(1), 25-7. Retrieved from http://www.ncbi.nlm.nih.gov/pubmed/20063219

Roberts, L. W., Green Hammond, K. A., Geppert, C. M. A., \& Warner, T. D. (2004). The positive role of professionalism and ethics training in medical education: a comparison of medical student and resident perspectives. Academic Psychiatry: The Journal of the American Association of Directors of Psychiatric Residency Training and the Association for Academic Psychiatry, 28(3), 17082. doi:10.1176/appi.ap.28.3.170

Roff, S., \& Dherwani, K. (2011). Development of inventory for polyprofessionalism lapses at the proto-professional stage of health professions education 
together with recommended responses. Medical Teacher, 33(3), 239-43. doi:10.3109/0142159X.2010.535867

Ross, S., Lai, K., Walton, J. M., Kirwan, P., \& White, J. S. (2013). "I have the right to a private life": medical students' views about professionalism in a digital world. Medical Teacher, 35(10), 826-31. doi:10.3109/0142159X.2013.802301

Sandars, J. (2009). The use of reflection in medical education: AMEE Guide No. 44. Medical Teacher, 31(8), 685-95. doi:10.1080/01421590903050374

Siegler, M. (2002). Training doctors for professionalism: some lessons from teaching clinical medical ethics. The Mount Sinai Journal of Medicine, New York, 69(6), 404-9. Retrieved from http://www.ncbi.nlm.nih.gov/pubmed/12429959

Sivalingam, N., \& Mal, M. (2001). Teaching and Learning of Professionalism in Medical Schools (Vol. 6, pp. 706-710).

Smith, K. L., Saavedra, R., Raeke, J. L., \& O'Donell, A. A. (2007). The journey to creating a campus-wide culture of professionalism. Academic Medicine : Journal of the Association of American Medical Colleges, 82(11), 1015-21. doi:10.1097/ACM.0b013e318157633e

Stark, P., Roberts, C., Newble, D., \& Bax, N. (2006). Discovering professionalism through guided reflection. Medical Teacher, 28(1), e25-31. doi:10.1080/01421590600568520

Steinert, Y., Cruess, R. L., Cruess, S. R., Boudreau, J. D., \& Fuks, A. (2007). Faculty development as an instrument of change: a case study on teaching professionalism. Academic Medicine : Journal of the Association of American Medical Colleges, 82(11), 1057-64. doi:10.1097/01.ACM.0000285346.87708.67

Steinert, Y., Cruess, S., Cruess, R., \& Snell, L. (2005). Faculty development for teaching and evaluating professionalism: from programme design to curriculum change. Medical Education, 39(2), 127-36. doi:10.1111/j.13652929.2004.02069.x

Stephenson, A., Higgs, R., \& Sugarman, J. (2001). Medical education quartet Teaching professional development in medical schools, 357, 867-870. Stern, D. T. (2003). Can professionalism be taught? The Virtual Mentor : VM, 5(12). doi:10.1001/virtualmentor.2003.5.12.oped1-0312

Suchman, A. L., Williamson, P. R., Litzelman, D. K., Frankel, R. M., Mossbarger, D. L., Inui, T. S., ... Team, D. (2004). Toward an Informal Curriculum that Teaches Professionalism. Journal of General Internal Medicine, 14610(19), 501-504. 
Swick, H. M. (2000). Toward a Normative Definition of Medical Professionalism. Academic Medicine, 75(6), 612-616. doi:10.1097/00001888-20000600000010

Tosteson, D. C. (1979). Learning in medicine. The New England Journal of Medicine, 301(13), 690-4. doi:10.1056/NEJM197909273011304

Van Mook, W. N. K. A., van Luijk, S. J., O'Sullivan, H., Wass, V., Harm Zwaveling, J., Schuwirth, L. W., \& van der Vleuten, C. P. M. (2009). The concepts of professionalism and professional behaviour: conflicts in both definition and learning outcomes. European Journal of Internal Medicine, 20(4), e85-9. doi:10.1016/j.ejim.2008.10.006

Varga-Atkins, T., Dangerfield, P., \& Brigden, D. (2010). Developing professionalism through the use of wikis: A study with first-year undergraduate medical students. Medical Teacher, 32(10), 824-9. doi:10.3109/01421591003686245

Wear, D., \& Castellani, B. (2000). The development of professionalism: curriculum matters. Academic Medicine : Journal of the Association of American Medical Colleges, 75(6), 602-11. Retrieved from http://www.ncbi.nlm.nih.gov/pubmed/10875504

Weaver, R., \& Wilson, I. (2011). Australian medical students' perceptions of professionalism and ethics in medical television programs. BMC Medical Education, 11, 50. doi:10.1186/1472-6920-11-50

Welie, J. V. M. (2012). Social contract theory as a foundation of the social responsibilities of health professionals. Medicine, Health Care, and Philosophy, 15(3), 347-55. doi:10.1007/s11019-011-9355-7

Wilson, I., Cowin, L. S., Johnson, M., \& Young, H. (2013). Professional identity in medical students: pedagogical challenges to medical education. Teaching and Learning in Medicine, 25(4), 369-73. doi:10.1080/10401334.2013.827968

Wong, A., \& Trollope-Kumar, K. (2014). Reflections: an inquiry into medical students' professional identity formation. Medical Education, 48(5), 489-501. doi:10.1111/medu.12382

Wood, W. (2004). The heart, mind, and soul of professionalism in occupational therapy. The American Journal of Occupational Therapy : Official Publication of the American Occupational Therapy Association, 58(3), 249-57. Retrieved from http://www.ncbi.nlm.nih.gov/pubmed/15202622

Woollard, R. F. (2006). Caring for a common future: medical schools' social accountability. Medical Education, 40(4), 301-13. doi:10.1111/j.13652929.2006.02416.x 
Wright, S., Wong, A., \& Newill, C. (1997). The impact of role models on medical students. Journal of General Internal Medicine, 12(1), 53-6. Retrieved from http://www.pubmedcentral.nih.gov/articlerender.fcgi?artid=1497058\&tool= pmcentrez\&rendertype $=$ abstract

Wynia, M. K., Papadakis, M. a, Sullivan, W. M., \& Hafferty, F. W. (2014). More than a list of values and desired behaviors: a foundational understanding of medical professionalism. Academic Medicine : Journal of the Association of American Medical Colleges, 89(5), 712-4.

doi:10.1097/ACM.0000000000000212 


\section{Chapter 9}

\section{General Discussion}

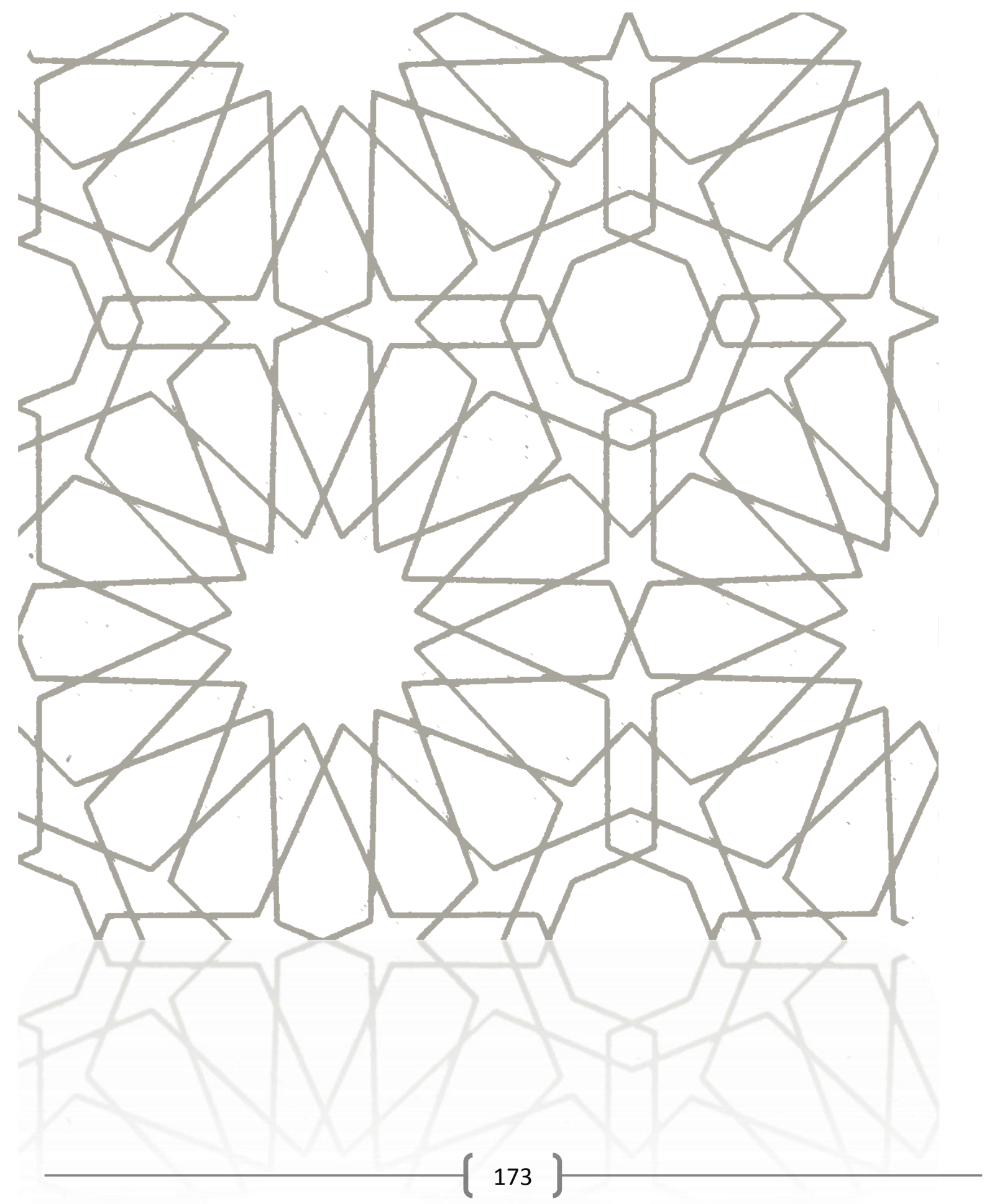


$174)$ 
This final chapter elaborates on: (1) answers to the research questions in view of the results of the six reported studies (Chapters 2-7), (2) theoretical inferences and venues for future research, (3) salient products of the thesis, (4) strengths and limitations, (5) practical implications in the format of 'letters to stakeholders', and (6) conclusion.

\section{Answering the Research Questions}

This thesis aimed to answer seven research questions:

1- What are the basic domains of professionalism in the Arabian context?

2- How to develop and validate a culture-specific instrument to measure attitudes on professionalism in the Arabian context?

3- What are the attitudes of Arabian medical students on professionalism?

4- How do attitudes of medical students on professionalism differ from those of their teachers in an Arabian context?

5- How to develop a consensus on a cognitive base for professionalism among faculty members on an institutional level?

6- How to develop and evaluate a faculty development program for professionalism in an Arabian context?

7- What are practical tips for teaching professionalism across all levels of medical education?

With regard to the first research question, what are the basic domains of professionalism in the Arabian context, the six domains of professionalism in the American Board of Internal Medicine (ABIM) framework, namely: altruism, accountability, duty, excellence, integrity/honour and respect to others were found to be appropriate in the Arabian context (Al-Eraky \& Chandratilake, 2012). Chapter 2 suggested adding a new seventh domain, professional autonomy, to emphasize on the liberty of clinicians to exploit all of their potential as healers. The Western models of professionalism, which advocated autonomy of patients to decide for their own treatment plans (Gilbar \& Miola, 2014; Gillon, 2003; Holm, 1995). In the Arabian context, a paternalistic model of patient care was reported with more emphasis on the professional autonomy of physicians, not patients. Arab doctors are perceived as 'masters' who are supposed to know (and decide) what is best for their patients and they may even lose their confidence if they express diagnostic uncertainty (Jha, Mclean, Gibbs, \& Sandars, 2014; Morrow, 
Rothwell, Burford, \& Illing, 2013). This paternalistic model of patient care is not exclusive to the Arabian context, but was also reported from Pakistan (Humayun et al., 2008), Uganda (Baingana et al., 2010), Malaysia and India (Yousuf, Fauzi, How, Rasool, \& Rehana, 2007). These findings support the context-specific nature of professionalism and how to identify its domains on a cultural basis.

Chapter 3 responded to the second research question by describing the process of development and validation of the LAMPS (Learners' Attitudes on Medical Professionalism Scale) to measure attitudes on professionalism in Arabian context. Development of the LAMPS passed through four steps: (1) defining the constructs/domains of professionalism that are being measured, (2) generating behavioural items for each domain, (3) pilot testing of the LAMPS, and (4) finalizing the scale based on data collected in Step 3. The second step was the most challenging one, because the abstract domains of professionalism, such as: integrity, accountability and confidentiality have to be explained in tangible behaviours that describe real-life situations, for example, hiding information from patients, admitting wrong diagnoses, issuing false sick leaves, and discussing patients' cases with colleagues in a crowded elevator. The generation of behavioural items needed joint efforts of a wide spectrum of experts to portray the different aspects of professionalism. Thirty-two experts contributed to item generation in specific domains. In piloting, a five-point Likert scale was used to record responses on items from Arab medical students in two universities. The LAMPS has been matured though a number of processes for content validation, item filtration and factor analysis. The final version of the LAMPS has 28 items in five domains, with an overall reliability of 0.79 , which can be considered high in view of the multifaceted nature of the construct being measured (medical professionalism).

The third research question was: What are the attitudes of Arabian medical students on professionalism? Chapter 4 compared attitudes of medical students in Egypt and Saudi Arabia and used the Cultural Dimension Theory (Hofstede, 2014b) to decipher the cultural codes of professionalism as recommended by scholars in the field (Chandratilake, McAleer, \& Gibson, 2012; Morrow et al., 2013). Saudi medical students were significantly more attentive towards behaviours related to Respect as compared to Egyptian students. This can be justified with the large power distance in Saudi societies; here, the less powerful members of a society accept and expect that power is distributed unequally and hierarchy, even within the same family, is the norm. This resonates with the findings of Chapter 2, where 
Professional autonomy emerged as a salient domain of professionalism in the Arabian context. It was not surprising then to find that Saudi students scored higher in behaviours reflecting Honour and Integrity, because they need to preserve the trust they earn from their patients. It is difficult, however, to connect two complex constructs like professionalism and cultures, because there are unlimited variables in Egypt and Saudi Arabia that may contribute to students' attitudes. Further research is needed to confirm these correlations with more indepth studies on professionalism in other Arab countries.

The fourth research question was: How do attitudes of medical students on professionalism differ from those of their teachers in an Arabian context? Chapter 5 reported that medical students scored significantly higher than teachers in behaviours related to altruism, respect, excellence, duty and accountability. These findings reinforce the evident decline of professional attitudes over time, which signposts that the factors contributing to 'attrition' were more influential than those working for 'attainment' in the proto-professionalism model of Hilton and Slotnick (2005). These findings are consistent with the body of evidence that indicates that medical teachers, not students, are more vulnerable for attrition on key professionalism qualities. Surprisingly, teachers scored higher in the Honour/Integrity domain, because they were more vigilant to unprofessional behaviours such as: Giving wrong information to patients to protect a colleague; issuing a false sick leave for a kid of a friend to study home, or changing actual data in a report as per supervisor's advice. These findings can be interpreted by the inability of medical students to view the big picture of clinical practice, while teachers were more likely to disagree with these behaviours, because they were mature enough to sensibly recognize and anticipate the destructive repercussions of those particular behaviours on their professional identity and reputation.

The fifth research question was: How to develop consensus on a cognitive base for professionalism among faculty members on an institutional level? Each institution should develop its own cognitive base on medical professionalism (R. L. Cruess \& Cruess, 2006). This cognitive base encompasses definition, description, elements and attributes of medical professionalism and it should remain constant across the continuum of medical education in undergraduate, postgraduate and continuing medical education. Chapter 6 reported the process of gaining consensus using a Delphi study to develop a new genuine framework on professionalism, namely the Four-Gates model (Al-Eraky, Donkers, Wajid, \& van Merrienboer, 2014). Eight professional traits were shortlisted and coupled in four 
themes (Gates): dealing with self, dealing with tasks, dealing with others and dealing with God. The fourth gate (dealing with God) attested that faith plays an axiomatic role in shaping medical professionalism in the Arabian context, because it interprets self-accountability as 'taqwa' (fear from God in Arabic), and selfmotivation as 'ehtesab' (seeking reward from God in Arabic).

The Four-Gates model resonates with recent studies that correlate professional values with local beliefs of a particular culture, apart from the Western models. For instance, Nishigori et al. (2014) linked professionalism with Bushido concepts of ancient samurai warriors in Japan. In the same vein, Pan et al. (2013) identified Confucian values like 'ren ai' (humane love) and 'gong xin' (public spiritedness) as key attributes of professionalism in the Chinese context. The significance of personal integrity and social relations in the Confucian cultural traditions guide Taiwanese physicians to harmonize their personal and professional lives, unlike Western frameworks on professionalism which usually dichotomize those roles (Ho, 2013). These studies inaugurate a new discourse on defining professionalism apart from Western models and welcome a richer discussion from the viewpoints of different cultures, on the meaning of professionalism in today's health care practice.

With respect to the sixth research question, Chapter 7 reported on how to develop and evaluate a faculty development program for professionalism in an Arabian context, in three steps: (1) orientation workshop for teachers, (2) vignette development, and (3) teaching professionalism to students. Planning was the most demanding phase and the program should be tailored according to the needs of participants and within the institutional cognitive base on professionalism that has to be decided before start. The easiest part of the program was conducting the faculty-wide orientation, but the vignette development was tricky, because the developed professionalism vignettes were not generic, but had to be discipline-specific to address professionalism dilemmas in Pediatrics, Surgery, Obstetrics, or Psychiatry.

The good news is that medical teachers may create different versions of the same vignettes by fine-tuning history data, modification of the venue (outpatient, emergency or home-care) or swapping of the roles to consider the same scenario from perspectives of the nurse, patient or colleague. Faculty development for professionalism requires a participatory design approach, where teachers 
contribute by their professional experience in defining the common unprofessional lapses, developing vignettes to portray frequent professionalism dilemmas, designing an appropriate learning setting, and propose triggers to guide students' reflection. There is a need to study how to teach reflection to medical teachers as a prerequisite for teaching medical professionalism.

Chapter 8 answered the seventh research question by describing researchbased practical tips for teaching professionalism in all levels of medical education. Twelve Tips are described and organized in four clusters with relevance to (1) the context, (2) the teachers, (3) the curriculum, and (4) the networking. With a better understanding of the guiding educational principles for teaching medical professionalism, medical educators will be able to teach one of the most challenging constructs in medical education. Teaching professionalism, however, is not an end, but a means to professional identity formation (Cruess, Cruess, Boudreau, Snell, \& Steinert, 2014). Our future graduates should gradually think, act and feel like physicians (Cruess et al., 2014; Wilson, Cowin, Johnson, \& Young, 2013) and learn to appreciate the significant roles played by members of other professions like nurses (Helmich et al., 2010). Medical educators should help students to be sensitive to their emotions, maintain a portfolio of narrative reflections and suggest alternative interpretations that foster the development of desired professional identities (Helmich, Bolhuis, Laan, Prins, \& Koopmans, 2012; Wong \& Trollope-Kumar, 2014). This is the overarching strategy and the implicit objective for addressing medical professionalism as a fundamental theme of medical education.

The studies presented in this thesis assist faculty development planners to address professionalism in the Arabian context, when solving the central problem of the unpreparedness of medical teachers to teach professionalism. Professionalism is culture-specific and, therefore, has to be defined on the basis of a pre-set framework, such as the ABIM or in a new genuine model, like the Four-Gates model. The needs assessment should be conducted by measuring attitudes on professionalism among students and teachers with the use of a validated instrument (such as the LAMPS). The faculty development program should be based on a cognitive base on the institutional level and the developers have to capitalize on the expertise of medical teachers to teach professionalism in their discipline. 


\section{Theoretical Inferences and Venues for Future Research}

This section is structured in three themes: defining professionalism, teaching professionalism, and emerging issues on professionalism.

Defining Professionalism

Asking the right question. The reported studies in this thesis indicated that asking What is the definition of medical professionalism? is a fundamental question, yet not a complete one. Medical professionalism embodies a series of obligations and expectations based on mutual trust between society and medicine (Cruess, 2006), which designates the cultural underpinning of professionalism. Professionalism, therefore, has to be defined within a particular context. The complete question should be: What is the definition of medical professionalism as perceived by Chinese, or Arabs, or ...etc.? Seeking a global standard for professional behaviours may not be feasible, because one-size-doesnot-fit-all in medical professionalism (Ho, Yu, Hirsh, Huang, \& Yang, 2011). Studying medical professionalism across cultures poses a challenge, particularly with the growing numbers of Arab students and physicians who travel to study or work in Western or Eastern cultures. To this end, other more intricate questions may inspire new venues for research. For instance, do Arab medical students and practitioners acquire the professionalism model of the new culture or do they preserve their own model? How long does it take for them to adapt themselves to the new social contract? When they return, will they revert back to their homeland professionalism codes (with more professional autonomy) or do they continue practicing as they have been trained in the West (with more patient autonomy)?

Intercultural awareness. To be effective in other cultures, practitioners need to be interested in these other cultures, sensitive enough to notice variances from their own and then adjust their behaviours accordingly as an indication of respect to the people of other cultures. Medical students, academics and practitioners need to learn about how to be 'culturally fit' and move across stages of the intercultural continuum from denial to acceptance and adaptation (Jha et al., 2014). The onus rests with medical educationalists and researchers worldwide to acknowledge cultural fitness as an outcome and graduate culturally tolerant physicians who can work as professionals without 
(cultural) borders. It seems that there is still a long road to decipher the cultural codes of professionalism and this thesis may mark a step forward, hopefully in the right direction.

Geographical context at three scales. Several authors have recognized professionalism as a complex social construct, making context and geographical location important considerations in any discussion of professionalism (Chandratilake et al., 2012; Cruess, Cruess, \& Steinert, 2010; Ginsburg et al., 2000; Ho et al., 2011; Jha et al., 2014). This thesis, however, motivates researchers to conceptualize medical professionalism on three different geographical scales: regional, national and institutional.

On the regional scale, similarities and differences have been identified in professionalism profiles across different regions of the world. For instance, being accessible to patients was essential to Asian and North American doctors, but not to UK doctors (Chandratilake et al., 2012). Altruism was prioritized in Asian doctors, perhaps due to the collective nature of Asian societies in comparison to the predominantly individualist Western cultures. Professional autonomy of physicians stands out as a salient domain of professionalism in the Arabian context (Al-Eraky \& Chandratilake, 2012).

Professionalism has to be conceptualized on a national scale as well. For instance, in Saudi Arabia, large power distance and hierarchy exists even among members of the same family, a social construct that permeates medical practice particularly in issues related to physicians' responsibility to confidentiality ( $\mathrm{Ho}$, 2013). It is not uncommon for Saudi doctors to share confidential information with the head of the patient's family instead of the patient. When the patient is an adult female, Saudi doctors have to obtain consent from her 'Wali Amr' or male guardian (a husband, father, brother, or son) (Ho, 2013). In contrast to this practice, British physicians are advocated to seek consent from minors, under 16year-old for their treatment, which may include contraceptive advice or abortion, without parental knowledge or consent according to the 'Gillick competence' in UK (Larcher \& Hutchinson, 2010). These contradicting British vs. Saudi perspectives to patient autonomy and confidentiality represent two extremes of a single domain of professionalism, yet in practice both behaviours are legally sound and accepted by the local society in either Saudi Arabia or the UK. This thesis advocates a paradigm shift in understanding professionalism from the judgmental mindset, perceiving that behaviours of students or medical 
practitioners can be either professional (white) or not (black), admitting a wide spectrum of colours of professional practices in different contexts.

Describing professionalism on the institutional scale is also of paramount importance, because it dictates what will be taught to and expected from students, trainees and physicians across the continuum of medical education within the institute (Cruess \& Cruess, 2006). The institutional cognitive base is used as a foundation to align the high-minded rhetoric of lectures and classroom discussions about professionalism and the actual behaviours of members of the institution in clinical practice. The Four-Gates model, for instance, represents the institutional profile on professionalism at the University of Dammam. Future research is invited to study the multifaceted concept of professionalism on regional, national and institutional scales.

Borrow or tailor your white coat. Identifying attributes of medical professionals in a particular context may follow two strategies that represent two approaches to content analysis of qualitative data (Hsieh \& Shannon, 2005). The first one is called: directive content analysis, where an established framework on professionalism is used as scaffold to structure responses. It is like borrowing someone's white coat in order to check if it fits your size. Over the past two decades, authors from different cultures seek validation of Western frameworks on professionalism, such as the Physicians Charter or the ABIM framework, to their local settings in Taiwan (Tsai, Lin, \& Harasym, 2008), Iran (Aramesh, Mohebbi, Jessri, \& Sanagou, 2009), Japan (Suzuki, 2009) and also in the Arab world (Al-Eraky \& Chandratilake, 2012).

In 2013, a new wave of studies to define professionalism transpired in the literature. The strategy of the borrowed coat was replaced by a customized approach to tailor your own white coat, which is based on conventional content analysis (Hsieh \& Shannon, 2005). Here, there is no preset reference framework to anticipate elements of professionalism. The absence of a preliminary framework is challenging. This strategy investigates professionalism as grounded in the minds of native experts, without imposing preconceived categories or theoretical perspectives, which makes it also more authentic and defensible. Knowledge generated from conventional content analysis is founded on the unique perspectives of participants who are supposed to respond to open-ended questions in order to explore what they consider as the essential tenets of medical professionalism in their own cultural context. From 2013 onwards, it 
became more frequent to encounter studies to discuss professionalism apart from the Western ideologies, but as rooted in Confucian values in China (Pan et al., 2013) and Taiwan (Ho et al., 2014), and in view of the Bushido concepts in Japan (Nishigori et al., 2014). There is still a need for more studies to define professionalism in other regions, such as: African, Indian and Latin American contexts.

Inviting other stakeholders

The thesis registered professionalism in the Arabian context as perceived by medical students, teachers and experts using a variety of study designs. Still there is a need for further research to capture a more comprehensive profile about professionalism in this context. Taking account of other stakeholders, for example, patient's views, in defining and teaching professionalism can improve our understanding from yet another perspective. Systemic analysis of unsolicited patients' complaints can offer valuable insights into patient care-related professionalism aspects on individual, interpersonal, departmental and institutional levels (van Mook et al., 2012). These complaints from a particular context can be studied and employed as ready-made 'professionalism dilemmas' to trigger reflection in teaching and learning professionalism.

Teaching Professionalism

Setting expectations. Teaching professionalism starts with setting clear expectations. The thesis reported that expectations for teaching professionalism can be expressed as abstract attributes like in the Four-Gates model to express what doctors should be (macro-level) or as in a list of behaviours or vignettes to assist decision making on what doctors should/not do in specific situations (microlevel). With critical appraisal on this notion, we can also think of an intermediate level that is still missing, not only in this dissertation, but in the vast majority of scholarly studies on medical professionalism in various contexts. Expectations for teaching professionalism have to be also communicated to educators in the form of competencies (meso-level). It is not enough to schedule reflection sessions to discuss alternatives for a decision in a series of particular scenarios, as described in the faculty development program. Competencies statements can assist teachers and students to assemble scenarios, behaviors and attributes, as pieces of a jigsaw puzzle into a big picture of a professional graduate. Setting 
expectations as attributes, behaviors and competencies also facilitate formative assessment within each course and throughout the program.

Theoretical frameworks for teaching professionalism. Situated learning theory was nominated in the introductory section as an overarching theoretical basis for teaching professionalism, because it brings together the cognitive base and the experiential learning that is needed to facilitate the acquisition of professionalism (Cruess, R. L., Cruess, S. R., \& Steinert, 2009). Situated learning theory is based on the notion that knowledge is contextually situated and fundamentally influenced by the activity, context and culture in which it is used (Lave \& Wenger, 1991) and it bridges the gap between the "know what" and the "know how" by embedding learning in authentic activities Situated learning theory helped in this dissertation in operationalizing abstract attributes of professionalism, such as respect and integrity into behavioral items of the LAMPS and into professionalism dilemmas/vignettes.

When teachers used these vignettes for teaching professionalism to their students, situated learning theory was found to be useful, but not comprehensive enough to guide professionalism education. Students discussed professionalism vignettes in groups and therefore tackled these situations as communities of learning, not as individuals. The interaction among students while learning professionalism implies the significance of the social constructivism theory. To social constructivists, knowledge is also a human product, but it is socially and culturally constructed and they advocate that meaningful learning only occurs when individuals are engaged in social activities (Hodson \& Hodson, 1998; Powell \& Kalina, 2008). A number of authors considered both situated learning theory and social constructive theory to emphasize the critical importance of culture and the social context for cognitive development, which resonates well with the socially-constructed nature of professionalism (Elliott et al., 2009; Mossop \& Cobb, 2013). Since no single theory was found conclusive to professionalism education, both theories can be used to inform teaching and learning of professionalism, yet further research is needed to provide more evidence of their applicability in different contexts and educational stages.

Professionalism in preclinical years. Professionalism was predominantly discussed in the realm of clinical subjects. Almost all teachers who contributed in the faculty development were clinicians and it was hard to persuade basic science teachers to address professionalism. In traditional medical education with clear 
demarcation between basic and clinical sciences, it is irrational to wait for three years before introducing professionalism to medical students. Professional growth started from the first day of medical school and many authors referred to the neglected opportunities to teach professionalism in for instance anatomy (Escobar-Poni \& Poni, 2006) and neurophysiology (Siegler, 2002). The myth that medical professionalism is only pertinent to patient care in clinical practice can be easily challenged. For instance dissection in anatomical laboratories offers a unique opportunity for educators to orient preclinical students on issues related to respect of human body, death and dying. Donation of one's body after death can be perceived as a sign of altruism at its peak. There is a need to research appropriate venues for addressing professionalism early in basic sciences and use professionalism as a tool for integration between medical subjects.

Professionalism in several stages of development. The studies of this thesis were conducted mainly in undergraduate medical education. The capacity of the learners to internalize professional values and reflect on experience varies according to their educational stages and professional maturity. It is recommendable to provide stage-appropriate experiences. For instance, at the undergraduate level, professionalism dilemmas should focus on issues related to consent, confidentiality, altruism and empathy with patients, while in residency training it is more appropriate to demonstrate concerns related to doctors' relationship with industry (pharmaceutical and insurance), managing time, burn out and setting priorities. According to Hilton and Southgate (2007), mature physicians can transform the principles and ethos of professionalism into applied concepts and rational behaviours in reality, as they develop what is called practical wisdom. This notion calls for further research to present professionalism to practitioners from a more fundamental and comprehensive standpoint.

Emerging Issues on Professionalism

E-professionalism. The popularity of social media, including Facebook, Twitter and YouTube, has added a new dimension to defining and teaching professionalism. Kaczmarczyk et al. (2013) coined the term e-professionalism to embrace the attitudes and behaviours that reflect traditional professionalism paradigms, but are manifested through digital media. Medical students, teachers and physicians need to learn what is and what is not appropriate to do on the Internet, and they must recognize that actions online and content posted may negatively affect their reputation among patients and colleagues and may have 
serious consequences for their medical career. The gist of addressing eprofessionalism is to preserve the traditional core values of medicine (privacy, confidentiality, one-on-one interactions, and formal conduct) in the milieu of social media which promotes other values (sharing and openness, connection, transparency, and informality). Although it was not specifically addressed in the faculty development program, e-professionalism is a new frontier in medical education and studying the opportunities and challenges to professionalism education based on digital grounds merits further research.

Professionalism of medical educators. This thesis complements the growing literature on medical professionalism, but what about professionalism in medical education? There is a need to describe attributes of educators and educationalists who are figuratively working in the control rooms of medical schools and contributing to shaping future practitioners. Figure 8.1 demonstrates the exponential impact of medical education as we move away from direct contact with patients (layer \#1) to higher layers.

The onus of medical errors rests not only with practitioners, but also with professionals in other layers. However, they usually escape the blame because there is no direct nexus to them. For instance, the root cause analysis of failure of documentation should be traced back to medical schools, because perhaps educators did not stress on documentation in blueprinting of exams so that doctors managed to be graduated without being competent in that area. Working in the control rooms (layers \#2, \#3 and \#4) is not only a privilege, but also a responsibility. I always keep this metaphor in mind to portray and communicate the serious impact of medical education on clinical practice.

Surprisingly, literature on professionalism elaborates mainly on medical professionalism of physicians in layer \#1, as the first line of defense to patientcare. That sounds reasonable, but it is not satisfactory. There is a need to study the attributes and behaviours of professionals in the other layers in order to develop more effective faculty development programs. To do this, research is clearly needed to investigate the expectations of society from educators, educationalists and scholars in medical education to outline the concept of 'medical education professionalism'. 


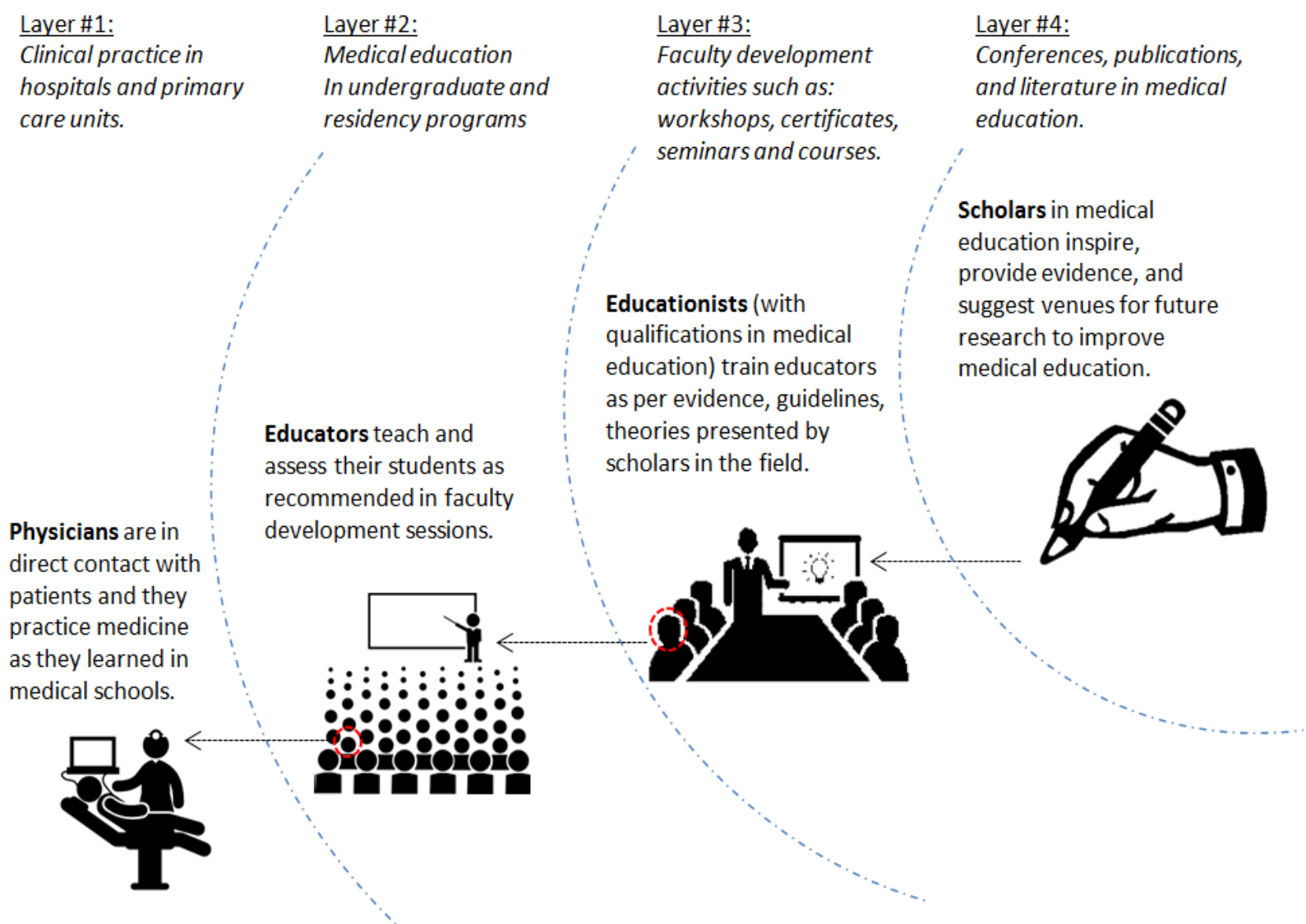

Figure 8.1 Layers of professionals in medical education and clinical practices.

\section{Four Tangible Products of this Thesis}

At least four products can be harvested from the thesis, namely the LAMPS, the Four-Gates Model, the faculty development program and the Twelve Tips for teaching professionalism. The LAMPS or the Learners Attitudes to Medical Professionalism Scale is the first reported instrument on professionalism in the Arabian context, with an overall Cronbach's alpha of 0.79 , which is considered high in view of the multifaceted nature of medical professionalism. The LAMPS expressed the abstract domains of professionalism into behavioral items. The LAMPS can be used as a diagnostic tool to identify learning gaps in professionalism, to compare groups of learners and to track attitude changes on 
professionalism over time and as a result of interventions in cross-sectional or longitudinal studies.

The second product of the thesis is the Four-Gates Model, which communicates professionalism as grounded in the minds of native Arabian medical faculty members at the University of Dammam. The model embraces key professional attributes that embody the institutional cognitive base for teaching, learning and assessing professionalism across the continuum of medical education. Most attributes of the model have been already addressed in the literature, but Arabs perceive these attributes differently. For instance, accountability in the Western context was linked with meeting societal expectations, while it is deciphered as being answerable to God (Allah) in the Arabian context. Four out of eight attributes of the model started with self, which indicated the significance of preparing professionalism - themselves - to work in incredibly sophisticated modern healthcare systems. Success - and failure by the way - starts from within; a notion that is rarely attended to in the discourse of medical professionalism. The model is not claimed to be comprehensive or conclusive, but it may act as a primer to invite discussion on professionalism in the Arabian context.

The third product of the thesis is the faculty development program on professionalism that was reported as a three-step approach: (1) orientation workshop, (2) vignettes development and (3) teaching professionalism. Faculty development on professionalism empowers medical teachers with effective strategies on teaching professionalism, but those strategies are specific to many variables such as: local culture, specialty, available resources, common dilemmas in clinical practice and educational maturity of learners. Since this is one of the first studies for faculty development on professionalism in the Arabian context, a comprehensive manual was submitted to include details on process, outcomes, topics for presentations, sample vignettes and triggers for reflection to help educators to design similar, if not even better, programs in their institutions.

The last product of the thesis is the Twelve Tips for teaching professionalism at all levels of medical education. The tips include: (1) determine the cultural context, (2) outline the cognitive base, (3) seek institutional support, (4) promote a professional environment, (5) roster role-modelling, (6) train faculty members to teach professionalism, (7) define expectations as observable behaviours, (8) provide learning opportunities appropriate to the level of the 
learners, (9) allow structured time for guided reflection, (10) evaluate the outcome, provide feedback and suggest appropriate remediation plans, (11) share your teaching experiences, and (12) consider the evolving digital aspects of medical professionalism (e-Professionalism). These tips can be a nucleus for a manual for medical teachers and faculty developers to teach one of the most challenging constructs in medical education, namely, professionalism.

\section{Strengths and Limitations}

To the best of our knowledge, this is the first comprehensive study on professionalism in the Arabian context and it contributes to the scarce literature that addresses faculty development on professionalism. The thesis recruited participants from different categories; junior and senior medical students, practitioners, and medical teachers from different specialties in undergraduate and postgraduate medical education to represent a wide view on professionalism in the Arabian context. Attitudes were measured and compared among groups based on nationality and educational stage to explore how professionalism matures over time. Studies aimed at depicting a comprehensive portray of professionalism in the Arabian context from different perspectives. The thesis also employed a wide spectrum of methods and designs, such as: the Delphi method and participatory design that collected both quantitative data and qualitative data to provide answers to the research questions. The methods described in the six studies can be replicated to answer the same research questions in other Arabian countries, for example, Lebanon and Algeria to confirm the findings and explore the similarities and differences of professionalism across the Arabian 'cultural continuum'.

The thesis is not without limitations. The thesis used empirical data to decipher the cultural codes of professionalism on the basis of the cultural dimensions theory (Hofstede, 2014a). Correlations reported were only suggestive, because both culture and professionalism are more complex, multi-layered and dynamic constructs that cannot be abstracted in numeric indices and static matrices. The similarities and differences of professional attitudes of medical 
attitudes, based on nationality or educational stage should be interpreted in view of unlimited variables on national and institutional grounds.

Studies were conducted predominantly in two Arab countries: Egypt and Saudi Arabia. While the Arab world constitutes several countries, one may argue that the inferences of the LAMPS may not be externally valid (generalizable) citing the differences between countries. According to Barakat (1993), although there are differences, the 'Arab world' is a single, overarching society rather than a collection of several independent states. The thesis deliberately enrolled medical students, and teachers mainly from Egypt and Saudi Arabia, where almost one quarter of Arabs live. Reported results of the thesis were based on self-reports from medical students, teachers and experts on hypothetical situations on professionalism, which may not offer convincing inferences about people's actual behaviours. Yet the intention was not to assess professional behaviours in students or teachers, but to measure their personal views and perceptions on particular professionalism situations and dilemmas.

\section{Practical Implications in the format of 'Letters to Stakeholders'}

A number of practical implications and recommendations can be suggested, with respect to medical professionalism, to seven groups of stakeholders in the format of personal letters:

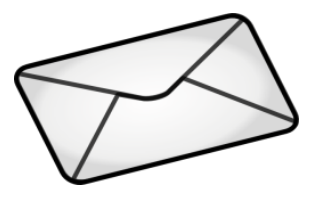

\section{Dear Medical Students,}

You have already noticed that arteries are not red and veins are not blue in reality. Besides books, lectures and clinical rounds, you can learn a lot about medicine by reflecting on each encounter with your peers, supervisors, patients and their families. Doctor care for people, but also learn from them.

Medicine is a prestigious profession, particularly in the Arab world. I expect that people have already started calling you $D r . X$ once you have joined medical school. Evidences proved that the socialization process of medical education 
fosters the development of arrogance, vanity, assertiveness, and a sense of entitlement in the physician. Remember why you have joined the medical school. Your mission was to be a doctor to alleviate pain and agony, right? Remember that your title (Dr. $\mathrm{X}$ ) is not an achievement by itself. Your value of a person is determined by the legacy you leave behind in whichever career you choose.

Be attentive to the transformation in your attitudes towards patients, as you progress in your clinical education. Evidence confirmed an erosion of empathy in the third year of your study. Patients in the clinical rounds are human beings with illnesses, not just clinical cases. To remind yourself with this notion, you can listen to these patients, beyond history taking, to consider the social, economic, psychological burdens of their illness. These stories of agony, fear and uncertainty guide you to explore dimensions and emotions that are usually discounted by textbooks and clinical rounds. Remind yourself that you are dealing with humans, not cases.

You have been raised in a competitive culture, where most of Arabian families drive their kids to rank \#1. There is no such thing as the \#1 doctor in a particular specialty, but people regard physicians as successful or not. As you mature in medical education and clinical practice you will soon recognize that your peers who scored high in final exams were not necessarily the most successful ones. Aspiring towards excellence is a life-long journey, not an A+ destination.

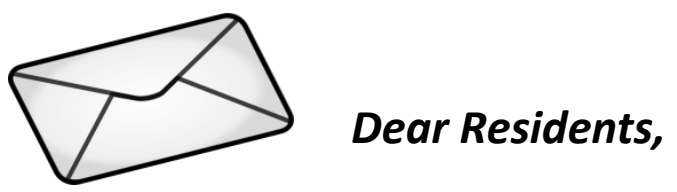

After being graduated, you will need to think broad on your future career in medical practice, beyond diagnosis and treatment of cases. Medical practice is much more than managing patients. As you progress in your medical education and residency training, you will realize that you need a totally different generic, but fundamental set of skills and personal qualities beyond the known scope of clinical expertise. These skills can be learned, practiced and assessed, and they include: emotional intelligence, conflict management, team-building, decisionmaking, information management and professionalism. These skills will shape your future career as a successful professional. 
As a resident, you are practicing multiple roles; as a clinician, husband/wife, father/mother, postgraduate student, trainer for undergraduate students, and so forth. Balancing between your professional commitments and personal ones in residency is a great challenge. Remember that every virtue is mid-way between two non-virtues. For instance, extreme altruism can lead to burn-out with the consequences of impairment and lack of conscientiousness. Then you and your family will suffer. You need to be fair. Respect your duties, without violating the rights of your family members or yourself. True professional residents can harmonize their roles at home and at hospital. Don't stress yourself to impress someone else.

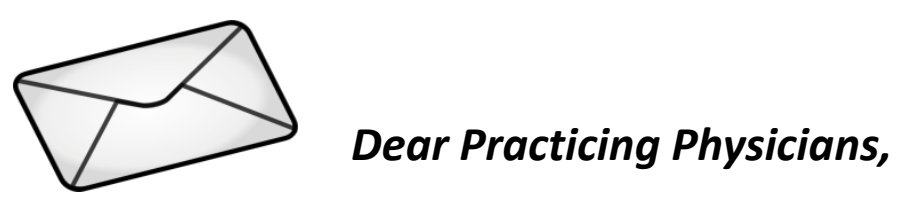

You are working in incredibly sophisticated healthcare systems with countless temptations and obligations. The booming of medical insurance business drives cost-containment and infringes upon your autonomy, while pharmaceutical industry promotes profit generation out of selling their products, sometimes at the expense of altruism. The better informed society became more aware about their rights for healthcare services, based on accountability and transparency. Each clinical encounter represents a processional dilemma and usually conflicts of interests emerged with every prescription or request for an investigation. You need to keep your internal serenity and true north to make an appropriate decision not only as per the hospital guidelines, but the decision that fulfill your personal values and traditions.

Be attentive to the expectations of every single patient. Some may be eager to learn more about their illnesses and contribute to decision making on management plans, while others do not. You always need to demonstrate good behavior, high values and positive attitudes towards your patients and colleagues. Be compassionate to your patients and they will feel it. Pay attention to their concerns and speak in terms they can understand.

As an Arabian doctor, you are perceived as a 'master' who is supposed to know and decide what is best for your patients and you may lose the confidence of your patients when you express diagnostic uncertainty. Your patients are less 
inclined to question the doctor and may be embarrassed to be asked for their opinion of treatment options. Yet, always keep in mind that people who honour you now, may turn their back once they lose trust in your abilities or integrity.

In case you will be practicing medicine in a different context, you may experience other cultural and social attitudes, values and beliefs that differ from your own, as an Arabian doctor. Study the cultural background of the society you are working for to avoid unpleasant conflicts with patients, peers and professional bodies. Learn from your patients about the attributes and behaviors they perceive for a professional doctor. Be an intuitive learner, not a lesson for others to learn.

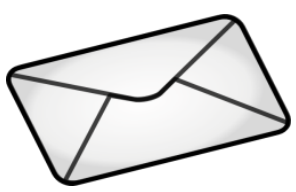

\section{Dear Hospital Directors,}

In the Arab region it is not uncommon to recruit foreign physicians and nurses who have been graduated and trained in other cultures. You need to plan a comprehensive orientation program beyond addressing hospital policies and diagnostic algorithms. New medical and nursing staff members have to be familiarized with the local culture of your institution and the societal expectations, which may vary from those in their home land.

You don't have to study professionalism from books and articles. Mind the recurrent medical errors, incidence reports, patients' complaints, and medical litigations in your hospital. These are valuable resources for you to set priorities for professionalism issues. For instance, if events of improper documentation, conflicts of interests, lack of conscientiousness were repeatedly encountered, these issues have to be addressed while hiring new staff or training the current ones. 


\section{Dear Medical Teachers,}

You need to recognize the significance of professionalism in modern medical education. You should seek training to be informed about the strategies for teaching and learning professionalism. Start by setting clear expectations as attributes and behaviors of professionals in your specialties.

Reflect on the most frequent professionalism dilemmas you have personally encountered, apart from medical expertise of diagnosis and treatment. Use your own experiences to develop real-life vignettes for discussion for your students. Lectures are not suitable to teach professionalism, but it has to be situated in scenarios that indicate issues of confidentiality, consent, misrepresentation and conflicts of interest.

Be attentive to your behaviors, because you are a role model to your students, colleagues, and patients. Role-modelling remains an essential strategy to teach professional attributes and behaviors.

Finally, when teaching a complex construct that is full of uncertainty like professionalism, you need to shift from the judgmental mindset of viewing actions as either right or wrong and accommodate a full range of good and feasible options for each professionalism dilemma. This could be the most challenging facet for teaching professionalism in the Arabian context. Good luck!

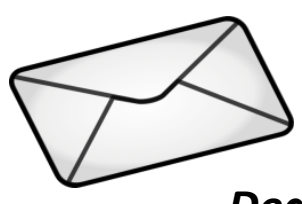

Dear Deans of Medical Colleges and Educational Leaders,

You are familiar with the frequent shopping approach to curriculum development in the Arab medical schools, where Deans decide to import a curriculum from a prestigious college with a good reputation. Deceptively, this is the easiest and fastest way to embrace a credible and reliable curriculum, but it is unlikely that the trade-in curriculum fits in the local context. The rationale and details of the new college-delivery curriculum remain mysterious to your staff, 
educators and administrators. Medical curricula should fit for the local context, particularly with respect to professionalism.

As iterated earlier, professionalism is based on a social contract between medicine and the society. It is a privilege that is being granted by the society in return of specific expectations from medical professionals. You, Deans and educational leaders, need to define medical professionalism on the institutional level to provide a cognitive base that encompasses the core professional values, attributes and behaviours that should be addressed in teaching and learning professionalism across the continuum of medical education. Your support is imperative to professionalism education and has to be manifested by decisions to allocate space, teaching time and financial resources. These signs send a clear message that professionalism is a fundamental competency for your medical graduates.

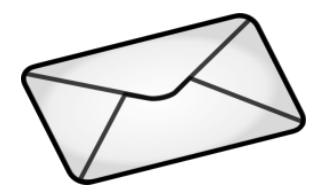

\section{Dear Fellow Researchers in Medical Education,}

You know that professionalism is culture-specific and has to respond to the local societal expectations. But we are now living in a small village and there are recent voices that invite a conversation amongst medical educators to outline shared values of a so-called global professionalism. Evidence from literature actually rejects the convergence of cultures in understanding professionalism, because the Western frameworks of medical professionalism do not resonate with the cultural values of non-Western countries. A trade-off has to be negotiated to define professionalism based on local values, yet also recognize the shared values to graduate professionals who are culturally fit enough to work in different contexts.

When you plan for faculty development on professionalism, be prepared to learn from the vast experience of your participants (medical teachers). They can contribute to the development of scenarios of professionalism dilemmas from their real-life clinical practice. Then they will feel the ownership of the program and can be your change agents for a future curricular reform to include professionalism as a core competence in your institution. 
Be ready to explore new challenges for research in professionalism, such as: teaching professionalism in basic sciences, professionalism in the digital age (eprofessionalism, and drafting the outlines of professionalism in medical education (not practice) to define the attributes and behaviours of professional educators and educationalists. When reviewing the recent literature on professionalism, you will realize that after almost two decades of discussing the subject, the research expedition on professionalism has just started. Bon Voyage!

\section{Conclusion}

The thesis added further evidence that professionalism is context-specific and suggested to define professionalism on a cultural basis on three scales: regional, national and institutional. The thesis referred to the social constructive theory to complement the situated learning theory in teaching professionalism. Both theories emphasize the significance of culture and social context for cognitive development, which fits the socially-constructed nature of professionalism. The thesis attempted to answer seven research questions related to the concept of professionalism in the Arabian context, how it is perceived in the minds of medical students and teachers and how to develop and evaluate faculty development on professionalism.

Further inquiries emerged that can lead further research in the area with respect to the challenge of professionalism in the digital age (e-professionalism), how professionalism can be addressed in basic sciences, and how to define attributes and behaviours of medical education professionalism. Till the date of print of this thesis, professionalism has not been explicitly addressed in the curriculum of undergraduates or postgraduates in many Arabian medical schools. This thesis may hopefully stimulate researchers, educationalist and national accreditation bodies to recognize professionalism as a core competency that should be taught and assessed in the future generations of Arab health professionals.

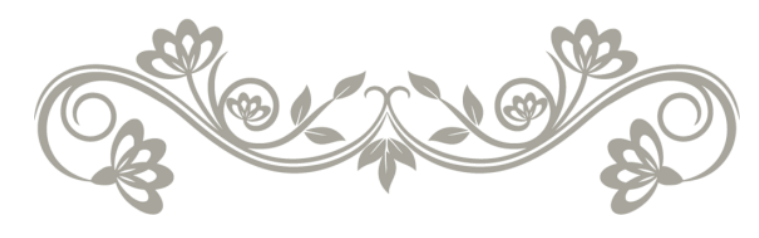




\section{References}

Al-Eraky, M. M., \& Chandratilake, M. (2012). How medical professionalism is conceptualised in Arabian context: A validation study. Medical Teacher.

Al-Eraky, M. M., Donkers, J., Wajid, G., \& van Merrienboer, J. J. G. (2014). A Delphi study of medical professionalism in Arabian countries: the Four-Gates model. Medical Teacher, 36 Suppl 1, S8-16. doi:10.3109/0142159X.2014.886013

Aramesh, K., Mohebbi, M., Jessri, M., \& Sanagou, M. (2009). Measuring professionalism in residency training programs in Iran. Medical Teacher, 31(8), e356-61. Retrieved from http://www.ncbi.nlm.nih.gov/pubmed/19811199

Baingana, R. K., Nakasujja, N., Galukande, M., Omona, K., Mafigiri, D. K., \& Sewankambo, N. K. (2010). Learning health professionalism at Makerere University: an exploratory study amongst undergraduate students. BMC Medical Education, 10, 76. doi:10.1186/1472-6920-10-76

Barakat, H. (1993). Society, Culture, and State (pp. 1-314). Berkeley: University of California Press.

Chandratilake, M., McAleer, S., \& Gibson, J. (2012). Cultural similarities and differences in medical professionalism: a multi-region study. Medical Education, 46(3), 257-66. doi:10.1111/j.1365-2923.2011.04153.x

Cruess, R. L., \& Cruess, S. R. (2006). Teaching professionalism: general principles. Medical Teacher, 28(3), 205-8. doi:10.1080/01421590600643653

Cruess, R. L., Cruess, S. R., Boudreau, J. D., Snell, L., \& Steinert, Y. (2014). Reframing medical education to support professional identity formation. Academic Medicine : Journal of the Association of American Medical Colleges, 89(11), 1446-51. doi:10.1097/ACM.0000000000000427

Cruess, S. R. (2006). Professionalism and medicine's social contract with society. Clinical Orthopaedics and Related Research, 449, 170-6. doi:10.1097/01.blo.0000229275.66570.97 
Cruess, S. R., Cruess, R. L., \& Steinert, Y. (2010). Teaching professionalism across cultural and national borders: lessons learned from an AMEE workshop. Medical Teacher, 32(5), 371-4. doi:10.3109/01421591003692730

Cruess, R. L., Cruess, S. R., \& Steinert, Y. (2009). Teaching Medical Professionalism. New York, New York, USA: Cambridge University Press..

Elliott, D. D., May, W., Schaff, P. B., Nyquist, J. G., Trial, J., Reilly, J. M., \& Lattore, P. (2009). Shaping professionalism in pre-clinical medical students:

Professionalism and the practice of medicine. Medical Teacher, 31(7), e295302. Retrieved from http://www.ncbi.nlm.nih.gov/pubmed/19811137

Escobar-Poni, B., \& Poni, E. S. (2006). The role of gross anatomy in promoting professionalism: a neglected opportunity! Clinical Anatomy (New York, N.Y.), 19(5), 461-7. doi:10.1002/ca.20353

Gilbar, R., \& Miola, J. (2014). ONE SIZE FITS ALL? ON PATIENT AUTONOMY, MEDICAL DECISION-MAKING, AND THE IMPACT OF CULTURE. Medical Law Review. doi:10.1093/medlaw/fwu032

Gillon, R. (2003). Ethics needs principles--four can encompass the rest--and respect for autonomy should be "first among equals". Journal of Medical Ethics, 29(5), 307-12. Retrieved from http://www.pubmedcentral.nih.gov/articlerender.fcgi?artid=1733792\&tool= pmcentrez\&rendertype=abstract

Ginsburg, S., Regehr, G., Hatala, R., McNaughton, N., Frohna, A., Hodges, B., ... Stern, D. (2000). Context, conflict, and resolution: a new conceptual framework for evaluating professionalism. Academic Medicine : Journal of the Association of American Medical Colleges, 75(10 Suppl), S6-S11. Retrieved from http://www.ncbi.nlm.nih.gov/pubmed/11031159

Helmich, E., Bolhuis, S., Laan, R., Prins, J., \& Koopmans, R. (2012). Medical students' responses to their first clinical experiences. Medical Teacher, 34(5), 424-5. doi:10.3109/0142159X.2012.669091

Helmich, E., Derksen, E., Prevoo, M., Laan, R., Bolhuis, S., \& Koopmans, R. (2010). Medical students' professional identity development in an early nursing 
attachment. Medical Education, 44(7), 674-82. doi:10.1111/j.1365-

2923.2010.03710.x

Hilton, S. R., \& Slotnick, H. B. (2005). Proto-professionalism: how professionalisation occurs across the continuum of medical education. Medical Education, 39(1), 58-65. doi:10.1111/j.1365-2929.2004.02033.x

Hilton, S., \& Southgate, L. (2007). Professionalism in medical education. Teaching and Teacher Education, 23(3), 265-279.

Ho, M.-J. (2013). Culturally sensitive medical professionalism. Academic Medicine : Journal of the Association of American Medical Colleges, 88(7), 1014. doi:10.1097/ACM.0b013e318294fc95

Ho, M.-J., Yu, K.-H., Hirsh, D., Huang, T.-S., \& Yang, P.-C. (2011). Does one size fit all? Building a framework for medical professionalism. Academic Medicine : Journal of the Association of American Medical Colleges, 86(11), 1407-14. doi:10.1097/ACM.0b013e31823059d1

Ho, M.-J., Yu, K.-H., Pan, H., Norris, J. L., Liang, Y.-S., Li, J.-N., \& Hirsh, D. (2014). A tale of two cities: understanding the differences in medical professionalism between two Chinese cultural contexts. Academic Medicine : Journal of the Association of American Medical Colleges, 89(6), 944-50.

Hodson, D., \& Hodson, J. (1998). From constructivism to social constructivism : a Vygotskian perspective on teaching and learning science. School Science Review, 79(289), 33-41. Retrieved from http://cat.inist.fr/?aModele=afficheN\&cpsidt=2450462

Hofstede, G. (2014a). Culture. Retrieved December 26, 2014, from http://geerthofstede.nl/culture.aspx

Hofstede, G. (2014b). National Cultural Dimensions. Retrieved December 26, 2014, from http://geert-hofstede.com/countries.html

Holm, S. (1995). Not just autonomy--the principles of American biomedical ethics. Journal of Medical Ethics, 21(6), 332-338. doi:10.1136/jme.21.6.332 
Hsieh, H.-F., \& Shannon, S. E. (2005). Three approaches to qualitative content analysis. Qualitative Health Research, 15(9), 1277-88. doi:10.1177/1049732305276687

Humayun, A., Fatima, N., Naqqash, S., Hussain, S., Rasheed, A., Imtiaz, H., \& Imam, S. Z. (2008). Patients' perception and actual practice of informed consent, privacy and confidentiality in general medical outpatient departments of two tertiary care hospitals of Lahore. BMC Medical Ethics, 9(1), 14. doi:10.1186/1472-6939-9-14

Jha, V., Mclean, M., Gibbs, T. J., \& Sandars, J. (2014). Medical professionalism across cultures: A challenge for medicine and medical education. Medical Teacher, 1-7. doi:10.3109/0142159X.2014.920492

Kaczmarczyk, J. M., Chuang, A., Dugoff, L., Abbott, J. F., Cullimore, A. J., Dalrymple, J., ... Casey, P. M. (2013). e-Professionalism: a new frontier in medical education. Teaching and Learning in Medicine, 25(2), 165-70.

Larcher, V., \& Hutchinson, A. (2010). How should paediatricians assess Gillick competence? Archives of Disease in Childhood, 95(4), 307-11.

Lave, J., \& Wenger, E. (1991). Situated Learning: Legitimate Peripheral Participation. New York, NY, USA: Cambridge University Press.. Retrieved from http://books.google.com/books?hl=ar\&lr=\&id=CAVIOrW3vYAC\&pgis=1

Morrow, G., Rothwell, C., Burford, B., \& Illing, J. (2013). Cultural dimensions in the transition of overseas medical graduates to the UK workplace. Medical Teacher, 35(10), e1537-45. doi:10.3109/0142159X.2013.802298

Mossop, L. H., \& Cobb, K. (2013). Teaching and assessing veterinary professionalism. Journal of Veterinary Medical Education, 40(3), 223-32. doi:10.3138/jvme.0113-016R

Nishigori, H., Harrison, R., Busari, J., \& Dornan, T. (2014). Bushido and medical professionalism in Japan. Academic Medicine : Journal of the Association of American Medical Colleges, 89(4), 560-3.

Pan, H., Norris, J. L., Liang, Y.-S., Li, J.-N., \& Ho, M.-J. (2013). Building a professionalism framework for healthcare providers in China: a nominal 
group technique study. Medical Teacher, 35(10), e1531-6.

doi:10.3109/0142159X.2013.802299

Powell, K. C., \& Kalina, C. J. (2008). Cognitive and Social Constructivism:

Developing Tools for an Effective Classroom. Education, 130(2), 241-250.

Retrieved from http://eric.ed.gov/?id=EJ871658

Siegler, M. (2002). Training doctors for professionalism: some lessons from teaching clinical medical ethics. The Mount Sinai Journal of Medicine, New York, 69(6), 404-9. Retrieved from http://www.ncbi.nlm.nih.gov/pubmed/12429959

Suzuki, N. (2009). [Certification for specialists on neurology by Japanese Society of Neurology]. Rinshō Shinkeigaku = Clinical Neurology, 49(11), 745-6. Retrieved from http://www.ncbi.nlm.nih.gov/pubmed/20030199

Tsai, T., Lin, C., \& Harasym, P. H. (2008). Students ' perception on medical professionalism : the psychometric perspective, 6(4), 1-4.

Van Mook, W. N. K. A., Gorter, S. L., Kieboom, W., Castermans, M. G. T. H., de Feijter, J., de Grave, W. S., ... van der Vleuten, C. P. M. (2012). Poor professionalism identified through investigation of unsolicited healthcare complaints. Postgraduate Medical Journal, 88(1042), 443-50. doi:10.1136/postgradmedj-2011-130083

Wilson, I., Cowin, L. S., Johnson, M., \& Young, H. (2013). Professional identity in medical students: pedagogical challenges to medical education. Teaching and Learning in Medicine, 25(4), 369-73. doi:10.1080/10401334.2013.827968

Wong, A., \& Trollope-Kumar, K. (2014). Reflections: an inquiry into medical students' professional identity formation. Medical Education, 48(5), 489-501. doi:10.1111/medu.12382

Yousuf, R. M., Fauzi, A. R. M., How, S. H., Rasool, A. G., \& Rehana, K. (2007). Awareness, knowledge and attitude toward informed consent among doctors in two different cultures in Asia: a cross-sectional comparative study in Malaysia and Kashmir, India. Singapore Medical Journal, 48(6), 559-65. Retrieved from http://www.ncbi.nlm.nih.gov/pubmed/17538757 
202

$202 \sqrt{2}$ 


\section{Summary}

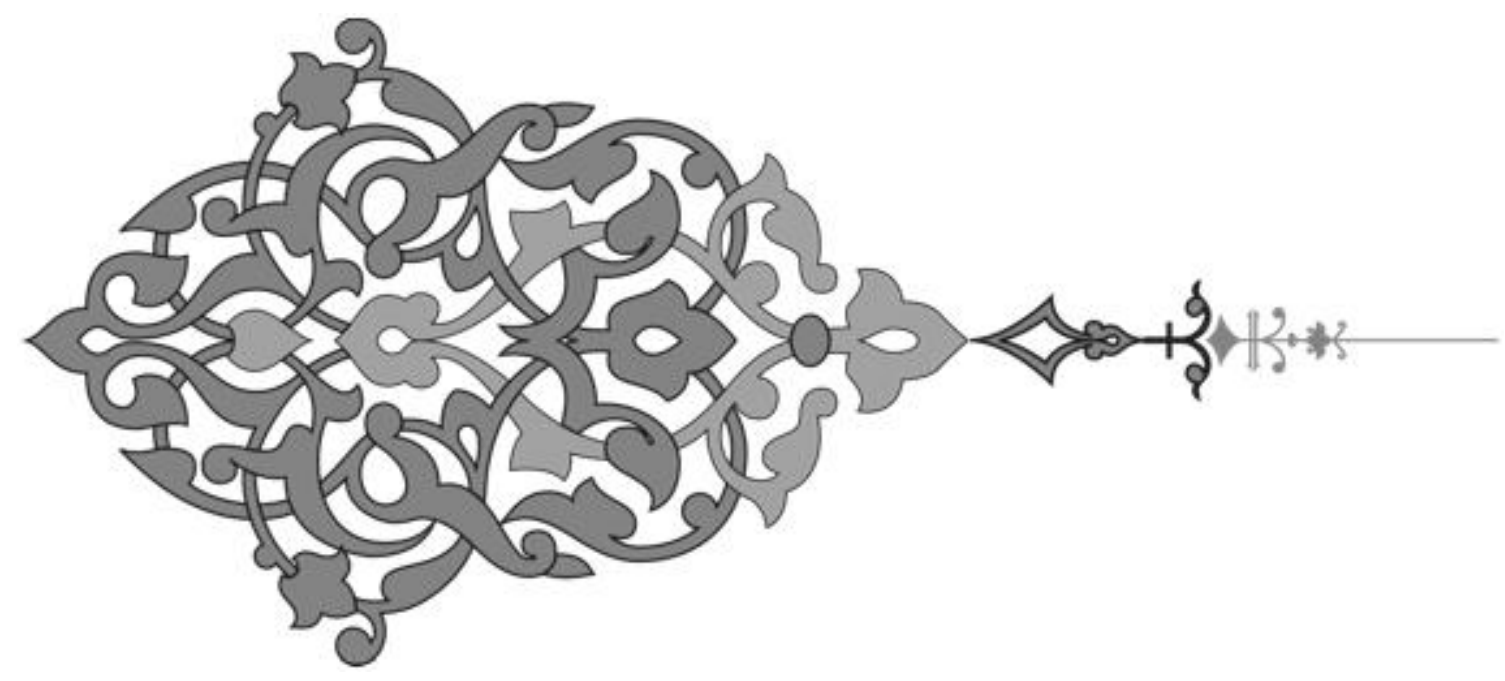


$204)$ 
Professionalism is gaining interest over the past few years, mainly from Western perspectives. There is a need to define medical professionalism in the Arabian context from the perspectives of Arabian medical students and teachers, in order to develop a genuine framework on medical professionalism that can be used as the foundation for design and evaluation of faculty development programs on professionalism in the Arabian context.

This thesis encompasses seven related studies in a logical sequence to answer seven research questions, as follows: (1) What are the basic domains of professionalism in the Arabian context? (2) How to develop and validate a culture-specific instrument to measure attitudes on professionalism in the Arabian context? (3) What are the attitudes of Arabian medical students on professionalism? (4) How do attitudes of medical students on professionalism differ from those of their teachers in an Arabian context? (5) How to develop a consensus on a cognitive base for professionalism among faculty members on an institutional level? (6) How to develop and evaluate a faculty development program for professionalism in an Arabian context? and (7) What are practical tips for teaching professionalism across all levels of medical education? The answers to the above questions provided a framework for medical professionalism in the Arabian context and offered a basis for faculty development on professionalism.

The first study addressed the first research question: What are the basic domains of professionalism in the Arabian context? Since professionalism is culture-sensitive, Study 1 aimed to validate the components of the professionalism framework of the American Board of Internal Medicine (ABIM) to the Arabian context. The authors invited a heterogeneous group of native Arab health professionals and academics to contribute to a reference panel. Medical practitioners and educationalists were invited to contribute to the reference panel. They had to be (a) native Arabic speakers, (b) professionals working in healthcare or health professions education in an Arab country, and (c) engaged in undergraduate medical education and/or residency training in their organizations. They represented a wide range of specialties and seniority levels in a variety of healthcare organizations and medical schools in Egypt, Saudi Arabia and United Arab Emirates. They were queried about their perception of the importance of each domain of professionalism as proposed by the ABIM, and were encouraged to suggest new domains if they thought it necessary. Thirty-two out of the 45 invited health professionals and educators (71\%) contributed to the reference panel. The panel confirmed the appropriateness of the six ABIM domains to the 
Arabian context, and further proposed the Autonomy of professionals as a new seventh domain to emphasize on the liberty of clinicians to exploit all of their potential as 'healers'. In the Arabian context, a paternalistic model of patient care was reported with more emphasis on the professional autonomy of physicians, not patients. Arab doctors are perceived as 'masters' who are supposed to know (and decide) what is best for their patients and they may even lose their confidence if they express diagnostic uncertainty. The modified framework, based on ABIM domains, demonstrated the Arabian conceptualisation of professionalism.

Study 2 addressed the second question to describe the process of developing and validating a culture-specific instrument, called the LAMPS (Learners' Attitudes on Medical Professionalism Scale) to measure attitudes on professionalism in the Arabian context. Development of the LAMPS passed through four steps: (1) defining the constructs/domains of professionalism that are being measured, (2) generating behavioural items for each domain, (3) pilot testing of the LAMPS, and (4) finalizing the scale based on data collected in Step 3. Along with the authors, 32 experts contributed to item generation in particular domains. The instrument was administered to a total of 413 medical students and interns. Responses were collected using five-point Likert scales. Data were analyzed to estimate the reliability of the instrument. The final version of the LAMPS has 28 items in five domains, with an average reliability of 0.79 , which can be considered high in view of the multifaceted nature of the construct being measured (medical professionalism). The LAMPS is the first context-specific, reliable, and valid inventory on medical professionalism in the Arabian context and it was compared with similar instruments in the literature. The LAMPS can help teachers identify learning gaps regarding professionalism amongst their students and track attitude changes over time or as the result of interventions.

The third study used the LAMPS to study the attitudes of Arabian medical students on professionalism. The study compared responses of medical students from two universities in Egypt and Saudi Arabia. The study further aimed to interpret the findings on a cultural basis between the two countries to suggest correlations between cultural dimensions and professionalism domains. According to Hofstede's cultural dimensions, Saudis have a large power distance than the Egyptians. In a society with a large power distance, the less powerful members accept and expect that power is distributed unequally and hierarchical, even within the same family.. On the other hand, the privileged ones, like Saudi 
doctors, should be vigilant on issues related to integrity and honour to preserve the respect and the trust they earn from their patients. This may justify why Saudi medical students were significantly more attentive towards behaviours related to Honour/Integrity and Respect as compared to Egyptian students. Hofstede's dimensions were used in this study, along with others, to explore the cultural underpinning of professionalism in a particular societyFurther research is needed to confirm these correlations with more in-depth studies on professionalism in other Arab countries.

Despite the growing interest in professionalism, few studies addressed its development across the continuum of medical education. Study 4 compared attitudes on professionalism among three cohorts: pre-clinical students, clinical students and medical teachers in five domains of professionalism: Altruism, Duty/Accountability, Excellence/Autonomy, Integrity/Honour, and Respect. Teachers showed significantly lower attitudes than clinical students on four domains, but in Integrity/honour they scored unexpectedly higher than the clinical students. Teachers were more likely to disagree with behaviours related to misrepresentation, forgery, lying, deception, hiding information and unethical practices, probably because they sensibly recognize the destructive repercussions of committing them to their professional identity and reputation. Students, in contrast, may not be able to view the big picture of clinical practice and anticipate the impact of these serious behaviours. Comparing three groups does not imply that professionalism is developed in three stages. Staged development of professionalism was based on stage theories and is in line with our results, but it has to be validated by longitudinal studies. The findings shed some light on how professionalism is acquired with the influence of a blend of biological (nature) and environmental (nurture) factors. Study 4 marks one step in understanding the genesis of medical professionalism in the Arabian context. It also informs medical teachers about how they can teach professionalism in different stages of medical education to support professional identity formation over time.

Medical professionalism has been described as a set of attributes and behaviours, yet the Western frameworks of medical professionalism may not resonate with the cultural values of non-Western countries. Study 5 aims to formulate a professionalism framework for healthcare providers as interpreted by local medical professionals in Arabian countries. The study reported the process of gaining consensus using a Delphi study to develop a new genuine framework on professionalism, namely the Four-Gates model. Eight professional traits were 
shortlisted and coupled in four themes (Gates): dealing with self, dealing with tasks, dealing with others and dealing with God. The fourth gate (dealing with God) attested that faith plays an axiomatic role in shaping medical professionalism in the Arabian context, because it interprets self-accountability as 'taqwa' (fear from God in Arabic), and self-motivation as 'ehtesab' (seeking reward from God in Arabic). The Four-Gates model resonates with recent studies that correlate professional values with local beliefs of non-Western cultures. Professionalism was recently interpreted in view of Bushido concepts in Japan and Confucian values in China and Taiwan. These studies inaugurate a new discourse on defining professionalism apart from Western models and welcome a richer discussion from the viewpoints of different cultures, on the meaning of professionalism in today's health care practice.

Professionalism must be explicitly taught, but teaching professionalism is challenging because medical teachers are often not well prepared to teach this content area. Study 6 provided a work plan to teach and learn professionalism in practice using a tailored module of faculty development on professionalism. The study used a participatory design, where authors and 28 faculty members shared the responsibility of programme design in three steps: (1) orientation workshop for teachers, (2) vignette development, and (3) teaching professionalism to students. The workshop provided the cognitive base on the salient attributes of professionalism in the Arabian context. After the workshop, authors helped teachers to develop a total of 32 vignettes on various clinical aspects, portraying a blend of professionalism dilemmas. A battery of seven questions/triggers was suggested to guide students' reflection. The programme has fulfilled the guiding principles for its design and it has emerged from a genuine professionalism framework from local scholarly studies in the Arabian context. Programme outcomes were evaluated at the four levels of Kirkpatrick's model; reaction, learning, behaviour and results. The study confirmed that professionalism can be taught using vignettes that demonstrate professionalism dilemmas in a particular context. It also advocated the significance of transforming faculty development from the training discourse of standalone interventions to the mentorship paradigm in communities of learning.

The aim of the last study was to outline a practical manual for teaching professionalism at all levels of medical education. Drawing from research literature and author's experience, Twelve Tips are listed and organized in four clusters with relevance to (1) the context, (2) the teachers, (3) the curriculum, and 
(4) the networking. With a better understanding of the guiding educational principles for teaching medical professionalism, medical educators will be able to teach one of the most challenging constructs in medical education. Teaching professionalism is not an end, but a means to shape the professional identity of future graduates to think, feel and act as physicians. This is the overarching strategy and the implicit objective for addressing medical professionalism as a fundamental theme of medical education.

The seven studies of the thesis reiterate the significance of understanding medical professionalism within a particular society with respect to its core values, ethics and codes. Still there is a need to investigate the cultural codes of professionalism and future research is invited to study the multifaceted concept of professionalism on regional, national and institutional scales. There is, for instance, a need to define professionalism, apart from the Western models, in African, Indian and Latin American contexts. Teaching professionalism starts by setting clear expectations, which have to be defined in desirable attributes and behaviours of medical professionals. There is a need to develop more structured faculty development programs to prepare teachers to teach this challenging construct and learn how to help students reflect on daily professionalism dilemmas.

The thesis invited peer researchers to study the concept of eprofessionalism in order to preserve the traditional core values of medicine (privacy, confidentiality, one-on-one interactions, and formal conduct) in the milieu of social media which promotes other values (sharing and openness, connection, transparency, and informality). Last, but not least, professionalism of medical teachers should be further studied to explore the expectations of society from educators, educationalists and scholars in medical education in order to outline the concept of 'medical education professionalism'.

This thesis may hopefully stimulate researchers, educationalists and national accreditation bodies to recognize professionalism as a core competency that should be taught and assessed in the future generations of Arab health professionals. 
210 


\section{Samenvatting}

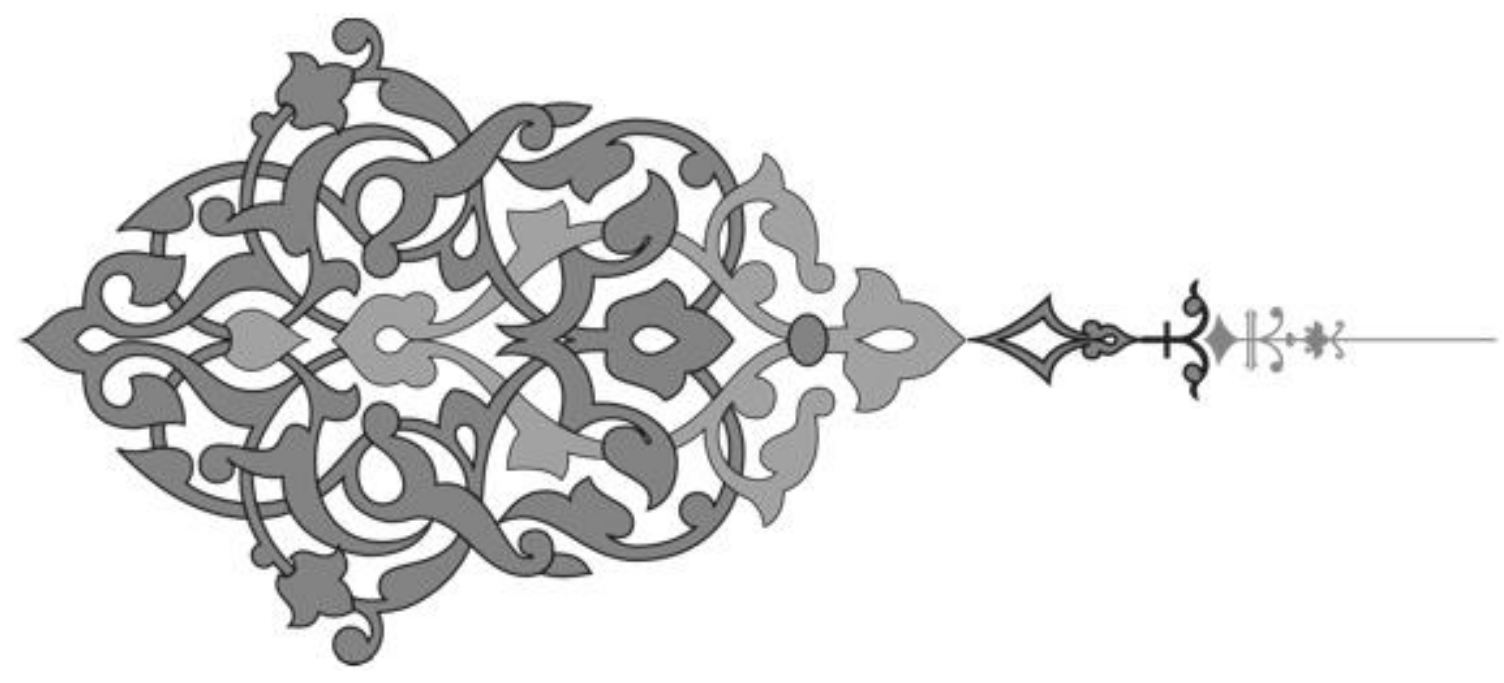


212 
Professionaliteit staat de laatste jaren steeds meer in de schijnwerpers, met name bezien vanuit een Westers perspectief. Minder duidelijk is echter wat het begrip "medische professionaliteit" nu eigenlijk inhoudt in de Arabische context, vanuit het oogpunt van Arabische studenten en docenten Geneeskunde. Het is nodig hier een invulling aan te geven, opdat een heus kader voor medische professionaliteit ontwikkeld kan worden dat zich als basis kan lenen voor het ontwerp en de evaluatie van docentprofessionaliseringstrajecten in de Arabische context.

Dit proefschrift bestaat uit 7 samenhangende studies die in een logische volgorde gepresenteerd worden teneinde de volgende 7 onderzoeksvragen te beantwoorden: (1) Welke basisdomeinen van professionaliteit kent de Arabische context?; (2) Hoe ontwikkel en valideer je een cultuurspecifiek instrument waarmee professioneel gedrag kan worden gemeten in de Arabische context?; (3) Hoe professioneel gedragen Arabische Geneeskundestudenten zich?; (4) Op welke manier verschillen Geneeskundestudenten van hun docenten in de Arabische context betreft het professioneel gedrag dat zij vertonen?; (5) Hoe zorg je ervoor dat faculteitsleden op instellingsniveau overeenstemming bereiken over een cognitieve basis voor professionaliteit? (6) Hoe ontwikkel en evalueer je een docentprofessionaliseringstraject in de Arabische context?; en (7) Wat zijn praktische tips voor het onderwijzen van professionaliteit op alle niveaus van het medisch onderwijs? De antwoorden op bovenstaande vragen voorzien in een kader voor medische professionaliteit in de Arabische context, alsook in een basis voor docentprofessionalisering.

basisdomeinen van professionaliteit kent de Arabische context? Aangezien professionaliteit cultuurgevoelig is, beoogde studie 1 de componenten van het professionaliteitskader van het American Board of Internal Medicine (ABIM)* te valideren ten aanzien van de Arabische context. De auteurs nodigden een gemengde groep van autochtone Arabische gezondheidsprofessionals en academici uit om bij te dragen aan een adviespanel. Medici en onderwijsdeskundigen werden uitgenodigd om een bijdrage te leveren. Hiervoor moesten zij aan een aantal voorwaarden voldoen. Zij moesten: (a) Arabisch als moedertaal hebben, (b) als professional actief zijn in de gezondheidszorg of gezondheidsonderwijs in een Arabisch land, en (c) in hun organisatie betrokken zijn bij de opleiding tot basisarts en/of een medische vervolgopleiding.

*Amerikaans College Interne Geneeskunde 
Zij vertegenwoordigden een breed scala aan specialismen en senioriteitsniveaus verspreid over diverse gezondheidszorgorganisaties en Geneeskundeopleidingen in Egypte, Saudi-Arabië en de Verenigde Arabische Emiraten (VAE).

Zij werden gevraagd naar het belang dat zij hechtten aan elk afzonderlijk domein van professionaliteit dat door het ABIM werd voorgesteld, en aangemoedigd voorstellen voor nieuwe domeinen te doen indien zij dat nodig achtten. Tweeëndertig van de 45 genodigde gezondheidsprofessionals en opleiders (71\%) droegen bij aan het adviespanel. Het panel bevond alle 6 domeinen van het ABIM geschikt voor de Arabische context, en stelde verder voor de "Onafhankelijkheid van professionals" als zevende domein toe te voegen waarmee de nadruk werd gelegd op de vrijheid van clinici om al hun potentieel als "genezers" te benutten. Uit het onderzoek kwam naar voren dat in de Arabische setting een paternalistisch model van patiëntenzorg gangbaar was waarbij de klemtoon lag op de professionele onafhankelijkheid van artsen in plaats van patiënten. Arabische artsen worden gezien als "meesters" die behoren te weten (en te beslissen over) wat de beste therapie is voor hun patiënten en zij kunnen zelfs het vertrouwen van hun patiënten verliezen als zij ook maar enige mate van onzekerheid m.b.t. de te stellen diagnose tonen. Met dit aangepaste kader dat gebaseerd was op de ABIM-domeinen, werd de Arabische professionaliteit geconceptualiseerd.

In de tweede studie werd de tweede vraag behandeld en dus het proces beschreven voor het ontwikkelen en valideren van een cultuurspecifiek instrument, de LAMPS genaamd (Learners' Attitudes on Medical Professionalism Scale)**, waarmee het professioneel gedrag gemeten kan worden in de Arabische context. De ontwikkelingsfase van deze LAMPS bestond uit vier stappen: (1) het bepalen van de te meten bouwstenen/domeinen van professionaliteit, (2) het genereren van gedragsitems voor elk domein, (3) het proeftesten van de LAMPS, en (4) het verfijnen van de schaal op basis van de bij stap 3 verkregen gegevens. Samen met de auteurs hielpen 32 deskundigen mee met het genereren van items binnen de specifieke domeinen. Het instrument werd voorgelegd aan in totaal 413 Geneeskundestudenten en coassistenten. De antwoorden werden verzameld d.m.v. een 5-punts Likertschaal. Om tot een schatting te komen van de betrouwbaarheid van het instrument werden de gegevens geanalyseerd.

** Schaal die gebruikt wordt om te peilen naar het medisch professioneel gedrag van leerlingen. 
De uiteindelijke versie van de LAMPS bestaat uit 28 items verdeeld over vijf domeinen, met een gemiddelde betrouwbaarheid van 0,79; dit is vrij hoog, gezien de veelzijdige aard van de te meten competentie (medische professionaliteit). De LAMPS is de eerste context-specifieke, betrouwbare en valide inventarisatie van het begrip "medische professionaliteit" in de Arabische context en werd vergeleken met verwante instrumenten uit de literatuur. De LAMPS kan docenten helpen leerachterstanden m.b.t. professionaliteit bij hun studenten te identificeren en gedragsveranderingen over een bepaalde tijdsperiode als gevolg van hun ingrepen te monitoren.

Bij de derde studie werd de LAMPS aangewend om het professioneel gedrag van Arabische Geneeskundestudenten te onderzoeken. De antwoorden van Geneeskundestudenten afkomstig van twee universiteiten in Egypte en SaudiArabië werden met elkaar vergeleken. Verder beoogde de studie de bevindingen voor elk van de twee landen vanuit een culturele zienswijze te interpreteren om eventuele correlaties tussen culturele dimensies en professionaliteitsdomeinen te kunnen aantonen. Volgens Hofstedes culturele dimensies heerst er in SaudiArabië een grotere machtsafstand dan in Egypte. In een samenleving waarbinnen de machtsafstand groot is, accepteren en verwachten de ondergeschikte leden een oneven en hiërarchische machtsverdeling, zelfs binnen het eigen gezin. Bevoordeelden zoals Saudische artsen daarentegen, worden geacht zaken die hun integriteit en reputatie aangaan goed te bewaken, om het respect en vertrouwen dat patiënten in hen stellen waardig te blijven. Dit kan verklaren waarom Saudische Geneeskundestudenten ten opzichte van Egyptische studenten gevoeliger waren voor gedragsaspecten als Integriteit/Reputatie en Respect. In deze studie werd onder andere gebruik gemaakt van Hofstedes dimensies om de culturele bodem van een specifieke samenleving waarin professionaliteit verankerd is, te verkennen. Om deze correlaties te kunnen bevestigen, is nader onderzoek nodig met diepgaandere studies over professionaliteit in andere Arabische landen.

Ondanks het feit dat "professionaliteit" steeds meer in de belangstelling staat, is er weinig onderzoek verricht naar de ontwikkeling van deze competentie gedurende het hele continuüm van het medische onderwijs. In studie 4 werd het professioneel gedrag van drie cohorten met elkaar vergeleken, nl. dat van 
bachelorstudenten, coassistenten en docenten Geneeskunde. De volgende vijf domeinen van professionaliteit werden daarbij onder de loep genomen: altruïsme, plichtsbesef/verantwoordelijkheidsgevoel, prestatiegerichtheid /onafhankelijkheid, integriteit/reputatie en respect. Ten opzichte van coassistenten vertoonden de docenten in vier domeinen aanzienlijk minder professioneel gedrag, maar op het gebied van integriteit/reputatie scoorden zij verbazingwekkend hoog t.o.v. diezelfde groep. Docenten waren eerder geneigd gedragingen als bedrog, vervalsing, liegen, misleiding, achterhouden van informatie en onethische praktijken te verwerpen, waarschijnlijk omdat zij sneller inzagen wat de destructieve gevolgen van het plegen van een dergelijke daad zouden zijn voor hun professionele identiteit en reputatie. Studenten daarentegen, hebben misschien nog geen volledig beeld van de klinische praktijk waardoor zij de gevolgen van zulke misdragingen nog niet zo goed kunnen overzien. Het feit dat wij drie groepen met elkaar vergeleken hebben wil niet zeggen dat professionaliteit zich daadwerkelijk over drie fases ontwikkelt. Gefaseerde ontwikkeling van professionaliteit was gebaseerd op fasentheorieën die overeenkomen met onze bevindingen, maar dit moet nog door longitudinale studies gevalideerd worden. De bevindingen geven wat meer inzicht in hoe de ontwikkeling tot een professional onder invloed van een mix van biologische (aard) en omgevings- (voeding) factoren plaatsvindt. Studie 4 brengt ons een stap dichterbij het begrijpen van het ontstaan van medische professionaliteit in de Arabische context. Ook verschaft het docenten Geneeskunde nuttige informatie over hoe zij in de verschillende stadia van het medisch onderwijs hun studenten kunnen opleiden tot professionals, om zo de vorming van een professionele identiteit in de loop der jaren te kunnen bevorderen.

Medische professionaliteit wordt beschreven als een set kwaliteiten en gedragingen; het Westerse kader van medische professionaliteit zou echter wel eens kunnen contrasteren met de culturele waarden van niet-Westerse landen. Studie 5 heeft ten doel een professionaliteitskader voor zorgverleners te formuleren, zoals dat door plaatselijke medische professionals in Arabische landen werd geïnterpreteerd. In de studie werd beschreven hoe d.m.v. een Delphi-studie consensus verkregen werd, op basis waarvan een nieuw, heus professionaliteitskader, het Vier-Poortenmodel genaamd, werd ontwikkeld. Er werd een lijst gemaakt van acht professionele eigenschappen die op hun beurt werden ondergebracht in vier thema's (Poorten): omgaan met jezelf, omgaan met je taken, omgaan met anderen en omgaan met God. De vierde poort (omgaan met God) getuigde van het feit dat in de Arabische context het geloof een 
axiomatische rol speelt in de ontwikkeling van medische professionaliteit, aangezien zelfverantwoordelijkheid geïnterpreteerd wordt als "taqwa" (in het Arabisch: angst voor God) en zelfmotivatie synoniem is aan "ehtesab" (in het Arabisch: vragen om een beloning van God). Het Vier-Poortenmodel weergalmt recente studies die professionele waarden in correlatie brengen met plaatselijke overtuigingen van niet-Westerse culturen. Recentelijk werd professionaliteit geïnterpreteerd in het licht van Bushido-concepten in Japan en Confucianistische waardes in China en Taiwan. Deze studies introduceren een nieuwe opvatting van het begrip "professionaliteit", los gezien van de bekende Westerse modellen, en stellen zich open voor een rijkere discussie vanuit het oogpunt van verschillende culturen over de betekenis van professionaliteit in de gezondheidszorgpraktijk van vandaag.

Professionaliteit dient nadrukkelijk te worden onderwezen, echter, dit vormt een grote uitdaging aangezien Geneeskundedocenten vaak niet goed voorbereid zijn op het onderrichten van dergelijke materie. Studie 6 voorzag in een werkplan waarmee professionaliteit in de praktijk kan worden onderwezen en aangeleerd door middel van een afgestemde docentprofessionaliseringsmodule. De studie maakte gebruik van gebruikersparticipatie, waarbij auteurs en 28 faculteitsleden de verantwoordelijkheid droegen voor het programmaontwerp. Dit gebeurde in drie stappen: (1) oriëntatieworkshop voor docenten; (2) ontwikkelen van vignetten; en (3) het onderrichten van studenten in professionaliteit. Tijdens de workshop leerden de docenten de cognitieve beginselen, ofwel de saillante eigenschappen van professionaliteit in de Arabische context. Na afloop van de workshop hielpen de auteurs de docenten mee om een totaal van 32 vignetten over verschillende klinische aspecten te ontwikkelen, waarbij een mix van dilemma's m.b.t. professionaliteit werd geschetst. Een reeks van zeven vragen/prikkels werd voorgesteld om studenten te sturen in hun reflectie. Het programma voldeed aan de richtlijnen voor het ontwerp en kwam voort uit een heus professionaliteitskader dat zijn oorsprong vond in plaatselijke wetenschappelijke studies in de Arabische context. De programmaresultaten werden gemeten aan de hand van de vier niveaus van Kirkpatrick's model: reacties, leerervaring, overdracht en resultaten. De studie bevestigde dat professionaliteit onderwezen kan worden met behulp van vignetten die professionaliteitsdilemma's schetsen in een bepaalde context. Ook werd in deze studie het belang benadrukt van een 
verschuiving in docentprofessionalisering van losse op zichzelf staande ingrepen naar een mentorschapsmodel dat gevestigd is in leergemeenschappen.

De laatste studie had ten doel een praktische handleiding op te stellen over het onderrichten van professionaliteit op alle niveaus van het medisch onderwijs. Puttend uit de onderzoeksliteratuur en persoonlijke ervaringen van de auteur, worden 12 tips gepresenteerd die zijn onderverdeeld in vier clusters die betrekking hebben op (1) de context; (2) de docenten; (3) het curriculum; en (4) netwerken. Met een beter begrip van de didactische richtlijnen voor het onderwijzen van medische professionaliteit zullen Geneeskundeopleiders beter in staat zijn een van de in het medisch onderwijs meest uitdagende competenties te onderwijzen. Het onderwijzen van professionaliteit is geen doel, maar een middel waarmee de professionele identiteit van toekomstige alumni zodanig vormgegeven kan worden dat zij leren te denken, voelen en handelen als artsen. Dít is de overkoepelende strategie en het impliciete doel achter het introduceren van medische professionaliteit als een fundamenteel thema binnen het medisch onderwijs.

De zeven studies van dit proefschrift geven nogmaals aan hoe belangrijk het is om medische professionaliteit binnen een bepaalde samenleving te begrijpen vanuit haar kernwaarden, ethiek en codes. Onderzoek naar de culturele codes van professionaliteit blijft echter noodzakelijk en wij nodigen toekomstige onderzoekers dan ook uit om het veelzijdige concept "professionaliteit" nader te onderzoeken op regionale, nationale en institutionele schaal. Zo is het bijvoorbeeld nodig om "professionaliteit" te definiëren voor de Afrikaanse, Indiase en Latijns-Amerikaanse context, los gezien van de Westerse modellen. Om professionaliteit te kunnen onderwijzen is het van belang vooraf duidelijke verwachtingen te formuleren, in de vorm van wenselijke eigenschappen en gedragingen van medische professionals. $\mathrm{Er}$ is behoefte aan meer gestructureerde docentprofessionaliseringsprogramma's die docenten voorbereiden op de uitdagende taak deze competentie te onderwijzen en hen leren studenten te helpen op dagelijkse dilemma's aangaande professionaliteit te reflecteren.

Dit proefschrift nodigde medeonderzoekers uit om het concept eprofessionaliteit nader te onderzoeken, opdat traditionele kernwaarden van Geneeskunde (privacy, vertrouwelijkheid, één op één interacties en formeel gedrag) behouden blijven in de wereld van de sociale media waarin andere 
waarden gelden (delen en openheid, verbinding, transparantie en informaliteit). Als laatste, maar daarom niet minder belangrijk, dient professionaliteit van medische docenten nader onderzocht te worden op de verwachtingen die de samenleving heeft van opleiders, onderwijskundigen en academici in de medische onderwijswereld om zo een definitie te verkrijgen van het concept "medische onderwijskundige professionaliteit".

We hopen dat dit proefschrift onderzoekers, onderwijskundigen en nationale accreditatieorganen zal aanmoedigen om professionaliteit te erkennen als een kerncompetentie die onderwezen en getoetst moet worden in toekomstige generaties van gezondheidsprofessionals in de Arabische wereld. 


$$
220
$$




\section{Valorisation}

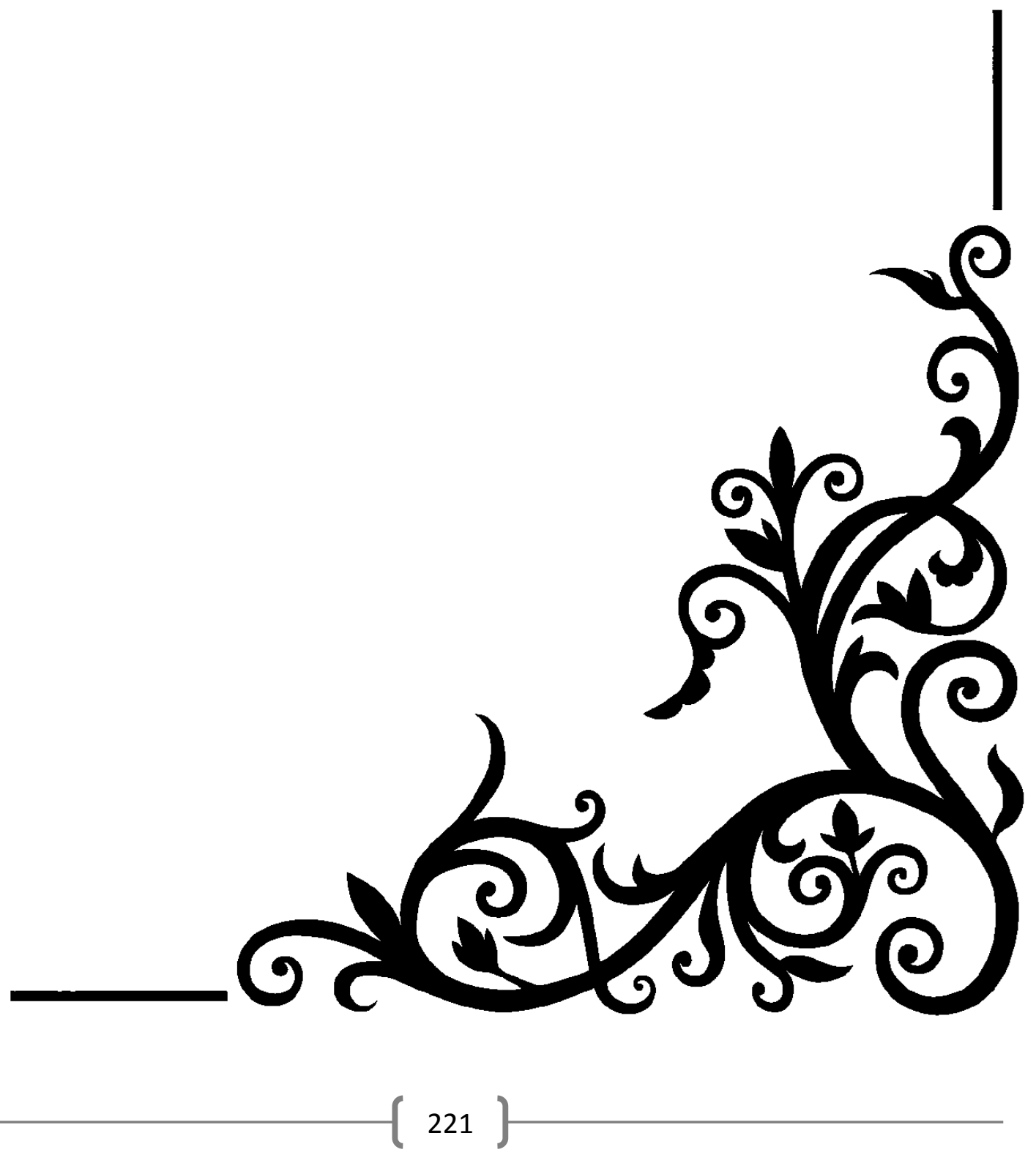


222

222


This valorization section provides directions for creating value from the research work reported in this thesis. The knowledge presented in the seven studies of the thesis can serve as the basis for the development of several commercial products such as: An online survey, a book, a database, a multi-media library, and storyboards for virtual patients.

The LAMPS or the Learners Attitudes to Medical Professionalism Scale (Chapter 3) can be used as a commercial online survey on a larger scale for different target populations to serve various purposes. The 28-item survey, with a reliability of 0.79 , can be used as a diagnostic tool to (1) identify learning gaps in professionalism among learners, (2) compare attitudes on professionalism in different groups or populations within the Arabian context, and (3) track attitude changes on professionalism over time and as a result of interventions in crosssectional or longitudinal studies. Fine tuning the scale of the LAMPS introduces new implications. The LAMPS can be used to estimate the trend of these behaviours in a college or the community at large. The leading question can be changed from: "Do you agree when the doctor . . .?" to "How often do you encounter a doctor . . .?" The Likert scale will need to be modified accordingly to range from 1 (never) to 5 (always). The LAMPS was developed primarily to be used by educators, but it can also be used by deans, hospital directors and human resource managers to explore the professionalism orientation of potential applicants prior to employment.

With some elaboration, the twelve tips (Chapter 8) can be the foundation of a manual (or book) for teaching medical professionalism. The tips include: (1) determine the cultural context, (2) outline the cognitive base, (3) seek institutional support, (4) promote a professional environment, (5) foster rolemodelling, (6) train faculty members to teach professionalism, (7) define expectations as observable behaviours, (8) provide learning opportunities appropriate to the level of the learners, throughout: orientation, early and later undergraduate years, residency and during independent medical practice, (9) 
allow structured time for guided reflection, (10) evaluate the outcome, provide feedback and suggest appropriate remediation plans, (11) share your teaching experience, and (12) consider the evolving digital aspects of medical professionalism (e-Professionalism). These tips can be a nucleus for a manual for medical teachers and faculty developers to teach one of the most challenging constructs in medical education, namely: professionalism. Professionalism remains one of the most challenging competencies to define, teach and evaluate, because of its complex and context-specific nature (Bryden, Ginsburg, \& Kurabi, 2010; Hafferty \& Castellani, 2010; Stern, 2003; Swick, 2000). A practical manual on teaching professionalism is expected to empower educators, particularly in the Arabian context, to address this relatively complex social construct at different levels of medical education.

The faculty development program on professionalism (Chapter 7) presented a number of vignettes depicting professionalism dilemmas. The IDEAL consortium database stores MCQ items from 28 schools or organisations from 14 different countries (IDEAL Consortium, 2015). Similarly, this thesis invites teachers and researchers in the field to develop and share their experience to establish a bank of professionalism vignettes. Each vignette should include: A scenario, options for decision making, consequences for each decision track, learning outcomes, 'what if' alternatives of the scenario and trigger questions for guided reflection among learners. Professionalism vignettes can be categorised using 'tags' to facilitate search and retrieval according to: (1) the level of the learner (undergraduate, postgraduate or professional), (3) the discipline/specialty (medicine, surgery, anaesthesia, paediatrics etc.), (3) the organization of the problem (ill-structured or well-structured) (van Merriënboer, 2013) and, of course (4) the domain(s) of professionalism addressed in the scenario (altruism, excellence, self-accountability etc.).

Vignettes in the thesis were presented in text format, but they can also be portrayed and presented in a more appealing form. The scenarios of professionalism dilemmas can be role-played, recorded and stored as reusable 
learning objects in a professionalism multi-media library. The same scenarios can guide the development of storyboards for virtual patients (VPs) for teaching professionalism. Yet, there are two main challenges in creating the above commercial products. First, a high level of technical expertise in software development, animation, instructional design, multi-media and e-learning is required for VPs. Second, the financial costs of production are high. One solution is to apply for grants to develop one or more of the above products, which makes it feasible and rewarding.

This thesis advocates teaching professionalism in medical school. This directly results in better professionalism training, leading to societal benefits as can be manifested by more knowledgeable teachers, better doctors, and less medical errors. Teaching professionalism contributes to maintaining trust in medicine as a valuable profession and empowers doctors to attend to and meet societal expectations. The thesis was conducted in medical education, but methods used are not restricted to medicine. Actually the same approach can be used to teach the non-technical, non-cognitive and decision-making skills related to professional practice in different sectors for: lawyers, judges, accountants, scientists, pilots, and so on. Professionalism can be considered an integral part of the practical wisdom (Hilton \& Slotnick, 2005).

The use of dilemmas as an instructional design technique is transferrable across disciplines. Examples like the prisoners' dilemma or the bargaining problem in game theory (Von Neumann \& Morgenstern, 1944) guided decision making not only in economics, but also in political sciences, biology, and philosophy. Experts in every profession can decide what rule needs to be broken, under which condition and to what extent. This 'tacit knowledge' has to be explored and explicitly inculcated in relevant curricula to graduate future professionals. Even pilots, who should strictly follow aviation policies and procedures, have to feel the rationale and spirit of these policies in action. They need to be trained to take proper decisions in complex real-life situations that are sometimes not listed in their manuals. Life is full of uncertainty and unstructured problems and teaching professionalism can prepare our graduates for it. 
The thesis provided answers for seven questions, but other questions emerged to suggest venues for future developments. First, how do certain cultural dimensions influence the domains of professionalism? The dimensions of national culture were correlated with cross-national differences in communications skills (Meeuwesen, van den Brink-Muinen, \& Hofstede, 2009), but can we also find correlations between certain cultural dimensions, such as: power distance (Hofstede, 2014) of a society and their attention to particular domains of professionalism, such as: respect.

Studies of the current thesis solicited data mainly from medical students, teachers and practitioners. Since professionalism is a granted privilege by the society, there is a need also to measure the attitudes of patients (van Mook et al., 2012) and the public at large (Chandratilake, McAleer, Gibson, \& Roff, 2010) towards medical professionals. Regarding the public, what are the variables that affect one's attitude on medical professionalism? In other words, do the expectations of patients and public from medical professionals vary according to their level of education, socio-economic status, or past experience?

There is another enigmatic point related to professionalism research. Much of the existing literature on professionalism discusses three key questions: (1) what is professionalism in view of different contexts? (Al-Eraky \& Chandratilake, 2012; Pan, Norris, Liang, Li, \& Ho, 2013), (2) how can professionalism be taught? (Birden et al., 2013; Cruess \& Cruess, 2006), and (3) how can it be assessed? (Hodges et al., 2011; O'Sullivan \& Toohey, 2008; van Mook et al., 2009) Few authors have tackled an equally important issue, namely, to decipher how professionalism develops across the continuum of medical education (Rees, 2005). If professionalism is an acquired state, then what are the contributing factors that assist its development in the minds and hearts of medical graduates?

The thesis provided a model for teaching professionalism with the use of vignettes and reflection in groups. Teaching professionalism is still challenging to many faculty members, because they are not prepared to address this complex 
issue within their courses (Steinert, Cruess, Cruess, \& Snell, 2005). Teaching professionalism is not an end, but a means to professional identity formation (Cruess, Cruess, Boudreau, Snell, \& Steinert, 2014). Our future graduates should gradually think, act and feel like physicians (Cruess et al., 2014; Wilson, Cowin, Johnson, \& Young, 2013).

The popularity of social media, including Facebook, Twitter and YouTube, has added a new dimension to defining and teaching professionalism. The thesis also referred to the concept of e-professionalism (Kaczmarczyk et al., 2013) that indicates the professional attitudes and behaviours as manifested through digital media. Medical students, teachers and physicians need to learn what is and what is not appropriate to do on the Internet, and they must recognize that actions online and content posted may have serious consequences for their medical career. There is a need to further investigate how to preserve the traditional core values of medicine (privacy, confidentiality, one-on-one interactions, and formal conduct) in the milieu of social media which promotes other values (sharing and openness, connection, transparency, and informality).

To conclude, this thesis provides a manual for medical teacher to address professionalism in a practical approach. The studies explored how people think of professionalism and developed a conceptual framework on how professional attributes are interrelated in the Arabian context in four themes (gates). The thesis further enables teachers to develop contextual vignettes that depict conflicts of interests in real-life scenarios. Reflection on these situations is expected to help students, and teachers, to conceptualize professionalism in the Arabian context.

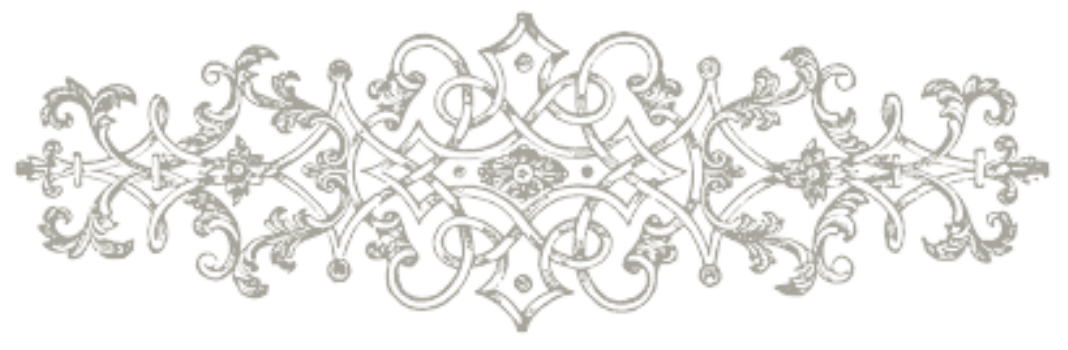




\section{References}

Al-Eraky, M. M., \& Chandratilake, M. (2012). How medical professionalism is conceptualised in Arabian context: A validation study. Medical Teacher.

Birden, H., Glass, N., Wilson, I., Harrison, M., Usherwood, T., \& Nass, D. (2013).

Teaching professionalism in medical education: a Best Evidence Medical Education (BEME) systematic review. BEME Guide No. 25. Medical Teacher, 35(7), e1252-66. doi:10.3109/0142159X.2013.789132

Bryden, P., Ginsburg, S., \& Kurabi, B. (2010). Professing Professionalism : Are We Our Own Worst Enemy ? Faculty Members' Experiences of Teaching and Evaluating Professionalism in Medical Education at One School, 85(June), 1025-1034.

Chandratilake, M., McAleer, S., Gibson, J., \& Roff, S. (2010). Medical professionalism: what does the public think? Clinical Medicine (London, England), 10(4), 364-9. Retrieved from

http://www.ncbi.nlm.nih.gov/pubmed/20849011

Cruess, R. L., \& Cruess, S. R. (2006). Teaching professionalism: general principles. Medical Teacher, 28(3), 205-8. doi:10.1080/01421590600643653

Cruess, R. L., Cruess, S. R., Boudreau, J. D., Snell, L., \& Steinert, Y. (2014).

Reframing medical education to support professional identity formation. Academic Medicine : Journal of the Association of American Medical Colleges, 89(11), 1446-51. doi:10.1097/ACM.0000000000000427

Hafferty, F. W., \& Castellani, B. (2010). The increasing complexities of professionalism. Academic Medicine : Journal of the Association of American Medical Colleges, 85(2), 288-301. doi:10.1097/ACM.0b013e3181c85b43

Hilton, S. R., \& Slotnick, H. B. (2005). Proto-professionalism: how professionalisation occurs across the continuum of medical education. Medical Education, 39(1), 58-65. doi:10.1111/j.1365-2929.2004.02033.x 
Hodges, B. D., Ginsburg, S., Cruess, R., Cruess, S., Delport, R., Hafferty, F., ... Wade, W. (2011). Assessment of professionalism: recommendations from the Ottawa 2010 Conference. Medical Teacher, 33(5), 354-63. doi:10.3109/0142159X.2011.577300

Hofstede, G. (2014). Culture. Retrieved from http://geerthofstede.nl/culture.aspx

IDEAL Consortium. (2015). Retrieved February 5, 2015, from http://temporary.idealmed.org/wp/membership/our-current-members/

Kaczmarczyk, J. M., Chuang, A., Dugoff, L., Abbott, J. F., Cullimore, A. J., Dalrymple, J., ... Casey, P. M. (2013). e-Professionalism: a new frontier in medical education. Teaching and Learning in Medicine, 25(2), 165-70. doi:10.1080/10401334.2013.770741

Meeuwesen, L., van den Brink-Muinen, A., \& Hofstede, G. (2009). Can dimensions of national culture predict cross-national differences in medical communication? Patient Education and Counseling, 75(1), 58-66. doi:10.1016/j.pec.2008.09.015

O'Sullivan, A. J., \& Toohey, S. M. (2008). Assessment of professionalism in undergraduate medical students. Medical Teacher, 30(3), 280-6. doi:10.1080/01421590701758640

Pan, H., Norris, J. L., Liang, Y.-S., Li, J.-N., \& Ho, M.-J. (2013). Building a professionalism framework for healthcare providers in China: a nominal group technique study. Medical Teacher, 35(10), e1531-6. doi:10.3109/0142159X.2013.802299

Rees, C. (2005). Proto-professionalism and the three questions about development. Medical Education, 39(1), 9-11. doi:10.1111/j.13652929.2004.02025.x

Steinert, Y., Cruess, S., Cruess, R., \& Snell, L. (2005). Faculty development for teaching and evaluating professionalism: from programme design to curriculum change. Medical Education, 39(2), 127-36. doi:10.1111/j.13652929.2004.02069.x 
Stern, D. T. (2003). Can professionalism be taught? The Virtual Mentor : VM, 5(12). doi:10.1001/virtualmentor.2003.5.12.oped1-0312

Swick, H. M. (2000). Toward a Normative Definition of Medical Professionalism. Academic Medicine, 75(6), 612-616. doi:10.1097/00001888-20000600000010

Van Merriënboer, J. J. G. (2013). Perspectives on problem solving and instruction. Computers \& Education, 64, 153-160. doi:10.1016/j.compedu.2012.11.025

Van Mook, W. N. K. A., Gorter, S. L., Kieboom, W., Castermans, M. G. T. H., de Feijter, J., de Grave, W. S., ... van der Vleuten, C. P. M. (2012). Poor professionalism identified through investigation of unsolicited healthcare complaints. Postgraduate Medical Journal, 88(1042), 443-50. doi:10.1136/postgradmedj-2011-130083

Van Mook, W. N. K. A., Gorter, S. L., O'Sullivan, H., Wass, V., Schuwirth, L. W., \& van der Vleuten, C. P. M. (2009). Approaches to professional behaviour assessment: tools in the professionalism toolbox. European Journal of Internal Medicine, 20(8), e153-7. doi:10.1016/j.ejim.2009.07.012

Von Neumann, J., \& Morgenstern, O. (1944). Theory of Games and Economic Behavior. London: Princeton University Press.

doi:10.1177/1468795X06065810

Wilson, I., Cowin, L. S., Johnson, M., \& Young, H. (2013). Professional identity in medical students: pedagogical challenges to medical education. Teaching and Learning in Medicine, 25(4), 369-73. doi:10.1080/10401334.2013.827968 


\section{Acknowledgement}

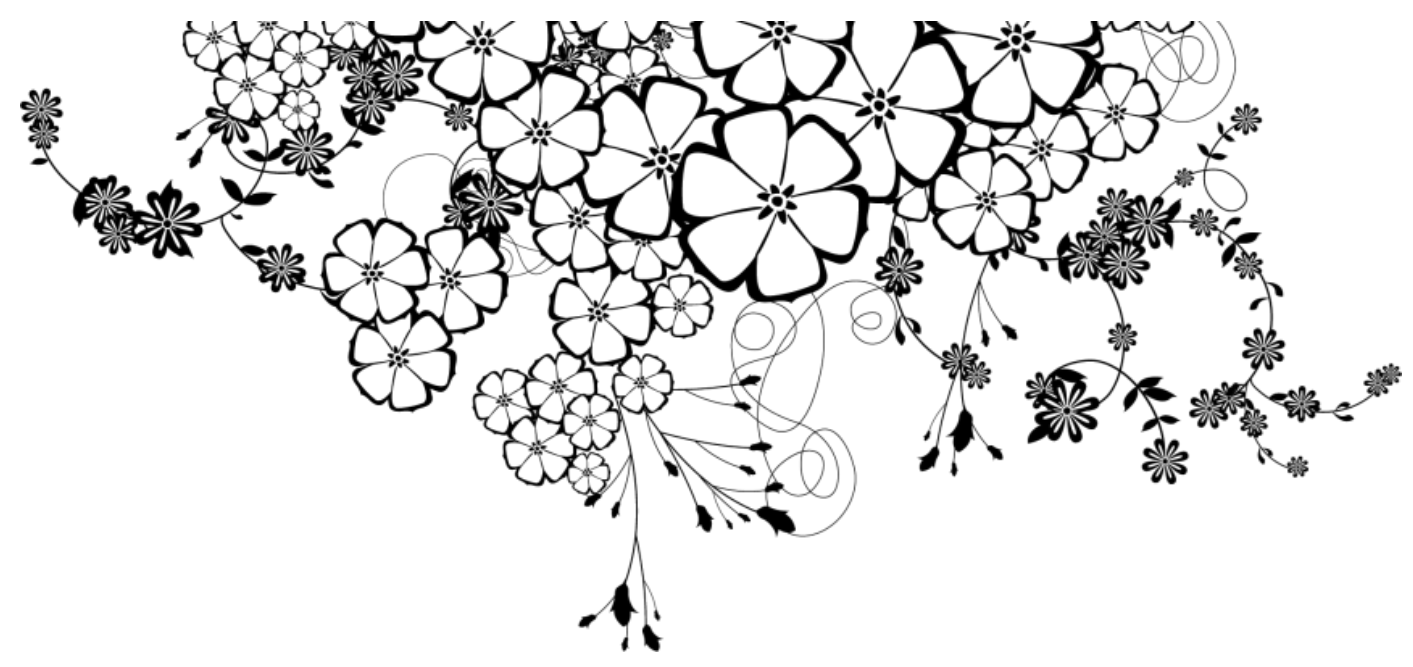

1 would like to thank Prof. dr. Jeroen van Merriënboer for sharing his pearls of wisdom and knowledge with me throughout the course of my PhD. 1 extend my gratitude to Dr. Jeroen. Donkers for his always valuable and eye-opening comments. Further, 1 am indebted to Dr. Gohar Wajid for his ongoing motivation and guidance on the personal and professional levels. 


\section{Dedication}

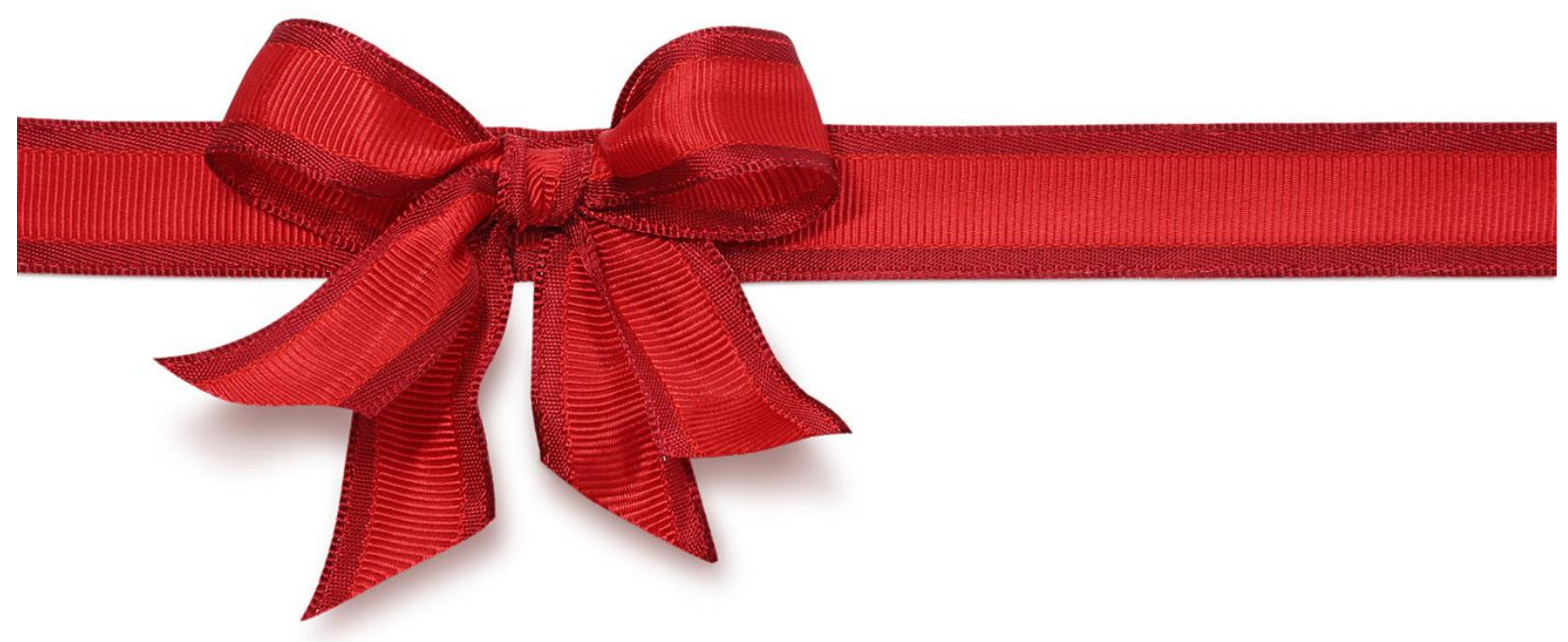

1 heartily dedicate my thesis ...

To the soul of my father who inspired me to preserve integrity and pursue excellence,

To the soul of my father-in-law who anticipated my public defense on his birthday,

To my mother who always keeps me in her prayers to be the best one in the world, To my wife who sweetened my life and supported me throughout my studies, To my two sisters who used to have high expectations from their elder brother,

\& finally ...

To everyone who finds this thesis helpful to shape future health professionals. 


\section{Curriculum Vitae}

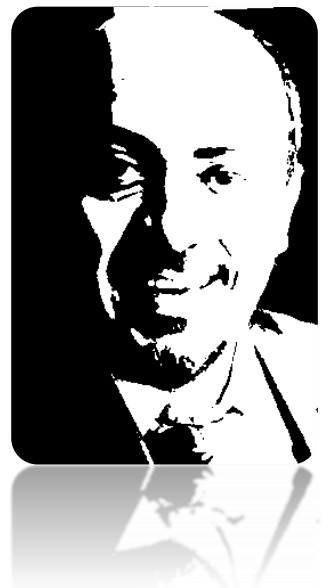

Mohamed Mostafa Al-Eraky is an Egyptian medical doctor who has been graduated from the College of Medicine of Zagazig University (Egypt) in 1996. Since then, he developed a passion for medical education, while acting as one of the founding members of the Medical Education Development Unit at Zagazig University. This passion inspired him to make a U-turn in his career. After concluding his Master in clinical pathology, he got a Certificate then Diploma and eventually a Master Degree in medical education, with Distinction, from the University of Dundee (UK).

As you are reading these lines, he has almost concluded his PhD from School of Health Professions Education (SHE) at Maastricht University (Netherlands). Dr. Al-Eraky is currently working as a lecturer of medical education at the University of Dammam in Saudi Arabia. He has actively contributed with presentations, workshops and courses at a number of national, regional and international events in Egypt, Saudi Arabia, Bahrain, UAE, Czech Republic, Italy, Netherlands, UK, Canada, Pakistan and Singapore.

On a personal note, Mohamed is married to Omnia, a French language teacher. They have three lovely kids and a fourth one is expected few weeks after the public defense of this PhD. 


\section{Al-Eraky MM Publications}

$\square$ Al-Eraky MM, Donkers J, Wajid G, Van Merrienboer JJ. Faculty development for learning and teaching of medical professionalism. Med Teach. 2015 Apr;37 Suppl 1:S40-6. doi: 10.3109/0142159X.2015.1006604. PubMed PMID: 25803591.

$\square$ Al-Eraky MM. Twelve Tips for teaching medical professionalism at all levels of medical education. Med Teach. 2015 Mar 17:1-8. [Epub ahead of print] PubMed PMID: 25776227.

$\square$ Al-Eraky MM, Donkers J, Wajid G, van Merrienboer JJ. A Delphi study of medical professionalism in Arabian countries: the Four-Gates model. Med Teach. 2014 Apr;36 Suppl 1:S8-16. doi: 10.3109/0142159X.2014.886013. PubMed PMID: 24617789.

- Al-Eraky M. The cultural flavours of problem-based learning. Med Educ. 2013 Oct;47 (10):1049. doi: 10.1111/medu.12285. PubMed PMID: 24016176.

$\square$ Al-Eraky MM, Chandratilake M, Wajid G, Donkers J, van Merrienboer J. Medical professionalism: development and validation of the Arabian LAMPS. Med Teach. 2013;35 Suppl 1:S56-62. doi: 10.3109/0142159X.2013.765553. PubMed PMID: 23581897.

- Al-Eraky MM. Curriculum Navigator: aspiring towards a comprehensive package for curriculum planning. Med Teach. 2012;34(9):724-32. doi: 0.3109/0142159X. 2012. 689445. Epub 2012 May 30. PubMed PMID: 22646300.

- Al-Eraky MM. AM last page. Robert Gagné's nine events of instruction, revisited. Acad Med. 2012 May;87(5):677. doi: 10.1097/ACM.0b013e318250e01d. PubMed PMID: 22531595.

$\square$ Al-Eraky MM, Chandratilake M. How medical professionalism is conceptualised in Arabian context: a validation study. Med Teach. 2012;34 Suppl 1:S90-5. doi: 10.3109/0142159X.2012.656754. PubMed PMID: 22409198.

- Al-Eraky MM, McLean M. The Compass Model to plan faculty development programs. Medical Education Development 01/2012; 2(1). DOI: 10.4081/med.2012.e4

The articles of this PhD are indicated with $\square$ sign. 


$$
238
$$




\section{SHE Dissertations Series}

The SHE Dissertation Series publishes dissertations of PhD candidates from the School of Health Professions Education (SHE) who defended their PhD theses at Maastricht University. The most recent ones are listed below. For more information go to: www.maastrichtuniversity.nl/she.

Wearne, S. (08.04.2015) Is it remotely possible? Remote supervision of general practice registrars

Embo, M. (13.03.2015) Integrating workplace learning, assessment and supervision in health care education

Zwanikken, P. (23.01.2015) Public health and international health educational programmes for low- and middle-income countries: questioning their outcomes and impact

Hill, E. (11-12-2014) A cutting culture: gender and identification in the figured world of surgery

Diemers, A. (03-10-2014) Learning from pre-clinical patient contacts

Tjiam, I. (17-09.2014) Learning in Urology. Designing simulator based skills Training \& Assessment

Berkenbosch, L. (30-06-2014) Management and leadership education for medical residents

Bergman, E.M. (30-06-2014) Dissecting anatomy education in the medical curriculum

Dijkstra, J. (25-06-2014) Guidelines for designing programmes of assessment

Van Loon, M.H. (08-05-2014) Fostering monitoring and regulation of learning 
Frambach, J.M. (26-03-2014) The cultural complexity of problem-based learning across the world

Hommes, J.E. (26-02-2014) How relations, time \& size matter in medical education

Van der Zwet, J. (30-01-2014) Identity, Interaction and Power. Explaining the affordances of doctor-student interaction during clerkships

Watling, C.J. (22-01-2014) Cognition, Culture, and Credibility. Deconstructing Feedback in Medical Education

Winston, K. (12-12-2013) Remediation Theory and Practice: Transforming At-Risk Medical Students

Kamp, R.J.A. (28-11-2013) Peer Feedback to Enhance Learning in Problem-Based Tutorial Groups

Junod Perron, N. (24-10-2013) Towards a learner-centered approach to postgraduate communications skills teaching

Pratidina Susilo, A. (24-10-2013) Learning to be the Patient Advocate The Development of a Communication Skills Course to Enhance Nurses' Contribution to the Informed Consent Process

Alves de Lima, A. (23-10-2013) Assessment of clinical competence: Reliability, Validity, Feasibility and Educational Impact of the mini-CEX

Sibbald, M. (09-10-2013) Is that your final answer? How doctors should check decisions

Ladhani, Z. (05-07-2013) Competency based education and professional competencies: a study of institutional structures, perspectives and practices in Pakistan

Jippes, M. (01-02-2013) Culture matters in medical schools: How values shape a successful curriculum change 
Duvivier, R. J. (12-12-2012) Teaching and Learning Clinical Skills. Mastering the Art of Medicine

De Feijter, J.M. (09-11-2012) Learning from error to improve patient safety

Prescott, L. (09-11-2012) Ensuring the Competence of Dental Practitioners through the Development of a Workplace-Based System of Assessment

Cilliers, F.J. (05-09-2012) The Pre-assessment Learning Effects of Consequential Assessment: Modelling how the Examination Game is Played

Spanjers, I. A.E. (05-07-2012) Segmentation of Animations: Explaining the Effects on the Learning Process and Learning Outcomes

Al-Kadri, H.M.F. (28-06-2012) Does Assessment Drive Students' Learning?

Leppink, J. (20-06-2012) Propositional manipulation for conceptual understanding of statistics

Van Zundert, M.J. (04-05-2012) Conditions of Peer Assessment for Complex Learning

Claramita, M. (30-03-2012) Doctor-patient communication in a culturally hierarchical context of Southeast Asia: A partnership approach

Kleijnen, J.C.B.M. (21-03-2012) Internal quality management and organizational values in higher education

Persoon, M.C. (19-01-2012) Learning in Urology; The influence of simulators and human factors

Pawlikowska, T.R.B. (21-12-2011) Patient Enablement; A Living Dialogue

Sok Ying Liaw, (14-12-2011) Rescuing A Patient In Deteriorating Situations (RAPIDS): A programmatic approach in developing and evaluating a simulationbased educational program 
Singaram, V.S. (7-12-2011) Exploring the Impact of Diversity Factors on ProblemBased Collaborative Learning

Balslev, T. (24-11-2011) Learning to diagnose using patient video cases in paediatrics: Perceptive and cognitive processes

Widyandana, D. (19-10-2011) Integrating Pre-clinical skills training in skills laboratory and primary health care centers to prepare medical students for their clerkships

Durning, S.J. (09-09-2011) Exploring the Influence of Contextual Factors of the Clinical Encounter on Clinical Reasoning Success (Unraveling context specificity)

Govaerts, M.J.B. (08-09-2011) Climbing the Pyramid;Towards Understanding Performance Assessment

Stalmeijer, R. E. (07-07-2011) Evaluating Clinical Teaching through Cognitive Apprenticeship

Malling, B.V.G. (01-07-2011) Managing word-based postgraduate medical education in clinical departments

Veldhuijzen, J.W. (17-06-2011) Challenging the patient-centred paradigm: designing feasible guidelines for doctor patient communication

Van Blankenstein, F. (18-05-2011) Elaboration during problem-based, small group discussion: A new approach to study collaborative learning

Van Mook, W. (13-05-2011) Teaching and assessment of professional behavior: Rhetoric and reality 
243 
244 


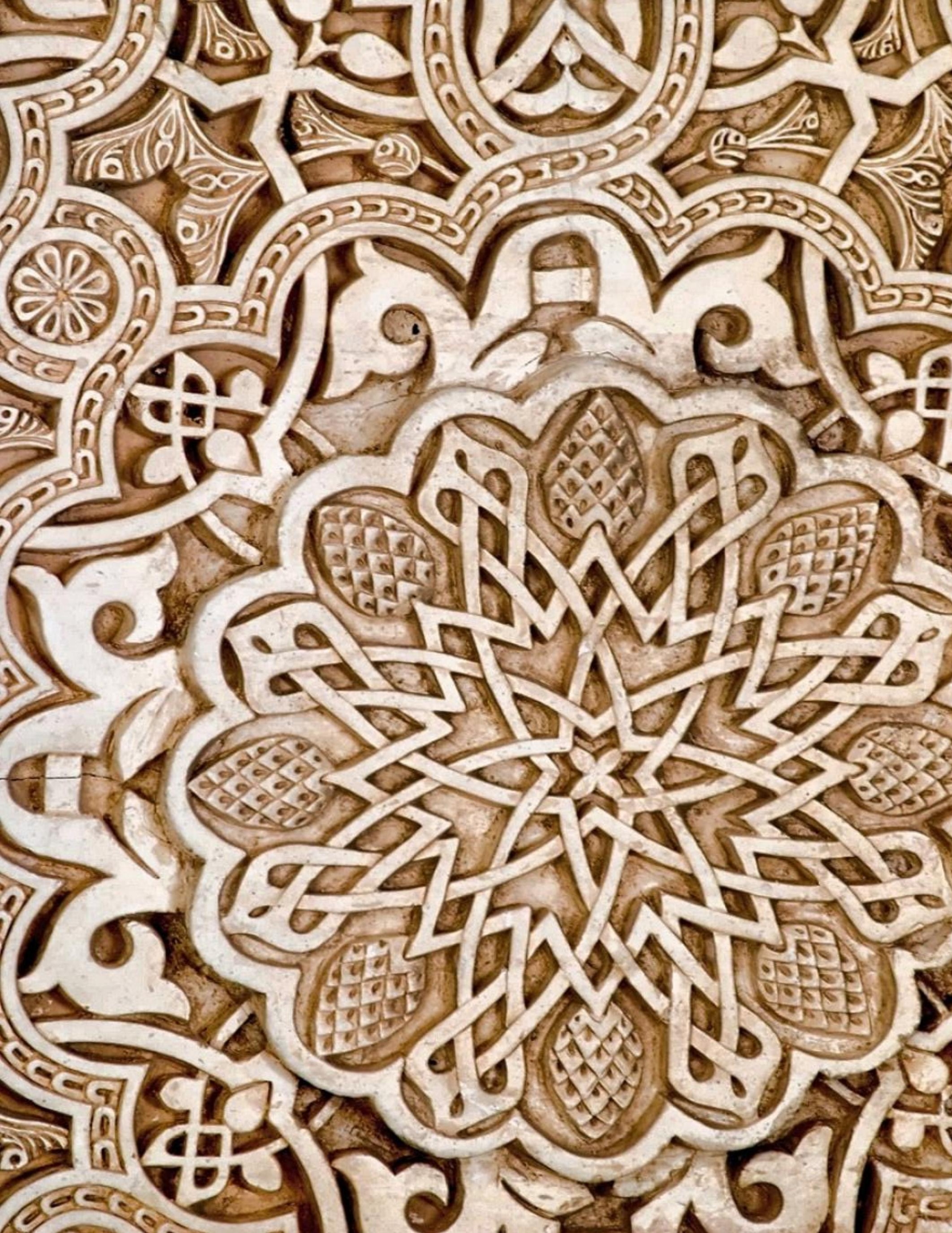

